\title{
MICROWAVE REMOTE SENSING FOR SOIL MOISTURE MONITORING: SYNERGY OF ACTIVE AND PASSIVE OBSERVATIONS AND VALIDATION OF RETRIEVED PRODUCTS
}




\section{Examining committee}

Chair

Prof. dr. ir. A. Tom Veldkamp

University of Twente

Promotor

Prof. dr. Zhongbo Su

University of Twente

Members

Prof. dr. ir. Wouter Verhoef

Prof. dr. Gerard van der Steenhoven

University of Twente

University of Twente

Prof. dr. ir. Paolo Ferrazzoli

Prof. dr. Jun Wen

University of Rome Tor Vergata

Prof. dr. Dara Entekhabi

Chinese Academy of Sciences

Massachusetts Institute of Technology

ITC dissertation number 284

ITC, P.O. Box 6, 7500 AA Enschede, The Netherlands

ISBN 978-90-365-4112-1

DOI 10.3990/1.9789036541121

Cover designed by Laura Dente and Benno Masselink

Printed by ITC Printing Department, Enschede, The Netherlands

Copyright (C) 2016 by Laura Dente

\section{UNIVERSITY OF TWENTE.}

-C Faculty of gEO-INFORMATION SCIENCE AND EARTH OBSERVATION 


\section{MICROWAVE REMOTE SENSING \\ FOR SOIL MOISTURE MONITORING: \\ SYNERGY OF ACTIVE AND PASSIVE OBSERVATIONS \\ AND VALIDATION OF RETRIEVED PRODUCTS}

DISSERTATION

to obtain

the degree of doctor at the University of Twente

on the authority of the rector magnificus,

Prof. dr. H. Brinksma

on account of the decision of the graduation committee, to be publicly defended

on Thursday 28 April 2016 at 14:45 hrs

by

Laura Dente

born on 3 January 1974

in Cerignola, Italy 
This thesis is approved by:

Prof. dr. Zhongbo Su, promotor 
Dedicated to my father Dedicato a mio padre 



\section{Summary}

Soil moisture is an Essential Climate Variable (ECV) that plays a crucial role in several land surface processes, affects vegetation growth, contributes to the interaction between land surface and atmosphere. Because of its importance, there is a need to accurately monitor soil moisture content. Microwave remote sensing is a useful tool for the soil moisture monitoring of large areas. Despite numerous studies and achievements in this field, the accurate retrieval of soil moisture from satellite data acquired by active and passive microwave sensors remains a challenge. This is because microwave observations are sensitive to factors other than soil moisture, such as soil roughness, vegetation, and surface temperature. However, active and passive microwave observations provide complementary information, because they respond differently to soil and vegetation parameters. The soil moisture retrieval can therefore benefit from the combination of these two data sources.

This dissertation contributes to the accuracy assessment of current satellite-derived soil moisture products and proposes a new method to synergistically use active and passive microwave satellite data. The objective of this work is to improve the understanding and modelling of microwave responses over land surfaces and to provide the basis for an accurate soil moisture retrieval.

Large soil moisture measurement networks were set up in the Maqu region (China) and in Twente (The Netherlands) to provide ground reference data for validation purposes. A preliminary analysis of these data confirmed that the spatial variability of soil moisture is accurately monitored at both sites and that the spatial average of the measurements is a good indicator of the soil moisture content in the network area.

Temporal agreement, correlation, bias, seasonal patterns and anomalies from the seasonality were investigated between in situ measurements and AMSR-E, ASCAT and SMOS soil moisture products. The validation analyses showed that the general seasonal behaviour 
of soil moisture for the reference regions was well described by the AMSR-E, ASCAT and SMOS soil moisture products. The coefficient of determination between in situ data and satellite-derived products was approximately 0.5 for all datasets. The satellite products were characterized by noise, occasional disagreements, seasonal systematic errors, unrealistically large temporal variability and bias. On average the AMSR-E products obtained from descending pass observations showed better agreement with in situ data, whereas the SMOS ascending products showed poorer agreement for Maqu and Twente regions than the other products. Several causes of error were identified affecting the accuracy of the satellite estimates, such as limitations of the retrieval methods, sensitivity to vegetation cover, uncertainties regarding the surface temperature, and radio frequency interference.

In this dissertation, a new approach is proposed to combine active and passive microwave satellite data. The two datasets were synergistically used to constrain a discrete scattering model, limiting the need for detailed information on several surface and vegetation parameters. The Tor Vergata model was used to simulate both emissivity and backscattering coefficient. Both active and passive microwave data were used to calibrate the model. The calibration consisted of varying the unknown input parameters of the model to obtain a good match between model outputs and both AMSR-E brightness temperatures and ASCAT backscattering coefficients.

The combined use of active and passive microwave datasets led to a better model calibration than if passive only or active only were used. The calibrated model outputs showed a high level of agreement with the satellite data, in particular for the active case. The results obtained for the passive case strongly depended on the accuracy of the surface temperature information (used to obtain the brightness temperature from the modelled emissivity).

In conclusion, this dissertation confirms that the accuracy of the soil moisture retrieval can be improved by combining active and passive microwave data. With the proposed method, a discrete scattering model, requiring several input parameters generally unavailable on a large scale, is successfully constrained and the microwave responses are interpreted unambiguously. These results are fundamental to reduce uncertainties in the soil moisture retrieval process. 


\section{Samenvatting}

Bodemvocht is een essentiële klimaatvariabele die een cruciale rol speelt in diverse processen aan het aardoppervlak, groei van vegetatie beïnvloedt, en bijdraagt aan de interactie tussen aardoppervlak en atmosfeer. Vanwege zijn belang is er een noodzaak om nauwkeurig veranderingen in bodemvochtgehalte bij te houden. Remote sensing met behulp van microgolven is een belangrijk middel om dit te doen voor grote gebieden. Ondanks talrijke studies en resultaten op dit gebied is de nauwkeurige schatting van bodemvochtgehalte met satellietgegevens verkregen door actieve en passieve microgolfsensoren nog altijd een uitdaging. De reden is dat microgolfmetingen niet slechts gevoelig zijn voor bodemvocht, maar ook voor factoren zoals bodemruwheid, vegetatiebedekking, en oppervlaktetemperatuur. Echter, microgolfmetingen van actieve en passieve sensoren bieden complementaire informatie, omdat ze verschillend reageren op bodem- en vegetatieparameters. Het schatten van bodemvocht kan daarom profiteren van de combinatie van deze twee gegevensbronnen.

Dit proefschrift draagt bij aan de beoordeling van de nauwkeurigheid van huidige satelliet-afgeleide bodemvochtproducten en stelt een nieuwe methode voor om satellietgegevens van actieve en passieve microgolf sensoren synergetisch te gebruiken. Het doel van dit werk is om het begrip en de modellering van microgolf-emissie en terugkaatsing van het landoppervlak te verbeteren en zo een basis te leggen voor nauwkeuriger schattingen van bodemvocht.

Grote bodemvocht-meetnetwerken zijn geïnstalleerd in het gebied rond Maqu (China) en in Twente (Nederland) om in situ referentiegegevens te verkrijgen voor validatie doeleinden. Een eerste analyse van deze gegevens bevestigde dat de ruimtelijke variabiliteit van bodemvochtgehalte nauwkeurig bepaald kan worden voor beide gebieden en dat het ruimtelijk gemiddelde een goede indicator is voor veranderingen in bodemvochtgehalte binnen het netwerkgebied. 
Temporele overeenkomst, correlatie, gemiddelde afwijking, seizoensgebonden patronen, en afwijkingen van deze patronen werden onderzocht door vergelijking van in situ gegevens met bodemvochtproducten afgeleid van AMSR-E, ASCAT, en SMOS. Deze validatie analyses lieten zien dat de seizoensveranderingen van bodemvocht goed beschreven worden door de drie bodemvochtproducten. De determinatiecoëfficiënt tussen de in situ gegevens en de satelliet-afgeleide producten was ongeveer 0,5 voor alle producten. De producten werden gekenmerkt door ruis, tijdelijke verschillen, systematische fouten per seizoen, onrealistisch grote temporele variabiliteit en afwijkingen in gemiddelde waardes. Gemiddeld lieten de AMSR-E producten afgeleid van metingen gedurende de dalende (van noord naar zuid) satellietbaan een betere overeenkomst zien met in situ gegevens, terwijl de SMOS producten afgeleid van klimmende satellietbanen een slechtere overeenkomst hadden voor Maqu en Twente dan de overige producten. Verschillende foutenbronnen werden geïdentificeerd die de nauwkeurigheid van de satelliet-afgeleide bodemvochtschattingen beïnvloeden, zoals beperkingen van de schattingsmethodes, gevoeligheid van het microgolfsignaal voor vegetatiebedekking, onzekerheden met betrekking tot de oppervlaktetemperatuur, en elektromagnetische interferentie.

In dit proefschrift wordt een nieuwe benadering voorgesteld om actieve en passieve microgolfmetingen van satellieten te combineren. Door de twee gegevensbronnen samen te gebruiken konden parameterwaardes van een discreet verstrooiingsmodel beperkt worden, wat de noodzaak voor gedetailleerde informatie over verschillende oppervlakte- en vegetatieparameters verminderde. Het Tor Vergata model werd gebruikt om zowel emissiviteit (passief) als terugkaatsing (actief) van microgolven te simuleren. Actieve en passieve microgolfmetingen werden samen benut voor de kalibratie van het model. De kalibratie bestond uit het variëren van de onbekende invoerparameters van het model om zo tot een goede overeenkomst te komen tussen modelresultaten enerzijds en helderheidstemperaturen van AMSR-E alsmede terugkaatsingscoëfficiënten van ASCAT anderzijds.

Het gecombineerde gebruik van actieve en passieve microgolfgegevens leidde tot een betere modelkalibratie dan 
wanneer alleen passieve of alleen actieve gegevens werden gebruikt. De resultaten van het gekalibreerde model hadden een sterke overeenstemming met de satellietgegevens, in het bijzonder voor de actieve gegevens. De verkregen resultaten voor de passieve gegevens waren sterk afhankelijk van de nauwkeurigheid van de informatie over oppervlaktetemperatuur (die gebruikt werd om helderheidstemperaturen van gemodelleerde emissiviteit af te leiden).

Samenvattend bevestigt dit proefschrift dat de nauwkeurigheid van bodemvochtschattingen verbeterd kan worden door het combineren van actieve en passieve microgolfmetingen. Met de voorgestelde methode kunnen parameterwaardes van een discreet verstrooiingsmodel, die verschillende invoerparameters nodig heeft die doorgaans niet beschikbaar zijn voor grote gebieden, met succes beperkt worden. Zodoende kunnen microgolf-emissies en terugkaatsingen eenduidig worden geïnterpreteerd. Deze resultaten zijn van fundamenteel belang om onzekerheden in het schatten van bodemvocht te verminderen. 


\section{Table of contents}

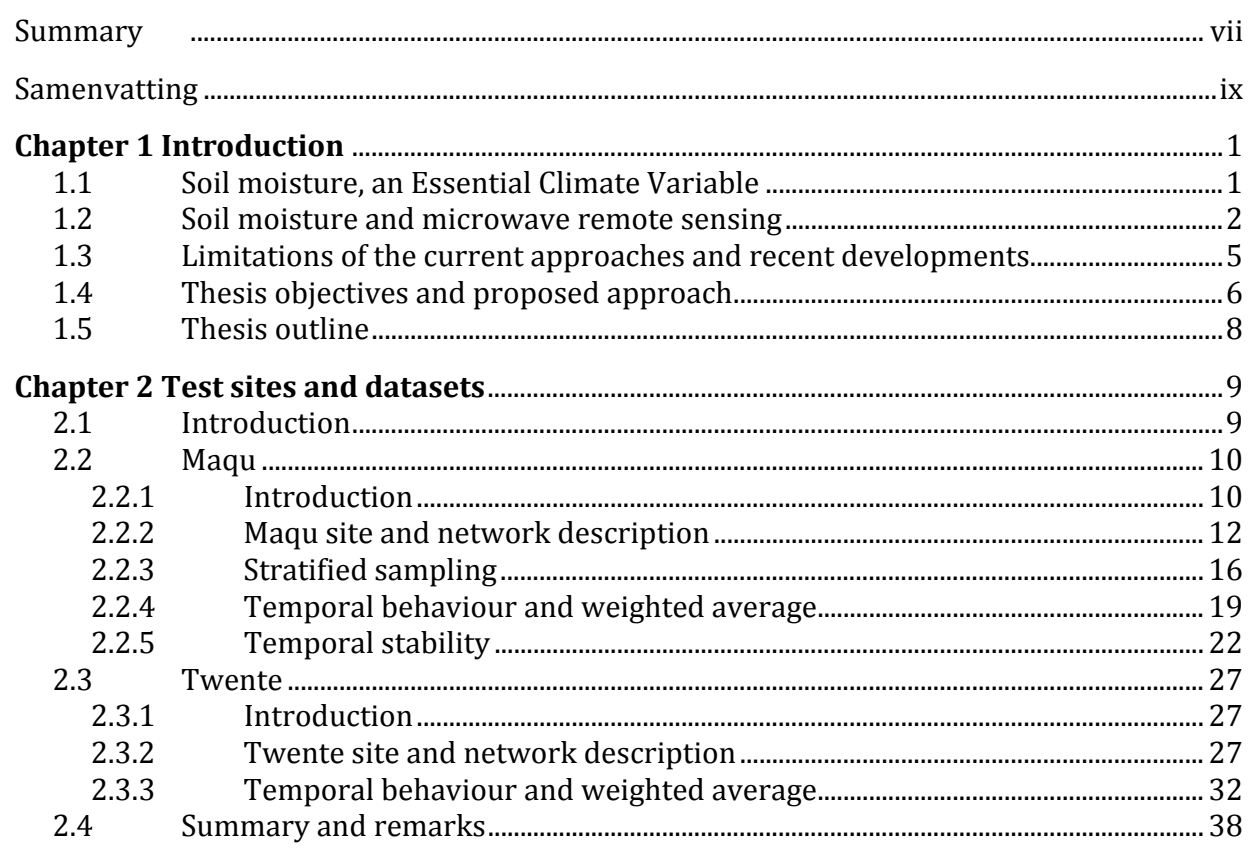

Chapter 3 Validation of AMSR-E and ASCAT soil moisture products over the Maqu

\begin{tabular}{|c|c|}
\hline 3.1 & Introduction. \\
\hline 3.2 & Description of the soil moisture products... \\
\hline 3.2 .1 & AMSR-E soil moisture \\
\hline 3.2 .2 & ASCAT soil moisture \\
\hline 3.3 & Validation of AMSR-E and ASCAT soil moisture products over Maqu region..... 44 \\
\hline 4 & Conclusions \\
\hline
\end{tabular}

\section{Chapter 4 Validation of SMOS soil moisture products over the Maqu and Twente}

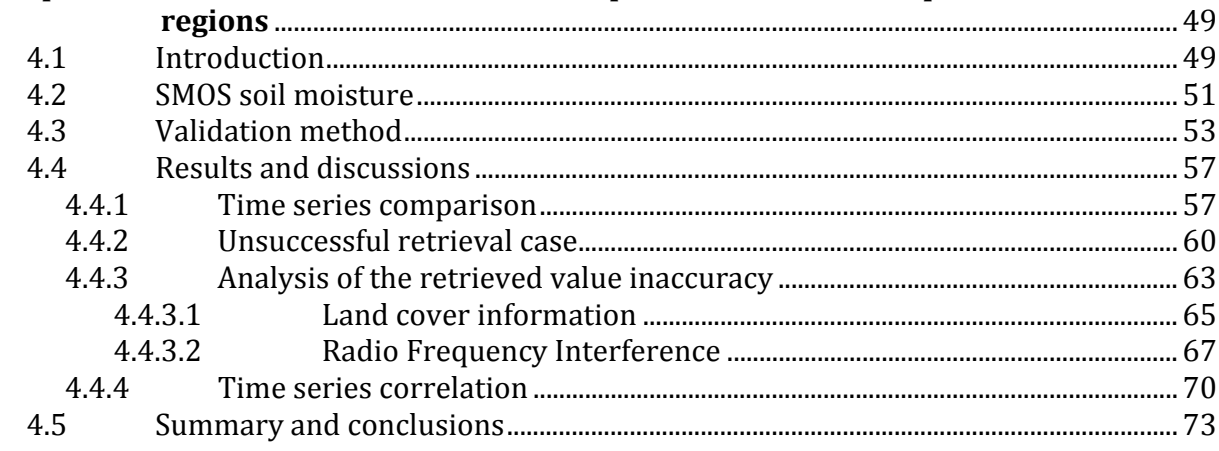




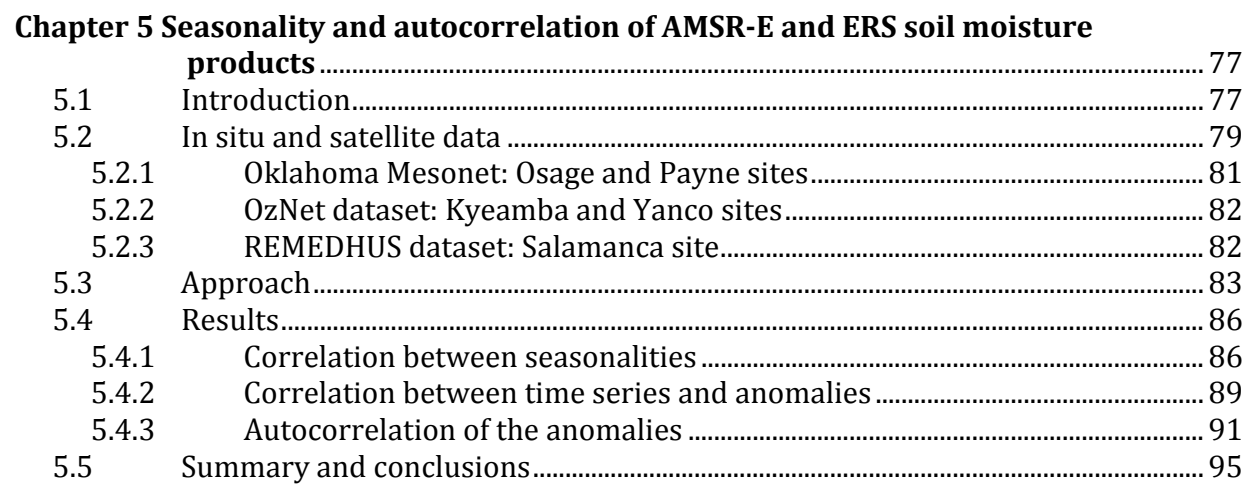

Chapter 6 Combined use of active and passive microwave satellite data to

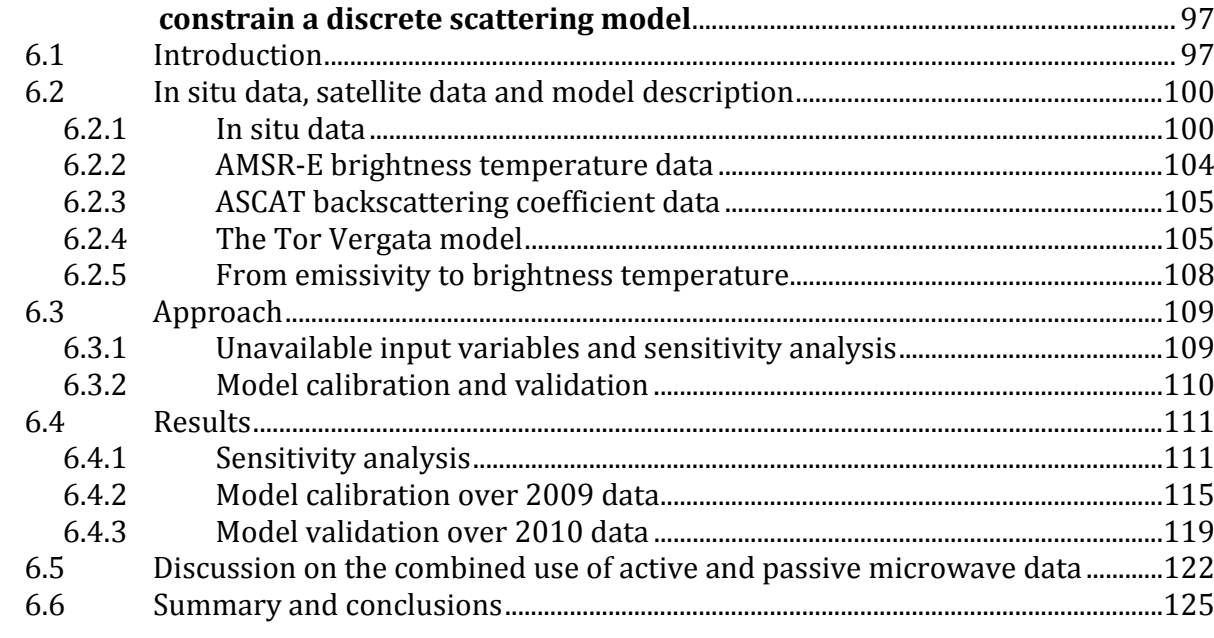

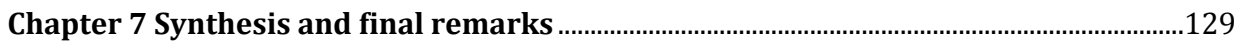

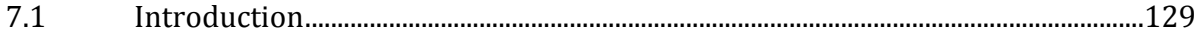

7.2 Validation of the satellite-derived soil moisture products ....................................130

7.2.1 Validation of AMSR-E soil moisture products ...................................................131

7.2.2 Validation of ERS and ASCAT soil moisture products .....................................131

7.2.3 Validation of SMOS soil moisture products ......................................................132

7.3 Combined use of active and passive microwave data .............................................133

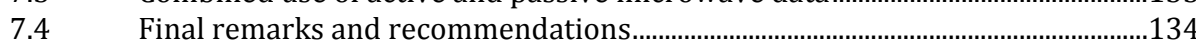

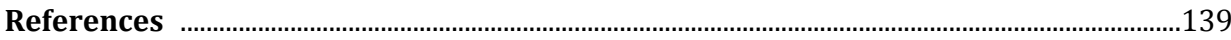

Appendix A Fieldwork report - Maqu monitoring network ……........................................153

Appendix B Comparison of different methods to estimate the surface

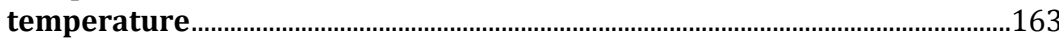

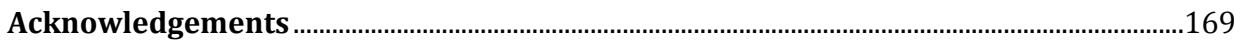




\section{Chapter 1}

\section{Introduction}

\subsection{Soil moisture, an Essential Climate Variable}

Soil moisture has been included in 2010 in the list of the Essential Climate Variables (ECV), as it is considered to have an important role in characterising Earth's climate (GCOS 2010). In order to contribute to the understanding of the climate system and climate change, it is recommended to monitor this variable and to focus research studies on the validation and improvement of the current estimation methodologies (GCOS 2008).

Soil moisture is indeed an important variable in hydrology, biogeography, agronomy, geomorphology and climatology (Legates et al. 2010). Soil moisture can affect the partitioning of precipitation in surface runoff and infiltration, as well as the erosion and sedimentation driven by overland flow. Droughts and floods are directly related to the antecedent soil moisture conditions. Plants depend heavily on soil moisture to acquire the water they need to perform photosynthesis and to grow. Soil moisture availability also affects the spatial and temporal vegetation patterns and agricultural production.

Moreover, soil moisture plays an important role in the interaction between land surface and atmosphere. Soil moisture contributes to regulating the rate of plant transpiration and soil evapotranspiration, 
which in turn affects the near surface air-temperature, humidity and atmospheric water vapour. Therefore, changes to soil moisture can alter the development of clouds, the precipitation, the temperature and the atmospheric circulation. Consequently, soil moisture is an important factor in defining the climate of a given region.

For these reasons, accurate information about soil moisture on a large scale certainly contributes to the understanding of land surface processes and land-atmosphere interaction and it is essential to constrain and improve both land surface models and climate models. Accurate models are fundamentally important to support water resource and crop management, marketing strategies, policy decisions, disaster forecasting and, above all, to monitor climate changes.

However, large-scale measurement of soil moisture is a challenging task. The soil moisture is spatially highly variable, because of the spatial variability of several factors, including meteorological conditions, topography, pedology and vegetation cover.

The traditional measurement methods, such as gravimetric sampling and automatic probes, provide an estimate at a specific point that is representative of a small area. For this reason, using these methods to estimate the typical high spatial variability of soil moisture over large areas (i.e. from regional to global scale) is out of the question. Remote sensing techniques, therefore, are an essential tool to monitor the spatial distribution of soil moisture on a large scale.

\subsection{Soil moisture and microwave remote sensing}

Soil moisture retrieval using satellite sensors operating at the microwave bands of the electromagnetic spectrum is based on the principle that the dielectric properties of soil-water mixture strongly affect the soil scattering and emission in this frequency range. A change in soil moisture results in a measurable variation of the soil scattering and emission because the dielectric constant of the water is much higher than that of dry soil at the microwave bands. 
Moreover, the microwave remote sensing has the advantage of being operational in all weather conditions, both day and night.

The relationship between microwave scattering and emission and soil moisture was more intensively investigated beginning in the seventies (Attema and Ulaby 1978; Eagleman and Lin 1976; Schmugge et al. 1974; Ulaby 1974). Since then, several experimental and theoretical studies on passive and active microwave observations have improved the understanding of the sensitivity of satellite microwave observations to soil moisture, presented different retrieval approaches and led to high confidence in the possibility of a reliable retrieval from these data. Review articles have periodically reported the progresses achieved in this field (Barrett et al. 2009; Hall et al. 1995; Jackson et al. 1996; Kornelsen and Coulibaly 2013; Mladenova et al. 2014; Schmugge 1983; Wagner et al. 2007a; Wigneron et al. 2003).

Different approaches have been developed to retrieve soil moisture from microwave satellite data. Several studies used empirical methods, which are based on regression analyses that establish the direct relationship between soil moisture measurements and satellite observations. Though some of the empirical relationships found in these studies correctly determine the soil moisture, they are strongly site and time dependent, which prevents their applications on a large scale. The semi-empirical models are theoretically and physically based but with a simplified representation of the processes. These models are relatively widely applicable; however the adopted simplifications and approximations are often the cause of inaccuracies. An alternative approach is the change detection method, which is based on the concept that soil roughness and vegetation changes occur much slower than soil moisture changes and their effect on the variability of the satellite signatures (acquired with a similar viewing geometry) can be minimised. Obviously, the change detection approach is valid only for short time lags. Another common approach, though more mathematically complicated, consists of using a discrete scattering model to formulate the physical processes relating the remote sensing signatures to land surface parameters. The soil surface is represented by means of its statistical properties, such as height standard deviation, correlation length and autocorrelation function. The vegetation is represented as 
a collection of dielectric scatters whose position and orientation are given. These models can be applied in a wide range of surface conditions, but they require a considerable amount of inputs and a priori information. Several techniques can be applied to invert the scattering model and obtain the unknown surface parameters on the basis of the satellite observations. The most commonly used technique is based on look-up tables, which consists of running the model in a given remote sensor configuration for a range of input variables. Therefore, a complete set of backscattering coefficient and emissivity is obtained corresponding to a range of surface conditions. When a certain satellite signature occurs, the surface parameters can be estimated by checking the correspondences in the look-up table. The neural networks have been also used to retrieve the soil moisture. The neural network method aims to determine the nonlinear statistical relationship between the satellite observation and the soil moisture, without explicitly formulating the physical processes. In order to do this, the neural network is first trained, minimising the differences between a set of satellite observations and the corresponding soil moisture data. Then, it is used on the complete set of satellite data to retrieve the soil moisture. For this reason, the neural network requires less information about the land surface parameters than a scattering model. However, as the relationship between satellite signatures and soil moisture is very complex due to several other factors affecting it, there is the risk that the statistical neural network approach will not be able to describe this relationship perfectly.

In order to fulfil the need for large scale and global soil moisture data, the research in the last decade has focused on providing users with global soil moisture products obtained from the existing satellite data, though not optimised for soil moisture monitoring, such as: 1) Level 2 (L2) relative soil wetness index products retrieved from the European Remote Sensing-2 (ERS-2) scatterometer and from the MetOp Advanced SCATterometer (ASCAT) data (Naeimi et al. 2009; Wagner et al. 1999) (hereafter ERS and ASCAT soil moisture data, respectively); 2) Level $2 \mathrm{~b}$ (L2b) soil moisture products derived from the data of AQUA Advanced Microwave Scanning Radiometer for Earth Observing System (AMSR-E), using the algorithm by Njoku et al. (2003) (hereafter AMSR-E L2b soil moisture data); 3) soil moisture products derived from the AQUA AMSR-E data by the Vrije 
Universiteit Amsterdam (VUA) and NASA with the approach by Owe et al. (2008) (hereafter AMSR-E soil moisture data). Moreover, the space agencies have started to support dedicated satellite missions operating at L-band, as L-band signatures are less sensitive to the vegetation canopy and more sensitive to the soil moisture variation than C-band, and having multi-configuration capabilities such as the Soil Moisture and Ocean Salinity mission (SMOS, launched in November 2009 by ESA) and the Soil Moisture Active and Passive mission (SMAP, launched in January 2015 by NASA). SMOS provides passive microwave observations at different view angles. SMAP was expected to acquire both active and passive data at different polarisations, but, unfortunately, the radar could no longer transmit data a few months after the launch. Therefore, SMAP currently provides only passive microwave data.

\subsection{Limitations of the current approaches and recent developments}

The main reason limiting the accuracy of the operational soil moisture products obtained from scatterometer and radiometer data is the sensitivity of backscattering coefficient and brightness temperature to factors other than the soil moisture, such as soil roughness, vegetation physical and structural properties and surface temperature.

The main issue can, therefore, be summarised as follows: when a single source of remote sensing data is used (i.e. one single sensor, frequency, polarisation or incidence angle), the soil moisture retrieval problem is ill-posed because the number of the surface unknown parameters involved in the problem is higher than the number of known (input) variables.

Recently, a solution for this problem has been investigated by combining the information obtained from multiple sources in the retrieval process, such as remote sensing observations acquired by active and passive sensors or acquired at different frequencies, polarisations or incidence angles. This approach is based on the concept that the sensitivity of remote sensing data to each surface 
parameter depends strongly on the acquisition technique (active or passive) and on the frequency, polarisation and incidence angle, and, for this reason, each dataset provides diverse information. Including additional information in the retrieval process should contribute to better constraining it. In particular, active and passive microwave observations provide complementary information on the observed land surface, as they respond differently to soil and vegetation parameters. On this basis, the synergistic use of active and passive microwave data is very promising. A common method to combine active and passive data entails extracting information on roughness and vegetation properties from the data acquired by active sensors and then using this information to support the soil moisture retrieval from passive data (Chauhan 1997; Lee and Anagnostou 2004; O'Neill et al. 1996; Saatchi et al. 1995a; Theis et al. 1986; Wen et al. 2003; Zhan et al. 2006). By contrast, the complementary information provided by active and passive microwave observations has only been exploited in a few studies to constrain a single discrete scattering model that is capable of simulating both the emissivity and the backscattering coefficient (Chauhan and Levine 1994; Ferrazzoli et al. 1989; Saatchi et al. 1994).

Instead the a posteriori combination of active and passive data has been investigated in the recent years in view of the launch of SMAP, which combines the retrieved soil moisture products instead of the sensor signatures. A statistical approach to blend operational AMSR$\mathrm{E}$ and ASCAT soil moisture products to increase the spatial and temporal availability of satellite-derived soil moisture data was investigated by Liu et al. (2011). Whereas, a new method for downscaling coarse resolution radiometer soil moisture products with the aid of fine resolution radar retrievals to obtain high resolution products was presented by Das et al. (2011) and Piles et al. (2009).

\subsection{Thesis objectives and proposed approach}

In the context described above, the main objectives of the research described in this thesis are to analyse further the capability of the 
current operational soil moisture products to monitor this parameter accurately and to investigate further the potential of the synergistic use of active and passive microwave data to improve the soil moisture retrieval accuracy.

The satellite-derived soil moisture products, available at the time this research was carried out, were validated against in situ measurements. Two large soil moisture monitoring networks were set up for the purpose of this research (as well as in the framework of other studies); the first is located in the Maqu region (Tibetan Plateau, China) and the second in the Twente region (The Netherlands). The data measured in these two sites were used as ground reference for the validation of three currently available satellite-derived soil moisture products: ASCAT, AMSR-E and SMOS soil moisture products. As several studies, for example by Gruhier et al. (2008) and Sahoo et al. (2008), have shown that AMSR-E L2b products are of poor accuracy, they were not used in this study. The SMAP soil moisture products were not available at the time this study was carried out. Moreover, long time series of in situ data collected in Spain, Oklahoma and Australia were used to validate seasonal patterns, anomalies from the seasonality and autocorrelation of ERS and AMSR-E products.

A new approach was subsequently proposed to exploit the complementary information provided by active and passive microwave data. The two datasets were synergistically used to constrain a discrete scattering model that simulates both the emissivity and the backscattering coefficient, with the aim to limit the need for detailed knowledge of several surface and vegetation parameters reducing the model uncertainties. The Tor Vergata scattering model (Bracaglia et al. 1995; Ferrazzoli and Guerriero 1996) was employed for the scope and the analysis was carried out over the Maqu region. 


\subsection{Thesis outline}

This dissertation comprises seven chapters and two appendices. The two main validation sites of this study, the Maqu region and the Twente region, are presented in Chapter 2. This section includes a description of the soil moisture monitoring networks set up in these regions and a detailed analysis of the collected datasets. The capability of the two networks to provide the necessary information for the validation of remotely sensed soil moisture product is evaluated as well. The Appendix A reports more details about the Maqu region, the network installation, the instrumentation and its calibration.

The currently available satellite-derived soil moisture products are validated against in situ data in Chapters 3, 4 and 5. In Chapter 3, the soil moisture products obtained from AMSR-E and the relative soil wetness index products retrieved from ASCAT are validated for the Maqu region. In Chapter 4, the SMOS soil moisture products are validated for both the Maqu and the Twente regions. The seasonal behaviour, the anomalies behaviour and the autocorrelation of AMSR-E soil moisture and ERS relative soil wetness index are analysed in Chapter 5.

The new approach, which uses active and passive microwave data synergistically, is presented in Chapter 6. Firstly, the Tor Vergata discrete scattering model is described. Then, the model is used to simulate both emissivity and backscattering coefficient driven by a unique set of input parameters. Both the AMSR-E and ASCAT signatures are used to constrain the model calibration in order to minimise the difference between model outputs and satellite signatures. The advantage of using both active and passive microwave data is assessed and discussed. In Appendix B, different methods to estimate the surface temperature are evaluated. The surface temperature is necessary to convert the modelled emissivity in brightness temperature, allowing the comparison between model output and satellite data. Finally, Chapter $\mathbf{7}$ provides a summary of the major findings of this study, general remarks and recommendation for further analysis and future studies. 


\section{Chapter 2}

\section{Test sites and datasets}

This chapter is based on:

Dente L., Vekerdy Z., Wen J., Su Z. (2012). Maqu network for validation of satellitederived soil moisture products. International Journal of Applied Earth Observation and Geoinformation, 17, 55-65

Dente L., Vekerdy Z., Su Z., Ucer M. (2011) Twente Soil Moisture and Soil Temperature Monitoring Network. University of Twente-ITC: Enschede, The Netherlands, p. 19. http://www.itc.nl/library/papers 2011/scie/dente twe.pdf

\section{$2.1 \quad$ Introduction}

Two large soil moisture and soil temperature monitoring networks were set up in the frame of this research. The first network was installed in Maqu region at the north-eastern fringe of the Tibetan Plateau. The second network was installed in Twente region in the eastern part of The Netherlands. The two sites are significantly different in terms of topography, land cover and climate, allowing to analyse different aspects of the validation of satellite-derived soil moisture and scattering models.

Section 2.2 reports a detailed description of the Maqu site, the monitoring network, the sampling approach and the analyses of the collected data. The Twente site, the network and a qualitative 
analysis of the collected data are presented in Section 2.3. Summary and remarks are reported in Section 2.4.

\subsection{Maqu}

\subsubsection{Introduction}

Due to its high elevation, on average above $4000 \mathrm{~m}$ above sea level (a.s.l.), the Tibetan Plateau has a strong influence on the climatic system of Asia. Topography, snow cover, soil moisture and vegetation dynamics of the area exert aerodynamic and thermal effects on the atmosphere and thus affect the Asian monsoon (Song et al. 2010; Xie et al. 2010; You et al. 2010). Moreover, several rivers, such as the Yellow River, the Yangtze and the Mekong, have their origin on the Tibetan Plateau and make a major contribution to the water resources of China and South-East Asia (Immerzeel and Bierkens 2010). It is therefore possible that changes in the regional climate and water cycle of the Tibetan Plateau will have strong consequences for eastern and south-eastern Asia (Bao et al. 2010; Wang et al. 2010).

Despite the potential impact of these influences, monitoring of the most important hydrological and climatic parameters of the Tibetan Plateau is limited to a few sites and knowledge about the landatmosphere interaction, the monsoon system, precipitation patterns and the role of the plateau in Asia's climate is still poor. Several studies have been launched to address this situation, among them the CEOP-AEGIS project (Coordinated ASIA-European long term Observing system of Qinghai-Tibet Plateau hydro-meteorological processes and the Asian-monsoon system with Ground satellite Image data and numerical Simulations, http://www.ceop-aegis.net/); and the TPE programme (Third Pole Environment programme http://www.tpe.ac.cn/).

Soil moisture plays a major role in the water cycle and the climate of the plateau as it partitions the incoming radiative energy into sensible and latent heat fluxes, influencing the monsoon system and 
precipitation patterns. Therefore, long-term and large-scale soil moisture monitoring of the Tibetan Plateau has a central role to play in hydrological and climatic studies.

The large size and the high altitude of the plateau limit the feasibility of setting up dense in situ networks for monitoring soil moisture. Satellite-derived data could, therefore, make a fundamental contribution to knowledge about soil moisture in this region.

To validate the accuracy of the satellite-derived soil moisture products for the Tibetan Plateau, a large soil moisture and soil temperature monitoring network was set up in the water source region of the Yellow River, in Maqu county, situated in the northeastern part of the Tibetan Plateau. The network spans an area of approximately $40 \mathrm{~km} \times 80 \mathrm{~km}$ and consists of 20 stations for measuring soil moisture and soil temperature. This setup makes the network potentially suitable for the validation of coarse resolution satellite-derived soil moisture products (with a resolution of about 30-50 km) since the network covers more than one resolution cell. This is an important feature as it partially overcomes the problem of the large gap in scale between in situ soil moisture measurements and satellite-derived soil moisture estimates.

Maqu network is part of a plateau scale observatory, called the Tibetan Plateau observatory (Tibet-Obs), which was set up in 2008 with the main objectives to provide the necessary information for i) studying land surface processes in high elevation regions; ii) validating coarse resolution satellite products and land surface model outputs; iii) contributing to the understanding of the role of the Tibetan Plateau in the development of the Asian Monsoon and the global climatic system. The Tibet-Obs consists of three regionalscale monitoring networks, including Naqu network in the centre of the plateau, the Ngari network in the western part and the Maqu network on the north-eastern fringe of the plateau. More information on the Tibetan Plateau observatory can be found in Su et al. (2011).

The main objective of this part of the chapter is to present the first set of data measured at the Maqu area and to evaluate its suitability as a validation site for satellite-derived soil moisture products. For this reason, a detailed description of the study site, the network characteristics, the sampling approach (i.e. stratified sampling) and 
the surface soil moisture measurements is provided. The spatial variability and temporal stability of soil moisture were investigated, as these factors affect both the accuracy of the in situ monitoring and the estimation of the soil moisture from the satellite data.

The site and Maqu monitoring network are described in Section 2.2.2; the accuracy of the sampling approach is discussed in Section 2.2.3; the temporal and spatial behaviour of the surface soil moisture data are analysed and the weighted spatial average is computed in Section 2.2.4; and the temporal stability analysis is carried out in Section 2.2 .5 .

\subsubsection{Maqu site and network description}

The Maqu soil moisture monitoring network has been set up in the

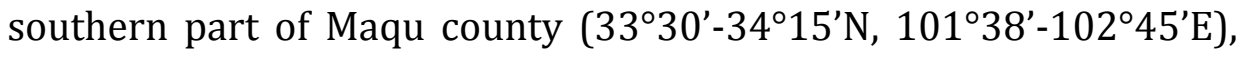
on the border between Gansu and Sichuan provinces in China (Figure 2.1). The network is located at the first major bend in the Yellow River, where it meets the Black river. Figure 2.2 shows the digital elevation model (DEM) of the area (data from the Shuttle Radar Topography Mission, SRTM, available from U.S. Geological Survey http://eros.usgs.gov/). The locations and names of the monitoring sites are also indicated.

The 20 sites are spread over the large valley of the Yellow River and its surrounding hills and in this area the elevation ranges from 3200 $\mathrm{m}$ to $4200 \mathrm{~m}$ above sea level (a.s.l.). The land cover consists of uniform short grass (i.e. Alpine steppe, (Coupland 1993)) used for grazing by sheep and yaks, with exception of small bare areas, and the wetlands cover a large part of the valley. The soil surface is covered by a thin layer of litter (less than $1 \mathrm{~cm}$ thick) that consists of dry grass leaves from the previous year. According to the Koeppen Classification System, it has a wet and cold climate, with dry winters (i.e. from November to March) and rainy summers (i.e. from April to October), due to the monsoon. Temperatures typically drop below freezing point during winter with mean air and $5 \mathrm{~cm}$ depth soil temperature of $-5{ }^{\circ} \mathrm{C}$ and $-1.4{ }^{\circ} \mathrm{C}$ respectively. As such, the soil is subject to freeze/thaw cycles during the entire season. 
The installation of the soil moisture and soil temperature monitoring sites started in May 2008 (with the stations named CST_X, short for China-Soil moisture and soil Temperature_x); the complete network has been operational since July 2008 (following the installation of the stations NST_x, short for Netherlands-Soil moisture and soil Temperature_x) and collects data every 15 minutes.

The monitoring network covers an area of approximately $40 \mathrm{~km} \times 80$ $\mathrm{km}$ and the site locations were selected in order to be able to monitor the area extensively for a variety of altitudes and slopes and different soil characteristics according to a stratified sampling approach. Identification of strata and the distribution of the monitoring stations among them will be described in Section 2.3. Although sampling within the strata was random, the locations of the stations were chosen with the aim of establishing a good spatial distribution within each stratum. The total number of stations installed in the Maqu study area is considered to be a good match between the need to sample soil moisture for all the identified strata over a wide area (covering at least one resolution cell of the satellitederived products), and practical limitations, such as constraints of cost and time for installation and site revisits.

Eleven monitoring stations were installed around the valleys of the Yellow and Black Rivers; 3 stations in the valleys between the hills in the eastern part of the area, 4 stations on hill slopes and 2 stations on wetlands. Table 2.1 summarises the characteristics of each of the monitoring sites.

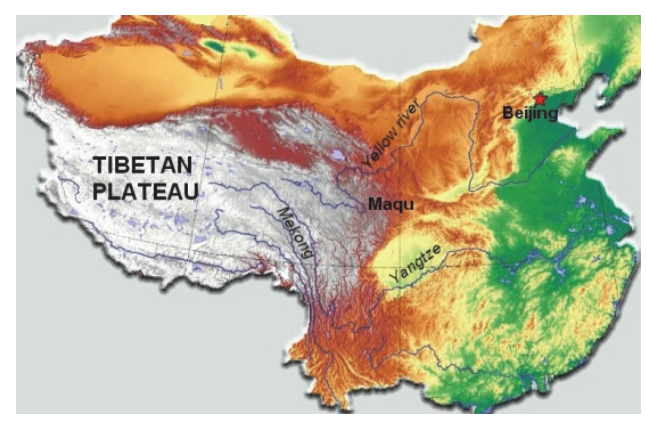

Figure 2.1 Location of Maqu in China. 


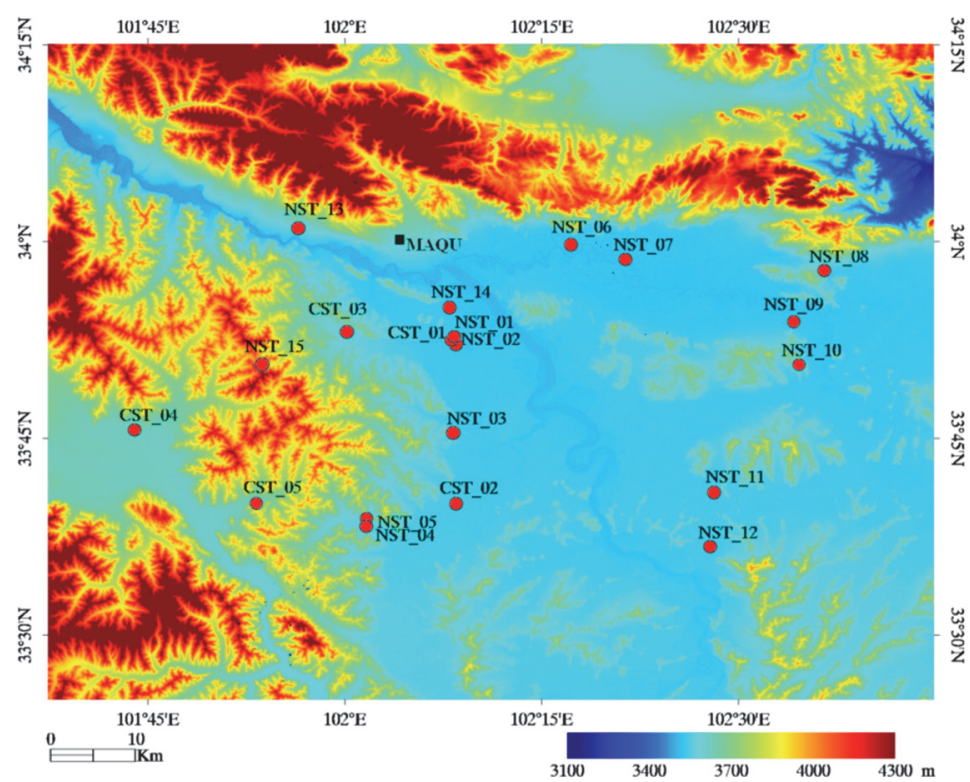

Figure 2.2 SRTM DEM of Maqu area and location of the 20 monitoring sites of the network.

Undisturbed soil samples collected at depths between 5 and $15 \mathrm{~cm}$ were used to analyse the particle size distribution and the organic matter content. The analyses showed that most of the stations are sited on silt loam soils (the most common soil in the area), except site NST_09, with sandy loam soil, and NST_10, with loam-silt loam soil. The wetland sites, NST_04 and NST_11, have the highest organic matter content (above $130 \mathrm{~g} \mathrm{~kg}^{-1}$ ), but also the sites NST_03 and NST_15 have a relatively high quantities of organic matter in the soil.

Soil moisture and soil temperature were monitored at each site at fixed depths; at all the sites, the probes were installed at depths of 5 and $10 \mathrm{~cm}$ and for some, also at other depths, down to $80 \mathrm{~cm}$ (see Table 2.1).

EC-TM $\mathrm{ECH}_{2} \mathrm{O}$ probes (Decagon Devices, Inc., USA) were used to measure both soil moisture and soil temperature. $\mathrm{EC}-\mathrm{TM} \mathrm{ECH}_{2} \mathrm{O}$ is a capacitance sensor measuring the dielectric permittivity of the soil surrounding the probe's pins. A general equation valid for all fine textured mineral soils is used to convert the dielectric permittivity in to the volumetric soil moisture. 
Table 2.1 Network site information (site name, elevation a.s.l., date of installation, depth of probes, local topography (T), land cover (LC), soil texture at $5-15 \mathrm{~cm}$ depth (ST), soil organic matter content at $5-15 \mathrm{~cm}$ depth (OMC)). NA stands for Not Available.

\begin{tabular}{|c|c|c|c|c|c|c|c|}
\hline Site ID & $\begin{array}{l}\text { Elev. } \\
\text { (m) }\end{array}$ & $\begin{array}{l}\text { Instal. } \\
\text { date }\end{array}$ & $\begin{array}{c}\text { Depth } \\
\text { (cm) }\end{array}$ & $T$ & LC & ST & $\begin{array}{c}\text { OMC } \\
\left(\mathrm{g} \mathrm{kg}^{-1}\right)\end{array}$ \\
\hline CST_01 & 3431 & May 08 & $\begin{array}{c}5,10,20 \\
40,80\end{array}$ & $\begin{array}{l}\text { River } \\
\text { valley }\end{array}$ & Grass & NA & NA \\
\hline CST_02 & 3449 & May 08 & $\begin{array}{c}5,10,20 \\
40,80\end{array}$ & $\begin{array}{l}\text { River } \\
\text { valley }\end{array}$ & Grass & NA & NA \\
\hline CST_03 & 3507 & May 08 & $\begin{array}{c}5,10,20 \\
40,80\end{array}$ & $\begin{array}{c}\text { Hill } \\
\text { valley }\end{array}$ & Grass & NA & NA \\
\hline CST_04 & 3504 & May 08 & $\begin{array}{c}5,10,20 \\
40,80\end{array}$ & $\begin{array}{c}\text { Hill } \\
\text { valley }\end{array}$ & Grass & NA & NA \\
\hline CST_05 & 3542 & May 08 & $\begin{array}{c}5,10,20 \\
40,80\end{array}$ & $\begin{array}{c}\text { Hill } \\
\text { valley }\end{array}$ & Grass & NA & NA \\
\hline NST_01 & 3431 & June 08 & $\begin{array}{c}5,10,20 \\
40,80 \\
\end{array}$ & $\begin{array}{l}\text { River } \\
\text { valley }\end{array}$ & Grass & Silt loam & 18 \\
\hline NST_02 & 3434 & June 08 & 5,10 & $\begin{array}{l}\text { River } \\
\text { valley }\end{array}$ & Grass & Silt loam & 18 \\
\hline NST_03 & 3513 & June 08 & 5,10 & $\begin{array}{c}\text { Hill } \\
\text { slope }\end{array}$ & Grass & Silt loam & 49 \\
\hline NST_04 & 3448 & June 08 & 5,10 & $\begin{array}{l}\text { River } \\
\text { valley }\end{array}$ & $\begin{array}{c}\text { Wetland } \\
\text { grass }\end{array}$ & Silt loam & 229 \\
\hline NST_05 & 3476 & June 08 & $\begin{array}{c}5,10,20 \\
40\end{array}$ & $\begin{array}{c}\text { Hill } \\
\text { slope }\end{array}$ & Grass & Silt loam & 22 \\
\hline NST_06 & 3428 & June 08 & $\begin{array}{c}5,10,20 \\
40\end{array}$ & $\begin{array}{l}\text { River } \\
\text { valley }\end{array}$ & Grass & Silt loam & 23 \\
\hline NST_07 & 3430 & June 08 & 5,10 & $\begin{array}{l}\text { River } \\
\text { valley }\end{array}$ & Grass & Silt loam & 23 \\
\hline NST_08 & 3473 & June 08 & 5,10 & valley & Grass & Silt loam & 34 \\
\hline NST_09 & 3434 & June 08 & 5,10 & $\begin{array}{l}\text { River } \\
\text { valley }\end{array}$ & Grass & $\begin{array}{c}\text { Sandy } \\
\text { loam }\end{array}$ & 17 \\
\hline NST_10 & 3512 & June 08 & $\begin{array}{c}5,10,20 \\
40 \\
\end{array}$ & $\begin{array}{c}\text { Hill } \\
\text { slope }\end{array}$ & Grass & $\begin{array}{c}\text { Loam- } \\
\text { silt loam }\end{array}$ & 24 \\
\hline NST_11 & 3442 & June 08 & 5,10 & $\begin{array}{l}\text { River } \\
\text { valley }\end{array}$ & $\begin{array}{c}\text { Wetland } \\
\text { grass }\end{array}$ & Silt loam & 136 \\
\hline NST_12 & 3441 & June 08 & $\begin{array}{c}5,10,20 \\
40,80\end{array}$ & $\begin{array}{l}\text { River } \\
\text { valley }\end{array}$ & Grass & Silt loam & 39 \\
\hline NST_13 & 3519 & June 08 & $\begin{array}{c}5,10,20 \\
40\end{array}$ & valley & Grass & Silt loam & 29 \\
\hline NST_14 & 3432 & June 08 & 5,10 & $\begin{array}{l}\text { River } \\
\text { valley }\end{array}$ & Grass & Silt loam & 30 \\
\hline NST_15 & 3752 & June 08 & 5,10 & $\begin{array}{c}\text { Hill } \\
\text { slope }\end{array}$ & Grass & Silt loam & 56 \\
\hline
\end{tabular}


The accuracy of the probe output was improved by performing a specific calibration for each soil type found in the Maqu area. This consisted of measuring in the laboratory the soil moisture of each soil type with both the $\mathrm{ECH}_{2} \mathrm{O}$ probes and the gravimetric method for a large range of soil water content. The soil-specific calibration equation consisted of the best fit between these two sets of independent measurements. The calibration resulted in a decrease in the root mean square error (RMSE) from 0.06 to $0.02 \mathrm{~m}^{3} \mathrm{~m}^{-3}$.

A micro-meteorological tower, the Maqu Source Water Region of Yellow River Station for Climate and Environment Observation and Research of Chinese Academy of Science, is located next to site CST_01 (see Figure 2.2), providing, among other parameters, precipitation data (accumulated every 30 minutes) and air temperature (measured at a height of $2.35 \mathrm{~m}$ ).

More details on the site description, the network set up and the probe calibration are reported in Appendix A.

\subsubsection{Stratified sampling}

The main factors affecting the spatial variability of soil moisture in the Maqu region are topography (i.e. elevation and slope) and soil texture (i.e. silt loam and wetland organic soil). Measurements in deep soil layers showed that the ground water table is in the largest part of the region too deep to affect the soil moisture at the surface, with exception of the wetlands. The spatial pattern of the precipitation only occasionally increased the spatial variability of soil moisture (see Section 2.4).

Four different strata were identified in the area covered by the Maqu network: 1) non-wetland valley, 2) wetland valley, 3) moderate slopes and 4) steep slopes. The first two strata are characterised by, in stratum 1 , a flat terrain with slopes ranging from $0^{\circ}$ to $3^{\circ}$ and silt loam soil and, in stratum 2, similarly flat terrain and organic soil. Stratum 3 applies to areas with moderate slopes, ranging from $3^{\circ}$ to $15^{\circ}$, and stratum 4 refers to the steep areas, with slopes exceeding $15^{\circ}$.

Surface slopes were estimated from the SRTM DEM of the area (Figure 2.2) and, based on the slope thresholds for each stratum, the 
proportion of each stratum present in the study area was estimated, as reported in Table 2.2. Note that the non-wetland stratum includes both silt loam and sandy loam soils. However, the information on soil texture of this area that is currently available is not sufficiently accurate to determine the extent of the sandy areas.

In the valleys, wetlands were distinguished from non-wetland areas using the corresponding Normalized Difference Vegetation Index (NDVI) time series of the 2009 monsoon season. The NDVI is a good indicator of vegetation growth and coverage. The vegetation growth is expected to differ on dry grassland and wetlands, in particular during the dry periods after the rains, when the soil is drying out. Grassland occurs where the ground water table is deeper, i.e. on higher parts of the valleys, while wetlands occur at the bottom of the valleys, where the ground water table is at or very close to the surface. MODIS (MOderate resolution Imaging Spectroradiometer) NDVI data (resolution $250 \mathrm{~m}$ ) averaged over 16 days were used for this purpose; these data are distributed by the Land Processes Distributed Active Archive Center, through the Warehouse Inventory Search Tool (WIST) (https://wist.echo.nasa.gov/api/).

Six areas in the surroundings of the monitored wetland sites were selected, as well as an equal number of areas in the surroundings of the non-wetland sites. The NDVI time series, averaged for wetland and non-wetland areas, are shown in Figure 2.3. The NDVI image of 11 July 2009 is very noisy (which is probably due to several cloudy days before this date), therefore the estimated NDVI has a large standard deviation. Figure 2.3 shows that the non-wetland NDVI slowly decreased from the end of July to the end of September, whereas the wetland NDVI did not begin to decrease before the end of August. In September, however, it decreased rapidly and by the end of the month the NDVI of valleys was homogenous. From these observations, it was possible to distinguish wetlands from nonwetlands and to determine that wetlands cover approximately 19\% of the valleys in the Maqu study area, a realistic estimate that matches information collected during a site visit.

Table 2.2 shows the coverage of the four selected strata in Maqu area and the corresponding proportion of observations as a percentage. The stratified sampling was slightly disproportionate, as more sites should have been monitored on the wetlands and the steep slopes, 
and less in the non-wetland stratum. The oversampling of soil moisture in the non-wetland stratum was mainly due to redundant sampling near the meteorological tower, which was done to be able to cross-validate the measurements from three stations and to ensure continuous soil moisture monitoring at the spot where the meteorological data is gathered. The undersampling in the wetland and steep slope strata was due to the difficult accessibility of these areas.

Table 2.2 Coverage of each stratum present in Maqu area and corresponding proportion of monitored sites as a percentage.

\begin{tabular}{|l|l|l|}
\hline Stratum & Coverage & $\begin{array}{l}\text { Monitored } \\
\text { sites }\end{array}$ \\
\hline Wetland - valley & $19 \%$ & $10 \%$ \\
\hline Not wetland - valley & $32 \%$ & $55 \%$ \\
\hline Moderate slope & $33 \%$ & $30 \%$ \\
\hline Steep slope & $16 \%$ & $5 \%$ \\
\hline
\end{tabular}

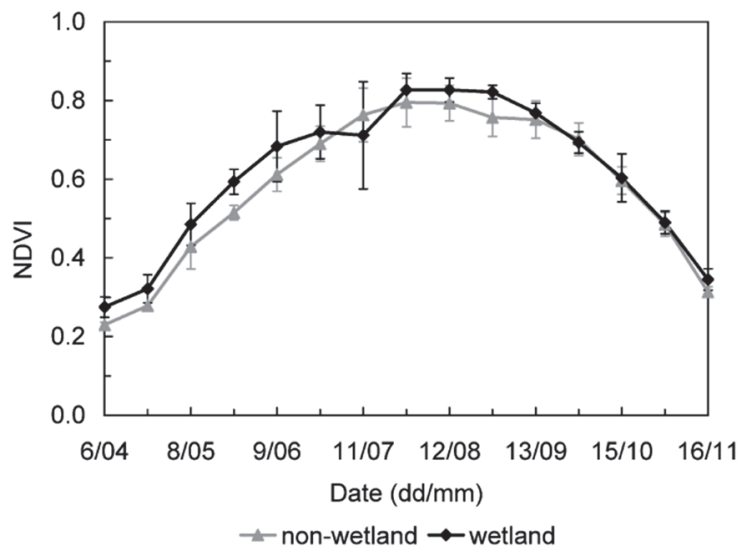

Figure 2.3 MODIS 16 days NDVI time series of 2009 averaged for six wetland areas (black line) and for six non-wetland areas (grey line) in the Maqu valley. 


\subsubsection{Temporal behaviour and weighted average}

Continuous volumetric soil moisture and soil temperature data averaged for 15 minute intervals have been collected from the 20 locations of the Maqu network since July 2008.

As an example of typical soil moisture and soil temperature behaviour at $5 \mathrm{~cm}$ depth in the Maqu study area, measurements collected at the CST_01 site from July 2008 to December 2009 are shown in Figure 2.4 and compared with precipitation and air temperature data collected at the same location (unfortunately meteorological data are missing from 3 to 17 July 2008 and from 17 December 2008 to 19 May 2009). There is a good agreement between soil moisture data and precipitation and between soil temperature and air temperature at $5 \mathrm{~cm}$ depth.
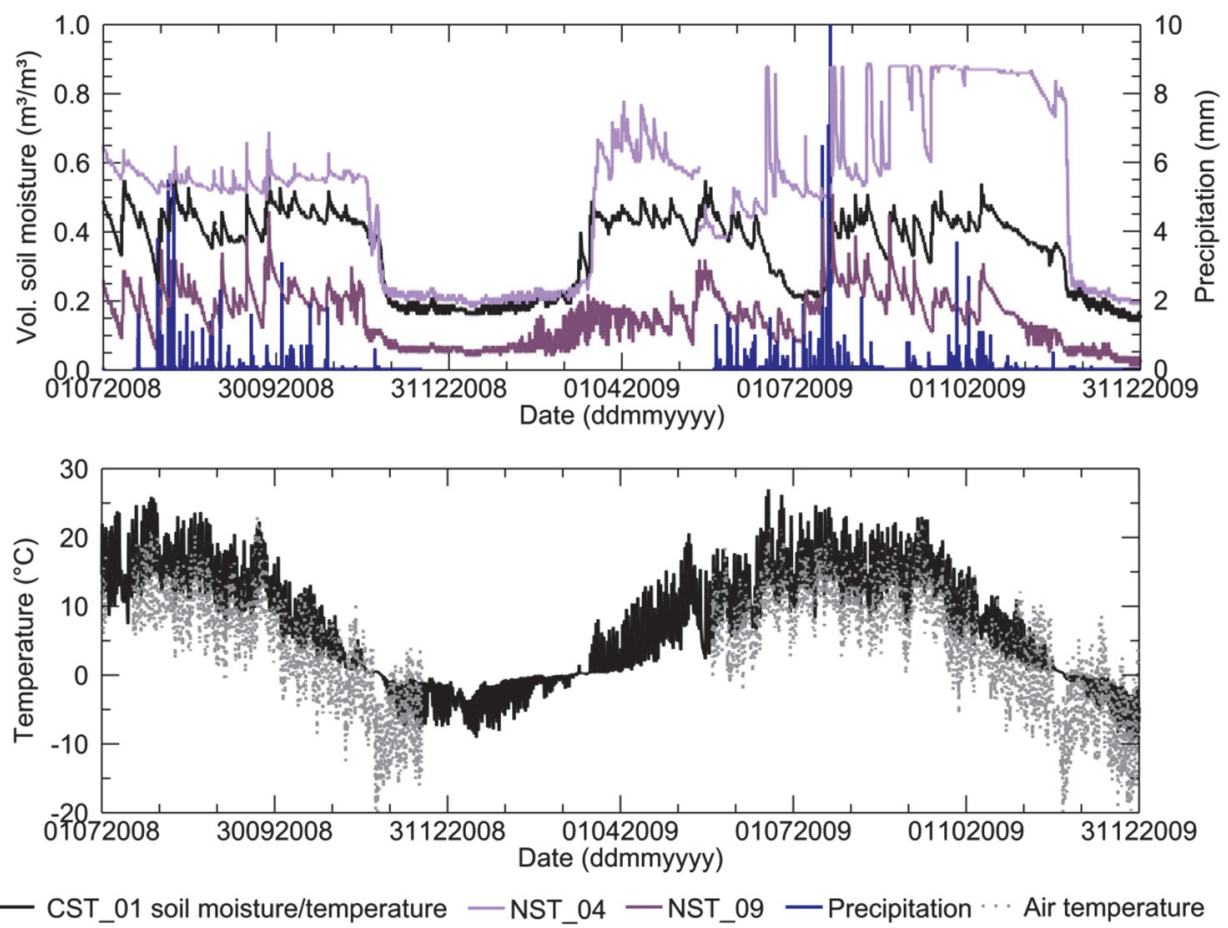

Figure 2.4 Temporal behaviour of soil moisture measured at sites CST_01, NST_04 and NST_09 (top) and soil temperature measured at site CST_01 (bottom) compared with precipitation and air temperature. 
From July to October 2008 and from April to October 2009, the climate was dominated by the monsoon, with higher average and larger daily gradients of soil temperature and frequent rainfall events. As the data show, during the monsoon soil temperature had a diurnal variability of approximately $10{ }^{\circ} \mathrm{C}$, reaching the maximum values of about $28{ }^{\circ} \mathrm{C}$ in June and July and showing a decrease in correspondence to heavy rain showers.

In April 2009, the soil at the CST_01 site was dry and the soil moisture was very sensitive to rainfall events. The water content increased quickly, but usually without reaching saturation. As soon as the rainfall event ended, the soil surface dried out, mainly due to percolation of the water to deeper layers (measurements at 10 and $20 \mathrm{~cm}$ depth show an increase of soil moisture after a rainfall event), but also due to soil evaporation caused by warm day temperatures. Average soil moisture increased in the monsoon season, reaching its maximum of approximately $0.55 \mathrm{~m}^{3} \mathrm{~m}^{-3}$.

In winter, air temperature at the CST_01 site was mostly below zero and the number of precipitation events decreased. Soil temperature decreased in October and reached a minimum of about $-10{ }^{\circ} \mathrm{C}$ in January. The soil moisture measured by the probes showed a decrease as well, reaching a minimum of approximately $0.1 \mathrm{~m}^{3} \mathrm{~m}^{-3}$ in February. However, this was very likely due to both the dryer weather and the measurement technique of the probes. As soon as soil temperatures drop below $0^{\circ} \mathrm{C}$, the soil water freezes, preventing the water molecules from moving freely. As a result, soil permittivity decreases and the probes register a low value of soil moisture (i.e. the remaining liquid water content), even though the total soil water content remains unchanged.

Soil moisture at several other locations in the area behaved similarly to the CST_01 site at $5 \mathrm{~cm}$ depth. Different behaviour was, however, observed at the sandy soil site NST_09 and the wetlands sites NST_04 and NST_11, where the two extremes of the soil moisture variability range of the area were observed (see Figure 2.4). At the sandy soil site NST_09, soil moisture was on average lower than that of the other sites, as expected for this kind of soil texture. In contrast, soil moisture in the wetlands (as at location NST_04, shown in Figure 2.4) was characterised by a higher average value and a larger variability range than for the CST_01 site. Due to the shallow ground water table, 
the wetlands do not dry out so easily as the other areas. Probes measured very high values in the wetlands, owing to their very low content of mineral soils but high organic matter content.

Figure 2.5 plots soil moisture data at $5 \mathrm{~cm}$ depth collected at all the sites from July 2008 to December 2009 and shows the large spatial variability of soil moisture in Maqu region. As mentioned, this is mainly due to the effects of topography and soil type on soil moisture. The average correlation of the soil moisture data measured at one site with that of all the others ranges from a minimum of 0.72 to a maximum of 0.91 . This confirms that the spatial variability of soil moisture was only rarely a consequence of the spatial variability of rainfall and that the soil moisture data were reliable and consistent over time.

The soil moisture collected at $5 \mathrm{~cm}$ depth is referred always in the following part of this manuscript. The data collected from deeper layers cannot be used for the direct validation of satellite-derived soil moisture products, as the penetrating depth of the C-band microwave radiation is generally not deeper than few centimetres from the surface.

In order to validate the satellite-derived soil moisture products, an area estimate of soil moisture needs to be extracted from the pointscale measurements collected from Maqu study area. The approach selected to tackle this issue consisted of estimating the weights to be assigned to the soil moisture measured in each sampling stratum and then computing the spatially weighted average. Within each stratum, the same weight was given to each measurement and the simple average was computed. The weight to be applied to the average soil moisture of each stratum was defined according to proportion of the spatial extent of the stratum (i.e. 0.19 for the wetland stratum, 0.32 for the non-wetland, 0.33 for the moderate slope and 0.16 for the steep slope). The weighted average, $\overline{S M}$, was then computed according to the equation:

$\overline{S M}=\frac{\sum_{k=1}^{N} w_{k} \overline{S M_{k}}}{\sum_{k=1}^{N} w_{k}}$ 
where $\overline{S M_{k}}$ is the average soil moisture measured within stratum $k$ $(k=1, \ldots N)$, where $N$ is the total number of strata identified in the area (in this case it is 4 ), and $w_{k}$ is the weight assigned to the average soil moisture of stratum $k$.

The weighted spatial average of the Maqu monitoring network was compared with the simple spatial average (i.e. $w_{k}=1$ for all $k$ in Equation 2.1) in Figure 2.5.

As mentioned in the previous section, the stratified sampling was slightly disproportionate, so the simple spatial average differs slightly from the weighted spatial average, in particular during the monsoon season. The mean absolute difference between the simple and the weighted average is $0.04 \mathrm{~m}^{3} \mathrm{~m}^{-3}$. There is a good match between the temporal behaviour of the two averages, with a correlation of 0.96 . In the analyses of this dissertation the weighted average will be used, as it is statistically more correct.

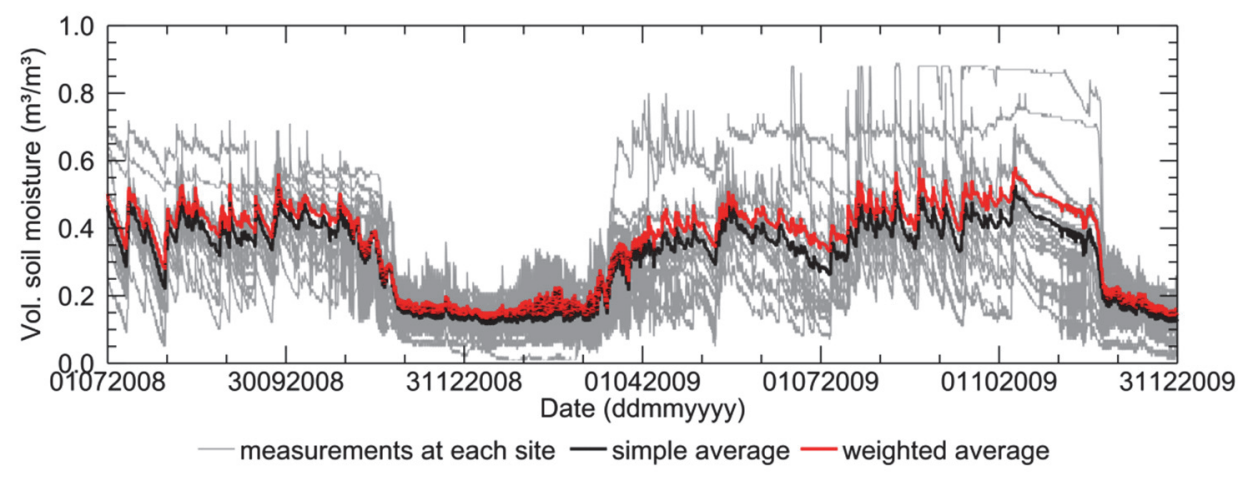

Figure 2.5 Soil moisture measured at $5 \mathrm{~cm}$ depth at all Maqu network sites (grey lines), simple spatial average (black line) and weighted spatial average (red line).

\subsubsection{Temporal stability}

The spatial and temporal variability of the soil moisture measured in the Maqu area was analysed using the mean relative difference (MRD) approach, which was developed by Vachaud et al. (1985) and has been applied in several studies since (Cosh et al. 2008; Martinez- 
Fernandez and Ceballos 2005; Schneider et al. 2008). The MRD is an indicator of the agreement between the soil moisture time series for each site and the spatial average. The standard deviation of the relative difference (STD) quantifies the variability of this agreement in time. This approach also enabled to identify which site of the Maqu network shows the lowest bias and variance with respect to the spatial average of the area that can be considered an accurate indicator of the soil moisture dynamics at the network scale.

According to Vachaud et al. (1985), the MRD of a site $i$ is defined as:

$M R D_{i}=\frac{1}{n} \sum_{j=1}^{n} \frac{S M_{i j}-\overline{S M_{j}}}{\overline{S M_{j}}}$

where $S M_{i j}$ is the measured soil moisture at site $i$ and at time $j, \overline{S M_{j}}$ is the soil moisture spatial weighted average of the Maqu area at time $j$ and $n$ is the number of records collected in the selected period.

The standard deviation of the relative difference, STD, of a site $i$ is defined as:

$S T D_{i}=\sqrt{\frac{1}{n-1} \sum_{j=1}^{n}\left(R D_{i j}-M R D_{i}\right)^{2}}$

where $R D_{i j}$ is the relative difference of site $i$ at time $j$, as defined by $R D_{i j}=\frac{S M_{i j}-\overline{S M_{j}}}{\overline{S M_{j}}}$.

Figure 2.6 shows the MRD and STD for all Maqu sites computed over all the 2008 and 2009 data available. Site NST_14 has the MRD closest to zero, with sites CST_01, CST_04, CST_05, NST_03 and NST_11 showing an MRD less than 0.1. Among these six sites, the MRDs of NST_14 and CST_04 site have the lowest STDs. However, there is no data for these two sites from June to September 2009 and from October 2008 to May 2009, respectively, which can strongly affect the results of this type of analysis. As a result, the data from these two sites was not taken into account for further analysis. When NST_14 and CST_04 are not included, NST_03 has the lowest STD; sites CST_01, CST_05 and NST_11 have slightly higher STDs than that of NST_03. 


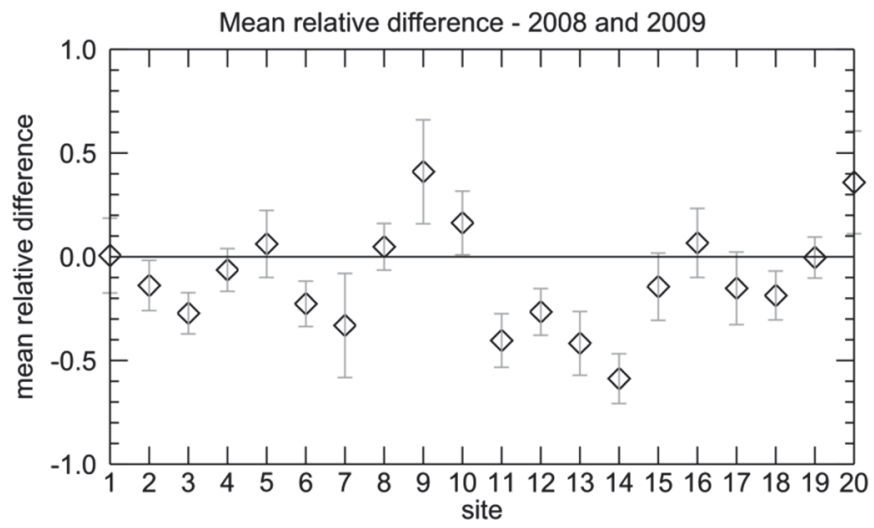

Figure 2.6 MRD and STD for all Maqu sites from July 2008 to December 2009: sites 1-5 correspond to CST_01-05 and sites 6-20 correspond to NST_01-15.

The largest difference compared to average soil moisture were found for two sites located on soils of high organic content, NST_04 and NST_15, and for one sandy site, NST_09. The MRDs for NST_04 and NST_15 also have high STDs, which is due to the large difference between the soil moisture measured at these sites and the weighted average during some parts of the monsoon season. Similar results could be expected for the other wetland site, NST_11, but this is not the case. Indeed, at this site the soil did not easily reach saturation as did at NST_04 and NST_15, although its soil moisture has a larger variability range than the Maqu area spatial average. For this reason, the MRD at the NST_11 site is relatively low, but its STD is high. There is no clear dependence between low MRD values and site location in the Maqu study area.

An interesting result was found for the sites located near the meteorological tower, i.e. CST_01, NST_01 and NST_02. As they are located within a few hundred metres of the tower, similar behaviour with respect to soil moisture could be expected. Instead, the NST_02 site has both a large MRD and STD. Indeed, a comparison of the measurements revealed that the drainage of the NST_02 site is higher than the other two and its soil moisture can reach much lower values when the soil dries out.

The dependence of the MRD on the season was investigated, applying the same approach to the data collected in the monsoon season only (May to September), in winter only (December to 
February) and in the period between the monsoon season and winter (March-April, October-November, called the transition season). The MRDs and STDs of these seasons are presented in Figure 2.7.

The winter data show, in general, a higher MRD and a smaller STD than the other seasons, primarily because the soil is frozen in this period, resulting in low values of soil moisture (i.e. the remaining free water in the frozen soils) at all sites and in reduced spatial variability. This explains why even small differences with respect to the spatial average can result in a large MRD, but a small STD.

The top two plots of Figure 2.7 show that in most of the sites the MRD does not change in absolute value or sign between the monsoon season and the transition season. This indicates a stable temporal pattern of soil moisture at these sites. However, at some sites the soil moisture patterns were not stable with respect to the spatial average. The MRD changes in absolute value for the sites CST_03, NST_02, NST_04, NST_12 and NST_15 and in sign for the sites CST_01, CST_05 and NST_11 from one season to the next. Owing to the change in MRD sign, CST_01 and CST_05 have low MRDs but high STDs, when the data of all seasons are considered (Figure 2.6).

NST_03 soil moisture is for most of the time in a good agreement with the weighted spatial average of Maqu area with low values of MRD and STD, although during the transition season both MRD and STD values are relatively higher. For this reason, it is not possible to conclude that NST_03 soil moisture is the best indicator of the soil moisture pattern at Maqu network scale. Moreover, the lack of data for the NST_14 and CST_04 sites in the time window considered for this analysis might affect the conclusions. For these reasons, the weighted average, and not the NST_03 soil moisture, was used for the validation of the satellite-derived products. 

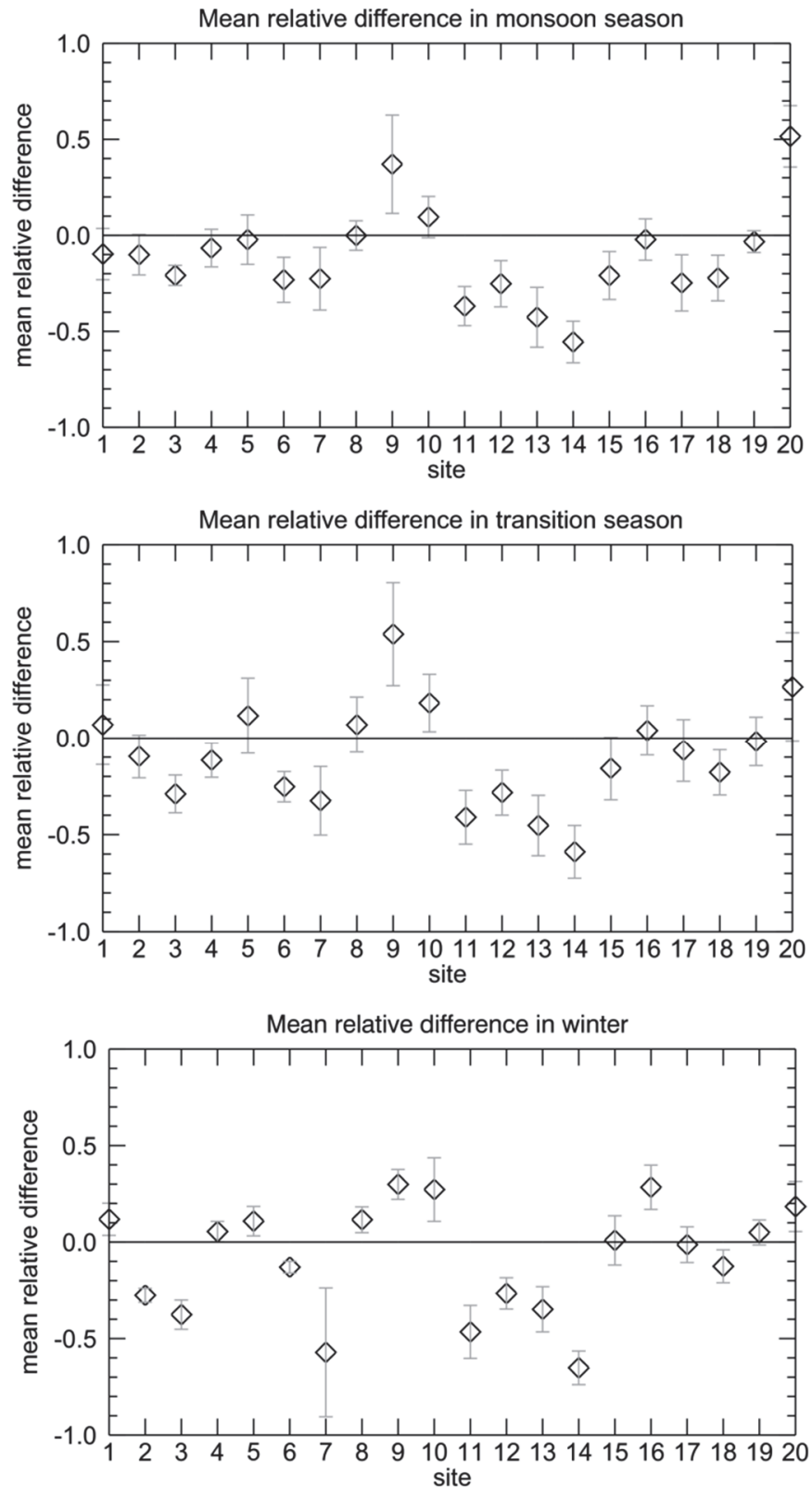

Figure 2.7 MDR and STD for all Maqu sites in monsoon seasons (May-August), transition seasons (March-April, October-November) and winter (DecemberFebruary) of 2008 and 2009: sites 1-5 correspond to CST_01-05 and sites 6-20 correspond to NST_01-15. 


\section{$2.3 \quad$ Twente}

\subsubsection{Introduction}

The second soil moisture and soil temperature monitoring network, which was set up in the frame of this research, is located in the Twente region of The Netherlands. The Twente region was chosen as validation site, because complementary to the Maqu region, in terms of topography, land cover and soil texture. The two regions also differ in climate, as the winter in the Twente region is milder (with on average higher temperatures and less snow) and the precipitations are more spread through the year than in the Maqu region. The differences between Maqu and Twente regions allow for different aspects of the validation of satellite-derived soil moisture to be analysed. The extensive network set up in Twente monitors continuously soil moisture and soil temperature at $5 \mathrm{~cm}$ depth, as well as at deeper layers, since November 2008. It consists of 20 stations and covers an area, of approximately $50 \mathrm{~km} \times 40 \mathrm{~km}$, larger than the typical coarse resolution cell of the satellite data used for soil moisture retrieval. With these important features the network can potentially provide the necessary information to validate the satellite-derived soil moisture products.

The main objective of this second part of Chapter 2 is to present the first set of data measured at the Twente area and to evaluate its suitability as a validation site for satellite-derived soil moisture products. A detailed description of the study site and the network characteristics is reported in Section 2.3.2; a qualitative analysis of temporal and spatial behaviour of the surface soil moisture and temperature data is presented in Section 2.3.3.

\subsubsection{Twente site and network description}

The Twente soil moisture monitoring network is located in the eastern part of the Overijssel province in The Netherlands, covering the region called Twente, part of the Salland region and Gelderland province $\left(52^{\circ} 05^{\prime}-52^{\circ} 27^{\prime} \mathrm{N}, 6^{\circ} 05^{\prime}-7^{\circ} 00^{\prime} \mathrm{E}\right)$. A map of The Netherlands, Overijssel province and Twente region is shown in Figure 2.8. A 
Landsat 5 TM image acquired on 27 June 2010 over the network area (with band 7 in red, band 4 in green and band 2 in blue) is shown in Figure 2.9. The locations of all the monitored sites are indicated with white squares. The different colours show a different land use: urban areas in magenta, open water in blue, forest in olive-green, sandy areas in violet, bare soils, sparsely vegetated fields and agricultural fields in pink and bright green (the colour depends on the vegetation development stage).

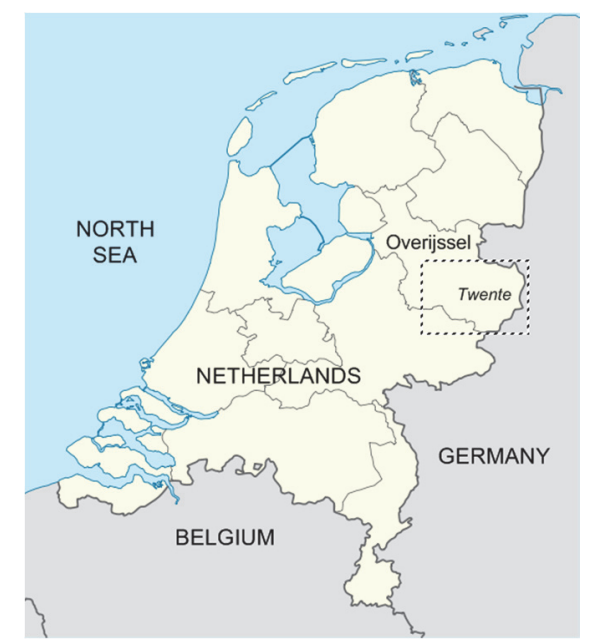

Figure 2.8 Maps of The Netherlands, Overijssel province and Twente region. The area of the monitoring network is highlighted by a rectangle with dashed line.

The region is flat with elevation ranging between $-3 \mathrm{~m}$ to $50 \mathrm{~m}$ above sea level. The most extensively occurring land cover is grassland for pasture, which is harvested and fertilized several times in the year. However, the land use of this region also includes a mosaic of agricultural fields, mainly corn fields (planted in April and harvested in September), cereals and potato. According to the Koeppen Classification System, the climate in The Netherlands is temperate. Monthly average air temperature and monthly accumulated precipitation, averaged from 1974 to 2009 , for the Twente region are shown in Figure 2.10. The data, provided by the Royal Netherlands Meteorological Institute (KNMI, http://www.knmi.nl/klimatologie/), were collected at one station (named Twente) located in the Twente region near Enschede. The yearly average precipitation is 
approximately $760 \mathrm{~mm}$, spread all over the year. The monthly average air temperature ranges between $3^{\circ} \mathrm{C}$ in January to approximately $17^{\circ} \mathrm{C}$ in July.

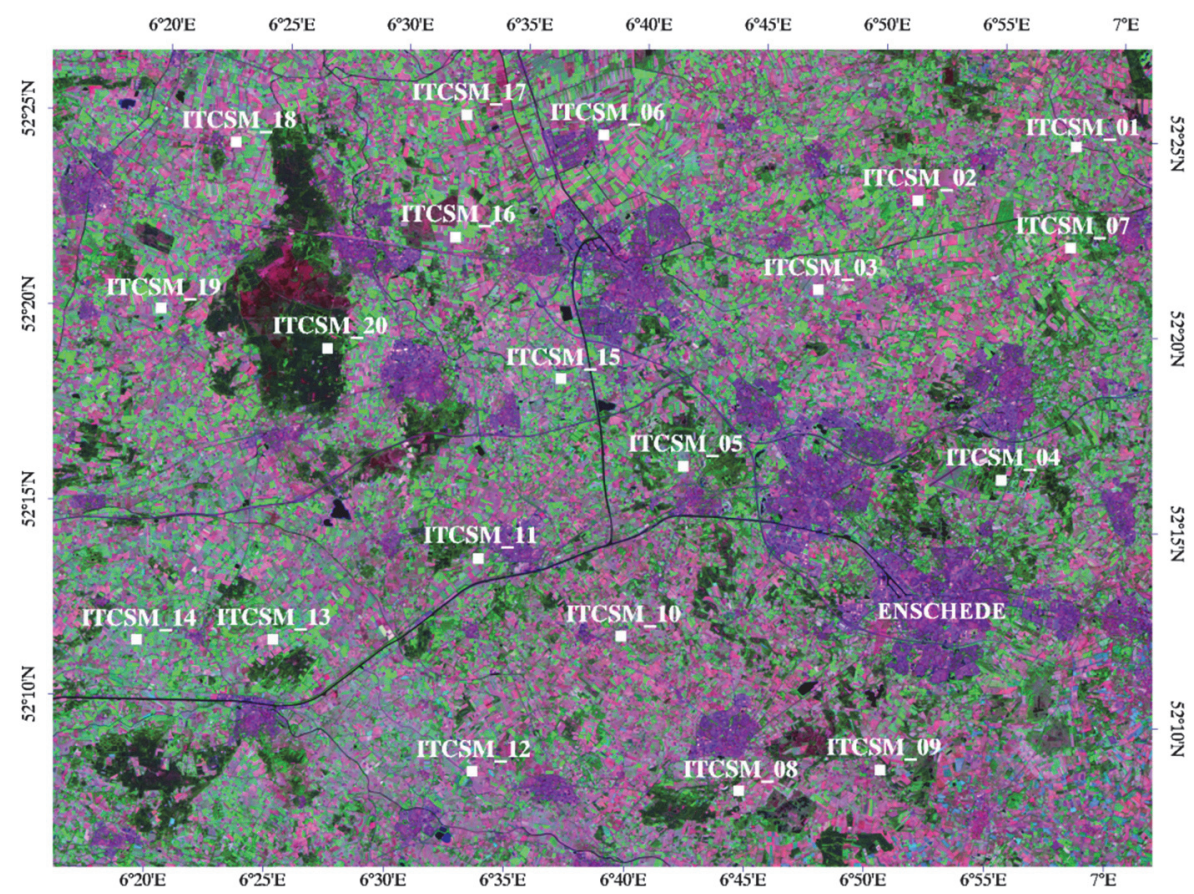

Figure 2.9 Landsat 5 TM image (RGB: band 7, band 4, band 2) acquired on 27 June 2010 over Twente monitoring network. The locations of the 20 monitored sites are highlighted with white squares.

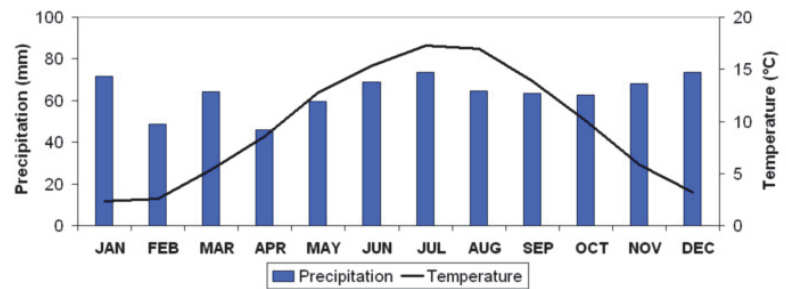

Figure 2.10 Monthly accumulated precipitation and monthly average air temperature at Twente site averaged over 35 years (from 1974 to 2009). 
An important factor affecting the spatial variability of soil moisture in this area is the ground water table. Due to groundwater management occurring in this region, the groundwater table may rise to $25 \mathrm{~cm}$ below the soil surface as well as drop to below $160 \mathrm{~cm}$. Information about the variability range of the ground water table were found in the soil texture map 1:50000 Bodemkaart van Nederland by Stichting voor Bodemkartering (Wageningen) of the network area. 8 possible variability ranges can be found in Twente region and are reported in Table 2.3.

Table 2.3 Legend of the ground water table information reported in the soil texture maps. Lowest and highest average depth ( $\mathrm{cm}$ from the surface) of the ground water table for different areas in Twente.

\begin{tabular}{|l|l|l|}
\hline & Lowest depth & Highest depth \\
\hline III & $80-120$ & $<40$ \\
\hline III* & $80-120$ & $25-40$ \\
\hline IV & $80-120$ & $>40$ \\
\hline V & $>120$ & $<40$ \\
\hline V* & $>120$ & $25-40$ \\
\hline VI & $>120$ & $40-80$ \\
\hline VII & $>160$ & $>80$ \\
\hline
\end{tabular}

Soil samples were collected in order to analyse bulk density and particle size distribution. Soil sample rings (aluminium cylinders of known volume) were collected at $5 \mathrm{~cm}$ depth and oven dried at $105^{\circ} \mathrm{C}$ to estimate the bulk density (i.e. dry soil mass in a known volume). The samples for particle size analysis were collected at a depth between 5 and $20 \mathrm{~cm}$. When the soil profile showed a variation at deeper layers, the sample collection and the analyses were repeated for the second horizon as well. The particle size distribution was analysed by means of the standard methods of sieving. The analysis results show that the soil of the network region is characterized by a very low content of clay.

The installation of the soil moisture and soil temperature monitoring stations started in November 2008 and was concluded in June 2009. The measurements are collected at 20 sites spread across an area of approximately $50 \mathrm{~km} \times 40 \mathrm{~km}$. The sites were selected in order to monitor the area extensively for a variety of soil types, land covers and variability ranges of ground water tables. 16 stations were 
installed in grassland fields, 3 in corn fields and 1 in a forest. 12 sites are located in sandy soils and 7 in loamy sand soils (no data available for one site).

Soil moisture and soil temperature are monitored at each station at different depths. At 4 out of the 20 sites probes measure data at 5, 10, 20 and $40 \mathrm{~cm}$ depth, at 8 sites 3 different depths are monitored down to $20 \mathrm{~cm}$ and at all the other sites data are collected only at 5 and 10 cm depth.

Figure 2.11 shows the landscape of all sites in winter and Table 2.4 summarises all the information related to each site of the network.

As for the case of the Maqu network, each monitoring station consists of one $\mathrm{Em} 50 \mathrm{ECH}_{2} \mathrm{O}$ datalogger, which records the data collected by two to four EC-TM ECH $\mathrm{E}_{2} \mathrm{O}$ probes able to measure both soil moisture and soil temperature (see Appendix A for a detailed description of the probes and installation procedure). The measurements are carried out every minute and then averaged and stored every 15 minutes.

A specific calibration of the probes was needed for the soil type of Twente area. Therefore soil samples were collected and laboratory calibrations were carried out (see Appendix A for a detailed description of the calibration procedure). The following calibration equation was found:

$S M_{\text {calibrated }}=0.77 \times S M_{E C H 2 O}+0.07$

where $S M_{E C H 2 O}$ is the soil moisture measured by the $\mathrm{ECH}_{2} \mathrm{O}$ probes and $S M_{\text {calibrated }}$ is the calibrated value. This calibration equation is valid for all sites except ITCSM_20, which is located in the forest. The soil in the forest has completely different characteristics than the other sites, as it is very rich of organic matter. Unfortunately, a specific laboratory calibration was not carried out. Applying the default calibration to the probe measurements collected during the laboratory experiment, the $R M S E$ with respect to the gravimetric measurements is $0.054 \mathrm{~m}^{3} \mathrm{~m}^{-3}$. Whereas, if the calibration equation (2.4) is applied the RMSE decreases to $0.023 \mathrm{~m}^{3} \mathrm{~m}^{-3}$. 


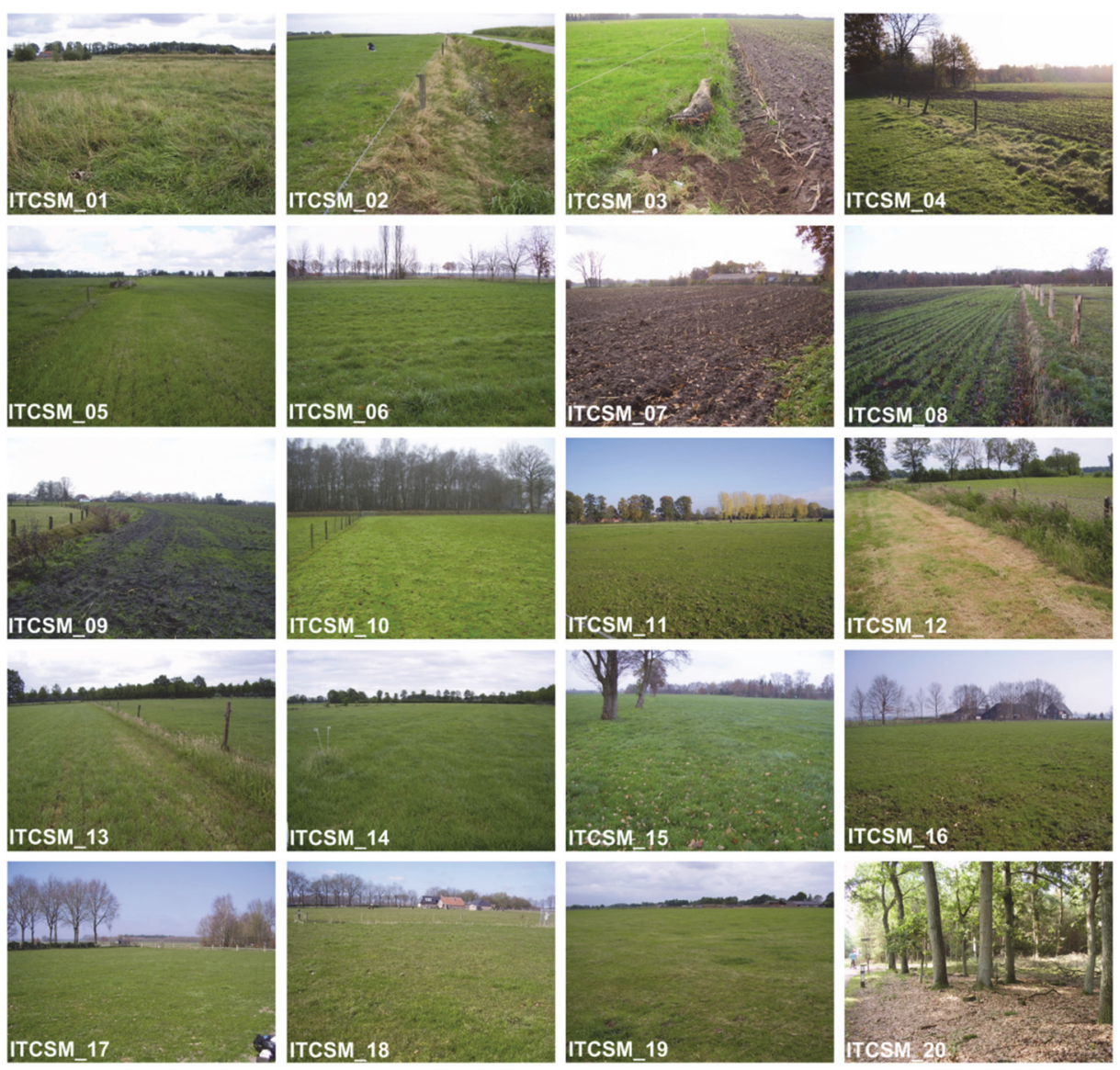

Figure 2.11 Landscape at the monitored sites of the Twente network in winter.

\subsubsection{Temporal behaviour and weighted average}

The quality of the data was checked observing the consistency of the soil moisture behaviour in time and space for all the sites, analysing the time series and comparing the behaviour of soil moisture and soil temperature with precipitation data.

The precipitation data were provided by Royal Netherlands Meteorological Institute (KNMI) and consisted of daily accumulated precipitation measured by 15 stations located in the area of the network (data available at http://www.knmi.nl/klimatologie). 
Table 2.4 Network site information (site name, elevation a.s.l., date of installation, depth of probes, land cover (LC), soil texture at 5-20 cm depth (ST) from laboratory analyses, ground water table classification (GW)). NA stands for Not Available.

\begin{tabular}{|c|c|c|c|c|c|c|}
\hline Site ID & $\begin{array}{l}\text { Elev. } \\
(\mathrm{m})\end{array}$ & $\begin{array}{l}\text { Instal. } \\
\text { date }\end{array}$ & $\begin{array}{l}\text { Depth } \\
\text { (cm) }\end{array}$ & LC & ST & GW \\
\hline ITCSM_01 & 3 & Dec 2008 & $\begin{array}{c}5,10 \\
20\end{array}$ & $\begin{array}{l}\text { Grass } \\
\text { bush }\end{array}$ & NA & IV \\
\hline ITCSM_02 & 28 & Nov 2008 & $\begin{array}{c}5,10 \\
20\end{array}$ & Grassland & Sand & VI \\
\hline ITCSM_03 & 7 & Nov 2008 & 5,10 & Grassland & Loamy sand & III \\
\hline ITCSM_04 & 44 & Nov 2008 & $\begin{array}{c}5,10 \\
20\end{array}$ & Grassland & Loamy sand & $\mathrm{V}$ \\
\hline ITCSM_05 & 17 & May 2009 & $\begin{array}{l}5,10 \\
20,40\end{array}$ & Grassland & Loamy sand & VII* \\
\hline ITCSM_06 & 6 & Nov 2008 & 5,10 & Grassland & Sand & III* \\
\hline ITCSM_07 & 17 & Nov 2008 & 5,10 & Corn & Loamy sand & III* \\
\hline ITCSM_08 & 21 & Nov 2008 & $\begin{array}{l}5,10 \\
20,40 \\
\end{array}$ & Corn & Sand & VI \\
\hline ITCSM_09 & 29 & Dec 2008 & 5,10 & Corn & Sand & $\mathrm{VI}$ \\
\hline ITCSM_10 & 11 & Dec 2008 & $\begin{array}{c}5,10 \\
20 \\
\end{array}$ & Grassland & Sand & III* \\
\hline ITCSM_11 & 7 & Dec 2008 & 5,10 & Grassland & Loamy sand & IV \\
\hline ITCSM_12 & 8 & May 2009 & $\begin{array}{c}5,10 \\
20\end{array}$ & Grassland & Sand & $\mathrm{V}^{*}$ \\
\hline ITCSM_13 & 8 & Jun 2009 & 5,10 & Grassland & Sand & VI \\
\hline ITCSM_14i & 7 & $\begin{array}{c}\text { Jun } 2009 \\
(- \text { Jun 2010) } \\
\end{array}$ & $\begin{array}{l}5,10 \\
20,30 \\
\end{array}$ & Grassland & Loamy sand & $\mathrm{V}$ \\
\hline ITCSM_14b & 7 & Apr 2011 & $\begin{array}{l}5,10 \\
20,30 \\
\end{array}$ & Grassland & Loamy sand & $\mathrm{V}$ \\
\hline ITCSM_15 & -3 & Nov 2008 & $\begin{array}{c}5,10 \\
20 \\
\end{array}$ & Grassland & Sand & III* \\
\hline ITCSM_16 & 5 & $\begin{array}{c}\text { Apr } 2009 \\
(- \text { Nov 2010) }\end{array}$ & 5,10 & Grassland & Sand & VI \\
\hline ITCSM_17i & 3 & Apr 2009 & 5,10 & Grassland & Sand & VII \\
\hline ITCSM_17b & 3 & Apr 2011 & 5,10 & Grassland & Sand & VII \\
\hline ITCSM_18 & -3 & Apr 2009 & $\begin{array}{c}5,10 \\
20 \\
\end{array}$ & Grassland & Loamy sand & V \\
\hline ITCSM_19 & 3 & Jun 2009 & $\begin{array}{l}5,10, \\
20,40 \\
\end{array}$ & Grassland & Sand & $\mathrm{V}^{*}$ \\
\hline ITCSM_20 & 17 & Sep 2009 & $\begin{array}{c}5,10 \\
20\end{array}$ & Forest & Sand & VII* \\
\hline
\end{tabular}

\footnotetext{
i On 20 April 2011 these two stations have been moved to a new location, with the same soil, land cover and ground water characteristics. The stations replacing these two have been renamed as ITCSM_14b and ITCSM_17b.
} 
An example of the data collected in one of the sites of the network (ITCSM_05) is shown in Figure 2.12. The volumetric soil moisture and the soil temperature measured at different depths are shown together with the daily precipitation recorded at the nearest KNMI station (Hengelo-0-668) from July 2009 to November 2010.

The measured data are consistent, indicating a good response of the $\mathrm{ECH}_{2} \mathrm{O}$ probes to soil wetting and drying. Both soil moisture and soil temperature, measured at 5 and $10 \mathrm{~cm}$ depth, show a temporal behaviour in good agreement with the precipitation events. The measured time series at 20 and $40 \mathrm{~cm}$ depth are smoother than at the surface layer.
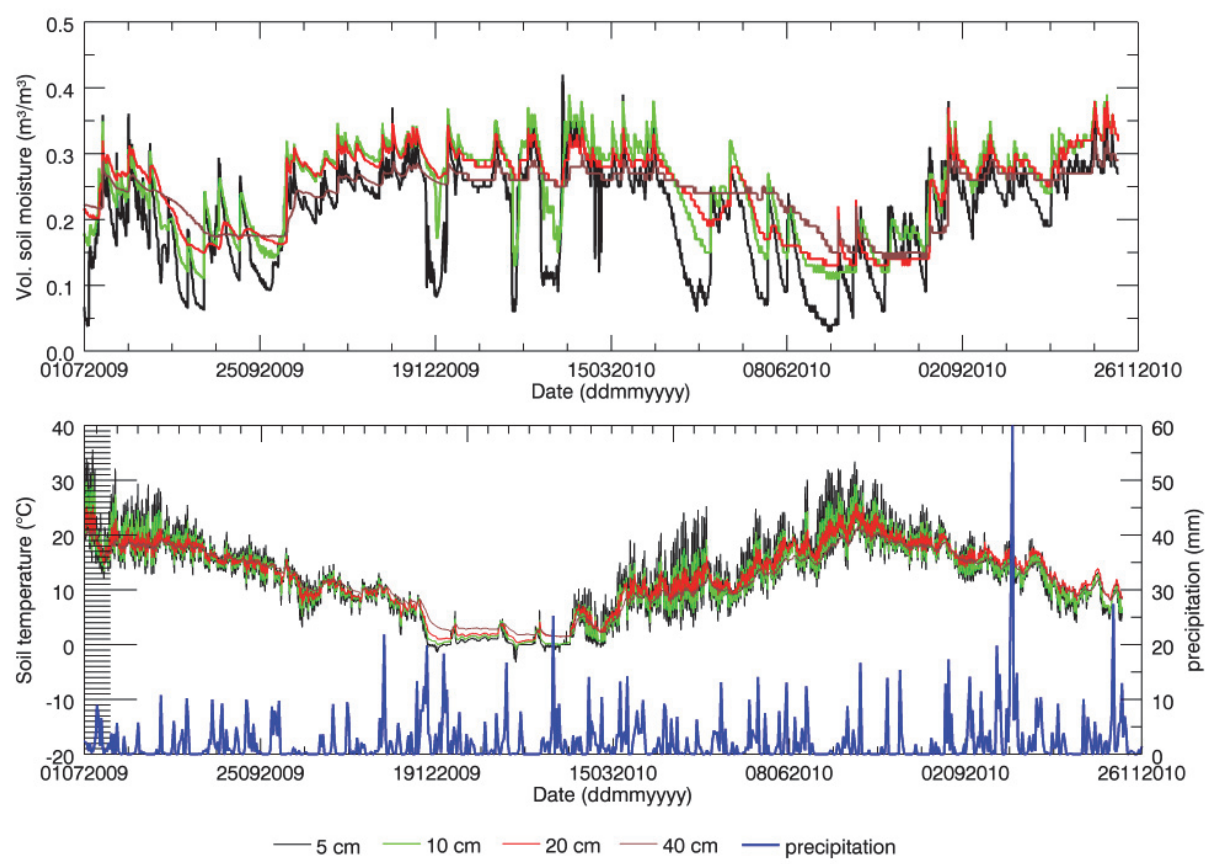

Figure 2.12 Volumetric soil moisture and soil temperature measured at different depths at ITCSM_05 site and daily precipitation recorded at the nearest KNMI station Hengelo-0-668.

From November to March the soil is wet (approximately $0.3 \mathrm{~m}^{3} \mathrm{~m}^{-3}$ on average) and in the rest of the year higher temperatures and evaporation contribute to dry the soil and to increase the variability 
range of soil moisture. In winter the probes at 5 and $10 \mathrm{~cm}$ depth measure occasionally low values of soil moisture though the soil is wet. This occurs when the soil temperature drops below zero. As for the case of measurements at Maqu network, the cause of this behaviour is very likely due to the measurement technique of the probe itself and not to an effective dry state of the soil. As soon as the soil temperature drops below $0^{\circ} \mathrm{C}$, the soil water content freezes, therefore the water molecules are not able to move freely anymore. Then the soil permittivity decreases and the probes measure a lower value of soil moisture, though the total soil water content is unchanged.

The calibrated volumetric soil moisture and the soil temperature measured at $5 \mathrm{~cm}$ depth in all the stations from July 2009 to November 2010 are shown in Figure 2.13.
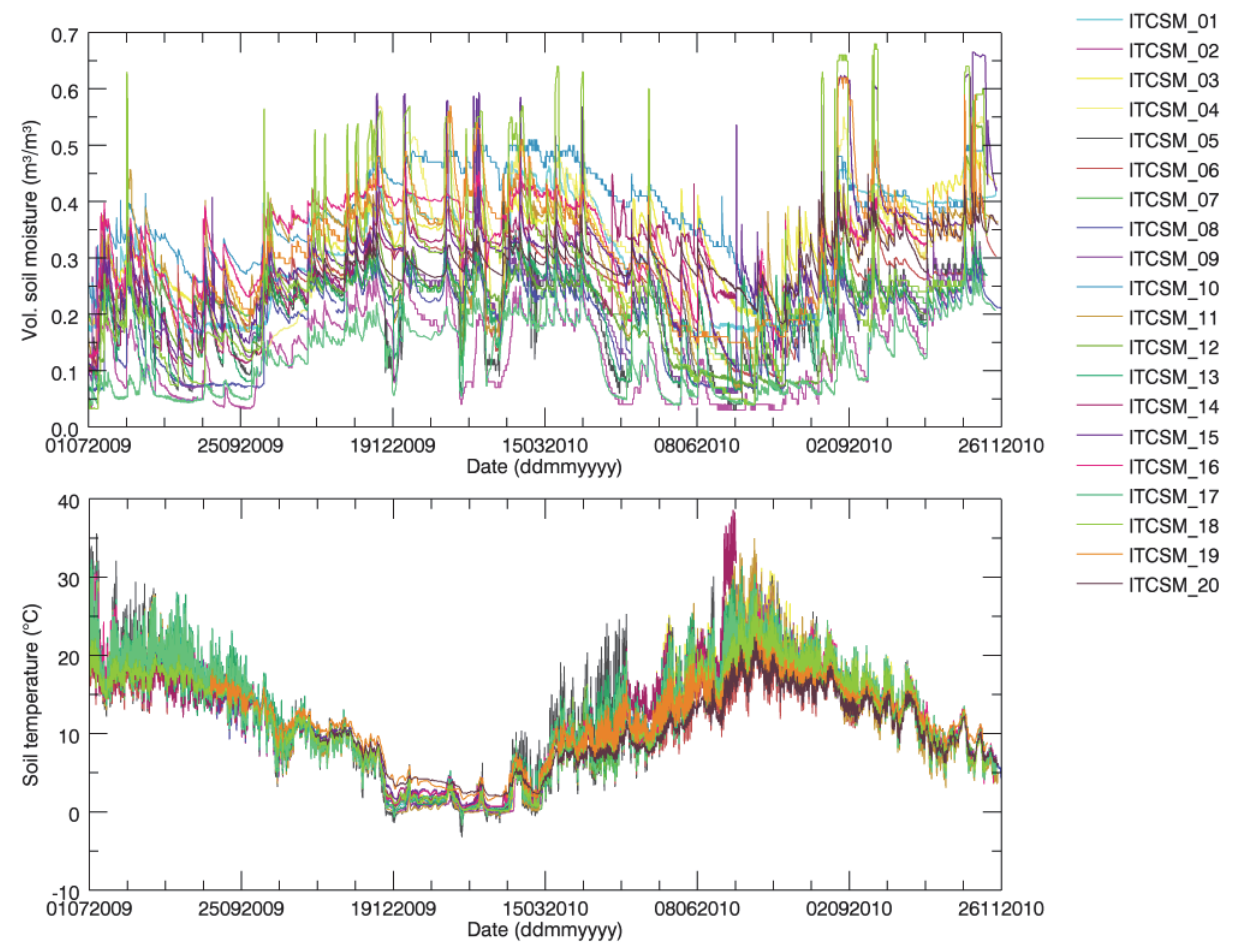

Figure 2.13 Volumetric soil moisture and soil temperature measured at $5 \mathrm{~cm}$ depth at all sites of Twente network. 
The plot shows an interesting spatial variability of surface soil moisture in the area, within a range of approximately $0.25 \mathrm{~m}^{3} \mathrm{~m}^{-3}$ between the driest and the wettest sites. The spatial variability range does not clearly depend on the season. Whereas, the surface soil temperature is characterized by a little spatial variability. Ground water table and land cover are the main factors causing a spatial variability with these characteristics (whereas the soil texture in the area is quite homogeneous). The sites with a high ground water table are generally wetter than the sites with a low ground water table. Figure 2.14 shows one example of relatively wet site, i.e. ITCSM_10, where the ground water table ranges between less than $40 \mathrm{~cm}$ to 120 $\mathrm{cm}$ below the surface, and one example of relatively dry field, i.e. ITCSM_05, where the ground water table varies from more than 80 $\mathrm{cm}$ to less than $160 \mathrm{~cm}$.

The probes at the ITCSM_02 and ITCSM_17 sites generally measured drier soil moisture than at all the other sites, but the reason is very probably due to the location of the sensors. In these two sites the monitoring station was installed very near a ditch, which is generally a dry area. Field experiments and data analyses (Wu 2010) showed that at these two sites the monitoring stations measured drier value of soil moisture than that observed in the rest of the field. For this reason in April 2011 the station at ITCSM_17 site was moved far from the ditch in the same field.

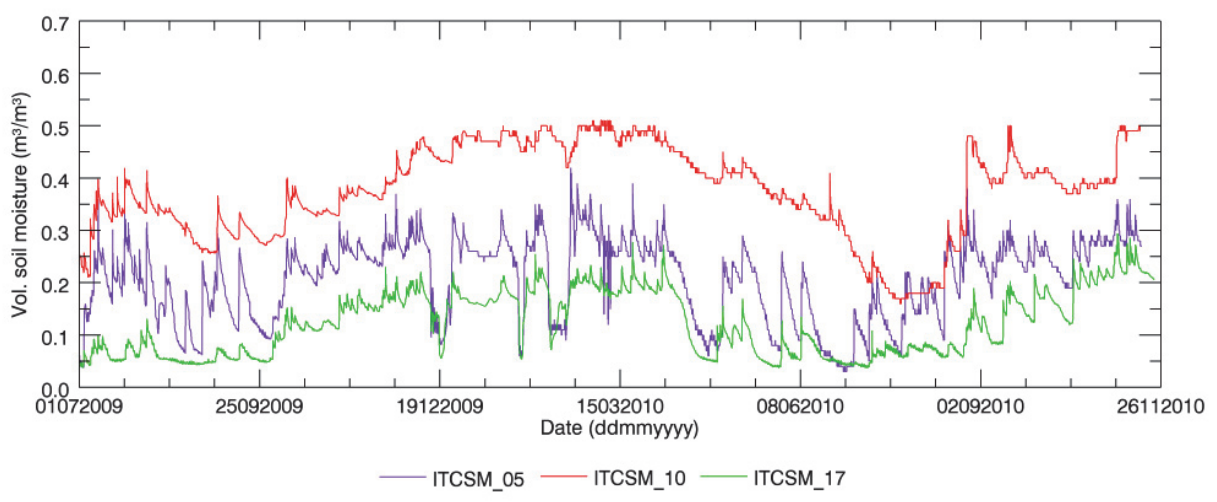

Figure 2.14 Time series of volumetric soil moisture measured at $5 \mathrm{~cm}$ depth at site ITCSM_10 (wettest), ITCSM_05 (driest) and ITCSM_17 (near ditch). 
The second important factor affecting the spatial and temporal variability of soil moisture in Twente network is the land cover. Figure 2.15 shows the time series of volumetric soil moisture measured at one of the corn fields, i.e. ITCSM_09, compared to the measurements at the meadow fields. The data collected at the other corn fields have a similar behaviour. The corn fields are drier than the meadow fields, especially in spring and summer, when the vegetation is high. The forest site measurements show a similar trend to the corn sites in winter, but wetter conditions in spring and summer (the forest data are uncalibrated).

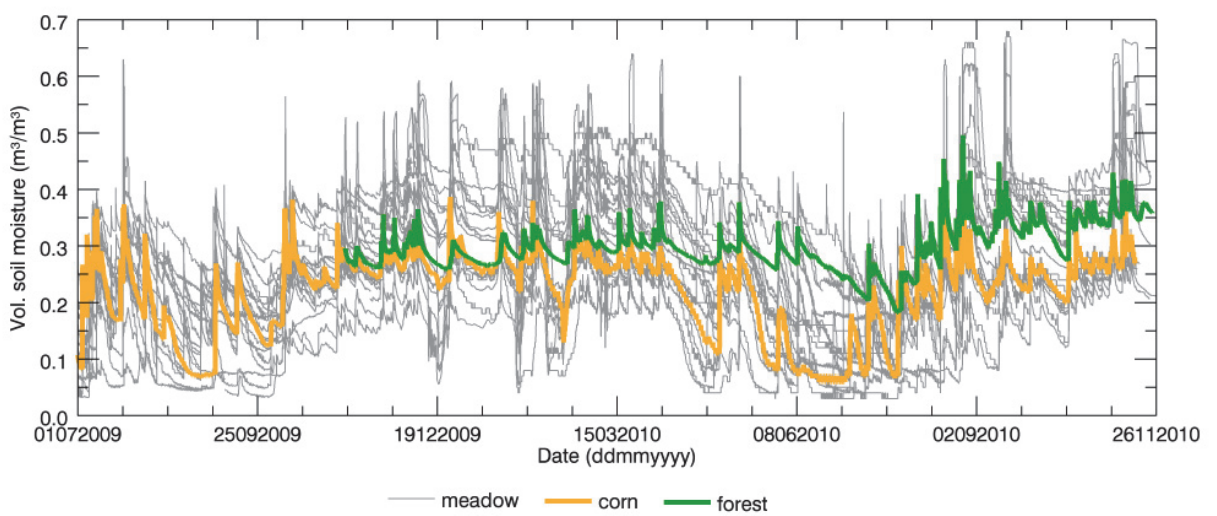

Figure 2.15 Time series of the volumetric soil moisture measured at $5 \mathrm{~cm}$ depth at one of the stations installed in a corn field (ITCSM_09) and at the forest site, compared with the measurements in meadow fields.

The mean volumetric soil moisture and the mean soil temperature obtained by computing the spatial average of the data collected at the 20 sites at $5 \mathrm{~cm}$ depth are shown in Figure 2.16 and are compared with the average daily precipitation recorded at $15 \mathrm{KNMI}$ stations within the network area. The mean time series show very clearly the seasonality behaviour of both soil moisture and temperature. From November to March the soil moisture is on average approximately $0.3 \mathrm{~m}^{3} \mathrm{~m}^{-3}$ and the soil temperature is $5^{\circ} \mathrm{C}$, dropping many times below $0^{\circ} \mathrm{C}$. In April the soil dries out as there is less precipitation and the temperature increases. From May to October the soil moisture is approximately $0.15 \mathrm{~m}^{3} \mathrm{~m}^{-3}$ on average and the soil temperature is $17^{\circ} \mathrm{C}$. The effect of frozen soils on the soil 
moisture measurements is evident in the mean soil moisture as well. This particular behaviour of the in situ data in winter should be carefully taken into account when the data are used to validate the satellite-derived products.
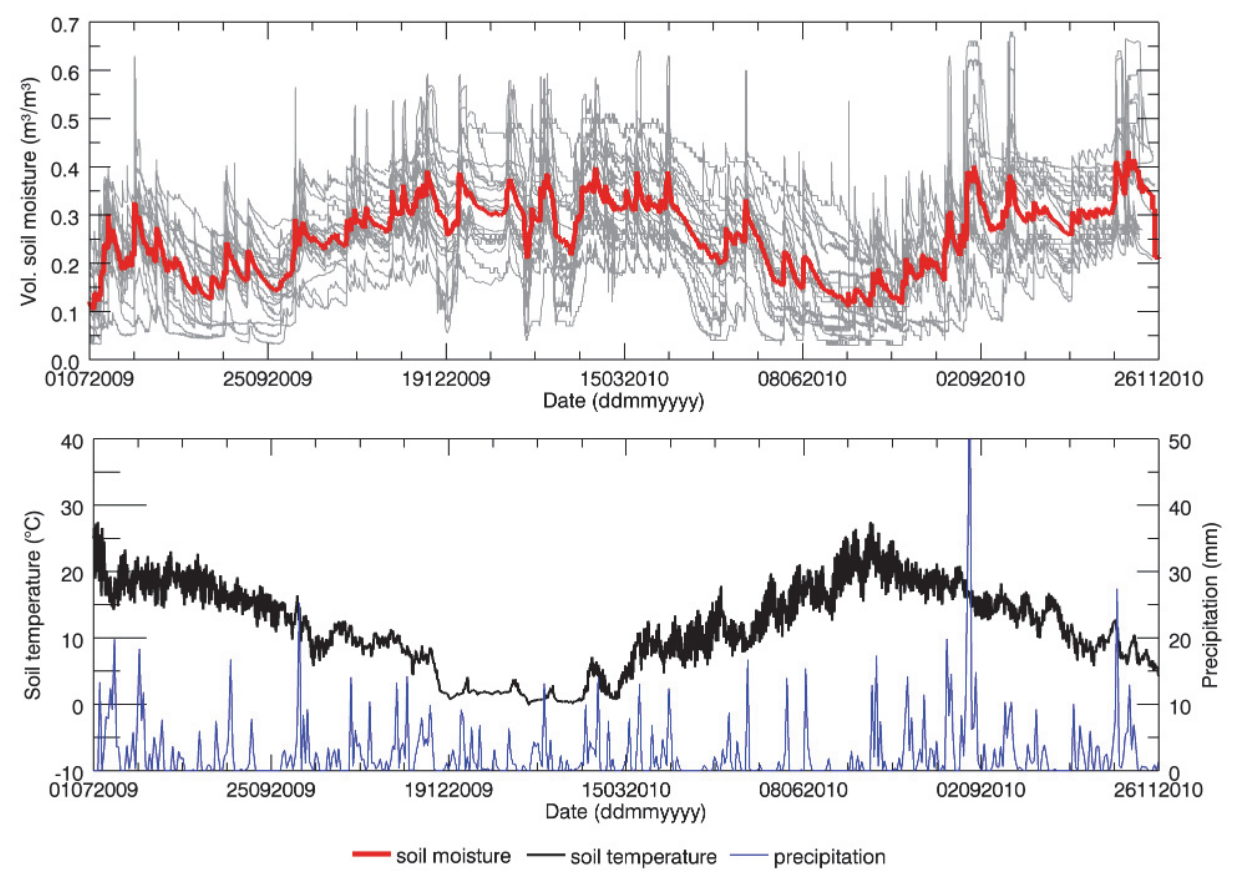

Figure 2.16 Mean volumetric soil moisture (red), mean soil temperature (black), at 5 $\mathrm{cm}$ depth, and average daily precipitation recorded in the area (blue).

\section{$2.4 \quad$ Summary and remarks}

The Maqu monitoring network and the data collected from July 2008 to December 2009 were presented in the first part of this chapter. The soil moisture measurements are in good agreement with the meteorological data and consistent in space and time, as confirmed by the high correlations among the measurements collected at different sites. Stratified sampling, which is only slightly disproportionate, ensures that the spatial variability of soil moisture 
of the Maqu area is well monitored. Therefore the weighted average, the weights of which depend on the percentage spatial coverage of each strata (i.e. non-wetlands, wetlands, moderate slopes and steeps slopes) can be considered an accurate indicator of the soil moisture dynamics at the network scale.

As a result of temporal stability analysis, one out of the 20 sites (NST_03) shows a small and stable bias with respect to the spatial average from July 2008 to December 2009, but more observations and further analysis are needed to conclude whether the soil moisture measured at this site is the best indicator of the parameter at the network scale, in place of the weighted average. Moreover the spatial pattern of soil moisture of the area is not always stable, as some sites are wetter than the average in one season and dryer in another season. The soil moisture in sandy areas and wetlands has the largest and unstable bias with respect to the average.

The Twente monitoring network and the data collected from July 2009 to November 2010 were presented in the second part of this chapter. Though only a simple qualitative analysis was carried out, it was confirmed that the measurements of soil moisture and soil temperature in the Twente region are consistent among the 20 sites and are in agreement with the precipitation data.

The analyses of the measurements collected at Twente and Maqu show clearly that the two data sets are complementary. Topography and soil texture are the main factors affecting the spatial variability range in the Maqu region, whereas land cover and ground water table are the most important factors in the Twente region. In the Maqu region the average soil moisture is approximately $0.4 \mathrm{~m}^{3} \mathrm{~m}^{-3}$ in the monsoon season (May-September) and $0.15 \mathrm{~m}^{3} \mathrm{~m}^{-3}$ in winter (December-February). However, the low values of soil moisture measured in winter are due to the soil frozen state and the measurement technique, rather than the dry soils. The average soil temperature in Maqu region ranges between $-1.4^{\circ} \mathrm{C}$ and $15^{\circ} \mathrm{C}$. In the Twente region the average soil moisture is approximately $0.15 \mathrm{~m}^{3} \mathrm{~m}^{-3}$ in the spring and summer (May-October) and $0.3 \mathrm{~m}^{3} \mathrm{~m}^{-3}$ in autumn and winter (November-March); the average soil temperature ranges between $0^{\circ} \mathrm{C}$ and $17^{\circ} \mathrm{C}$. 
Considering the network characteristics (i.e. density and extension), the spatially and temporally consistent in situ measurements and the accurate spatial sampling, it is possible to conclude that both the Maqu and the Twente networks are able to provide an accurate estimate of soil moisture in space and time and over an area covering more than one resolution cell of the microwave radiometer and scatterometer data currently available. The weighted spatial average and the standard spatial average of all observations can be considered an accurate indicator of the soil moisture dynamics at network scale and can be used as a ground reference, for Maqu region and Twente region respectively, for the validation of the satellite-derived soil moisture products. 


\section{Chapter 3}

\section{Validation of AMSR-E and ASCAT soil moisture products over the Maqu region}

This chapter is based on:

Dente L., Vekerdy Z., Wen J., Su Z. (2012). Maqu network for validation of satellitederived soil moisture products. International Journal of Applied Earth Observation and Geoinformation, 17, 55-65

Su Z., Wen J., Dente L., van der Velde R., Wang L., Ma Y., Yang K., Hu Z. (2011). The Tibetan Plateau observatory of plateau scale soil moisture and soil temperature (Tibet-Obs) for quantifying uncertainties in coarse resolution satellite and model products. Hydrology and Earth System Sciences, 15, 2303-2316

\subsection{Introduction}

The accuracy of two of the currently available satellite-derived soil moisture products is evaluated in this chapter by validating them against in situ measurements: soil moisture products derived from the AQUA AMSR-E data by VUA and NASA with the Land Parameter Retrieval Model (LPRM) described by Owe et al. (2008) (hereafter AMSR-E soil moisture data) and L2 relative soil wetness index products retrieved from MetOp ASCAT data by the Institute of Photogrammetry and Remote Sensing of Vienna University of 
Technology (TU Wien) using a change detection method (Naeimi et al. 2009; Wagner et al. 1999) (hereafter ASCAT soil moisture data). The validation was carried out over the Maqu region.

\subsection{Description of the soil moisture products}

\subsubsection{AMSR-E soil moisture}

The AMSR-E dataset consists of global soil moisture products obtained from AQUA AMSR-E brightness temperature data at C-band (6.9 GHz) from June 2002 to October 2011 by VUA-NASA (delivered by NASA). It has a total coverage every day at latitudes higher than $45^{\circ}$ and approximately every three days at the equator. The soil moisture is provided over a regular grid of $0.25^{\circ}$ spacing and it is related to the surface soil layer a few $\mathrm{cm}$ deep (the AMSR-E data are sensitive to the soil moisture of the surface layer whose thickness is approximately several tenths of the signal wavelength and depends on the soil moisture). AMSR-E mean overpass time at the equator is 1:30 a.m./p.m. (local time). Over the Maqu study area, AMSR-E ascending acquisitions took place in the afternoon between 2:00 and 3:00 p.m. (local time) and descending acquisitions at night between 2:45 and 3:45 a.m. (local time).

The surface soil moisture products are derived according to the LPRM model described by Owe et al. (2008). The model is based on the use of the microwave polarisation difference index (of the $\mathrm{H}$ and $\mathrm{V}$ polarised brightness temperature) and a nonlinear iterative optimisation procedure to solve a radiative transfer equation, given by Mo et al. (1982), for both soil dielectric constant and vegetation optical depth. The surface temperature is obtained from vertical polarized Ka-band observations (Holmes et al. 2009) and the surface roughness is described using the model of Wang and Choudhury (1981). LPRM applies the soil dielectric mixing model by Wang and Schmugge (1980) using a global database of soil physical properties (Rodell et al. 2004) to solve for surface soil moisture. The vegetation single scattering albedo is given by experimental data and is 
assumed to be constant in time. Thresholds on surface temperature and vegetation optical depth prevent the soil moisture retrieval over frozen soils and densely vegetated areas.

Draper et al. (2009) found better agreement between descending (night) AMSR-E data and measured soil moisture than the ascending (day) data, which has been confirmed in other studies. This is mainly due to the assumption used in the retrieval that the surface temperature is equal to soil temperature, which is more realistic during the night than during the day for vegetated areas. For this reason, the analysis was carried out separately for data acquired during ascending and during descending orbits in Section 3.3 and only for descending orbits in Chapter 5.

\subsubsection{ASCAT soil moisture}

ASCAT soil moisture dataset (delivered by EUMETSAT) is derived from the MetOp scatterometer data according to the algorithm developed by TU Wien. ASCAT radar operates at C-band (5.3 GHz) at a spatial resolution of $50 \mathrm{~km}$ and a temporal resolution of approximately 3-4 days. The ASCAT data are provided with global coverage from 2006 onwards over a regular grid of $0.25^{\circ}$ spacing. The sensitivity to soil moisture of ASCAT backscattering coefficient is limited to the surface soil layer whose thickness is a few $\mathrm{cm}$ and depends on the soil moisture. ASCAT mean overpass time at the equator is 9:30 a.m./p.m. (local time). Over the Maqu study area, ASCAT ascending acquisitions took place in the evening between 9:40 and 11:00 p.m. (local time) and descending acquisitions in the morning between 10:30 and 11:45 a.m. (local time).

The retrieval algorithm is based on a change detection method developed by Wagner et al. (1999) and provides relative changes of soil wetness. The scatterometer antenna is able to collect data of any surface area at three different azimuth angles with respect to the satellite track (i.e. fore, mid and aft beam at a $45^{\circ}, 90^{\circ}$ and $135^{\circ}$ azimuth angle) and with different incidence angles. As a result of the stability of the satellite and the large footprints of the measurements, yearly cycles of the backscatter-incidence angle relationship can be established for correcting seasonal vegetation effects. Taking into account of a typical yearly vegetation cycle and of its influence on the 
backscatter-incidence angle relationship, the backscattering is normalized to an incidence angle where there are minor vegetation effects. Moreover, the surface roughness is assumed to have a constant contribution in time, therefore its influence is minimized in a change detection algorithm. As a consequence the soil moisture variations are dominant in the resulted backscattering signal. The highest and the lowest values of backscattering coefficient over the whole observation period are considered as reference values of dry $(0 \%)$ and saturated conditions $(100 \%)$ of the surface. By scaling the backscattering coefficient between the reference values, a relative estimation of soil wetness is obtained. The absolute volumetric soil moisture can be obtained by using the soil database of FAO (2003) and applying the method described by Reynolds et al. (2000). This was done in this chapter, where the absolute values of soil moisture were needed to be compared to in situ data. Frozen areas are detected on the base of the analysis of modelled historic climate data and then masked. Densely vegetated areas are excluded from the retrieval, as well.

\subsection{Validation of AMSR-E and ASCAT soil moisture products over Maqu region}

Maqu monitoring network is able to provide an accurate estimate of soil moisture in space and time and over an area covering more than one resolution cell of the currently available microwave satellite data, as concluded in Chapter 2. Data from the network are therefore suitable for evaluating the accuracy of the satellite-derived soil moisture products. In this section, the AMSR-E soil moisture products and the ASCAT relative soil wetness index products are validated over the Maqu region. The latter were converted in absolute values by using the method described by Reynolds et al. (2000).

The time series of the satellite-derived soil moisture products were compared with in situ observations from July 2008 to December 2010. The analysis was carried out separately for data acquired during ascending and during descending orbits. The winter data 
were discarded from this analysis, because in this season the soil is frozen and the surface is very probably covered by snow. In these conditions both measuring the soil moisture in situ and estimating it from satellite data might be inaccurate and the satellite-derived soil moisture products are generally masked. The validation of the satellite products was carried out using time series plots, scatter plots and regression analysis. The weighted spatial average of soil moisture measurements at $5 \mathrm{~cm}$ depth, as computed in the Section 2.2.4, was used as a ground reference.

Figure 3.1 compares the in situ time series with AMSR-E and ASCAT soil moisture obtained from descending passes and Figure 3.2 from ascending passes. Soil moisture measured in situ at the time of satellite acquisitions is compared with satellite-derived products in the scatter plots. Table 3.1 reports the coefficient of determination $\left(R^{2}\right)$, the root mean square error (RMSE) and the bias between in situ and satellite-derived products for descending and ascending data.

As expected, there is a general better agreement between in situ data and descending (night) AMSR-E data, with $R^{2}$ approximately equal to 0.5 and $R M S E$ approximately equal to $0.06 \mathrm{~m}^{3} \mathrm{~m}^{-3}$ (over the entire period under study), than between in situ and ascending (day) AMSR-E data, with $R^{2}$ less than 0.01 and RMSE approximately 0.1 $\mathrm{m}^{3} \mathrm{~m}^{-3}$. The temporal behaviour and the absolute values of AMSR-E descending data are in generally good agreement with ground data, albeit with some noise, in 2008. The average bias is lower than 0.02 $\mathrm{m}^{3} \mathrm{~m}^{-3}$. The same comment is valid for 2009 data as well, but with a slight overestimation in April, which occurs also in 2010, and a slight underestimation from end of July to beginning of September. The AMSR-E data show a clear and unexplainable underestimation in July 2010.

The agreement of ASCAT soil moisture with in situ data is less dependent on the acquisition time, than for the AMSR-E case. Both the ascending and the descending data reproduce on average the in situ temporal variations with an $R^{2}$ approximately equal to 0.5. However, the ASCAT data are generally noisier than the AMSR-E data, showing often increases not corresponding to ground data variations. The descending (day) products are noisier than the ascending (night) products, with RMSE of $0.09 \mathrm{~m}^{3} \mathrm{~m}^{-3}$ for the day data against RMSE of $0.07 \mathrm{~m}^{3} \mathrm{~m}^{-3}$ for the night data. The descending products overestimate 
the soil moisture, with a bias of $0.05 \mathrm{~m}^{3} \mathrm{~m}^{-3}$ in 2008 and 2009 and of $0.06 \mathrm{~m}^{3} \mathrm{~m}^{-3}$ in 2010 , whereas the ascending data have a negligible bias. If the bias was removed, the ASCAT descending data largely underestimate the soil moisture in July 2010, as for the case of AMSR-E descending data. Whereas, the ascending data show a good agreement in July 2010 as well.
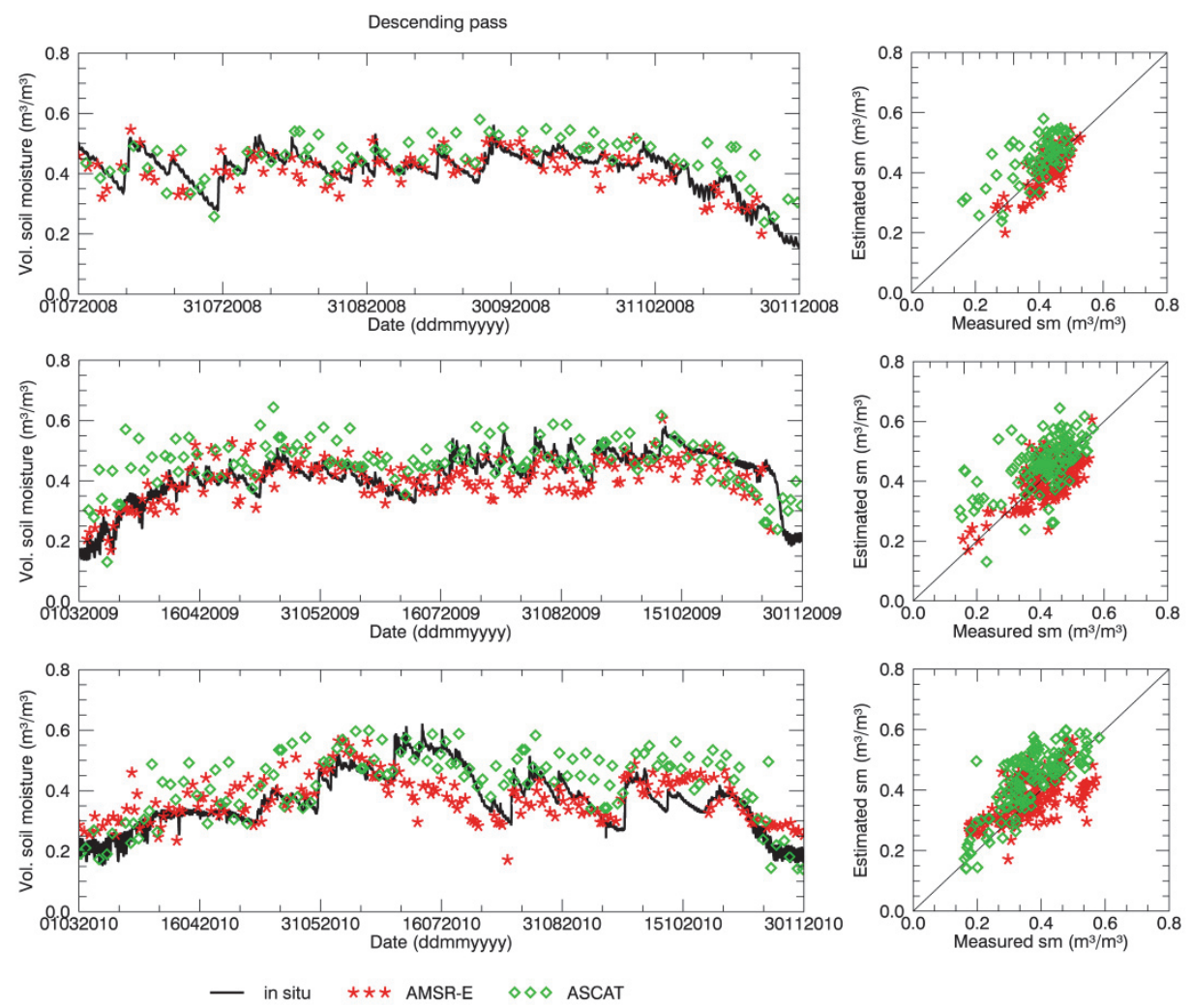

Figure 3.1 Time series comparison and scatter plots of in situ weighted average soil moisture, AMSR-E soil moisture and ASCAT soil moisture: data from descending passes from July to November 2008 (top), from March to November 2009 (centre) and from March to November 2010 (bottom). 

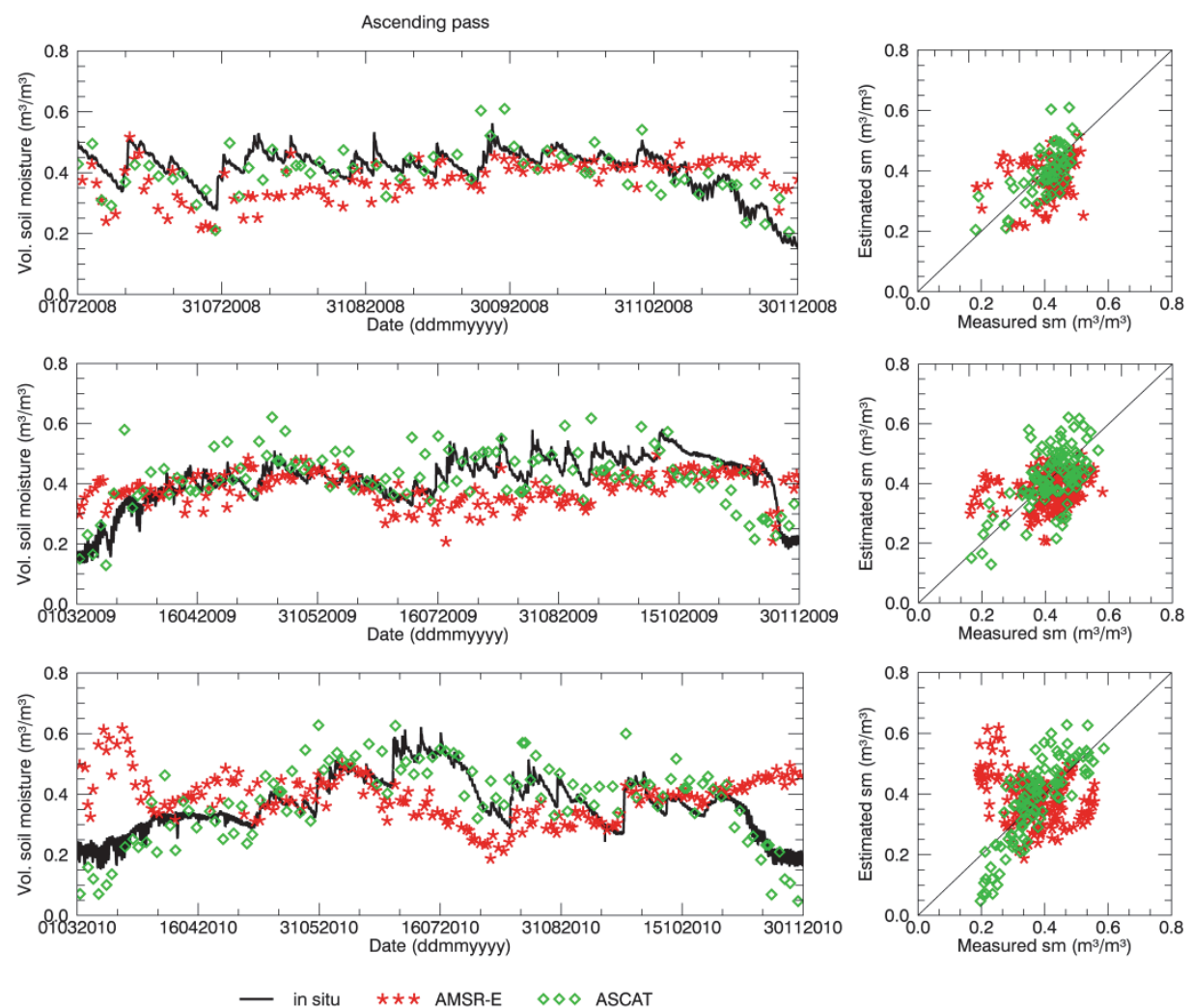

Figure 3.2 Same as Error! Reference source not found. for ascending passes.

Table 3.1 Coefficient of determination $\left(R^{2}\right)$, root mean square error $\left(R M S E, \mathrm{~m}^{3} \mathrm{~m}^{-3}\right)$ and bias $\left(\mathrm{m}^{3} \mathrm{~m}^{-3}\right)$ between satellite-derived soil moisture products and in situ average soil moisture from July 2008 to November 2010 (the winter data are disregarded).

\begin{tabular}{|c|c|c|c|c|c|c|c|}
\hline & \multicolumn{3}{|c|}{ DESCENDING } & \multicolumn{3}{|c|}{ ASCENDING } \\
\hline & & $R^{2}$ & RMSE & Bias & $R^{2}$ & RMSE & Bias \\
\hline \multirow{4}{*}{ AMSR-E } & $2008-2010$ & 0.47 & 0.06 & -0.01 & 0.0004 & 0.11 & -0.01 \\
\hline & 2008 (Jul-Nov) & 0.61 & 0.04 & -0.01 & 0.07 & 0.09 & -0.04 \\
\hline & 2009 (Mar-Nov) & 0.48 & 0.06 & -0.02 & 0.07 & 0.09 & -0.03 \\
\hline & 2010 (Mar-Nov) & 0.38 & 0.08 & 0.01 & 0.08 & 0.13 & 0.02 \\
\hline \multirow{4}{*}{ ASCAT } & $2008-2010$ & 0.51 & 0.09 & 0.05 & 0.53 & 0.07 & $0 . \overline{-} 01$ \\
\hline & 2008 (Jul-Nov) & 0.46 & 0.08 & 0.05 & 0.48 & 0.06 & -0.01 \\
\hline & 2009 (Mar-Nov) & 0.33 & 0.09 & 0.05 & 0.35 & 0.08 & $\begin{array}{c}- \\
0.003\end{array}$ \\
\hline & 2010 (Mar-Nov) & 0.64 & 0.09 & 0.06 & 0.68 & 0.08 & 0.01 \\
\hline
\end{tabular}




\subsection{Conclusions}

In conclusion, the validation of AMSR-E and ASCAT soil moisture products shows that both are able to estimate on average the soil moisture seasonal cycles of the Maqu region, with occasional disagreements and with a coefficient of determination approximately equal to 0.5. The agreement among the absolute values of the satellite-derived products and the in situ measurements is strongly affected by the noise characterizing both AMSR-E and ASCAT datasets, with $R M S E$ of $0.06 \mathrm{~m}^{3} \mathrm{~m}^{-3}$ and of $0.07 \mathrm{~m}^{3} \mathrm{~m}^{-3}$, respectively. The ASCAT data have often an unrealistically large variability. The AMSR-E ascending data do not reproduce well the in situ seasonal cycle and the ASCAT descending products have a positive bias.

The accuracy of AMSR-E and ASCAT soil moisture products can be further evaluated over the Twente region, by comparing the retrieved data with the in situ data. This analysis, planned as a future work, will allow to investigate the behaviour of the satellite-derived products over an area with a different topography and land cover than the Maqu region. 


\section{Chapter 4}

\section{Validation of SMOS soil moisture products over the Maqu and Twente regions}

This chapter is based on:

Dente L., Su Z., Wen J. (2012). Validation of SMOS Soil Moisture Products over the Maqu and Twente Regions. Sensors, 12, 9965-9986

\subsection{Introduction}

The SMOS satellite carrying the Microwave Imaging Radiometer with Aperture Synthesis (MIRAS), passive microwave 2-D interferometric radiometer, was launched in November 2009. The main aim of this ESA mission is to provide global maps of soil moisture and ocean salinity (Kerr et al. 2010; Kerr et al. 2001). MIRAS is able to provide measurements of brightness temperature at the L-band $(1.4 \mathrm{GHz})$ for a range of viewing angles from $0^{\circ}$ to $55^{\circ}$ and with a spatial resolution of 35 to $50 \mathrm{~km}$ (McMullan et al. 2008).

The main innovations of the MIRAS radiometer, compared to other radiometers currently in orbit, are the operating band and the new antenna system. The L-band was selected for several reasons: higher sensitivity to soil moisture and ocean salinity, lower attenuation of 
atmosphere and vegetation and larger penetration depth in the soil layer, than encountered at higher frequencies in the microwave range. To date, the use of the L-band was limited by requiring a very large antenna, but this was overcome in MIRAS by employing a synthetic aperture antenna. Another reason of operating in L-band was that this is a protected radio band, therefore the measurements should be free of interference. Unfortunately, since the beginning of the mission, the SMOS brightness temperature measurements revealed the presence of man-made sources contaminating the natural emission from several areas of the Earth (Anterrieu and Khazaal 2011). Studies on the detection and filtering of Radio Frequency Interference (RFI) in the SMOS data are ongoing and RFI is currently considered the most important source of error in the SMOS products.

The SMOS soil moisture retrieval algorithm is based on the inversion by minimization approach. This approach consists of minimizing the difference between the actual SMOS measurements and the brightness temperature estimated by a direct model of the surface by means of a cost function, knowing the land cover and soil texture (Kerr et al. 2012).

As both the SMOS sensor technology and the retrieval algorithm are new, there is currently uncertainty about the quality and reliability of the generated soil moisture products. For this reason, the validation of the SMOS soil moisture products is of crucial importance, not only to investigate the achievement of the mission objectives, but also in view of possible applications of these data and of future satellite missions for soil moisture retrieval in the L-band such as the Soil Moisture Active and Passive (SMAP) mission. Several measurement networks and campaigns were set up in order to assess the accuracy of the SMOS soil moisture products, and the performance of the SMOS retrieval over these sites is currently under investigation. Based on the results obtained by these studies, the SMOS retrieval algorithm will be refined. Therefore, it is expected that the quality and accuracy of SMOS L2 soil moisture products will be improved.

The main objective of the present study is to contribute to the accuracy assessment of the currently available SMOS soil moisture products (reprocessed data, version 5.05 of the Level 1 processor 
and version 5.01 of the soil moisture Level 2 processor). The SMOS retrieval performances were investigated in two regions: the Maqu region on the Tibetan Plateau in China and the Twente region in The Netherlands (Chapter 2).

\subsection{SMOS soil moisture}

SMOS Level 2 (L2) soil moisture products (reprocessed data, version 5.05 of the Level 1 processor and version 5.01 of the soil moisture Level 2 processor) from 15 January to 15 December 2010 were used in this study. The products are geolocated on an equal-area grid called Icosahedral Snyder Equal Area (ISEA), where the inter-cell distance is uniformly $15 \mathrm{~km}$. The equator crossing time of ascending and descending passes is at 6 a.m./p.m. (local time), respectively, and the complete globe is covered every 3 days.

An iterative approach is followed in order to retrieve soil moisture and vegetation optical thickness. This approach is based on the principle of finding the optimal set of soil moisture and vegetation parameters that minimizes the difference between modelled and measured brightness temperature (Kerr et al. 2012) for a variety of incidence angles, for a given surface cover and soil texture. The obtained soil moisture is an estimate for the surface layer of the soil, a few centimetres deep (Escorihuela et al. 2010). The retrieval algorithm is described in detail in the Algorithm Theoretical Basis Document (ATBD 2011). The forward model used in the SMOS Level 2 processor is the L-band microwave emission of the biosphere ( $\mathrm{L}$ MEB) model (Wigneron et al. 2007). L-MEB is based on a simplified zero-order radiative transfer equation (Mo et al. 1982), where the rough soil surface contribution to the brightness temperature is modelled following the approach by Wang and Choudhury (1981) and the vegetation contribution is modelled following the $\tau-\omega$ approach, i.e., the optical depth $\tau$ and the single scattering albedo $\omega$ are used to parameterize the vegetation attenuation and the scattering effects within the canopy layer. The soil effective temperature is computed as a function of soil temperature at the soil surface and at increasing depth, as described in Wigneron et al. 
(2001). The soil dielectric mixing model by Dobson et al. (1985) is used to relate the soil permittivity to soil parameters such as soil moisture.

The retrieval is carried out at each node of the ISEA grid and the parameterization of L-MEB depends on the dominant land cover at the node and its surrounding area. Information on the land cover class along with soil and vegetation properties are provided to the SMOS L2 processor by the ECOCLIMAP land surface global database (Masson et al. 2003) at a resolution of $1 \mathrm{~km}$.

The land cover map in the ECOCLIMAP database is obtained by integrating various data sources, including two global land cover datasets: the International Geosphere-Biosphere Programme Data and Information System (IGBP-DIS) (Loveland and Belward 1997; Loveland et al. 2000) and the University of Maryland database (UMd) (Hansen et al. 2000). The location of the surfaces permanently covered by ice and wetlands is provided by the IGBP-DIS database, whereas all the other cover types are derived from the UMd global land cover map.

In the L2 processor working area of $123 \mathrm{~km} \times 123 \mathrm{~km}$ surrounding each node (the distance of $123 \mathrm{~km}$ corresponds to twice the largest extent of the $3 \mathrm{~dB}$ footprint occurring in SMOS soil moisture observations), different land cover types may be present, contributing to the surface microwave emission. Therefore, the weight of each contribution is determined taking into account the cover fraction and the SMOS radiometric sensitivity in the antenna pattern. In this way, the dominant cover type is assessed and if it consists of a surface type where soil moisture estimation is meaningful (for example low vegetation or forest), retrieval is carried out. For the non-dominant cover type of the node, the contribution to the overall emissivity of the node is taken into account by the L-MEB model, but no retrieval is performed. Any given node is covered by several views, each having a different spatial extent. Therefore, the application of the weight function may give different results for each view.

Auxiliary data, such as soil temperature at the surface and at depth, initial soil moisture values and information about snow cover, are provided by the European Centre for Medium-Range Weather 
Forecasts (ECMWF) model. When the ECMWF surface soil temperature drops below a given threshold, the soil is considered frozen and soil moisture data are not retrieved. When, according to the ECMWF model, dry snow is present, then the snow is considered transparent and retrieval is carried out as if there was no snow.

The L2 soil moisture products contain not only the retrieved parameters (soil moisture and optical thickness), but also ancillary information obtained during the retrieval, such as surface temperature, roughness parameters and dielectric constant, as well as several confidence, processing and science flags. The confidence and processing flags refer to the quality and characteristics of the retrieval, retrieval options and conditions adopted during the processing and information on L1c data used for the retrieval. The flags useful for the analysis carried out in this study include those indicating: if the retrieval values were outside the expected range; if there was a poor fit between modelled and observed brightness temperature; if the retrieval error was above a certain threshold. The science flags refer to features of the surface that might affect retrieval, for example presence of snow, frozen soils, wetlands and forest. Information about the suspected presence of Radio Frequency Interference (RFI) can be obtained from two bands of SMOS L2 products, N_RFI_X and N_RFI_Y, reporting, for any given node, the number of brightness temperature measurements in $\mathrm{X}$ and $\mathrm{Y}$ polarization, respectively, disregarded in the retrieval process because of suspected RFI. Combining this information with the total number of brightness temperature measurements available for the given node (M_AVA0) provides the percentage of brightness temperature measurements where RFI is suspected.

\subsection{Validation method}

There are 13 ISEA grid nodes included in the area of the Twente monitoring network and 23 nodes in the area of the Maqu monitoring network and soil moisture is nominally retrieved for each of them. Figure 4.1 and Figure 4.2 show two Landsat 5TM images covering the area of the Maqu network and of the Twente 
network, respectively, with the locations of the monitored sites highlighted as white rectangles and the centre of the SMOS grid nodes as white crosses. In order to validate the SMOS soil moisture over these two networks, the spatial average of the values estimated at all nodes included in the network areas was computed. The average was taken when SMOS data were available for at least three nodes. A time series of SMOS average soil moisture was obtained in both regions between 15 January and 15 December 2010. The data analysis was carried out separately for products retrieved from SMOS ascending data to those retrieved from descending data, because these are characterized by a different acquisition time and eventually by different RFI effects, as they each have a different swath coverage.

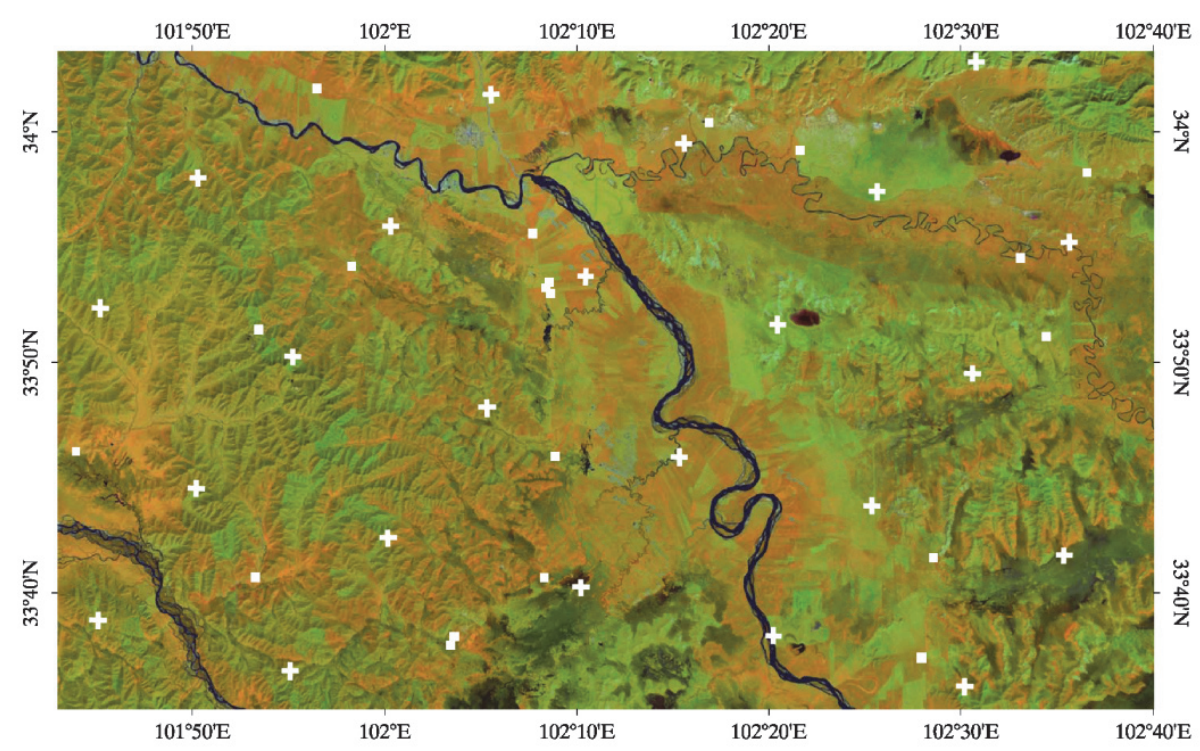

Figure 4.1 Color composite (R: band 4-G: band 5-B: band 1) of a Landsat 5TM image collected in September 2004 over the Maqu region (short vegetation in green, light brown and orange; forested areas in shades of reds and dark browns; urbanized areas in cyan; water bodies in dark blue). The location of the monitored sites is indicated by a white rectangle and the centre of the SMOS nodes by a white cross. 


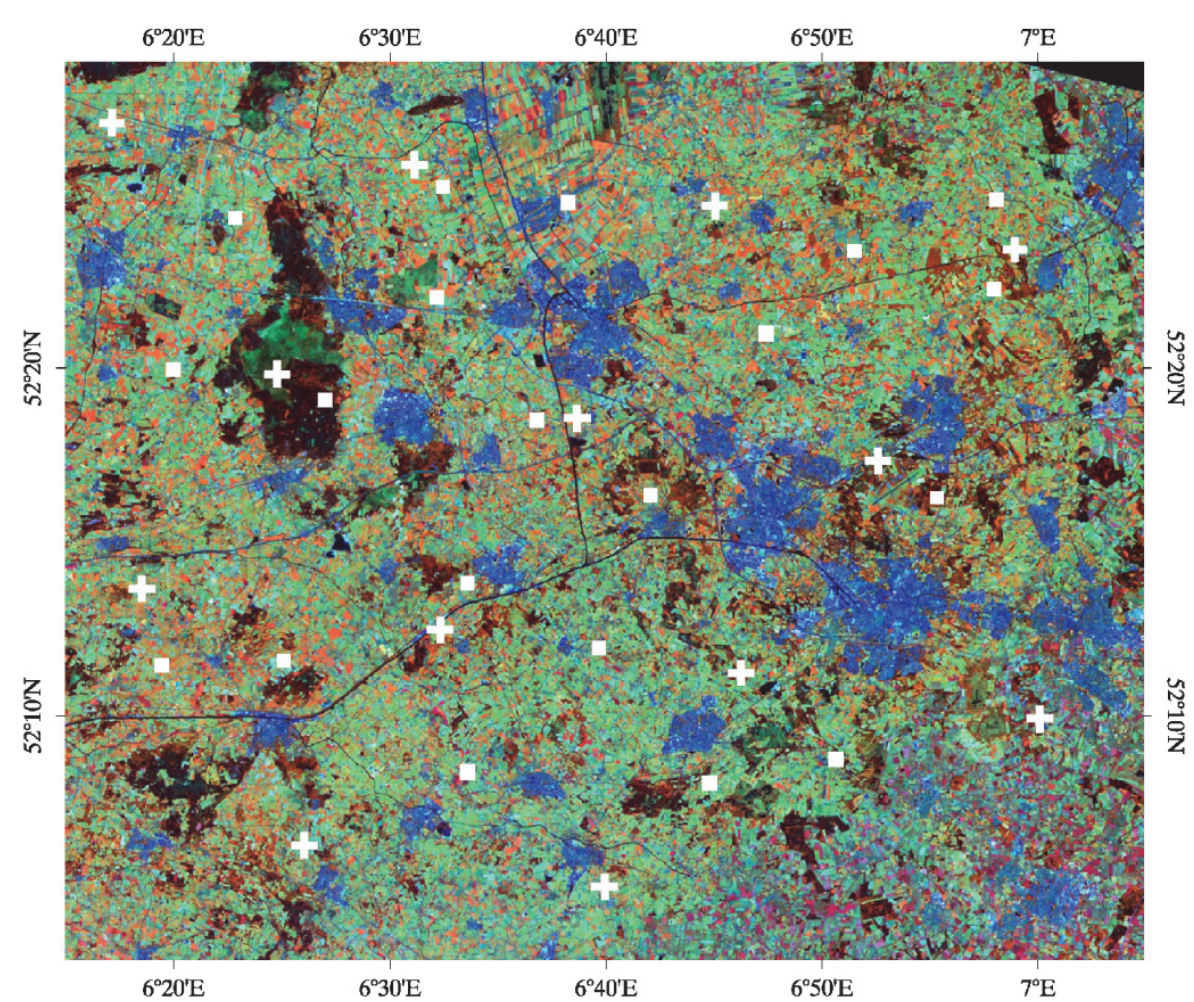

Figure 4.2 Same as Figure 4.1 but for the Twente region (image collected in June 2010).

Firstly, the general seasonal behaviour of the time series of the SMOS data spatial average was compared to the corresponding in situ spatial average of the measurements at $5 \mathrm{~cm}$ depth (Section 4.4.1). Then, several factors were investigated.

If SMOS retrieval is only carried out at a few nodes in the network areas, the spatial variability of the soil moisture might be not well monitored. Therefore, it was checked if the SMOS data covered at least half the area of interest and it was investigated if SMOS soil moisture inaccuracies were related to a partial coverage of the SMOS data.

The reason why SMOS data were not retrieved over a part or the entire area of interest was sought in the flags that are raised when no product is generated, such as the flag for frozen surface, the flag for retrieved values outside the expected range and the flag for high 
retrieval error (Section 4.4.2). The percentage of nodes with one of these raised flags was computed when missing retrieval interested a part of the area of interest and the entire area, by dividing the number of nodes with a raised flag by the total number of nodes without data. The consistency of the frost flag with the in situ measurements of soil temperature was investigated, as well.

The information concerning the suspected presence of RFI was also checked, as RFI may be another reason for retrieval not being attempted (Section 4.4.2). The percentage of brightness temperature measurements in L1c products for any given node where the presence of RFI was suspected was obtained by summing N_RFI_X and N_RFI_Y and dividing by M_AVA0. The spatial average of this percentage was computed over the Twente and the Maqu region.

Confidence and science flags were analysed for all the nodes where soil moisture was retrieved (Section 4.4.3), to obtain information about the performance of the retrieval algorithm and the input information provided to the L-MEB model, such as the flag indicating a poor fit between modelled and observed brightness temperature, the flag for snow presence and the flags regarding land cover (i.e. forest flag). This was done by counting the number of nodes where the retrieval was carried out and where a flag of interest was raised. Then, the obtained number was divided by the total number of nodes with data available and the result was expressed as a percentage. The presence of snow, as well as of forest, might be related to retrieval inaccuracies, due to the difficulties in modelling their contribution to the brightness temperature.

Another important factor that might have affected soil moisture retrieval is the accuracy of the land cover map, as, on the base of this information, the dominant land cover type at any given node was determined and the appropriate parameterization of the L-MEB model selected (as mentioned in Section 4.2). For this reason, the two maps used to obtain the ECOCLIMAP cover types, the UMd and the IGBP-DIS map, were compared, in Section 4.4.3.1) to another land cover map available over the Maqu region: the Multi-source Integrated Chinese Land Cover (MICLCover) map provided by the Cold and Arid Regions Environmental and Engineering Research Institute of the Chinese Academy of Sciences (CAREERI/CAS). Unfortunately, no detailed land cover map is currently available for 
the Twente region. The MICLCover map was obtained by integrating several classification maps over China including a vegetation map, a land use map for the year of 2000, a swamp-wetland map, a glacier map and a Moderate-Resolution Imaging Spectroradiometer land cover map for 2001 (MODIS2001) using a decision-fuse method based on the Dempster-Shafer evidence theory (Ran et al. 2011). The accuracy of the MICLCover map was assessed at 71\% all over China, which was shown to be higher than the MODIS2001 map accuracy. In order to simplify the comparison between the maps, some cover types were grouped into generic classes, such as forest, shrubland and cropland.

Finally, the coefficient of determination, $R^{2}$, and the root mean square error, RMSE, between the SMOS soil moisture spatial average and the in situ spatial average were computed considering the complete time series of SMOS data, as well as considering only the data covering at least half the area of interest (Section 4.4.4). Moreover, the same computation was carried out disregarding the SMOS nodes covering some targets that can negatively affect the retrieval, such as, mountainous areas and water bodies, in the Maqu region, and forested areas and urbanized areas, in the Twente region. $R^{2}$ and $R M S E$ were also computed only for the period of the year when no snow and frozen soils were present (May-September for Maqu and March-December for Twente), to investigate if the correlation between satellite and in situ data depended on the season.

\subsection{Results and discussions}

\subsubsection{Time series comparison}

The time series of SMOS data spatially averaged over the area of interest and the time series of the in situ average were compared, as shown in Figure 4.3 for the Maqu region and in Figure 4.4 for the Twente region. The comparison was done separately for ascending and descending products. 
The seasonal behaviour of SMOS L2 products is generally in agreement with the soil moisture behaviour for both the Maqu and the Twente region. SMOS data on average show relatively low values in the Maqu region in winter with an increase in the monsoon season, following the in situ behaviour. Instead, in the Twente region the in situ data show higher soil moisture values in winter and a decrease in summer with the SMOS data depicting a similar pattern.

However, noise was found in the satellite-derived products, consisting of variations in the SMOS estimates not corresponding to in situ data variations, and affecting the agreement between the two datasets. In both regions, the descending products are noisier than the ascending ones. Contribution to the noise is certainly partly due to the fact that several SMOS products covered only partially the area of interest, where the soil moisture retrieval in the rest of the area was unsuccessful. This might affect the validation results, as the SMOS data covering part of the area were compared with the spatial average of the complete network. The empty symbols in Figure 4.3 and Figure 4.4 indicate when SMOS products were not generated for at least half of the area, whereas filled symbols refer to a good coverage. The figures show that several SMOS products only partially covered the Maqu region, as well as the Twente region. In general, the two figures show that retrieval was more problematic in the Maqu region than in the Twente region, as data are missing more frequently over the Chinese site with more gaps in the time series, than over the Dutch site. The reason for data in space and time having been missed is investigated in Section 4.4.2. However, the agreement between the variations found in SMOS data and in situ data does not improve by leaving out the products with partial coverage of the area of interest.

From the time series comparison one can also conclude that the SMOS soil moisture is affected by general underestimation, which appears to be larger for the ascending products over both Maqu and Twente, than for the descending ones. Though with a bias, the SMOS data fall within the variability range of the in situ data for the Maqu region. However, for the Twente region several SMOS data are outside the in situ variability range. 


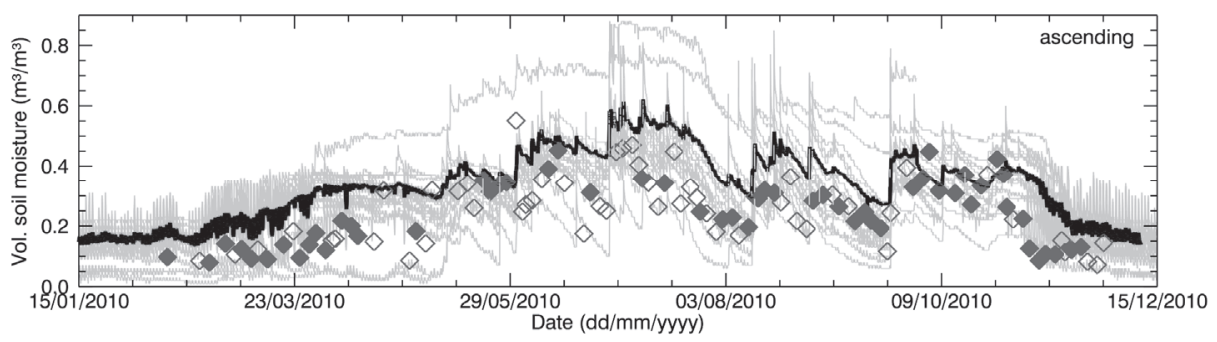

- in situ measurements - in situ spatial average $\diamond \diamond \diamond$ SMOS - coverage $<50 \% \diamond \diamond$ SMOS - coverage $>50 \%$

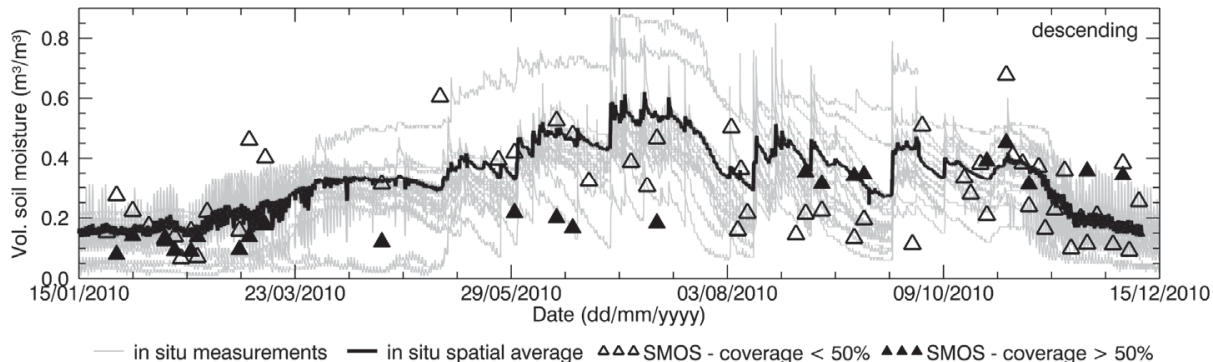

Figure 4.3 Spatial average of SMOS soil moisture obtained from ascending overpasses (top) and from descending overpasses (bottom) over the Maqu region compared with in situ average soil moisture and individual measurements. Empty symbols indicate that no SMOS products were generated over more than half the region, whereas filled symbols refer to good coverage.

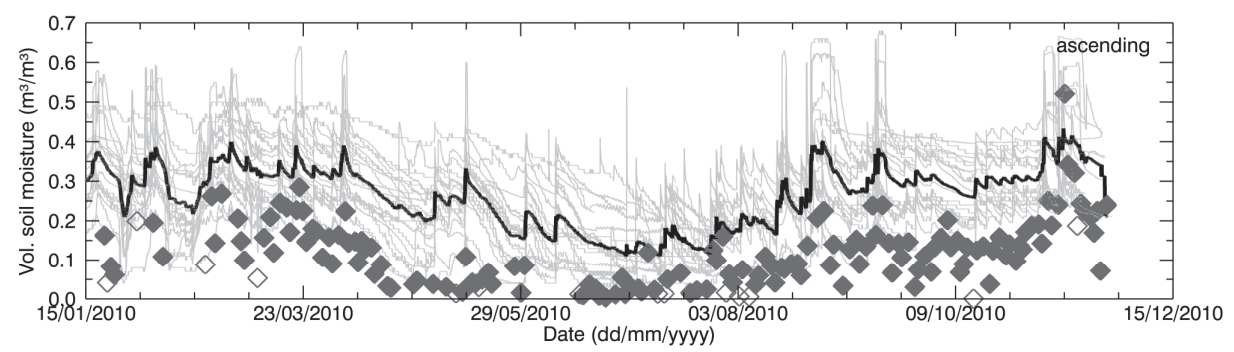

in situ measurements — in situ spatial average $\diamond \diamond \diamond$ SMOS - coverage $<50 \% \bullet \bullet$ SMOS - coverage $>50 \%$

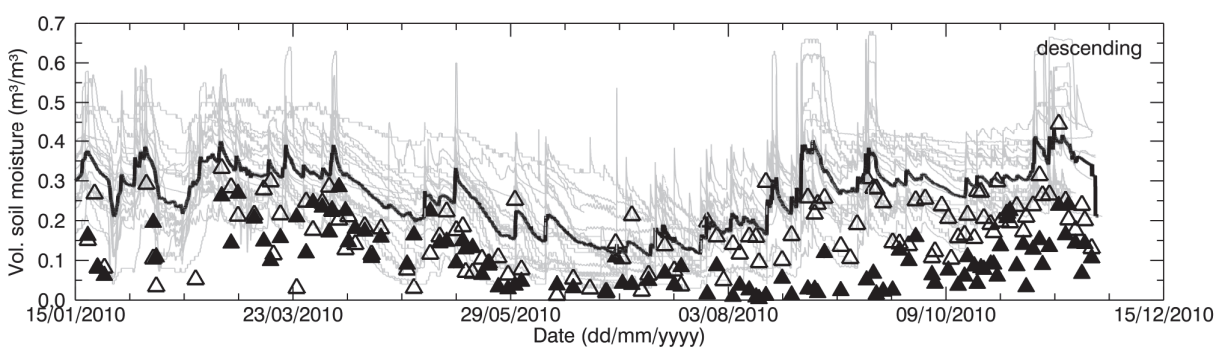

in situ measurements - in situ spatial average $\Delta \Delta \Delta$ SMOS - coverage $<50 \% \Delta \Delta \Delta$ SMOS - coverage $>50 \%$

Figure 4.4 Same as Figure 4.3 but for the Twente region. 
The SMOS mission commissioning phase ended in May 2010, therefore it might be that the data of the first few months of the year have a low quality. However, the agreement between satellitederived and in situ data does not show any clear dependency on this factor. The underestimation, as well as the noise, does not occur in a specific period of the year or for a particular soil moisture variability range.

The reasons for the noise and underestimation in the SMOS soil moisture products, as well as for the data missing in space and time, are investigated in the following sections. Confidence and science flags were analysed to obtain information about retrieval algorithm characteristics and problems occurring in the retrieval process.

\subsubsection{Unsuccessful retrieval case}

The reason of an unsuccessful retrieval over part of or the whole area of interest was investigated by checking the flags which indicate the supposed presence of frozen soil and RFI and checking the flags which indicate the performance of the retrieval algorithm, such as the flag for out-of-range retrieved values and the flag for high retrieval error. Therefore, in this section only the SMOS nodes without retrieval are included in the analysis.

As mentioned in Section 4.2, no retrieval is performed when the soil is frozen. Figure 4.5 (top-left) shows the percentage of nodes included in the Maqu region with a raised frost flag over the total number of nodes in the region lacking retrieval, for both the case of no retrieval over a part of the area and the case of no retrieval over the whole area. The same plot is presented for the Twente region in Figure 4.6. Figure 4.5 shows that the complete area of the Maqu network was characterized by the frost flag several times in winter, resulting in no data, whereas the Twente region was not considered to be covered by frozen soil except for a few days in January and December. When the soil moisture was only retrieved over part of the area, frozen soil was not the main cause of unsuccessful retrieval for the rest of the area.

However, the analysis revealed that for several products of the winter season when no soil moisture was retrieved, the Maqu region 
was completely frost flag free or only partially covered. The absence of the flag for frozen soils in winter over the whole or part of the Maqu area is in disagreement with the in situ measurements. The spatial average of the soil temperature measured in situ at $5 \mathrm{~cm}$ depth in the Maqu region is shown at the bottom left of Figure 4.5. The measurements at the Maqu site show that the soil temperature at $5 \mathrm{~cm}$ depth dropped below zero from January to February and from November to December 2010 at all sites of the network, meaning the upper layer of the soil was homogenously frozen in winter, whereas in March and October the frost conditions might not be spatially homogenous, though still present. The soil froze several times in January and February in the Twente region as well, as shown in Figure 4.6, but the frost flag was raised only once in the SMOS data. As mentioned in Section 4.2, the frozen soil flag is raised when the surface temperature falls below a certain threshold, input that is provided by the ECMWF model. Therefore, it is possible that surface temperatures provided to the SMOS L2 processor were not accurate, but further analysis would be needed to investigate this issue.

The main reason for unsuccessful retrieval, in particular when there is a partial SMOS data coverage over the area of interest, was found to be related to retrieval algorithm performance. Indeed, for most of the nodes where no data were retrieved, the confidence flags indicated that the retrieval attempt was unsuccessful because the retrieved parameters were out of range or the error of retrieval exceeded the maximum threshold (see Figure 4.5 and Figure 4.6). However, it was not possible to find further information in the L2 products as to what exactly caused this and at which level of the retrieval processing the problem occurred.

The suspected presence of RFI might be another reason for disregarding some SMOS data in the retrieval process, therefore the SMOS L2 product bands related to RFI were analysed. The number of disregarded SMOS L1c data per node because of suspected RFI, averaged over the Maqu and Twente region, and expressed as a percentage of the total number of brightness temperature observations (obtained as described in Section 4.3), is plotted in Figure 4.5 for Maqu and Figure 4.6 for Twente. The presence of RFI is definitely much higher in the Twente region than in the Maqu region. 
At the Dutch site it occurred several times that almost all the SMOS observations were affected by RFI, in particular when no retrieval was attempted over the entire network area. This was not the case for the Maqu region, where the site was suspected to be completely covered by RFI for only a few days. However, the Maqu region was not free of RFI on other days. Indeed, an average of 30\% of SMOS observations over the nodes without retrieval was considered to be affected by this interference.
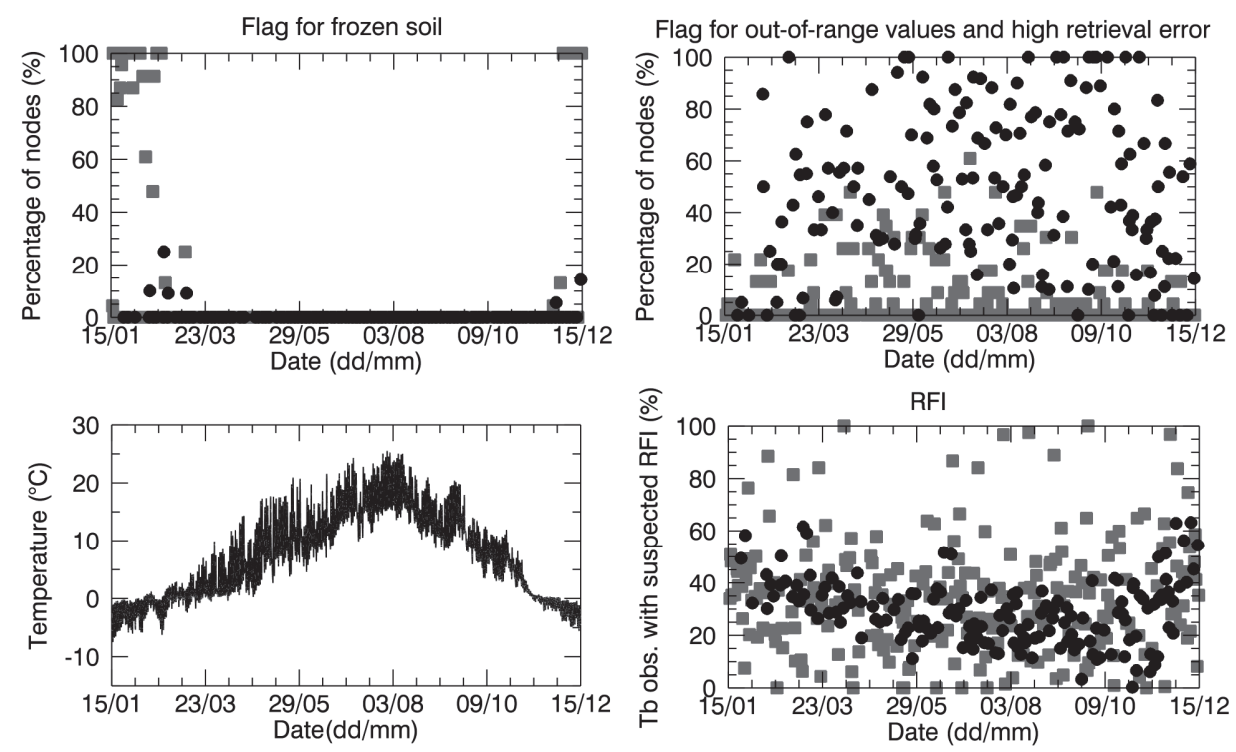

- " no retrieval over entire area $\cdots$ no retrieval over part of the area — soil temperature at $5 \mathrm{~cm}$ depth

Figure 4.5 Percentage of SMOS grid nodes in the Maqu region, where the flag for frozen soil (top-left) and for out-of-range values and high retrieval errors (top-right) were raised. Spatial average of soil temperature measured in the Maqu region at $5 \mathrm{~cm}$ depth (bottom-left). Percentage of disregarded SMOS brightness temperature observations because of suspected RFI, averaged over the Maqu region (bottom-right), when there was no retrieval. Legend refers to all figures. 

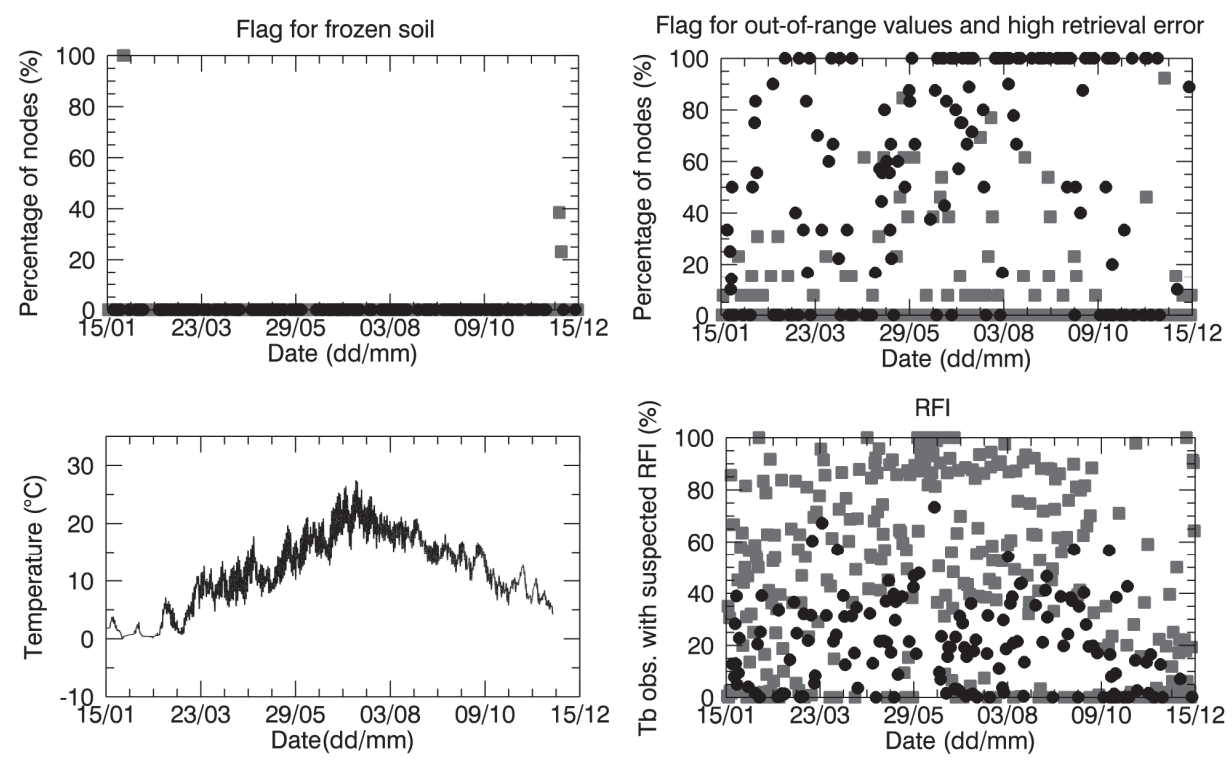

- - no retrieval over entire area $\cdots$ no retrieval over part of the area — soil temperature at $5 \mathrm{~cm}$ depth

Figure 4.6 Same as Figure 4.5 but for the Twente region.

\subsubsection{Analysis of the retrieved value inaccuracy}

The SMOS soil moisture data were further analysed, in order to investigate the causes of noise and inaccuracy. Therefore, different flags and bands of the SMOS products were checked for all nodes where soil moisture was retrieved, allowing understanding of which input information was used in the retrieval process that might have caused the noise.

Figure 4.7 and Figure 4.8 show that in all the data retrieved over the Maqu region and in most of the data retrieved over the Twente region the flag indicating a poor fit between modelled brightness temperature and SMOS observations was raised. This revealed that the performance of the retrieval algorithm were not optimal over either sites, probably due to inaccurate inputs.

As already mentioned in Section 4.2, the surface temperature used as input to the retrieval algorithm was very probably not accurate, in particular in winter, implying an inaccurate detection of frozen soils. According to the in situ measurements (Figure 4.5 and Figure 4.6), the soil surface was homogenously frozen in January and February 
and in November and December in the Maqu region, and in February for several days in the Twente region. Therefore, no SMOS soil moisture data were expected in these periods. However, several data are available, as the frozen soil was not correctly detected. Dry snow was sometimes assumed to be present (Figure 4.7 and Figure 4.8), but retrieval was performed as in the nominal conditions, as the snow was considered transparent (Section 4.2).

Frozen soils and snow might have caused an inaccurate retrieval not only in the mentioned periods, but also in the periods shortly before and shortly after, as the region of interest could have been partially frozen or partially covered by snow.
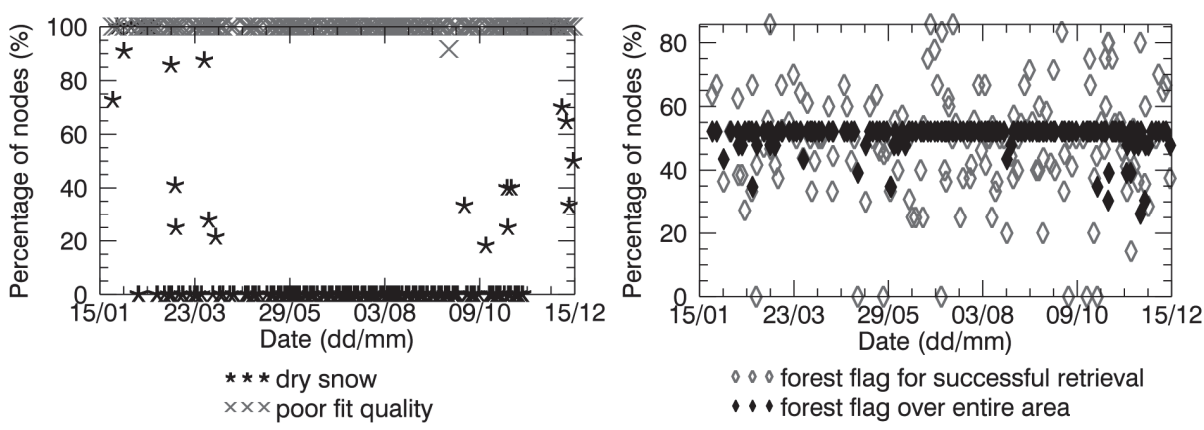

Figure 4.7 Percentage of SMOS grid nodes (over the total number of nodes where soil moisture was retrieved) in the Maqu region, where the flag of dry snow, poor fit quality and forest were raised.
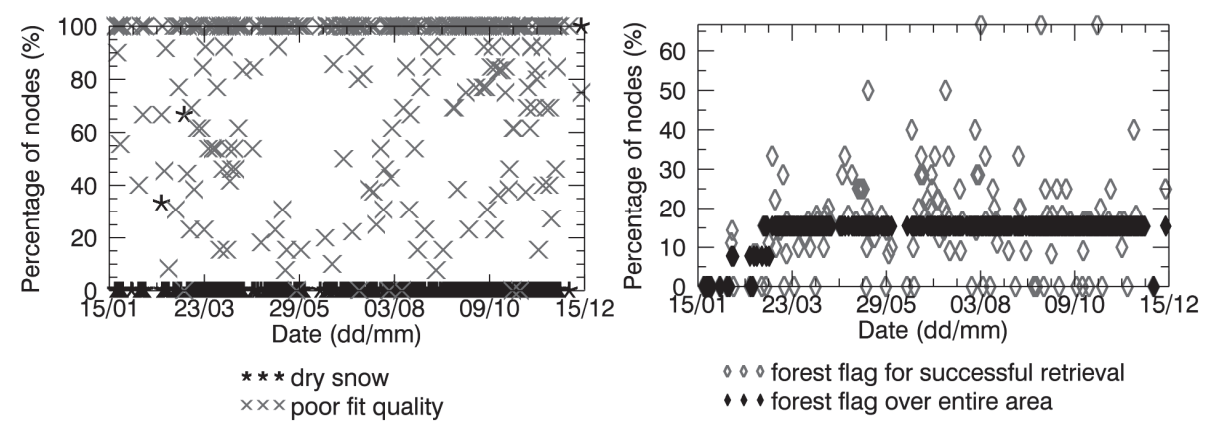

Figure 4.8 Same as Figure 4.7 but for the Twente region. 


\subsubsection{Land cover information}

Another important input to the SMOS retrieval algorithm is land cover. For this reason, the flags indicating the land cover assumed to be present in each node of the SMOS products were analysed. Figure 4.7 and Figure 4.8 plot the percentage of nodes where the forest science flag was raised over the total number of SMOS nodes in the Maqu region and in the Twente region, respectively, as well as the percentage of nodes with a raised forest flag where the retrieval was carried out successfully. The figures show that half of the nodes in the Maqu region and approximately 15\% of the nodes in the Twente region were considered to be covered by forest in most of the SMOS data and that this number varied with time. The assumption of forest cover in $15 \%$ of the nodes in the Twente region is realistic, as is possible to see in the colour composite image of Figure 4.2, whereas the land cover assumed for the Maqu region is not correct.

Therefore, there are two important issues that arise with the analysis of the forest flag. The first issue concerns its variability in time. If the number of nodes with a forest flag set to one is variable in time, it means that a forest fraction is sometimes assumed to be present in a certain node and other times not. The reason of the variability in time of the forest flag for a specific node can be found in the method used in the SMOS retrieval algorithm to determine the dominant land cover at each node, as is explained in Section 4.2. The consequence is that when the forest flag is raised at a certain node, the emissivity simulated by the L-MEB model includes a forest contribution, and when the forest flag is not raised, only low vegetation contribution is included. This can certainly affect the consistency in time of the soil moisture retrieval at a specific node.

The second issue concerns the incorrectly classified land cover in the Maqu region. According to information collected in situ, homogenous grasslands cover the network area and its surrounding areas within tens of kilometres, and the valley near to the Yellow River is characterized by wetlands. However, the forest flag is raised for half of the nodes in this region and the wetland flag is never raised. For this reason, accuracy of the land cover information used by the SMOS L2 processor was investigated. The two cover maps on which the ECOCLIMAP is based, the UMd map and the IGBP-DIS map, were 
compared with an independent land cover map, the MICLCover map. Figure 4.9 shows the three maps for the Maqu region.

According to the UMd map the Maqu region is mainly covered by grassland and wooded grassland, with some small areas of forest, and according to the IGBP-DIS map there are no wetlands. Both maps give inaccurate information, whereas more realistic information can be obtained from the MICLCover map, which shows the presence of mainly grasslands and wetlands, with small areas of barren and low vegetated lands. However, despite the UMd map's inaccuracy, if only the network area had been considered, the dominant vegetation type obtained from it for all nodes would probably be grassland/wooded grassland without any forest. Instead, the SMOS L2 processor working area for determination of the dominant land cover is 123 $\mathrm{km} \times 123 \mathrm{~km}$ large, thus the surrounding area within at least one degree around the network has to be taken into account in the present discussion. The UMd map shows the presence of dense and large forests at less than 20 min of a degree east of the network area, as well as of forest mixed with grassland and wooded grassland to the south and west. The forested areas shown in the UMd map contributed to the determination of the dominant vegetation type when the SMOS view covered them. When the presence of forest was detected, then the forest flag was raised. The nodes with raised forest flags are mainly located near both the eastern and the western borders, which means that not only the dense forest in the eastern part of the UMd map affected the dominant land cover type determination in the network area, but the forest in the western part did as well. The nodes located in the centre of the Maqu region were not characterized by a raised forest flag. The percentage of land covered by forest in the areas surrounding the network is much lower on the MICLCover map, which corresponds with the information collected in situ. If the MICLCover map had been used in the SMOS L2 processor, the number of nodes with a forest flag would probably be much reduced, although the flag would be still raised in a few eastern nodes due to the presence of the forest to the east of the Maqu network. 


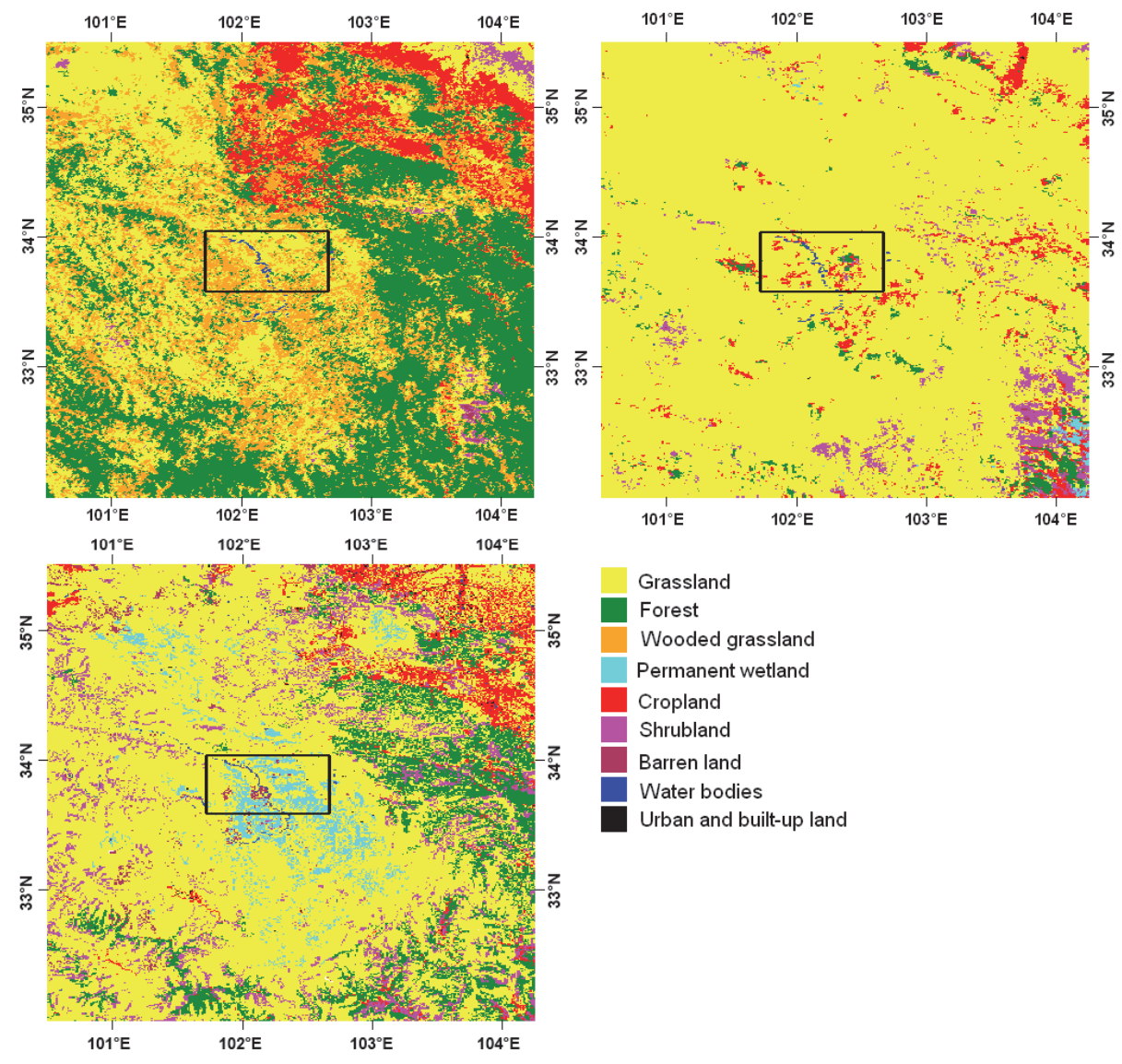

Figure 4.9 UMd map (top-left), IGBP-DIS map (top-right) and MICLCover map (bottomright) over the Maqu region and surrounding areas. The black rectangle highlights the Maqu network location.

\subsubsection{Radio Frequency Interference}

The quality of the L1c SMOS products, used as input to the L2 processor, strongly affects the accuracy of the retrieved soil moisture. As mentioned in Section 4.1, RFI is currently the most important cause of decreased quality of both the SMOS L1c and L2 products.

A preliminary and not comprehensive analysis of the SMOS L1c brightness temperature data was carried out to investigate the possible presence of RFI over the Maqu and the Twente region. A 
proper rotation was applied to the data, converting the brightness temperature in the antenna reference (X and $\mathrm{Y}$ polarization) to that in the Earth reference ( $\mathrm{H}$ and $\mathrm{V}$ polarization). The analysis revealed that for both sites several data are characterized by out of range brightness temperature values, indicating the presence of RFI in the area. Those data were generally filtered out and disregarded by the retrieval process. However, it was also found that several data are characterized by brightness temperatures with acceptable values, but with an unexpected feature in the angular pattern. The angular pattern of both horizontal and vertical polarized brightness temperature was found to have abrupt variations corresponding to small incidence angle increases, instead of the expected smooth variations. All the data collected over the Maqu region, as well as all the descending plus several ascending data over the Twente region, are characterized by this feature. Figure 4.10 shows an example of the irregular angular pattern of the horizontal and vertical polarized brightness temperature measured at one of the nodes in the Maqu region on July 5, 2010. As explained in Misra and Ruf (2012) and Skou et al. (2010), the brightness temperature angular pattern can be strongly affected by the presence of RFI. Moreover, if the RFI is weak, the observed brightness temperature might range between acceptable values, while the angular pattern is irregular. In this situation, the filtering of RFI-affected observations is not straightforward and studies about RFI detection are ongoing. The use of L1c data improperly filtered might be the cause of less accurate soil moisture retrieval.

Several SMOS observations were disregarded in the soil moisture retrieval process. However, in particular for those dates when a large number of SMOS data was suspected to have been affected by RFI, one cannot exclude that RFI might also have been present in the remaining data used for the retrieval. As the RFI caused a bias in the measured brightness temperature, consequently the retrieved soil moisture might be affected by a bias as well. Most of the time, when the brightness temperature bias due to RFI is positive, then the corresponding bias in the soil moisture is negative. This could be one of the reasons for the dry bias observed in the SMOS soil moisture products. Figure 4.11 shows the number of disregarded SMOS L1c data per node because of suspected RFI, averaged over the Maqu and the Twente region, and expressed as a percentage over the total 
number of brightness temperature observations (obtained as described in Section 4.3). Only the nodes where soil moisture was retrieved were considered for this plot.

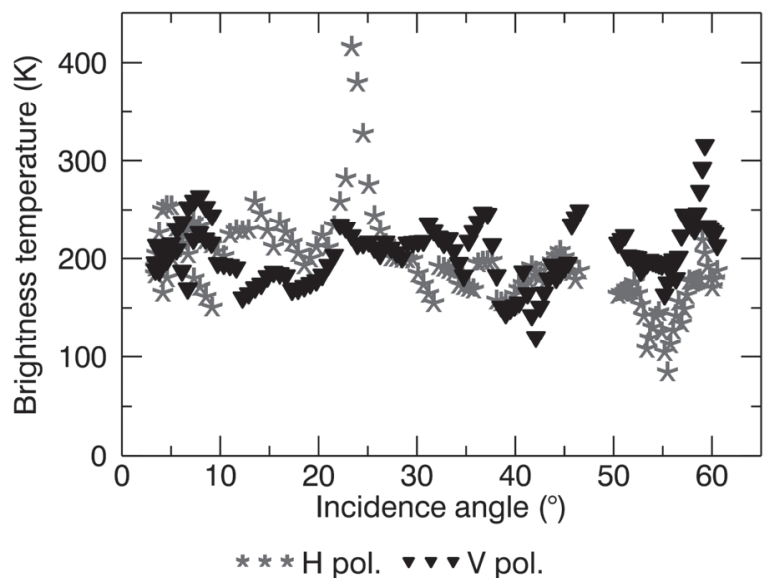

Figure 4.10 Angular pattern of the brightness temperature of one node in the Maqu region on 5 July 2010.
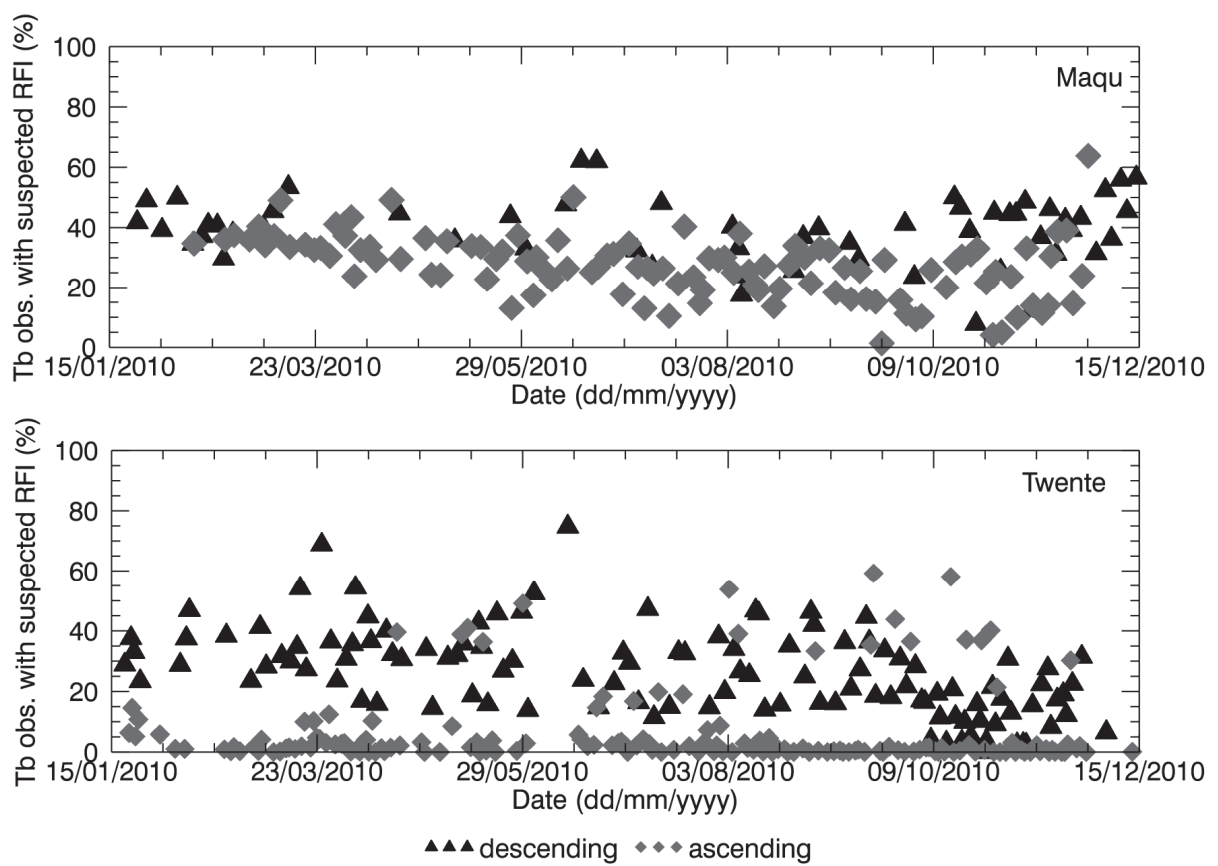

Figure 4.11 Disregarded SMOS brightness temperature observations because of suspected RFI, averaged over the Maqu (top) and the Twente (bottom) region and expressed as a percentage of the total number of SMOS observations. 
Over the Maqu region, approximately $40 \%$ of the SMOS descending observations were disregarded in the retrieval process, as suspected of being affected by RFI. The number of ascending data not used in the retrieval was approximately $40 \%$ at the beginning of 2010 , but slowly decreased during the year. Over the Twente region, the descending data were clearly more affected by RFI than the ascending data. The average percentage of disregarded descending observations was approximately $30 \%$, but could on occasion rise above $60 \%$. Whereas, most of the ascending passes were free of RFI in the Twente region in 2010.

\subsubsection{Time series correlation}

In order to have a clearer view of the match between retrieved and measured soil moisture, the SMOS soil moisture spatial average was compared with the in situ measurements collected at the time of the satellite acquisitions, as shown in the scatter plots in Figure 4.12. Moreover, Table 4.1 reports the coefficient of determination, $R^{2}$, and the root mean square error, $R M S E$, between the two time series. The analysis was done separately for ascending and descending data.

For both the Maqu and the Twente region, there is closer agreement of the SMOS soil moisture retrieved from ascending data and the in situ data, than from descending data, though $R^{2}$ remains relatively low, i.e. 0.55 for the Maqu region and 0.51 for the Twente region. The plots show that the dry bias in the SMOS retrieval is more evident in the ascending case than in the descending case, but that the data are more spread out in the latter case than in the former. A quantification of the dry bias of the SMOS data was obtained with the computation of the RMSE. Products retrieved from ascending data over the Twente site show on average a dry bias of approximately $0.17 \mathrm{~m}^{3} \mathrm{~m}^{-3}$, whereas those over the Maqu site show a bias of approximately $0.13 \mathrm{~m}^{3} \mathrm{~m}^{-3}$. The correlation and the dry bias only slightly improves, if the SMOS data covering less than half the area of interest are disregarded (empty symbols in Figure 4.12 SMOS soil moisture averaged over the Maqu (top) and the Twente (bottom) region as a function of in situ average soil moisture at the satellite acquisition time, for ascending passes (left) and for descending passes (right). Empty symbols indicate that for more than half of the 
area no SMOS products were generated, whereas filled symbols refer to a good coverage.), though not for the descending data over Maqu. Disregarding the periods of possible presence of frozen soils and snow does not improve the match between the two datasets over Maqu and only slightly increase the coefficient of determination over Twente. Moreover, in order to check if the presence of mountainous areas, the river and the cities as well as the presence (or assumed presence) of forest in the observed area affected the agreement between satellite-derived and in situ data, the $R^{2}$ and $R M S E$ were also computed, disregarding the nodes covering these targets in the SMOS spatial average. Table 4.1 shows that the $R^{2}$ and $R M S E$ does not significantly change when the mountainous areas and the river of the Maqu region and the largest cities of the Twente region are excluded by the computation. Moreover, $R^{2}$ and $R M S E$ does not improve when the nodes with a raised forest flag are excluded from the SMOS spatial average. This leads to the conclusion that noise and bias of the SMOS soil moisture data over Maqu and Twente region are not due to the presence of these targets and are not related to the inclusion in the L-MEB model of a forest contribution. Moreover, they are not limited to the period of frost and snow.

The difference between the depth of the soil layer contributing to the brightness temperature measured by SMOS radiometer and the soil depth where the measurements were carried out certainly affects the relationship between satellite-derived and in situ data. Measuring soil moisture at deeper layers than the penetrating depth of the microwave radiation should lead to an underestimation in the dry season (as the upper soil layers are dryer than the deeper layers) and an overestimation in the rainy season or soon after a rainy event (as the upper layers are wetter than the deeper ones), but this is not the case for the SMOS data, as the dry bias is quite systematic in all seasons. Therefore, this effect does not explain the SMOS bias.

The RMSE found over the Maqu and Twente region are much higher than the SMOS mission requirements for soil moisture observations, i.e. $0.04 \mathrm{~m}^{3} \mathrm{~m}^{-3}$ (Kerr et al. 2010). The dry bias and noise in the SMOS data are not specific for the Maqu and the Twente sites, as they were also found at the upper Danube catchment (southern Germany) (dall'Amico et al. 2011), at two sites in Italy and one in Luxemburg (Lacava et al. 2012), at the REMEDHUS network area in Spain 
(Sánchez et al. 2012) and at several sites of the SCAN network in the U.S. (Al Bitar et al. 2012). However, there are also sites where bias was almost completely absent, as it was shown at the Walnut Gulch (AZ) watershed, the Little Washita (OK) watershed and the Little River (GA) watershed in the U.S. (Jackson et al. 2012) as well as at some of the sites of the SCAN network (Al Bitar et al. 2012). Considering all these studies one could conclude that the dry bias is not dependent on a specific land cover, surface condition or season, though it might be related to the presence of RFI. However further analyses are needed to understand the cause.
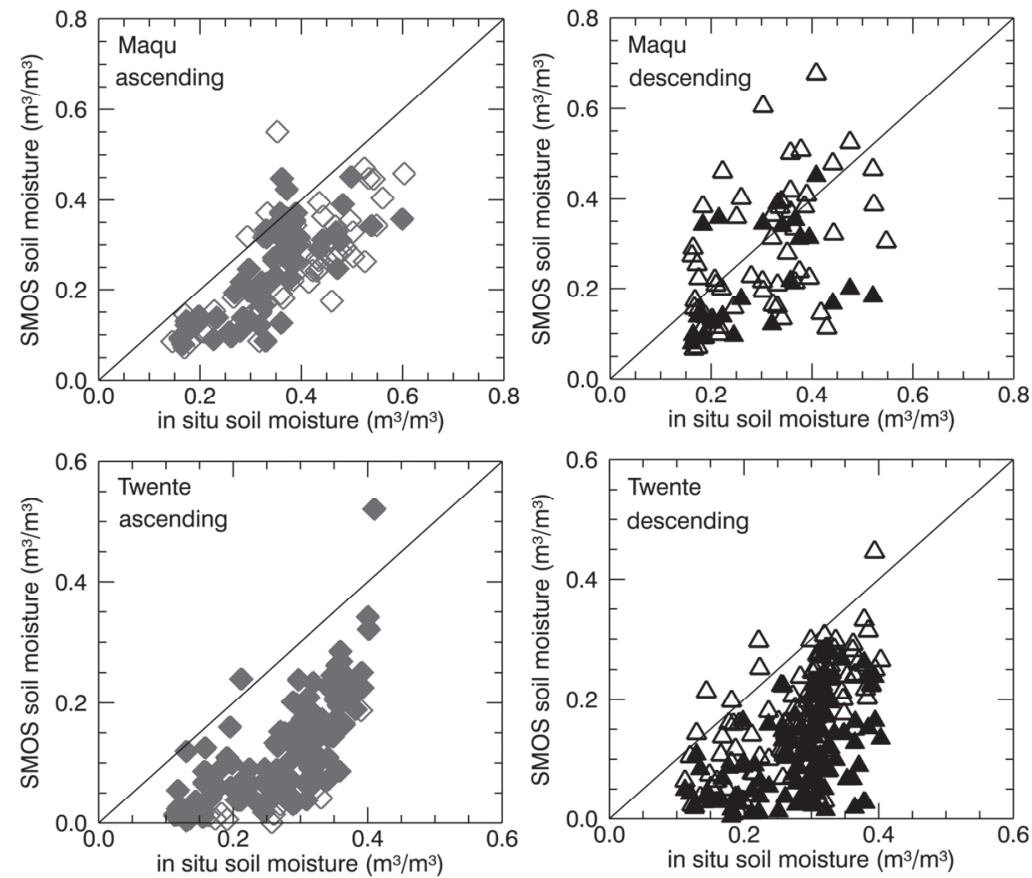

Figure 4.12 SMOS soil moisture averaged over the Maqu (top) and the Twente (bottom) region as a function of in situ average soil moisture at the satellite acquisition time, for ascending passes (left) and for descending passes (right). Empty symbols indicate that for more than half of the area no SMOS products were generated, whereas filled symbols refer to a good coverage. 
Table 4.1 Coefficient of determination $\left(R^{2}\right)$ and root mean square error $\left(R M S E, \mathrm{~m}^{3} \mathrm{~m}^{-3}\right)$ between SMOS ascending and descending soil moisture data and in situ measurements, considering all the data available, the data that cover at least half the area of interest, the data covering flat areas only, all the data except those covering the water bodies, the forest and the urban areas or collected in the winter/frost period.

\begin{tabular}{|c|c|c|c|c|c|}
\hline \multicolumn{2}{|c|}{} & \multicolumn{2}{c|}{ DESCENDING } & \multicolumn{2}{c|}{ ASCENDING } \\
\cline { 3 - 6 } & All data & $\boldsymbol{R}^{\mathbf{2}}$ & $\boldsymbol{R M S E}$ & $\boldsymbol{R}^{\mathbf{2}}$ & $\boldsymbol{R} \boldsymbol{M S E}$ \\
\hline \multirow{5}{*}{ MAQU } & 0.24 & 0.13 & 0.55 & 0.13 \\
\cline { 2 - 6 } & Data with coverage >50\% & 0.12 & 0.09 & 0.57 & 0.12 \\
\cline { 2 - 6 } & Data over flat areas & 0.20 & 0.14 & 0.50 & 0.14 \\
\cline { 2 - 6 } & Data without water bodies & 0.27 & 0.13 & 0.55 & 0.14 \\
\cline { 2 - 6 } & Data May-September & 0.03 & 0.17 & 0.33 & 0.15 \\
\cline { 2 - 6 } & Data without forest flag & 0.22 & 0.14 & 0.48 & 0.14 \\
\hline \multirow{5}{*}{ AWENTE } & 0.41 & 0.12 & 0.51 & 0.17 \\
\cline { 2 - 6 } & Data with coverage > 50\% & 0.42 & 0.12 & 0.52 & 0.16 \\
\cline { 2 - 6 } & Data without forest flag & 0.40 & 0.12 & 0.52 & 0.17 \\
\cline { 2 - 6 } & Data without cities & 0.43 & 0.12 & 0.52 & 0.16 \\
\cline { 2 - 6 } & Data March-December & 0.48 & 0.11 & 0.53 & 0.16 \\
\hline
\end{tabular}

\subsection{Summary and conclusions}

The seasonal behaviour of the SMOS products is generally in agreement with the in situ data over both regions. The validation analysis resulted in an $R^{2}$ of 0.55 and $R M S E$ of $0.13 \mathrm{~m}^{3} \mathrm{~m}^{-3}$ over the Chinese site and an $R^{2}$ of 0.51 and $R M S E$ of $0.17 \mathrm{~m}^{3} \mathrm{~m}^{-3}$ over the Dutch site for the ascending pass SMOS products. The agreement between the satellite-derived and in situ data is less when the descending pass data are considered, with an $R^{2}$ of 0.24 and $R M S E$ of $0.13 \mathrm{~m}^{3} \mathrm{~m}^{-3}$ for the Maqu region and an $R^{2}$ of 0.41 and $R M S E$ of 0.12 $\mathrm{m}^{3} \mathrm{~m}^{-3}$ for the Twente region. The relatively low $R^{2}$ and high $R M S E$ are due to the presence of noise and a systematic dry bias in the SMOS data.

It was found that the retrieval is more problematic in the Maqu region than in the Twente region. Several SMOS L2 data over the Maqu region are missing or cover only a small fraction of the network area, as the retrieval attempt was unsuccessful in the remaining part. However, the $R^{2}$ does not improve when the data covering less than half of the area are disregarded. It was also found that the presence of mountainous areas, water bodies, forest and 
cities does not affect the retrieval accuracy over these regions, as the $R^{2}$ and $R M S E$ do not improve when the SMOS nodes covering these targets are disregarded.

The presence of frozen soils and snow in the Maqu region, as well as in the Twente region, might be one of the causes of low retrieval accuracy in winter, amplified by the fact that the input information about frozen surfaces (i.e. surface temperature) used in the SMOS retrieval process was probably inaccurate. Further analyses of the surface temperature provided by the ECMWF model would be needed to assess its accuracy, as well as the impact of this factor on the soil moisture retrieval, not only in winter but also in the other seasons.

Another important input which resulted in inaccuracies for the Maqu region (but not for the Twente region) is the land cover type. The wrong land cover type being used in the SMOS retrieval over the Maqu region is due to both the inaccurate land cover information provided by ECOCLIMAP and the contribution of the land cover of the neighbouring areas in the determination of the dominant land cover type for the nodes within the network area. A dedicated study assessing the SMOS retrieval sensitivity to land cover map accuracy, by comparing soil moisture retrieved using different land cover maps (such as MODIS, GLC2000 and GLOBCOVER land cover maps), would be needed. Though improving the accuracy of the input land cover map might improve the accuracy of the SMOS products over the Maqu region, the contribution of neighbouring areas, to both the determination of the land cover in a specific node and the brightness temperature measured for that node, cannot be avoided when the satellite sensors have a low resolution, as the SMOS satellite has.

The presence of RFI was detected over both regions. This is probably the most important factor causing noise and bias in the SMOS soil moisture products. Several L1c data were filtered out of the retrieval process. However, it was found that an irregular angular pattern in the brightness temperature characterizes many of the L1c data employed in the retrieval. This is most probably due to a weak and not well filtered RFI. The SMOS ascending data over the Twente region are less affected by RFI than the other dataset, however they do not particularly show better agreement with the in situ data than the other dataset does. The SMOS soil moisture products will certainly 
benefit from the use of an improved RFI detection and filter method, as is currently under investigation.

Both further L1 data re-processing and further refinement of the soil moisture retrieval algorithm on the base of the validation campaign results are planned. Therefore, it is expected that the SMOS soil moisture data quality will rapidly be improved. 
Validation of SMOS soil moisture products over the Maqu and Twente regions 


\section{Chapter 5}

\section{Seasonality and autocorrelation of AMSR-E and ERS soil moisture products}

This chapter is based on:

Dente L., Vekerdy Z., de Jeu R., Su Z. (2012). Seasonality and autocorrelation of satellite-derived soil moisture products. International Journal of Remote Sensing, 34, 3231-3247

\section{$5.1 \quad$ Introduction}

The main objective of this section is to evaluate the long term reliability of the satellite-derived soil moisture products for applications that would benefit from the use of consistent time series of soil moisture, such as studies on climate and hydrological cycle. The analysis consists of the validation of seasonality and autocorrelation of the satellite-derived soil moisture products. In order to carry out this analysis, long time series, i.e. several years, are needed. AMSR-E soil moisture and ERS relative soil wetness index satisfy this important requirement and for this reason they were used in this part of the study. 
Both AMSR-E and ERS datasets were successfully employed in several studies to evaluate meteorological and climatic anomalies at small and large scale. Deviations from the average soil moisture, corresponding to heavy rainfall events or droughts due to El Niño effects, were observed in the ERS soil moisture at global scale by Kuenzer et al. (2009) and in TRMM/TMI, SMMR and AMSR-E products over Australia by Liu et al. (2009). Negative anomalies were found by Loew et al. (2009) in the AMSR-E soil moisture products over Europe in spring 2003, revealing a drought which could be the cause of an extreme heat wave affecting the same area later in the year. Zhao et al. (2008) found a good correspondence between rainfall patterns, drought and flood events and ERS soil moisture at local, regional and countrywide scale in China. These results lead to the conclusion that operational, global and long term satellitederived soil moisture products can be very useful to improve the accuracy of land surface and climatic models in order to support climate change studies and early warning systems of extreme hydrometeorological events. Scipal et al. (2008) found that the assimilation of ERS soil moisture products in ECMWF numerical weather prediction model increased the correlation between the model output and the ground measurements over Oklahoma.

Several studies have investigated the accuracy of both AMSR-E and ERS products comparing the soil moisture absolute values with in situ observations over different validation sites and in a limited period of time (Draper et al. 2009; Gruhier et al. 2008; Rudiger et al. 2009; Wagner et al. 2007b). However, for climatic studies, based on the use of long time series at large scale, the accuracy of the daily values is not the primary requirement, whereas it is very important that the soil moisture spatial and temporal trends, seasonalities and general statistics (i.e. correlation and autocorrelation in space and time) are consistent and reliable. The investigation of the spatial characteristics and a cross-validation of AMSR-E and ERS soil moisture products at global scale was carried out in de Jeu et al. (2008), where it is shown that the two datasets have a generally good spatial correlation over sparse to moderate vegetated regions with high seasonal and inter-annual soil moisture variations. However, a larger disagreement was found over densely vegetated regions, deserts and dry areas with a small range in soil moisture variability. 
Differently, in the present section, the accuracy of AMSR-E and ERS soil moisture was investigated in terms of agreement between temporal patterns, anomalies, seasonalities and autocorrelation functions of in situ observations and satellite products for long time series with the main objective to investigate the satellite data suitability for studies which require long term soil moisture data, such as climatic studies.

\subsection{In situ and satellite data}

In order to carry out the analysis for different climatic areas and different vegetation covers, five sites equipped with large and long term soil moisture monitoring networks, as well as meteorological stations, were selected: two areas in North Oklahoma, two areas in South-East Australia and one in the Salamanca region of Spain. The in situ data are described in details in the following paragraphs and Table 5.1 summarises the characteristics of the sites of interest and in situ data.

AMSR-E and ERS soil moisture datasets were selected for this study, as they consists of time series several years long and they are largely used by the scientific community. The AMSR-E soil moisture products were described in Section 3.2.1. The AMSR-E soil moisture products obtained from descending passes from January 2003 to December 2007 were used in this study. The ERS soil moisture products were obtained from ERS-2 scatterometer data (C-band, 5.3 GHz) by TU Wien (available at http://www.ipf.tuwien.ac.at/radar) applying the same approach described in Section 3.2.2 for the ASCAT soil moisture products. They consist of a relative soil wetness index scaled between the driest and wettest condition ever observed in the area of interest (Section 3.2.1). No conversion to absolute value was carried out. The products are available with a global coverage from 1992 to 2001, with a spatial resolution of $50 \mathrm{~km}$ and a temporal resolution of approximately 3-4 days (depending on the availability of ERS scatterometer data). From $1^{\text {st }}$ January 2001 to $12^{\text {th }}$ August 2003 there are no ERS data available and after this date until July 2011, the spatial coverage is limited to the area of several receiving 
stations (mainly located in the Northern hemisphere) and the revisit time is strongly reduced. Therefore, all the ERS soil moisture data available from $1^{\text {st }}$ January 1992 to 31 May 2007 were used in this study, but with a gap between $1^{\text {st }}$ January 2001 to $15^{\text {th }}$ August 2003 in Oklahoma, to $18^{\text {th }}$ January 2006 in Australia and to $5^{\text {th }}$ September 2005 in Salamanca. Table 5.2 summarizes the characteristics of the satellite-derived data.

Precipitation, air temperature and fAPAR (Fraction of Absorbed Photosynthetically Active Radiation) data were used to support the analysis. The fAPAR was derived from SeaWiFS and MERIS data using the algorithm developed by Gobron et al. (2000) (http://fapar.jrc.ec.europa.eu/Home.php) and it consists of a 10days time composite product spatially averaged over $3 \times 3$ pixels of about $2.7 \mathrm{~km}$ each, centred on the area of interest. Gobron et al. (2005) showed that fAPAR is a good indicator of the canopy state, as the intercepted PAR is the energy underlying the biochemical productivity process of plants and depends on the chlorophyll availability in leaves. Therefore, by estimating the variability of the vegetation cover in time with the fAPAR time series, the sensitivity of the soil moisture retrieval algorithms of AMSR-E and ERS products to the vegetation cover could be investigated.

Table 5.1 Size of the monitored area, land cover, period and depth of the soil moisture monitoring at the sites of interest for this study and period of data availability of the meteorological data.

\begin{tabular}{|c|c|c|c|c|c|}
\hline & AREA & $\begin{array}{l}\text { LAND } \\
\text { COVER }\end{array}$ & $\begin{array}{c}\text { SM } \\
\text { PERIOD }\end{array}$ & $\begin{array}{c}\text { SM } \\
\text { DEPTH }\end{array}$ & $\begin{array}{l}\text { METEO DATA } \\
\text { PERIOD }\end{array}$ \\
\hline OSAGE & $\begin{array}{l}100 \mathrm{~km} \mathrm{x} \\
80 \mathrm{~km}\end{array}$ & $\begin{array}{l}\text { cropland, } \\
\text { grassland, } \\
\text { water bodies }\end{array}$ & $\begin{array}{l}\text { Jan } 2000- \\
\text { Mar } 2005\end{array}$ & $5 \mathrm{~cm}$ & $\begin{array}{c}\text { Jan } 1997- \\
\text { Jan } 2005\end{array}$ \\
\hline PAYNE & $\begin{array}{c}75 \mathrm{~km} \mathrm{x} \\
45 \mathrm{~km} \\
\end{array}$ & $\begin{array}{l}\text { cropland, } \\
\text { grassland }\end{array}$ & $\begin{array}{l}\text { Jan } 2000- \\
\text { Mar } 2005\end{array}$ & $5 \mathrm{~cm}$ & $\begin{array}{l}\text { Jan } 1997- \\
\text { Jan } 2005 \\
\end{array}$ \\
\hline KYEAMBA & $600 \mathrm{~km}^{2}$ & grassland & $\begin{array}{l}\text { Jan } 2002- \\
\text { Dec } 2007\end{array}$ & $5 \mathrm{~cm}$ & $\begin{array}{l}\text { Nov } 2001- \\
\text { May } 2008^{\text {ii }}\end{array}$ \\
\hline YANCO & $\begin{array}{l}60 \mathrm{~km} \mathrm{x} \\
60 \mathrm{~km}\end{array}$ & $\begin{array}{l}\text { grassland, } \\
\text { cropland } \\
\text { (oat) }\end{array}$ & $\begin{array}{l}\text { Jan } 2002- \\
\text { Dec } 2007\end{array}$ & $5 \mathrm{~cm}$ & $\begin{array}{l}\text { Nov } 2001- \\
\text { May 2008ii }\end{array}$ \\
\hline REMEDHUS & $1285 \mathrm{~km}^{2}$ & $\begin{array}{l}\text { cropland } \\
\text { (cereal), } \\
\text { vineyards }\end{array}$ & $\begin{array}{l}\text { Mar 2005- } \\
\text { Dec } 2007\end{array}$ & $5 \mathrm{~cm}$ & $\begin{array}{l}\text { Jan } 1971- \\
\text { Dec } 2000\end{array}$ \\
\hline
\end{tabular}

\footnotetext{
ii Soil temperature at $5 \mathrm{~cm}$ depth is used instead of air temperature.
} 
Table 5.2 Period of data availability, pixel size and temporal resolution of the satellite-derived products used in this study.

\begin{tabular}{|l|c|c|c|}
\hline & PERIOD & PIXEL SIZE & $\begin{array}{c}\text { TEMPORAL } \\
\text { RESOLUTION }\end{array}$ \\
\hline AMSR-E soil moisture & Jan $2003-$ Dec 2007 & $0.25^{\circ}$ & Almost daily \\
\hline ERS soil moisture ${ }^{\text {iii }}$ & Jan $1992-$ May 2007 & About $12.5 \mathrm{~km}$ & $3-4$ days \\
\hline fAPAR & Sep $1997-$ Jun 2006 & $8.1 \mathrm{~km}$ & 10 days \\
\hline
\end{tabular}

\subsubsection{Oklahoma Mesonet: Osage and Payne sites}

The satellite products were compared with in situ soil moisture data collected by the Oklahoma Mesonet (http://www.mesonet.org), which consists of 116 stations measuring since 1999 different meteorological and soil parameters, including soil moisture at $5 \mathrm{~cm}$ depth, in the Oklahoma State (Hansen et al. 2000). In particular, the data used in this study were collected at $5 \mathrm{~cm}$ depth by the stations located in two different areas of Oklahoma, one (named Osage), including the counties of Osage-West, Kay, Pawnee and Noble $\left(36.32^{\circ}-36.91^{\circ} \mathrm{N}, 96.32^{\circ}-97.27^{\circ} \mathrm{W}\right)$, and the other (named Payne), including the counties of Payne and Logan-North $\left(35.77^{\circ}-36.17^{\circ} \mathrm{N}\right.$, $96.99^{\circ}-97.66^{\circ} \mathrm{W}$ ), from 1 January 2000 to 31 March 2005. 6 stations are installed in $100 \mathrm{~km}$ x $80 \mathrm{~km}$ Osage area and 5 in $75 \mathrm{~km} \mathrm{x} 45 \mathrm{~km}$ Payne area. After a quality analysis, it was concluded that the soil moisture data collected in these areas are temporally and spatially consistent, therefore suitable for this study. According to the land use/land cover map of Oklahoma distributed by Map Information Assembly and Display System (MIADS), both areas are characterised by cropland (mainly cereals) and rangeland-open grass (slightly higher percentage of cropland in Payne). The averaged temporal behaviour of fAPAR (shown in Figure 5.1) indicates that the vegetation cover is high from April to August in Osage and one month earlier in Payne, i.e. from March to July. In the Osage area, there is a larger presence of water bodies (Kaw Lake and Arkansas River).

\footnotetext{
iii Lack of data from $1^{\text {st }}$ January 2001 to $15^{\text {th }}$ August 2003 in Oklahoma, to $18^{\text {th }}$ January 2006 in Australia and to $5^{\text {th }}$ September 2005 in Salamanca.
} 
The precipitation and temperature data, used as a reference, were collected by the same network from 1 January 1997 to 1 January 2005.

\subsubsection{OzNet dataset: Kyeamba and Yanco sites}

OzNet is an Australian monitoring network for soil moisture and micrometeorology, which consists of 18 stations installed across the Murrumbidgee River Basin in New South Wales in 2003 (http://www.oznet.unimelb.edu.au/). Only the data collected at $5 \mathrm{~cm}$ depth in Yanco $\left(34.61^{\circ}-35.12^{\circ} \mathrm{S}, 145.83^{\circ}-146.43^{\circ} \mathrm{E}\right)$ and Kyeamba $\left(35.11^{\circ}-35.51^{\circ} \mathrm{S}, 147.33^{\circ}-147.61^{\circ} \mathrm{E}\right)$ site from 1 January 2002 to 31 December 2007 were used in this study. Both sites are located in the centre of the catchment: the first site has 13 stations, distributed over a quite flat area of about $60 \mathrm{~km} \mathrm{x} 60 \mathrm{~km}$ and the second has 14 stations, installed on steep slopes of a $600 \mathrm{~km}^{2}$ area. The land use in Kyeamba site is mainly grazing and in Yanco is both grazing and irrigated crops (mainly oats). According to the fAPAR timeseries (shown in Figure 5.1), the main vegetation development occurs from July to October in both sites.

The rainfall measurements and the soil temperature measurements at $5 \mathrm{~cm}$ depth (considered as an indicator of the air temperature, because of the unavailability of the latter) collected by the same stations from 14 November 2001 to 31 May 2008 were also used in the analysis.

\subsubsection{REMEDHUS dataset: Salamanca site}

In order to include in this study a European site characterized by land use and climate different from the previous sites, an area in Spain was selected.

It is located in the Duero basin, near Salamanca (Spain), where an extensive soil moisture network, REMEDHUS (Martinez-Fernandez and Ceballos 2005), was installed over an area of about $1285 \mathrm{~km}^{2}$ $\left(41.1^{\circ}-41.5^{\circ} \mathrm{N}, 5.2^{\circ}-5.6^{\circ} \mathrm{W}\right)$. It consists of 21 stations measuring the soil moisture at different depths. The climate in this hilly area is semiarid continental Mediterranean and the land is mainly used for 
agriculture (cereal $80 \%$, irrigated crops $4 \%$ and vineyards $4 \%$ ). As the fAPAR indicates (see Figure 5.1), the vegetation cover is higher between March and May. The soil moisture measured at $5 \mathrm{~cm}$ depth from 16 March 2005 to the end of 2007 was used in this study. The data were provided by the International Soil Moisture Network - A data hosting facility for in situ soil moisture data (http://www.ipf.tuwien.ac.at/insitu/).

The monthly average precipitation and temperature of Salamanca province computed from 30 years of data (1971-2000) were obtained from the Agencia Estatal de Meteorología (http://www.aemet.es/en/elclima/datosclimatologicos).

\subsection{Approach}

Different approaches were used to reach the aim of this study, including the comparison of the seasonality, of the anomalies and of the autocorrelation functions among AMSR-E, ERS and in situ time series.

The first step was to investigate whether the satellite products are characterised by a seasonal component comparable to the typical in situ soil moisture seasonality. This is an indicator of a consistency over periods of one year or longer.

The time series seasonal decomposition was carried out using the Census Method I, described by Makridakis et al. (1998). According to this method, the time series $\left(S M_{t}\right)$ are considered as the sum of three components: the trend-cycle component $\left(T C_{t}\right)$, the seasonal component $\left(S_{t}\right)$ and the irregular (random) component $\left(I_{t}\right)$ :

$S M_{t}=T C_{t}+S_{t}+I_{t}$

$T C_{t}$ is due to continuous or cyclical variations occurring in a long term period. $S_{t}$ is related to the impact of a periodically varying factor (e.g. seasonal weather conditions). $I_{t}$ consists of the residual or anomalies (due to the daily weather conditions), obtained after 
subtracting the trend-cycle and seasonal components from the time series.

In order to estimate $T C_{t}$, the time series was smoothed by moving average with a window width equal to the length of the seasonality, i.e. one year. The effect of the smoothing is to remove the seasonal and the irregular component. Averaging seasonally high periods with seasonally low periods eliminates the seasonality and, since the irregular component has no systematic pattern, the averaging reduces this component as well. However, it is not possible to compute the trend-cycle component of the time series used for this study, as they are too short to show a long term trend. For this reason, the satellite products and in situ time series were considered as only the sum of the seasonal and the irregular components in the present analysis.

To isolate $S_{t}$, the average of the different years of the time series was computed (the data of each day is the result of the average of values available in the same day in the whole time series). The resulting seasonal component is noisy, because the time series used in this study are not long (or have many gaps, as it is the case of ERS time series), therefore a simple and central moving average was applied to reduce this problem with an average window of 19 days (i.e. 9 days before and 9 after the central value). This is the minimum window width that can be used for the purpose. Shorter windows do not suppress the noise in the seasonal component. Longer windows, i.e. of the same length or longer than a season, suppress the seasonal component. In both cases, the seasonality would not be correctly estimated and removed from the time series.

The seasonal components of AMSR-E, ERS and in situ soil moisture were compared, as well as to the monthly average of air temperature and fAPAR and with the monthly precipitation sums. This helped to understand which are the variables affecting the soil moisture behaviour and the sensitivity of satellite sensors to soil moisture.

The time series, as well as the anomalies, were resized to cover only the overlapping period of data availability of AMSR-E products, ERS products and in situ data. Furthermore, as the datasets, in particular the ERS time series, are affected by some data gaps, it was necessary to fill the gaps, by using a linear interpolation before the correlation 
and autocorrelation computations. The interpolation length was chosen according to the average time length of gaps of ERS products over each site (i.e. 3 days in Oklahoma, 7 days in Australia and 8 days in Salamanca), as it is the dataset with longer gaps. Applying a different interpolation method (such as nearest-neighbour, bilinear and cubic interpolation) did not affect the results of this study.

Then, the linear correlation coefficient, $R_{i, j}$, between two of the time series was computed according to the following equation:

$$
R_{i, j}=\frac{\sum_{t}\left(S M_{i t}-\overline{S M_{i}}\right)\left(S M_{j t}-\overline{S M_{j}}\right)}{\left[\sum_{t}\left(S M_{i t}-\overline{S M_{i}}\right)^{2} \sum_{t}\left(S M_{j t}-\overline{S M_{j}}\right)^{2}\right]^{1 / 2}}
$$

where $i, j=$ AMSR-E, ERS or in situ, $S M_{i t}$ is one of the soil moisture time series at time $t$.

Finally, the autocorrelation of the different soil moisture datasets was computed for different time lags and compared. The correlogram of time series containing a seasonal fluctuation exhibits an oscillation with the same period. For the soil moisture case, this period is one year; therefore the correlogram obviously reaches its minimum at about 180 days lag and its maximum at one year lag. There is the possibility to extract more meaningful information from the autocorrelation of the anomalies obtained removing the seasonal component from the time series. The autocorrelation of the anomalies is an indicator of the correlation (or randomness) in time of the soil moisture variations due to meteorological effects. The autocorrelation, $r_{k}$, of the anomalies was computed, according to the following formula:

$$
r_{k}=\frac{\sum_{t=1}^{N-k}\left(I_{t}-\bar{I}\right)\left(I_{t+k}-\bar{I}\right)}{\sum_{t=1}^{N}\left(I_{t}-\bar{I}\right)^{2}}
$$


where $k$ is the time lag of the correlation coefficient and $N$ is the total number of observations in the analysed period.

As mentioned, the time series were interpolated, therefore the minimum correlation lag depends on the applied interpolation length. If the time series was interpolated every 3 days, then the minimum lag and its resolution cannot be smaller than 3 days.

\section{$5.4 \quad$ Results}

\subsubsection{Correlation between seasonalities}

The seasonal decomposition was applied over the complete time series available for each satellite-derived dataset and for each site (see Table 5.1 and Table 5.2). The seasonality of AMSR-E, ERS and in situ soil moisture is compared for all the sites in the plots of Figure 5.1. The ERS seasonality is reported on a secondary axis, because it consists of relative values of soil wetness, instead of absolute values of soil moisture. The monthly precipitation and the monthly air temperature averaged over all the available years are included in the plots as reference, as well as the 10-days composite fAPAR, averaged over all the available years (i.e. from September 1997 to June 2006).

The correlations between the seasonality of the satellite soil moisture and in situ soil moisture, as well as between those of soil moisture and fAPAR and precipitation time series, are listed in Table 5.3 .

AMSR-E soil moisture shows a clear seasonality in all the sites. Though ERS soil moisture consists of a longer time series than AMSR-E products, it is much noisier in all the sites, which is probably due to the large gaps characterizing this dataset.

The correlation between the seasonality of the satellite products and the in situ data is generally higher than 0.8, except for the case of ERS over the two Oklahoma sites. ERS products, indeed, do not show any seasonal behaviour in both Oklahoma sites which might be caused by the small variability range of in situ soil moisture characterising 
these sites. The sensitivity of the retrieval algorithm, used for ERS soil moisture products, to variations of surface parameters, such as soil roughness and vegetation cover, might be comparable to the sensitivity to soil moisture variations, for small variability ranges. Therefore, the retrieval results become noisy. AMSR-E seasonality of Oklahoma sites is slightly noisier than for other sites, which is very probably caused by the RFI affecting the AMSR-E brightness temperature in Oklahoma (as shown by Li et al. (2004)). The AMSR-E soil moisture of Osage shows an earlier increase than the in situ seasonality at the end of summer and beginning of autumn. Over this site the (inverse) correlation with fAPAR is higher for the AMSR-E seasonality than for the in situ seasonality, which is an indication of the sensitivity of the AMSR-E soil moisture retrieval to the vegetation development. However, this occurs only at the Oklahoma sites, where the variability range of soil moisture is small and the correlation between in situ seasonality and fAPAR is negative (i.e. inverse relationship between soil moisture and fAPAR).

The best agreement between both AMSR-E and ERS seasonality and in situ seasonality occurs over the Australian sites, with a high correlation along the whole year. The main difference with respect to the other sites consists of the short vegetation cover, as in Kyeamba there are grasslands and in Yanco there are grasslands and croplands (i.e. cereals). Therefore, the soil moisture retrieval is less affected by the vegetation in these sites. The correlation of AMSR-E and ERS seasonality and fAPAR is high over these sites, as well as the correlation of in situ seasonality and fAPAR. But, the correlation of the satellite products with fAPAR does not exceed the correlation with in situ soil moisture. 

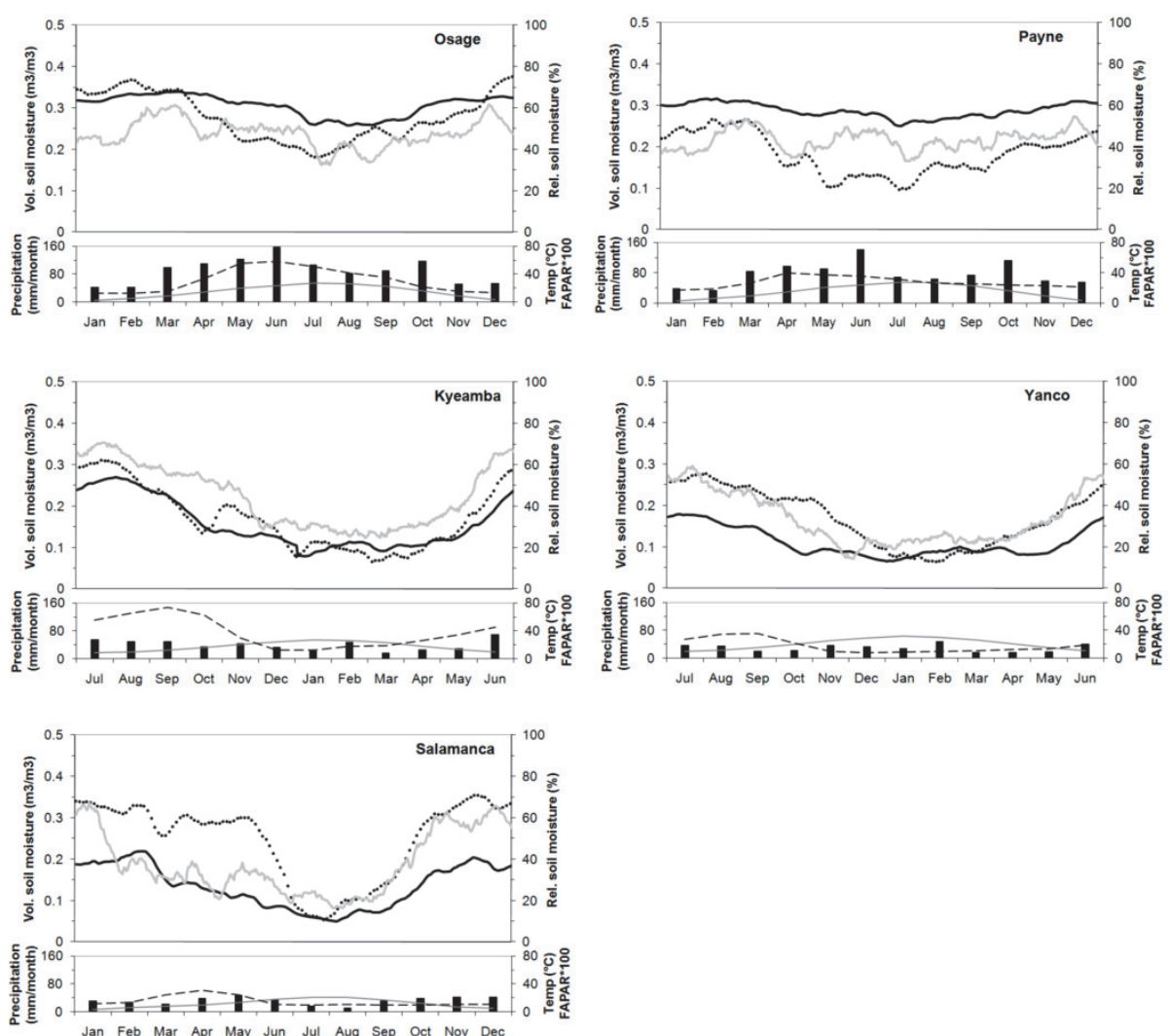

Jul Aug Sep Oct Nov Dec Jan Feb Mar Apr May Jun

Figure 5.1 Seasonality of in situ, AMSR-E, ERS soil moisture data compared with monthly precipitation, monthly air temperature average and fAPAR, over Oklahoma Osage, Oklahoma Payne, Australia Kyeamba, Australia Yanco and Spain Salamanca. The ranges of the left and right $y$-axis were arbitrary chosen.

Table 5.3 Correlation between AMSR-E and ERS soil moisture seasonality and in situ seasonality and between the soil moisture seasonalities and fAPAR time series.

\begin{tabular}{|l|c|c|c|c|c|}
\hline \multirow{2}{*}{ Osage } & In situ & \multicolumn{2}{|c|}{ AMSR-E } & \multicolumn{2}{c|}{ ERS } \\
\cline { 2 - 6 } & fAPAR & In situ & fAPAR & In situ & fAPAR \\
\hline Payne & -0.58 & 0.77 & -0.89 & 0.74 & -0.32 \\
\hline Kyeamba & -0.56 & 0.86 & -0.73 & 0.43 & -0.16 \\
\hline Yanco & 0.81 & 0.94 & 0.72 & 0.93 & 0.85 \\
\hline Salamanca & 0.75 & 0.83 & 0.82 & 0.93 & 0.76 \\
\hline
\end{tabular}


The sensitivity to the canopy development of active and passive microwave might be the cause of a different behaviour between the two satellite products in spring with respect to the in situ seasonality over Salamanca, where there is a higher percentage of croplands. The soil moisture in Salamanca decreases slowly from February to June, but the ERS soil moisture decrease occurs too early and AMSRE decrease occurs later than expected. The reason of a different behaviour can be that in spring the canopy, especially in agricultural fields such as cereals and corn, has a fast development and the green vegetation shades the soil surface which is drying out. This means that the soil contribution to the scattered signal is low and masked by the vegetation, therefore the main contribution to the signal received by the satellite is given by the vegetation. There is, in this case, a disagreement with the retrieval model assumptions of constant vegetation scattering albedo for AMSR-E retrieval and not pronounced vegetation effect for ERS retrieval, which might lead to a strong effect on the soil moisture retrieval. In the Australian sites, the effect is reduced because the vegetation is short (mainly grasslands) and because according to the fAPAR, the vegetation development occurs in winter (Jul-Sep), when the soil moisture and the soil contribution to the scattered signal is still high. However, further analyses of the seasonalities of AMSR-E and ERS soil moisture products over several vegetated areas is needed to draw general conclusions, but so far this is not possible due to the lack of accurate and long term ground reference (i.e. long term and extensive soil moisture monitoring).

\subsubsection{Correlation between time series and anomalies}

All datasets were resized to only the overlapping period among AMSR-E, ERS and in situ data available over each site. This resulted in shorter time series than the original: about 20 months in Oklahoma (from 15 August 2003 to 31 March 2005), about 13 months in Australia (from 18 January 2006 to 27 February 2007) and about 26 months in Salamanca (from 16 March 2005 to 17 March 2007). 
The time series resized and interpolated (as described in Section 5.3) are shown in Figure 5.2 and the correlations between these series, as well as between the anomalies are reported in Table 5.4.
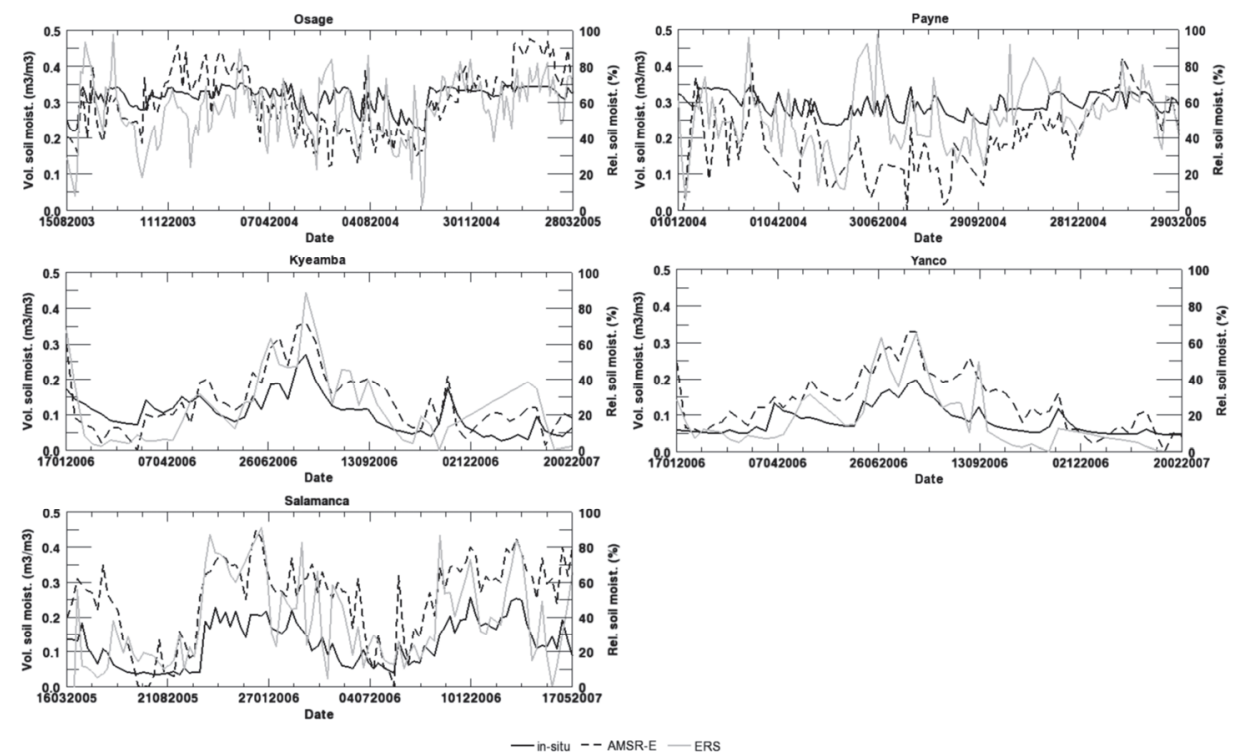

Figure 5.2 AMSR-E, ERS and in situ soil moisture resized to the overlapping period and interpolated to: 3 days in Oklahoma sites, 7 days in Australia sites and 8 days in Salamanca.

Table 5.4 Correlation between AMSR-E and in situ soil moisture time series and anomalies and between ERS and in situ soil moisture time series and anomalies over all test sites.

\begin{tabular}{|l|c|c|c|c|}
\hline & \multicolumn{2}{|c|}{ AMSR-E/in situ } & \multicolumn{2}{c|}{ ERS/in situ } \\
\cline { 2 - 5 } & Time series & Anomalies & Time series & Anomalies \\
\hline Osage & 0.66 & 0.42 & 0.66 & 0.63 \\
\hline Payne & 0.45 & 0.07 & 0.43 & 0.40 \\
\hline Kyeamba & 0.76 & 0.64 & 0.60 & 0.46 \\
\hline Yanco & 0.84 & 0.50 & 0.85 & 0.63 \\
\hline Salamanca & 0.82 & 0.63 & 0.55 & 0.26 \\
\hline
\end{tabular}

The highest correlation between the time series is experienced over the Australian sites. The correlations are lower over the sites where disagreements are observed between the seasonalities or a part of them, i.e. over Oklahoma and Salamanca. 
The anomaly correlation between AMSR-E/in situ and ERS/in situ is lower than 0.6. The reason is that after removing the seasonality of the satellite products, the remaining component is very noisy, more than the in situ anomalies. This noise of the satellite product anomalies prevents also the correlation between the time series to exceed the value of 0.8 . The two main factors which can cause a noise in the satellite products of the two Oklahoma sites are the RFI (for the case of AMSR-E products) and the small variability range of soil moisture (for the case of ERS products) as explained in Section 5.4.1. The vegetation effect on the retrieval accuracy, in particular when the soil is dry, is probably causing the noise of both satellite products over Salamanca (Section 5.4.1). All these factors are not present in the Australian sites. This is the main difference which can probably cause less noisy patterns of the satellite products over Yanco and Kyeamba, with consequently a higher correlation.

\subsubsection{Autocorrelation of the anomalies}

In order to plot the correlograms of the datasets and to estimate the autocorrelation length, firstly the seasonality was removed from the time series and then the computation was carried out only over the anomalies. As mentioned, a sinusoidal trend in the time series results in an oscillation of the same frequency of the correlograms, with the possibility to obtain only little information from it. As example, the correlograms of time series $(S+I)$ and anomalies $(I)$ over Osage are shown in Figure 5.3.

The correlograms of the time series before removing the seasonal component confirms what is already shown in Figure 5.1 for Osage. The correlogram of AMSR-E products, as well as the one of in situ data, shows an oscillation with a period of about 360 days, due to a clear seasonality. The seasonality removal results also in the removal of the correlogram oscillation. ERS products are not characterized by a clear seasonality over Osage, therefore the correlogram of the time series does not show any clear oscillation.

After removing the seasonality from the time series, the effects of all long term processes affecting the soil moisture are minimized, but additional information about the soil moisture correlation in time, due mainly to the weather effects, can be obtained. In particular, 
information about the drying out of the soil after a rain event can be evaluated, as the soil moisture remains temporally correlated until another rain event occurs.

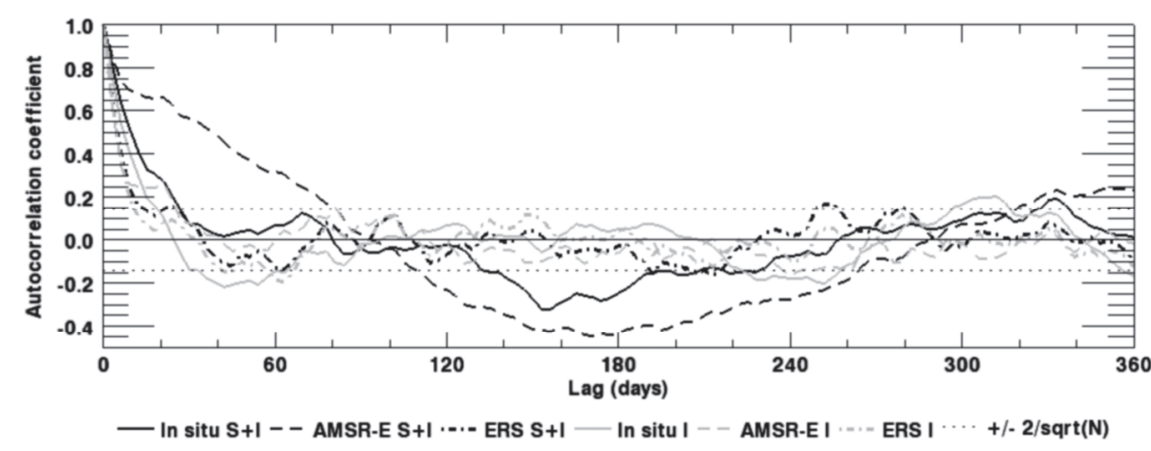

Figure 5.3 Correlograms of AMSR-E, ERS and in situ time series over Osage before $(S+I)$ and after removing the seasonal component (I).

The correlograms of the anomalies for all sites are shown in Figure 5.4 .

The correlogram is an indicator of the randomness of the time series. The series are not random if there is one (or more) lag with an autocorrelation value significantly different from zero, i.e. higher than $2 / \sqrt{N}$, where $\mathrm{N}$ is the total number of data of the time series. The autocorrelation length (number of days when the autocorrelation is crossing the $2 / \sqrt{N}$ threshold) found for each site is reported in Table 5.5, where it is compared with the average length of a dry spell, i.e. number of consecutive days without appreciable precipitation (higher than $0.1 \mathrm{~mm}$ ), in the analysed period.

The correlograms show that in all the sites the soil moisture anomalies, not only of in situ data but also of satellite products, are not random. Though in Section 5.4.2 it was shown that the anomalies of satellite time series are strongly affected by noise, with a low correlation with in situ data, the correlograms show that the anomaly statistics, in terms of autocorrelation, is still meaningful and comparable to the in situ data. 
The exponential curves of the autocorrelation functions are very similar for the first few lags in the Oklahoma sites and in Salamanca, whereas, the correlogram behaviour of the satellite products differs from that of in situ anomalies in the Australian sites. The best agreement between AMSR-E and ERS correlograms with the in situ one is observed over those sites, where the correlation between the time series (and between seasonalities and anomalies) is lower, i.e. Oklahoma and Salamanca. However the poor agreement between the correlograms for the Australian sites might be due to the relatively short time series used for the analysis (i.e. low $N$ ). The correlogram behaviour strongly depends on the length of time series (i.e. on $N$ ). As the resized time series used in this part of the analysis are short, the autocorrelation function can be unstable. This means that if shorter or longer time series are used, the resulting correlograms can be different, in particular when years drier or wetter than the seasonality are included or excluded from the analysis. Over the Osage site, for example, the correlation length of AMSR-E soil moisture drops from 24 to 6 days when data from 2005 are excluded, whereas the ERS and in situ correlograms do not show any change. The main reason is that in 2005 the soil moisture is wetter than the seasonality for a long period and this is much more evident in AMSRE data than in ERS and in situ data.

There is not a common behaviour of the correlograms which can lead to conclusions about its dependency on satellite products sensitivity to surface characteristics.

The different correlation lengths of in situ anomalies found in Australia, Oklahoma and Salamanca, mainly depend on the different rainfall patterns. The autocorrelation length of in situ soil moisture is longer for the Australian sites where there are longer dry spells, on average 6 to 7 days, than for the other sites. However, it was not found a clear relationship between the dry spell length and the correlation length of the anomalies of satellite data. 

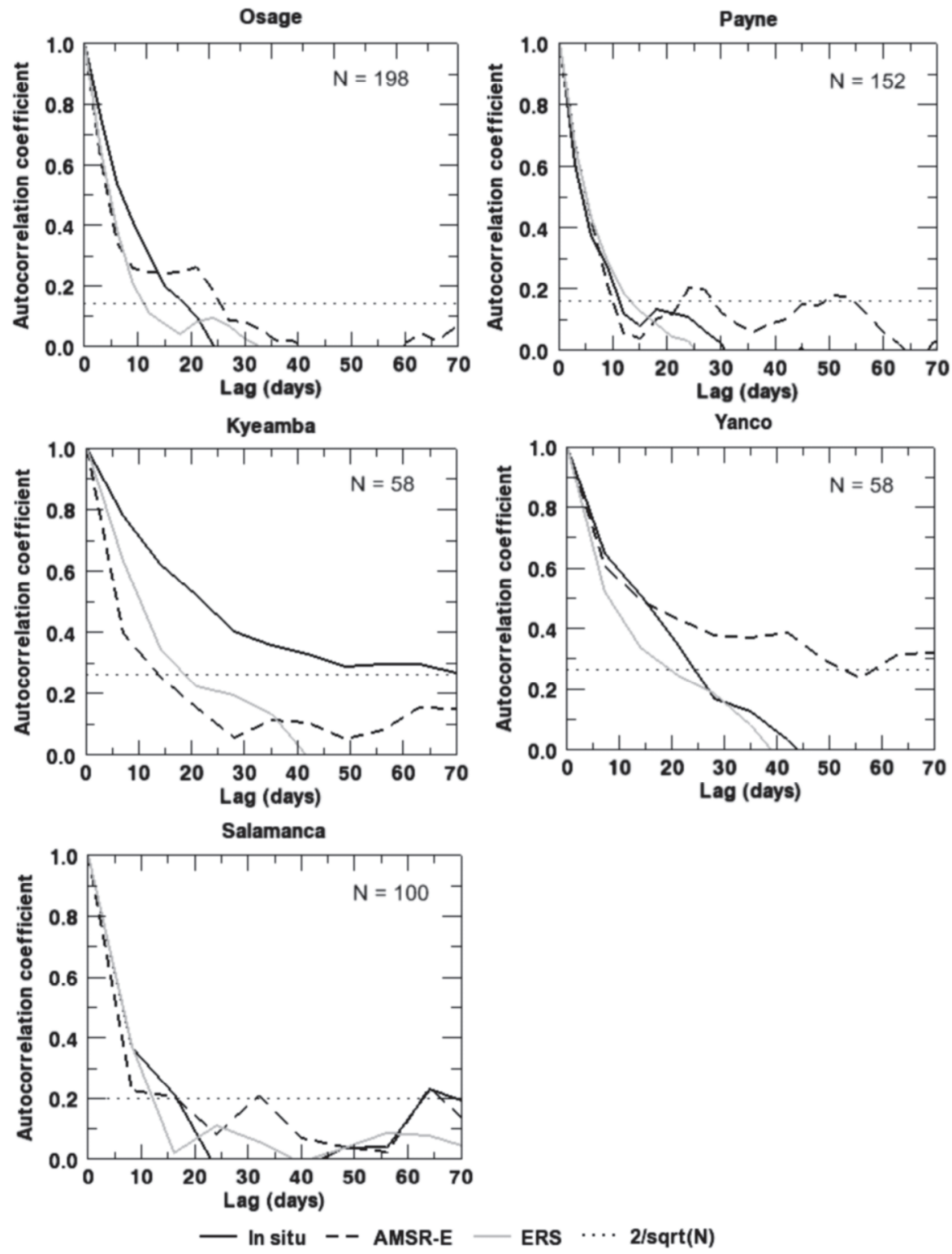

Figure 5.4 Correlograms of soil moisture anomalies of in situ, AMSR-E and ERS data for all the test sites. 
Table 5.5 Autocorrelation length of in situ, AMSR-E and ERS soil moisture anomalies and average length of the dry spell (in days) for all test sites.

\begin{tabular}{|l|c|c|c|c|}
\hline & $\begin{array}{l}\text { In situ } \\
\text { autocorr. }\end{array}$ & $\begin{array}{l}\text { AMSR-E } \\
\text { autocorr. }\end{array}$ & $\begin{array}{l}\text { ERS } \\
\text { autocorr. }\end{array}$ & $\begin{array}{l}\text { Dry spell } \\
\text { length }\end{array}$ \\
\hline Osage & 18 & 24 & 9 & 3 \\
\hline Payne & 9 & 9 & 12 & 4 \\
\hline Kyeamba & 70 & 7 & 14 & 6 \\
\hline Yanco & 21 & 49 & 14 & 8 \\
\hline Salamanca & 16 & 16 & 8 & 9 \\
\hline
\end{tabular}

\subsection{Summary and conclusions}

Temporal behaviour, seasonal components, anomalies, correlation and autocorrelation of AMSR-E soil moisture and ERS soil wetness index were compared with in situ observations, meteorological data and vegetation index (fAPAR). The analysis was carried out over five regions: two areas in North Oklahoma (over some Oklahoma Mesonet sites), two areas in South-East Australia (over Yanco and Kyeamba region of OzNet network) and one in Salamanca region of Spain (over REMEDHUS network area).

It was found that the seasonality of AMSR-E soil moisture has a general good agreement with in situ data over all the sites. The ERS seasonality is noisier than AMSR-E and in situ seasonality, which is mainly due to the large number of gaps in the ERS time series. The best agreement was found for the Australian sites, characterised by a large soil moisture variability range and short vegetation cover. Both AMSR-E and ERS seasonality of Oklahoma sites are noisier than the seasonalities of other sites. In particular, ERS data do not show a clear seasonal oscillation at Oklahoma sites. These sites are characterised by a small soil moisture variability range and by the presence of RFI, which can both be the cause of the noise of the satellite-derived data. AMSR-E data over Oklahoma are also affected by the vegetation development, as shown by the correlation with fAPAR, which is higher than the correlation between in situ soil moisture seasonality and fAPAR. 
A clear disagreement among the seasonalities was found also over Salamanca site in spring, which might be due to the vegetation effects on the retrieval of soil moisture over dry soils.

The anomalies of the satellite products, obtained by removing the seasonality from the soil moisture time series, are noisier than the in situ anomalies, with a correlation lower than 0.6.

However, the correlograms of the anomalies show that in all the sites the satellite-derived anomalies are not completely random, though noisy. The autocorrelation functions of AMSR-E and ERS products are almost overlapping the in situ one at Oklahoma and Salamanca sites for the first few lags, showing that, despite the noise, there are statistical similarities between the satellite soil moisture anomalies and the in situ data anomalies.

The disagreement between the correlogram of soil moisture anomalies over Australian sites is probably due to the short time series used for the analysis, causing instability of the correlograms.

Although longer soil moisture time series collected in situ over several vegetated areas and satellite products covering the same time period than in situ data are needed to have a deeper discussion, the present study reveals that AMSR-E VUA-NASA products and ERS TU Wien products contain useful information about soil moisture seasonality and anomaly behaviour. Unfortunately, this information is hidden by the noise caused by gaps in the datasets (as for the case of ERS), by RFI effects (as for the case of AMSR-E) and by the sensitivity of the retrieval algorithms to the vegetation cover.

It can be concluded that before using the AMSR-E and ERS soil moisture products for climatic studies and analysis of extreme hydrometeorological events, their consistency over long time periods, the eventual systematic errors in specific seasons and the negative effect of noise should be evaluated with care site by site. 


\section{Chapter 6}

\section{Combined use of active and passive microwave satellite data to constrain a discrete scattering model}

This chapter is based on:

Dente L., Ferrazzoli P., Su Z., van der Velde R., Guerriero L. (2014). Combined use of active and passive microwave data to constrain a discrete scattering model. Remote Sensing of Environment, 155, 222-238

\subsection{Introduction}

The investigations carried out in the previous chapter assessed the potential of monitoring soil moisture by means of both active and passive microwave satellite observations. However it was confirmed that the retrieval accuracy is strongly limited by the sensitivity of the satellite signatures to other factors than the soil moisture, such as soil roughness, vegetation morphology and surface temperature, and by the ability to characterize the contribution of each factor to the microwave scattering and emission. Lack of information on these parameters is a well-known problem, especially at large scale. As such, when a single source of remote sensing data is used, not 
enough information is available to constrain the soil moisture retrieval process and assumptions on the unknown parameters are needed. However, most of the uncertainties of the soil moisture products follow from these assumptions.

On the other hand, emissivity and backscattering coefficient respond differently to soil and vegetation parameters, and provide complementary information on the observed land surface. Therefore, the combined use of active and passive microwave information should lead to an improvement of the soil moisture retrieval accuracy, as additional information is used to constrain the retrieval process.

Several methods have been investigated to combine active and passive information. A frequently adopted approach was to obtain information on the surface roughness or vegetation properties from active microwave data, and to use this information within a soil moisture retrieval algorithm from passive microwave data (Chauhan 1997; Lee and Anagnostou 2004; O'Neill et al. 1996; Saatchi et al. 1995a; Theis et al. 1986; Wen et al. 2003; Zhan et al. 2006). Other studies focused on the development of statistical approaches to merge the soil moisture products retrieved from active and passive sensors. For instance, Liu et al. (2011) presented a method for blending operational AMSR-E and ASCAT soil moisture products to increase the spatial availability of satellite-derived soil moisture data. Das et al. (2011) and Piles et al. (2009) investigated methods for downscaling of coarse resolution radiometer soil moisture products with the aid of fine resolution radar retrievals to obtain high resolution products. The latter approach will be adopted for the 9$\mathrm{km}$ combined active/passive soil moisture product of NASA's SMAP satellite (Entekhabi et al. 2010) that is scheduled for launch in 2014 and will collect simultaneous L-band radiometer and radar measurements with spatial resolutions of $40 \mathrm{~km}$ and $3 \mathrm{~km}$, respectively.

Only few studies combined the complementary information provided by active and passive microwave observations through the application of discrete scattering models that are capable of simulating both emissivity and backscattering, given a detailed description of soil and vegetation (Chauhan and Levine 1994; Ferrazzoli et al. 1989; Saatchi et al. 1994). More recently, Colliander 
and $\mathrm{Xu}$ (2013) and Guerriero et al. (2012) used this approach to investigate the theoretical basis of indices that combine emissivity and backscattering for satellite applications. The main reason why the discrete scattering models were rarely applied at satellite scale is the difficulty to obtain a detailed parameterization needed as input. This problem can, however, be overcome by using both active and passive microwave observations to constrain the scattering model.

In this context, the main objective of this section was to investigate the advantage of using a unique scattering model driven by a unique set of input parameters to estimate both emissivity and backscattering coefficient. The discrete scattering model developed by the Tor Vergata University (Bracaglia et al. 1995; Ferrazzoli and Guerriero 1996) was used for this purpose. Both active and passive versions of the model have been validated over different land covers in several studies (Della Vecchia et al. 2006; Della Vecchia et al. 2008; Della Vecchia et al. 2007; Ferrazzoli et al. 2000). In the present study, the model simulations were compared against the observations collected by AMSR-E and by ASCAT (both C-band sensors) over the Maqu region in the north-eastern part of the Tibetan Plateau. Signatures collected in 2009 were used for a preliminary calibration of some model input variables, while signatures collected in 2010 were used for validation.

The operational soil moisture products obtained from ASCAT and AMSR-E data performed poorly over the Maqu region, as shown in Chapter 3. This section aimed, therefore, at contributing to a better understanding of ASCAT and AMSR-E data over this area, through the advantages offered by a joint interpretation of both active and passive microwave data. As such, the approach applied in this study demonstrates the use of detailed discrete scattering models at satellite-scale and provides an insight into the potential of SMAP-like data. Unfortunately, the L-band SMOS data could not be used in this section because of the significant presence of RFI in the SMOS observations over Maqu region, as shown in Chapter 4.

Section 6.2 describes the available estimates of the ground truth used as model inputs, the satellite data and the Tor Vergata model. Section 6.3 introduces the approach used in this study consisting of three steps: model sensitivity analysis, model calibration and model validation. Section 6.4 reports the results obtained in each step and 
Section 6.5 discusses the main findings related to the combined use of active and passive microwave data. Section 6.6 summarizes the most important results of the study and draws the general conclusions.

\subsection{In situ data, satellite data and model description}

\subsubsection{In situ data}

The analysis in this chapter was carried out on a specific area of the Maqu region $\left(33^{\circ} 45^{\prime}-34^{\circ} \mathrm{N}, 102^{\circ}-102^{\circ} 15^{\prime} \mathrm{E}\right)$ that is located approximately in the centre of the network and covers one grid cell (approximately $25 \mathrm{~km} \times 25 \mathrm{~km}$ large) of AMSR-E and ASCAT data. Figure 6.1 shows a Landsat 5TM image collected in July 2009 and resized over the area of interest. A total of 8 sites were monitored in (and near) the area covered by the AMSR-E and ASCAT grid cell and their locations are shown in Figure 6.1. As it is highlighted by the uniform colour of the Landsat 5TM, the area is uniformly characterized by short grass, with exception of small bare areas. The soil surface is covered by a thin layer of litter (less than $1 \mathrm{~cm}$ thick) that consists of dry grass leaves from the previous year.

Several input variables and parameters are needed to run the Tor Vergata model (explained in Section 6.2.4). Some of these inputs were available, such as incidence angle and frequency, or were estimated from in situ measurements and satellite data, such as volumetric soil moisture and LAI. Other parameters were calibrated following the method described in Section 6.3.2. The estimates of soil moisture and LAI, which are two important input variables of Tor Vergata model, are described in detail in this section.

The volumetric soil moisture controls directly the permittivity of the soil, and indirectly that of the litter, as the litter moisture is assumed to be linearly related to the soil moisture. It is well-known from literature that the depth of the soil layer determining the soil emissivity and scattering is equal to few tenths of a wavelength and inversely related to the average moisture content of the layer 
(Schmugge and Jackson 1994). For this study, the $5 \mathrm{~cm}$ depth volumetric soil moisture measured at the Maqu sites was assumed to be a good estimate of the moisture of the soil emitting and scattering layer at C-band. The limitations of this assumption are discussed in Section 6.4.

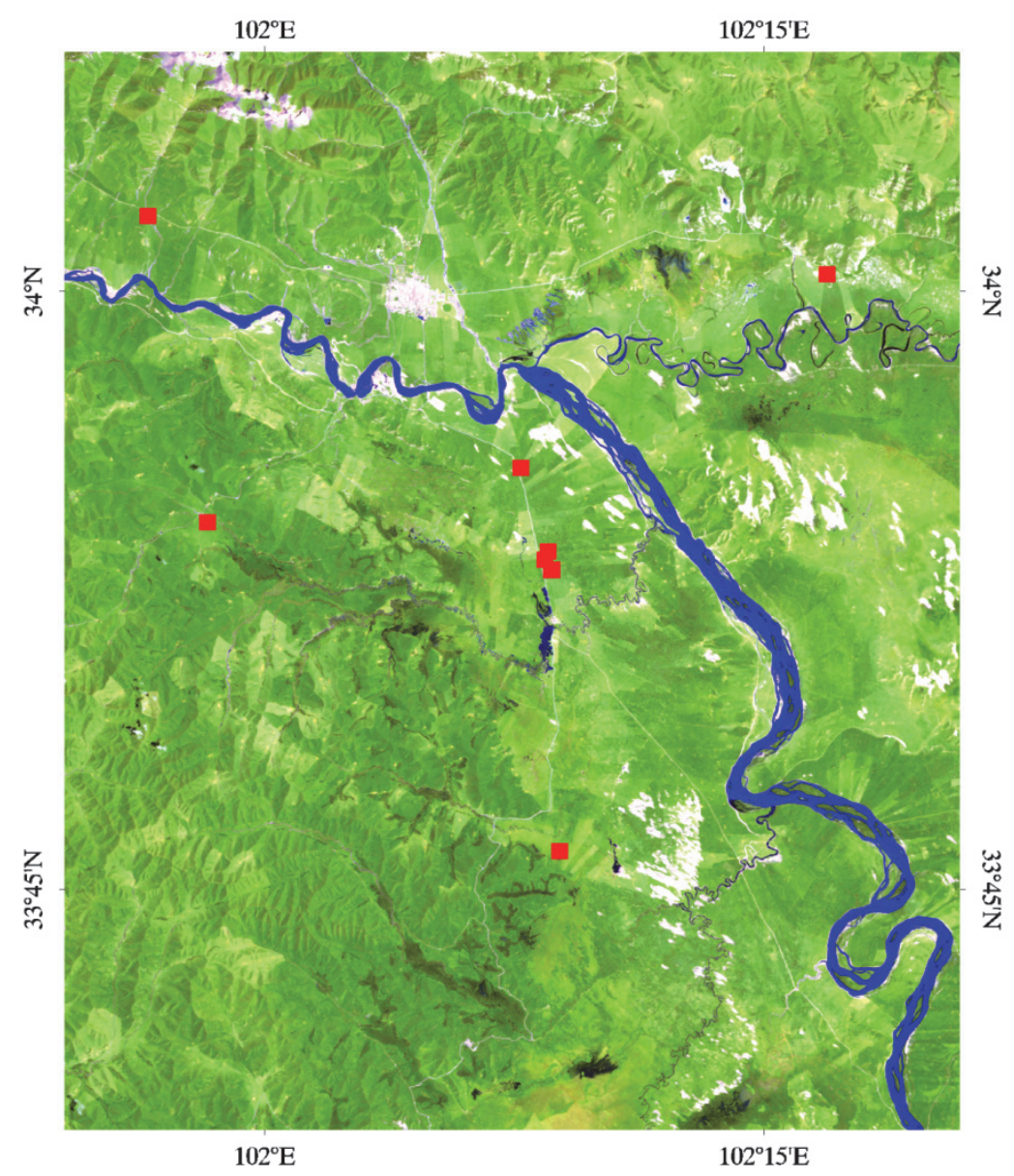

Figure 6.1 LANDSAT 5TM image collected in July 2009 (R: band 7, G: band 5, B: band $3)$. The red squares highlight the locations of the monitored sites.

The spatial average of the measurements collected in the 8 stations shown in Figure 6.1 was computed. Moreover, in order to use a unique soil moisture time series as input to the model for both the 
active and the passive case, data were selected for the dates when both AMSR-E and ASCAT observations were available and temporal averages were made between 9:40 p.m. (minimum ASCAT ascending overpass local time) and 3:45 a.m. (maximum AMSR-E descending overpass local time). The dates when precipitations occurred during the night were excluded from the analysis. The obtained soil moisture time series from April to October of 2009 and 2010 are shown in Figure 6.2. The measurements are consistent with the precipitation patterns measured by a meteorological station located in Maqu city $\left(34^{\circ} \mathrm{N} 102^{\circ} 05^{\prime} \mathrm{E}\right)$. The precipitation data, shown in Figure 6.2 and provided by the National Meteorological Information Centre of the China Meteorological Administration (NMIC/CMA), consist of the daily sums measured starting from 8 p.m. of the previous day.

Time series of LAI were obtained from MODIS/Terra+Aqua Leaf Area Index 8-day data (provided by NASA Land Processes Distributed Active Archive Centre, USGS/Earth Resources Observation and Science Centre, https://lpdaac.usgs.gov). The $1 \mathrm{~km}$ resolution data were averaged over the Maqu area. In order to suppress the effect of cloud cover on LAI and to estimate the values in the AMSR-E and ASCAT acquisition dates, a least squares quadratic interpolation and a moving average over 15 days were applied on the original data. Both the MODIS LAI 8-day data and the processed time series used as input for the model are shown in Figure 6.3.

It is worth to remind that temperatures typically drop below freezing point during winter in the Maqu region. Therefore, the soil is subject to freeze/thaw cycles during the entire season. Both active and passive microwave signals show a clear dependence on the water state in the soil (i.e. liquid versus frozen), due to the contrasting dielectric properties of the soil (Rignot and Way 1994; Schwank et al. 2004; Ulaby et al. 1982). Therefore, particular attention should be applied in the modelling of permittivity and microwave signal of frozen soils (Mironov et al. 2010). For the sake of simplicity of the present study, the Tor Vergata model was only applied to the monsoon season (i.e. unfrozen conditions). 

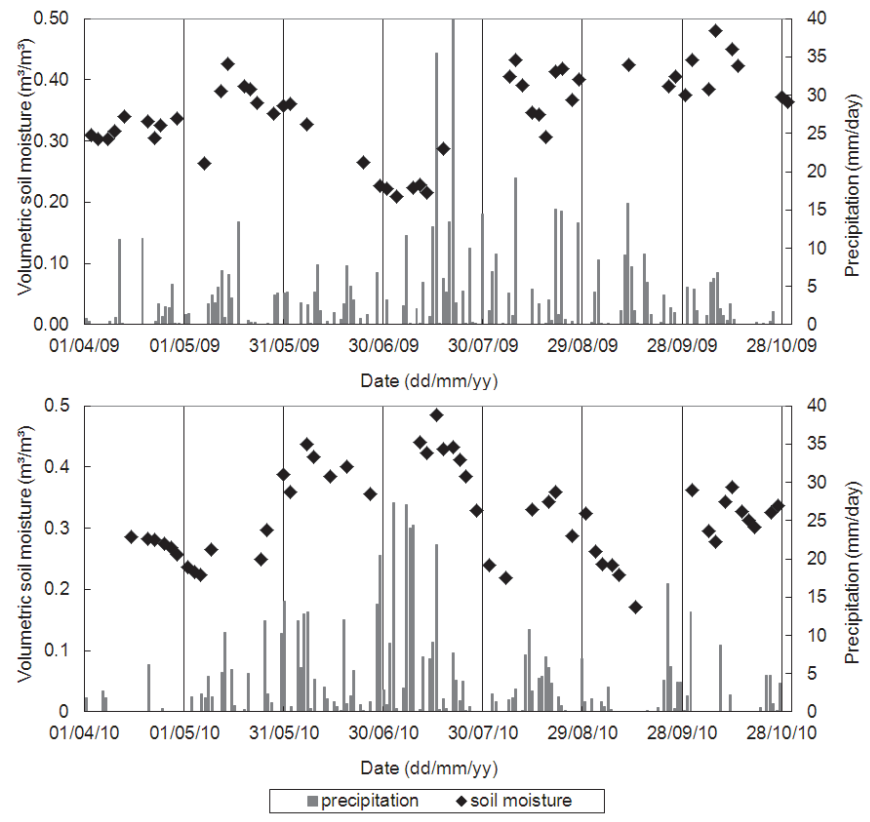

Figure 6.2 Spatial average of the volumetric soil moisture measured at $5 \mathrm{~cm}$ depth at the Maqu site at the time of AMSR-E and ASCAT acquisitions and daily precipitation measured at Maqu city.
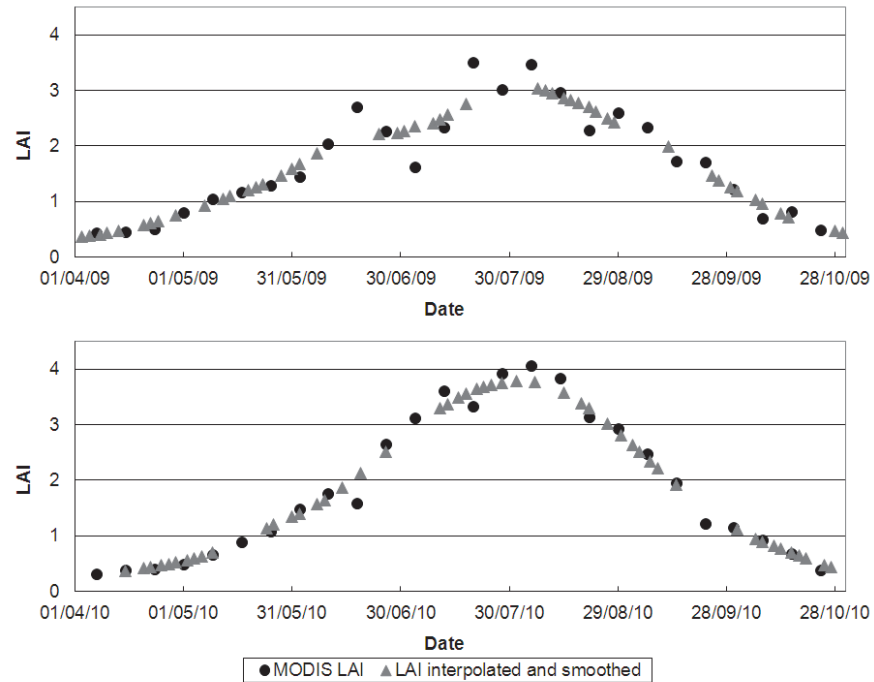

Figure 6.3 MODIS/Terra+Aqua Leaf Area Index 8-day data averaged over the Maqu site and values of interpolated and smoothed LAI on the AMSR-E and ASCAT acquisition dates. 


\subsubsection{AMSR-E brightness temperature data}

For the passive microwave case, the output of the Tor Vergata model was compared with the brightness temperature measured by AMSRE radiometer. From 2002 to 2011 AMSR-E measured horizontally and vertically polarized brightness temperature $\left(\mathrm{T}_{\mathrm{bV}}\right.$ and $\mathrm{T}_{\mathrm{bH}}$, respectively) at $55^{\circ}$ incidence angle and at 6 bands, including C-band $(6.9 \mathrm{GHz})$ and Ka-band $(36.5 \mathrm{GHz})$ with spatial resolutions of $56 \mathrm{~km}$ and $12 \mathrm{~km}$ respectively. The AMSR-E/Aqua Daily Global QuarterDegree Gridded Brightness Temperature data were used in this study, available in a global cylindrical, equidistant latitude-longitude projection at $0.25^{\circ}$ resolution (Knowles et al. 2012). Time series of AMSR-E brightness temperature were extracted for the monsoon season (i.e. April-October) of 2009 and 2010 over the selected Maqu area. Only the AMSR-E descending overpasses were considered, which occurred over Maqu region during the night, between 2:45 and 3:45 a.m. (local time).

At night, assuming that the temperature of the soil effective emitting layer is equal to the soil skin temperature is more reasonable than during the day for two reasons. Firstly, Van de Griend (2001) found that the error of assuming the effective temperature equal to the surface temperature is lower in the night time than in the day time, due to the smaller vertical temperature gradient near the soil surface. Secondly, vegetation cover and soil surface reach a thermodynamic equilibrium during the night and their temperatures converge to the same value. Accurate estimates of the effective temperature were needed in this section to convert the modelled emissivity in brightness temperature.

In addition, at night the surface soil moisture is less variable than during the day, at least when no precipitations occur. In this event, which is frequent in the Maqu region, the soil moisture at the AMSRE descending acquisition time is very similar to the soil moisture at the ASCAT ascending acquisition time (between 9:40 and 11:00 p.m., local time, of the previous day). A single soil moisture value can thus be used for runs with both the active and passive version of the Tor Vergata model. 


\subsubsection{ASCAT backscattering coefficient data}

For the active microwave case, the output of the model was compared with the backscattering coefficient measured by ASCAT scatterometer. Since 2006, ASCAT provides backscattering coefficient measurements at C-band $(5.255 \mathrm{GHz})$ and VV polarization by using two sets of three antennas, one on left side and one on right side of the satellite. Each antenna has a different azimuth angle with respect to the satellite track (i.e. $45^{\circ}, 90^{\circ}$ and $135^{\circ}$ ), called fore-, midand aft-beams. Consequently, each point of interest is observed from three directions and at incidence angles ranging across the swath from $34^{\circ}$ to $65^{\circ}$ in the fore- and aft-beams and from $25^{\circ}$ to $55^{\circ}$ in the mid-beam (Figa-Saldana et al. 2002). The corresponding backscattering coefficients will be named $\sigma_{\text {fore }}$ and $\sigma^{0}$ mid, respectively. The data analysed in this study have a resolution of $50 \mathrm{~km}$ and are projected on a grid along and across the swath with a node distance of $25 \mathrm{~km}$ (provided by EUMETSAT Archive Direct Service). Therefore, the grid spacing of ASCAT data is close to that of AMSR-E data. Time series of ASCAT backscattering coefficients of the node closest to the centre of the selected AMSR-E grid cell were extracted for the monsoon seasons (i.e. April-October) of 2009 and 2010. Only the ASCAT ascending overpasses were considered, which occurred over Maqu region during the night, between 9:40 p.m. and 11:00 p.m. (local time). The reason of this choice was explained in Section 6.2.2.

\subsubsection{The Tor Vergata model}

Tor Vergata model is a discrete medium scattering model based on a radiative transfer approach (Bracaglia et al. 1995; Ferrazzoli and Guerriero 1996). The scattering is expressed as the sum of three components: the vegetation component, the soil component attenuated by the vegetation and the component resulting from the interaction of vegetation and surface. The electromagnetic behaviour of the soil surface is the result of the superimposition of a diffuse incoherent contribution modelled by means of the Integral Equation Model (IEM) (Fung 1994) and a specular coherent contribution obtained by using the Fresnel formulas corrected by the roughness factor. The model takes into account scattering and absorption properties of individual vegetation elements, which are represented 
by simple geometrical shapes, i.e. discs for leaves and cylinders for stems. Dimensions and orientation of the elements can be selected according to vegetation morphology. For the case of this study, the grass in Maqu was described by thin dielectric discs with random distribution of orientation. The scattering coefficient of the dielectric discs is obtained by applying the Physical Optics approximation (Le Vine et al. 1983). In order to compute the grass scattering and absorption, leaf (disc) parameters are necessary, such as disc thickness, disc radius and leaf coverage (parameterized by LAI). The vegetation permittivity is computed using the method developed by Mätzler (1994), which needs as input the gravimetric moisture of the discs (i.e. plant moisture content defined as the difference between fresh and dry biomass normalized by the fresh biomass). Once the absorption and bistatic scattering of the vegetation elements are computed for a discrete set of incidence and scattering directions, the matrix doubling algorithm (Eom and Fung 1984) is used to take into consideration the multiple scattering interactions among the elements and to obtain the total vegetation contribution. An angular step of $5^{\circ}$ was used for the incidence angles and the $0^{\circ}-360^{\circ}$ azimuth interval was subdivided into 128 intervals. Further details about angular subdivision are given by Bracaglia et al. (1995) and Ferrazzoli and Guerriero (1996).

The presence of litter can be included in the soil scattering contribution by means of an additional module of Tor Vergata model. The module was initially developed for forest litter (Della Vecchia et al. 2007), but it was adapted to the case of grassland litter in this study. This module represents the litter as a mixture of air and dielectric material overlaying the soil. The litter thickness linearly depends on the input litter biomass, and the litter gravimetric moisture content is linearly related to the soil moisture, as proposed by Grant et al. (2007). The slope of the empirical relationship between thickness and biomass found for the forest case by Della Vecchia et al. (2007) was adapted in order to have more realistic values of thickness for the grassland case. Soil and litter are modelled as a unique homogeneous half-space with an equivalent permittivity, which is computed to produce the same reflectivity as the one due to soil-litter multiple reflections. Then, the roughness at the interface between air and medium is included and is described by the height standard deviation $(s)$, the correlation length $(I)$ and the 
autocorrelation function (ACF). The bistatic scattering of the soillitter medium is computed by means of the IEM.

A list of the input parameters required by the model is reported in Table 6.1.

As last step the matrix doubling algorithm is used to combine the vegetation contribution with that of the soil-litter medium.

Subsequently, the emissivity, $e$, is obtained applying the energy conservation law (see e.g. Ulaby et al. (1982)) and integrating the bistatic scattering over the half space above the surface, while the backscattering coefficient, $\sigma^{0}$, is obtained by considering the bistatic scattering coefficient in the opposite direction of incidence only. This capability of the model was important for this study, as it allowed the use of a unique scattering model, in combination with a unique set of input parameters, to estimate both $e$ and $\sigma^{\circ}$.

Table 6.1 Input parameters of the Tor Vergata model for both active and passive case.

\begin{tabular}{|c|c|}
\hline Satellite configuration & \\
\hline Incidence angle & $\begin{array}{l}\text { ASCAT fore/mid beam incidence angle (active); } \\
55^{\circ} \text { (passive) }\end{array}$ \\
\hline Frequency & $5.3 \mathrm{GHz}$ (active); $6.925 \mathrm{GHz}$ (passive) \\
\hline Surface & \\
\hline Volumetric soil moisture & $\begin{array}{l}\text { In situ measurements, spatial average of } 8 \text { sites } \\
\text { and temporal average between ASCAT and } \\
\text { AMSR-E overpass time }\end{array}$ \\
\hline Soil texture & In situ measurements \\
\hline $\begin{array}{lll}\begin{array}{l}\text { Roughness: } \\
\text { deviation }\end{array} & \text { height } & \text { standard } \\
\end{array}$ & $0.9 \mathrm{~cm}$, optimized parameter, constant in time \\
\hline Roughness: correlation length & $9.0 \mathrm{~cm}$, optimized parameter, constant in time \\
\hline $\begin{array}{l}\text { Roughness: autocorrelation } \\
\text { function }\end{array}$ & Exponential \\
\hline Litter moisture content & $\begin{array}{l}2 \text { x soil moisture, optimized parameter, } \\
\text { linearly related to soil moisture }\end{array}$ \\
\hline Litter biomass & $0.07 \mathrm{~g} / \mathrm{cm}^{2}$, optimized parameter, constant in time \\
\hline Litter thickness & $0.6 \mathrm{~cm}$, constant in time \\
\hline Vegetation & \\
\hline LAI & $\begin{array}{l}\text { MODIS/Terra+Aqua LAI 8-day interpolated } \\
\text { and smoothed }\end{array}$ \\
\hline Leaves: disc radius & $1.4 \mathrm{~cm}$, optimized parameter, constant in time \\
\hline Leaves: disc thickness & $0.02 \mathrm{~cm}$, constant in time \\
\hline Leaves: disc angular distribution & random \\
\hline Plant moisture content & 0.8 , optimized parameter, constant in time \\
\hline
\end{tabular}




\subsubsection{From emissivity to brightness temperature}

The modelled $e$ needs to be multiplied by the temperature of the effective emitting layer for comparison with $T_{b}$ observed by AMSR-E at C-band. As explained in Section 6.2.2, the effective temperature can be, under certain conditions, approximated by the surface temperature.

Different methods can be used to estimate the surface temperature. In order to evaluate the uncertainty introduced by this variable in this study, four methods were compared to estimate it: i) using the $V$ polarized Ka-band (37 GHz) AMSR-E $T_{b}$ observations, ii) using the in situ measurements of soil temperature at $5 \mathrm{~cm}$ depth, iii) using the in situ measurements of long wave upward radiation, and iv) using the ERA Interim-land dataset. The methods, as well as the results of this analysis, are described in Appendix B.

The surface temperature estimated from the $\mathrm{V}$ polarized Ka-band AMSR-E brightness temperature (hereafter referred to as $T_{K a V}$ ) was selected for this study, as explained in the appendix. TKaV can be estimated by using the linear equation proposed by Holmes et al. (2009). The effect of soil moisture is low at this frequency, polarization and incidence angle over bare fields (Owe and Van de Griend 2001), therefore the brightness temperature is linearly related to the surface skin temperature. For vegetated areas, as it is the case of Maqu region, this relationship remains valid at night time, when the vegetation temperature is approximately equal to the skin temperature. At $37 \mathrm{GHz}$, the atmospheric effects on the brightness temperature were found to be small in semi-arid regions, but as large as several tens of $\mathrm{K}$ in humid environments depending on atmospheric conditions (Owe and Van de Griend 2001). This might be the case for the Maqu region during the monsoon season. However, this method has the advantage of providing estimates of the surface temperature with the same grid spacing and acquisition time of AMSR-E C-band data. 


\subsection{Approach}

\subsubsection{Unavailable input variables and sensitivity analysis}

As in situ measurements of several input parameters of the model were not available, the first step consisted of the analysis of the model sensitivity to unavailable variables, in order to investigate which of them caused the largest variations in the model outputs and to understand the effect of this lack of knowledge on the results. The sensitivity analysis consisted of varying one parameter at a time in the selected range, keeping fixed all the others. The mean difference between the model output obtained with a reference set of input parameters and the model output obtained by varying each input parameter was computed to quantify the sensitivity. The analysed parameters, listed in Table 6.2, were: soil-litter medium height standard deviation, leaf radius, plant moisture content, litter biomass and litter moisture. A realistic range of variability was defined for the most significant input parameters, on the base of the experience gained in the field and from the literature. The ranges are indicated in Table 6.2. The analysis was carried out over 2009 data. Some assumptions had to be made on the temporal variability of some parameters, such as soil roughness and vegetation parameters (as reported in Table 6.1). The soil roughness was assumed to be constant for the entire monsoon season, as Maqu region is characterised by natural grassland. The vegetation temporal variability was defined by LAI, whereas the other vegetation parameters, such as leaf radius, thickness and gravimetric moisture content, were assumed to be constant for the period under study. 
Table 6.2 Mean difference between the model outputs obtained with a reference set of input parameters, indicated by dashes, and the model outputs obtained varying a single input parameter, for $\sigma^{\circ}$ in fore and mid beam configuration and for $\boldsymbol{T}_{b}$ at $\mathrm{H}$ and V polarization.

\begin{tabular}{|c|c|c|c|c|c|c|c|c|}
\hline & \multicolumn{2}{|c|}{$\sigma_{\text {fore }}^{\sigma_{\text {fB) }}}$} & \multicolumn{2}{|c|}{$\sigma_{\text {mid }}^{0}(\mathrm{~dB})$} & \multicolumn{2}{|c|}{$T_{b H}(\mathrm{~K})$} & \multicolumn{2}{|c|}{$T_{b V}(\mathrm{~K})$} \\
\hline LAI & $<1$ & $>1$ & $<1$ & $>1$ & $<1$ & $>1$ & $<1$ & $>1$ \\
\hline \multicolumn{9}{|l|}{$\begin{array}{l}\text { Height stand. } \\
\text { dev. }(\mathrm{cm})\end{array}$} \\
\hline 0.6 & -0.5 & -0.2 & -0.6 & -0.2 & -1.8 & -0.6 & 0.9 & 0.0 \\
\hline 0.7 & - & - & - & - & - & - & - & - \\
\hline 0.8 & 0.5 & 0.2 & 0.5 & 0.2 & 2.1 & 0.2 & $\begin{array}{l}-0.8 \\
\end{array}$ & 0.0 \\
\hline 0.9 & 0.9 & 0.3 & 0.9 & 0.4 & 3.2 & 0.6 & -0.9 & 0.0 \\
\hline \multicolumn{9}{|l|}{$\begin{array}{l}\text { Leaf radius } \\
(\mathrm{cm})\end{array}$} \\
\hline 1.0 & -0.4 & -0.6 & -0.3 & -0.6 & 1.7 & 2.2 & 1.1 & 0.0 \\
\hline 1.2 & - & - & - & - & - & - & - & - \\
\hline 1.4 & 0.2 & 0.4 & 0.2 & 0.4 & -1.1 & -2.2 & -0.5 & -2.2 \\
\hline \multicolumn{9}{|l|}{$\begin{array}{l}\text { Plant moisture } \\
\text { content }\end{array}$} \\
\hline 0.7 & -0.4 & -0.6 & -0.3 & -0.5 & -1.8 & -1.1 & 1.1 & 0.0 \\
\hline 0.8 & - & - & - & - & - & - & - & - \\
\hline 0.9 & 0.4 & 0.5 & 0.3 & 0.4 & 1.5 & 0.2 & -1.1 & -2.3 \\
\hline \multicolumn{9}{|l|}{$\begin{array}{l}\text { Litter biomass } \\
\left(\mathrm{g} / \mathrm{cm}^{2}\right)\end{array}$} \\
\hline 0.05 & 0.6 & 0.2 & 0.7 & 0.3 & -4.1 & -1.3 & -1.4 & -0.7 \\
\hline 0.07 & - & - & - & - & - & - & - & - \\
\hline 0.1 & -0.5 & -0.2 & -0.6 & -0.3 & 2.9 & 0.6 & 0.9 & 0.0 \\
\hline \multicolumn{9}{|l|}{ Litter moisture } \\
\hline$=$ soil moisture & 1.7 & 0.5 & 1.8 & 0.6 & -10.9 & -1.7 & -4.5 & -1.2 \\
\hline$=1.5$ soil moist. & 0.02 & 0.05 & 0.03 & 0.07 & 1.2 & 0.2 & 0.5 & 0.0 \\
\hline$=2$ soil moist. & - & - & - & - & - & - & - & - \\
\hline
\end{tabular}

\subsubsection{Model calibration and validation}

The model calibration was a crucial step of this study. It consisted of varying the model input parameters that were not available from in situ measurements until the best match between model outputs and satellite signatures was obtained. The important requirement in the calibration procedure was that a good match had to be found with both the active and the passive microwave satellite data. This was done by minimizing the following cost function, $J$ : 
$J=\frac{M A E\left(\sigma_{\text {fore }}^{0}\right)}{\Delta \sigma_{\text {fore }, A S C A T}^{0}}+\frac{M A E\left({\sigma^{0}{ }_{\text {mid }}}^{0}\right)}{\Delta \sigma_{\text {mid }, A S C A T}^{0}}+\frac{\operatorname{MAE}\left(T_{b H}\right)}{\Delta T_{b H, A M S R-E}}+\frac{\operatorname{MAE}\left(T_{b V}\right)}{\Delta T_{b V, A M S R-E}}$

where $M A E$ is the mean absolute error of the model estimation with respect to the satellite observations and $\Delta$ is the standard deviation of satellite observations. Both mean absolute error and standard deviation were computed using the model estimations, C-band AMSR-E data and ASCAT data of 2009 monsoon season.

The parameters listed in Table 6.2 were calibrated taking into account the results of the sensitivity analysis. The set of values that minimized the cost function was selected and defined as the optimal set of input parameters.

Moreover, the calibration procedure was repeated by using the data of a single satellite, i.e. AMSR-E data only and ASCAT data only. The corresponding minimum values of the cost function were compared to that found by using both datasets, in order to prove the advantage of combining active and passive microwave data.

Finally, the calibrated model was validated for the 2010 monsoon season over the same area in the Maqu region. The optimal set of input parameters, without any further refinement, was used as input of Tor Vergata model, as well as soil moisture and LAI estimates of 2010. The simulated outputs were compared with ASCAT backscattering coefficient and AMSR-E brightness temperature observed from April to October 2010.

\section{$6.4 \quad$ Results}

\subsubsection{Sensitivity analysis}

The sensitivity of backscattering and emissivity simulated by Tor Vergata model was evaluated for five parameters, as mentioned in Section 6.3.1, by varying each of them within a plausible range as it is indicated in Table 6.2. The model outputs were compared with the 
results obtained using a set of reference input parameters (indicated in Table 6.2 by dashes), by computing the mean difference over the 2009 monsoon season. The comparison was carried out for both active and passive cases. Table 6.2 reports the computed mean differences, where a distinction is made between sparse vegetation (LAI < 1.0) and moderately dense vegetation (LAI > 1.0). Figure 6.4 shows the model outputs of this analysis. The figure only shows the results obtained using the ASCAT fore beam incidence angle, but similar results were found in the ASCAT mid beam configuration.

As expected, the sensitivity to surface parameters, such as roughness height standard deviation, litter biomass and moisture, decreases when LAI increases for both the active and the passive case, because fully developed grass largely attenuates the soil-litter medium contribution to total emission and backscattering at C-band.

The figures also show that both $e$ and $\sigma^{0}$ increase with increasing surface roughness. Especially at high incidence angles, as for the case of ASCAT and AMSR-E, the roughness increase causes an increase in the emitting surface area, as well as $e$, and an increase in the surface diffuse scattering, as well as $\sigma^{0}$.

The effect of litter presence over the soil surface of a grassland was observed in some experimental and theoretical studies, such as Jackson et al. (1999), Saleh et al. (2006b) and Schmugge et al. (1988) for the passive case and Martin et al. (1989) and Saatchi et al. (1995b) for the active case, and it is also further explained in Section 6.5. Especially when it is wet, the litter layer acts as a strong absorber of the microwave signatures, therefore it produces a high emissivity and low backscattering. Moreover, the litter layer attenuates soil emission and scattering, and for this reason it reduces the sensitivity to soil moisture. Overall, the presence of litter increases the total emissivity and decreases the total backscattering coefficient. 


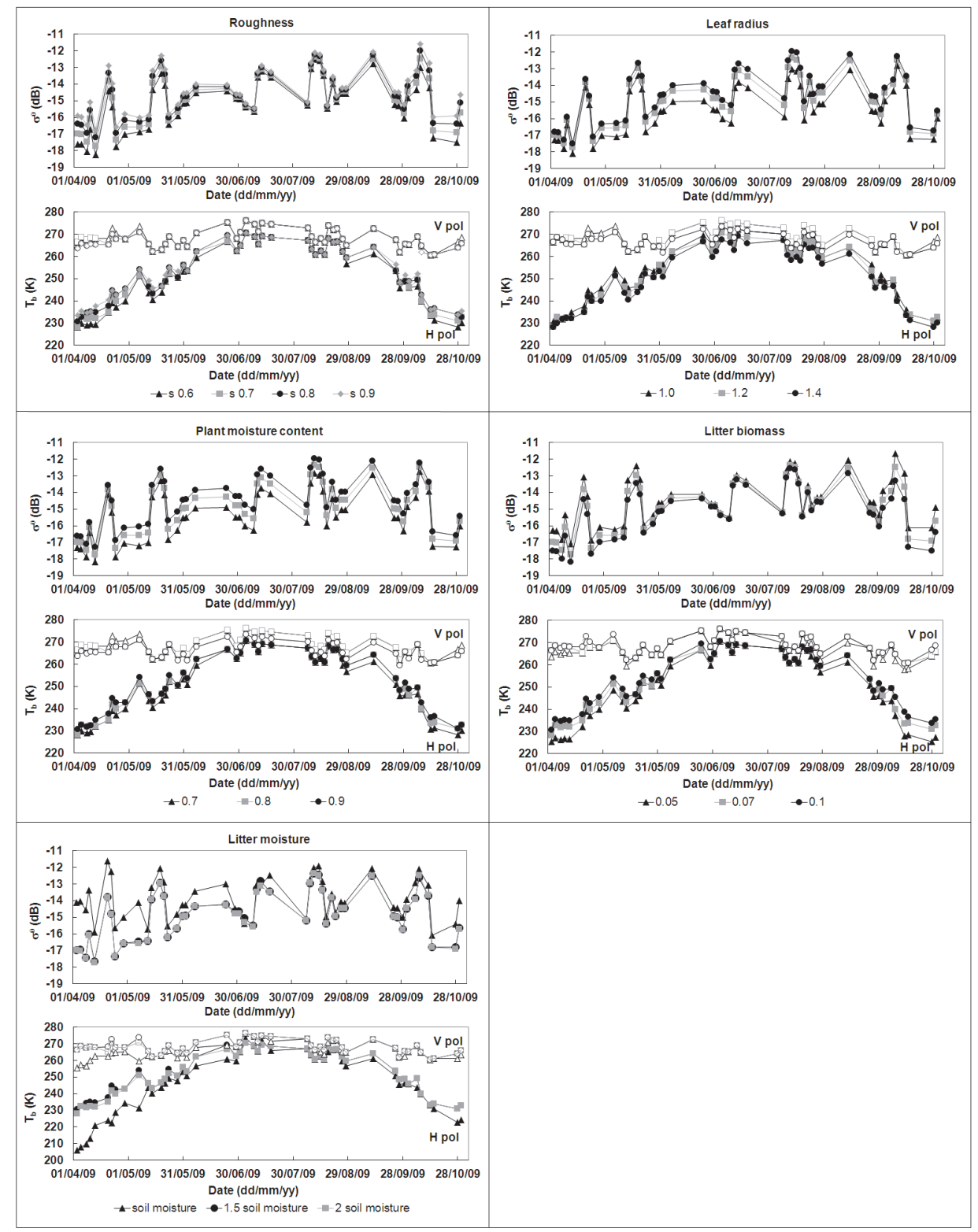

Figure 6.4 Modelled $\sigma^{0}$ and $T_{b}$ obtained varying a single parameter, indicated on top of the figure, and keeping fixed the others. $T_{b H}$ is shown with full symbols and $T_{b V}$ with empty symbols. 
Increasing the litter biomass causes a decrease of the total $\sigma^{0}$ and an increase of the total $e$. This effect is stronger for larger values of biomass than those considered in this study. The increase of litter biomass corresponds to an increase of dielectric material volume fraction within the litter and of litter thickness. This leads on the one hand to an increase of litter emission and backscattering. On the other hand, it leads to an increase of the litter absorption, which corresponds to a larger attenuation of the soil emission and backscattering component. However, when the litter biomass increases, the attenuation of the soil contribution is more important than the increase of the litter contribution for the active case and consequently the total backscattering decreases. For the passive case when the litter biomass increases, the increase in litter component is more important than the attenuation of soil component, and consequently the total emission increases.

The same reason holds to explain the high sensitivity to litter moisture variation. The litter absorption increases with the litter moisture, therefore the total $\sigma^{0}$ decreases and the total $e$ increases. However, there is no significant difference between the model outputs obtained setting the litter moisture equal to 1.5 and to 2 times the soil moisture.

The sensitivity to the radius of the discs representing the grass leaves is enhanced by the LAI increase. For a fixed LAI value and an increasing leaf radius, the vegetation cover does not change (since it is assumed to have a decrease in the number of discs), but the angular pattern of the scattering changes. This leads to an increase of $\sigma^{0}$. The emissivity is less affected by these directional properties of the scattering, but slightly decreases with the increase of the leaf radius, due to an increase in the vegetation reflectivity and soil emission attenuation.

A similar consideration can be done for the plant moisture content for the active case, where both moisture and LAI increase amplify the vegetation scattering. For the passive case, the sensitivity of the model to variations in plant moisture decreases when LAI increases. The main reason is that the decrease of the soil component attenuated by the vegetation compensates the increase of the vegetation contribution, when both plant moisture and LAI increase. 
In general, it can be observed that the sensitivity to LAI variations is much higher than that to the other vegetation parameters. Moreover, modelled $e$ and $\sigma^{o}$ show higher sensitivity to soil moisture and litter moisture (linearly related to soil moisture) than to the other surface parameters. These considerations support the conclusion that soil moisture and LAI (i.e. the measured variables) were the most important model inputs (together with the incidence angle for the active case), which determined the temporal variations of the outputs, whereas the other inputs slightly affected the absolute values of the outputs. For this reason, the lack of detailed measurements of several model inputs could be overcome with a proper calibration of the model parameters.

\subsubsection{Model calibration over 2009 data}

The model calibration determined the optimal set of input parameters that minimized the cost function in Equation (6.1) over the 2009 monsoon season. The list of the optimal input parameters, as well as the other model inputs, is reported in Table 6.1.

Figure 6.5 shows the backscattering coefficient obtained by using the parameters of Table 6.1 as input of Tor Vergata model and the ASCAT data for the fore- and mid-beam. The model was able to simulate with good accuracy $\sigma^{0}$ over Maqu region. From April to October, the model was correctly taking into account the variations of soil moisture and LAI, as well as the incidence angle variations. The coefficient of determination, $R^{2}$, between the two time series of $\sigma^{0}$ data is equal to 0.9 and the root mean square error, $R M S E$, to 0.5 $\mathrm{dB}$ for both the fore beam and the mid beam case, with a mean difference of $0.2 \mathrm{~dB}$ for the fore beam and of $-0.04 \mathrm{~dB}$ for the mid beam for the entire season.

The results obtained in the passive case strongly depended on the surface temperature used to convert $e$ into $T_{b}$, as shown in Appendix $\mathrm{B}$. The best match with $\mathrm{C}$-band satellite observations was found for the entire monsoon season when $T_{K a V}$ was used. In this case $R^{2}$ of 0.8 and RMSE of $6.3 \mathrm{~K}$ were found for the $\mathrm{H}$ polarization and $R^{2}$ of 0.5 and $R M S E$ of $5.9 \mathrm{~K}$ for the $\mathrm{V}$ polarization. The corresponding temporal trends and scatter plots are shown in Figure 6.6. 

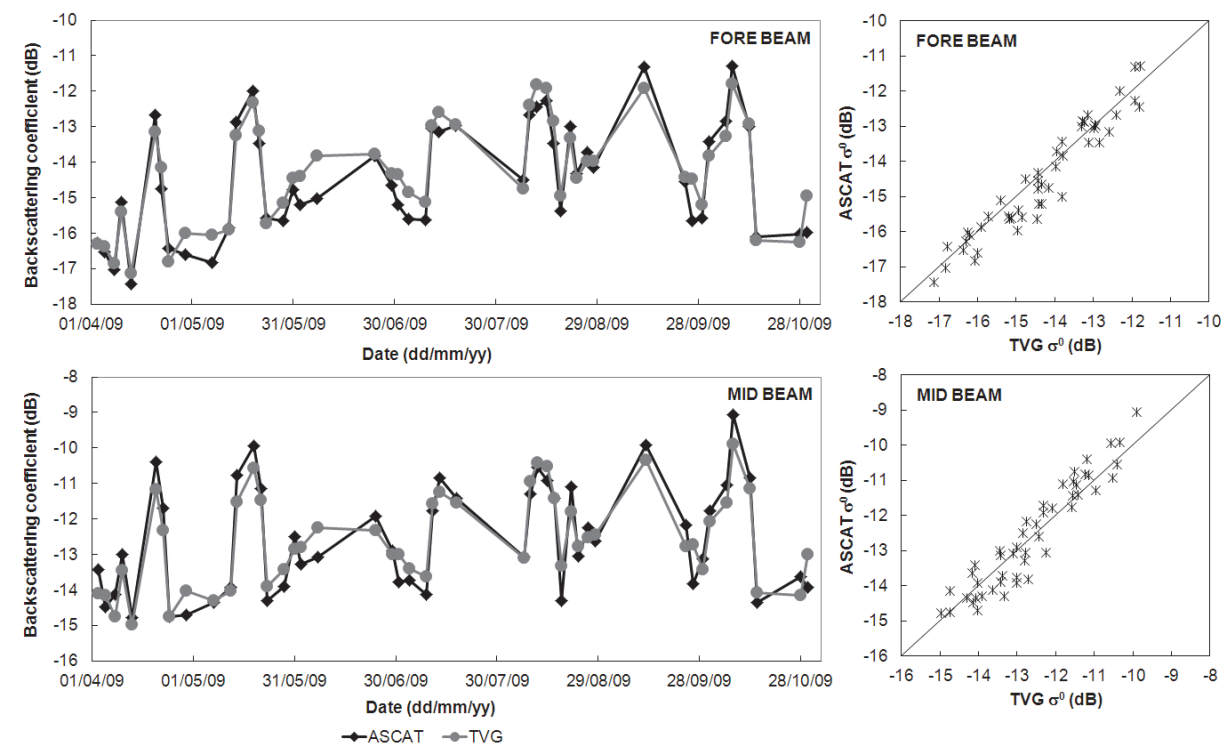

Figure 6.5 Backscattering coefficient obtained with the calibrated Tor Vergata (TVG) model compared with ASCAT data for fore (top) and mid (bottom) beam in 2009.
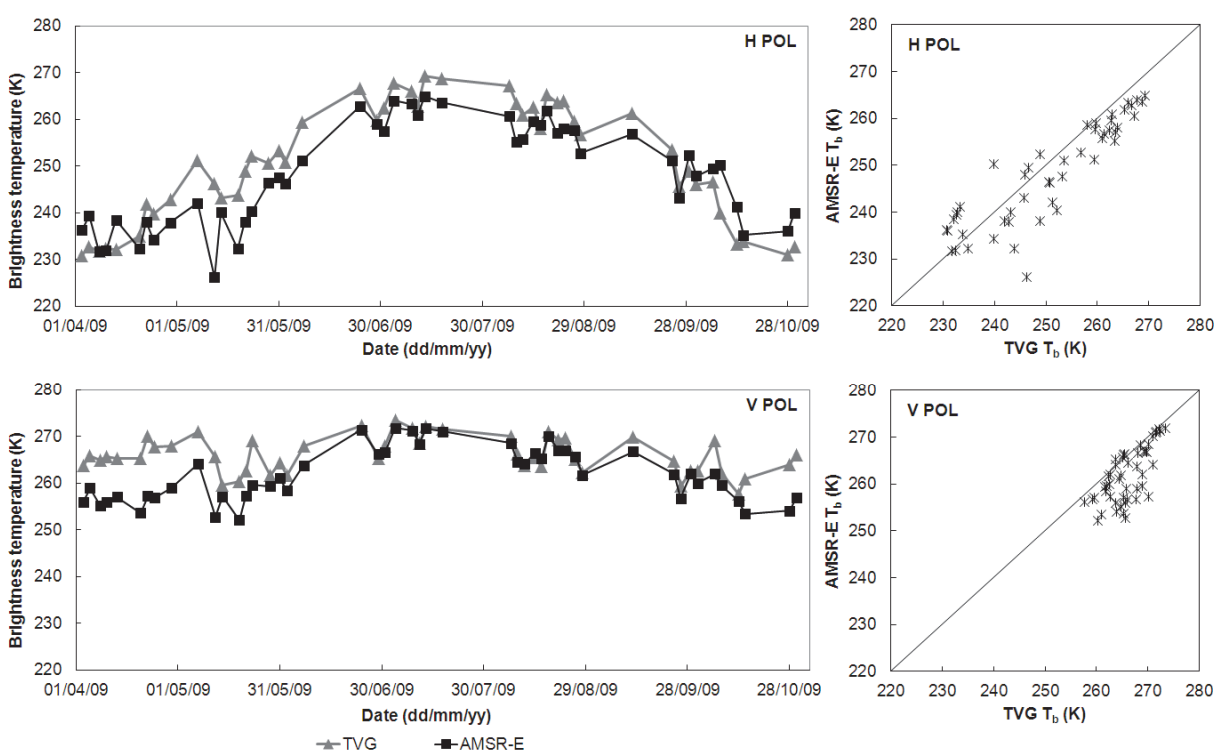

Figure 6.6 Brightness temperature obtained with the calibrated Tor Vergata (TVG) model (modelled emissivity multiplied by $T_{K a V}$ ) compared with the AMSR-E C-band data in $H$ polarization (top) and $V$ polarization (bottom) in 2009. 
The seasonal pattern of AMSR-E $T_{b}$ is well estimated by the model in the $\mathrm{H}$ polarization case. The modelled pattern in $\mathrm{V}$ polarization is slightly flatter than the AMSR-E data. The model underestimates $T_{b H}$ under sparsely vegetated conditions and overestimates it when the vegetation is more developed, with a mean difference with respect to the satellite data of $-1.7 \mathrm{~K}$ for $\mathrm{LAI}<1$ and $5.1 \mathrm{~K}$ for $\mathrm{LAI}>1$. In the $\mathrm{V}$ polarization case, the model overestimations affect mainly the beginning and the end of the season, with a mean difference with respect to the satellite data of $7.9 \mathrm{~K}$ for $\mathrm{LAI}<1$ and $2.3 \mathrm{~K}$ for $\mathrm{LAI}>1$. The difference between modelled $T_{b H}$ and $T_{b V}$ is larger than the observed difference mainly when the vegetation cover is low. Possible causes for this discrepancy might be limitations in the simulation of the emissivity component of the soil-litter medium and inaccuracies in the estimation of the vegetation cover. It was found that the surface component of the Tor Vergata model tends to overestimate the difference between the $\mathrm{H}$ and $\mathrm{V}$ polarization in particular over bare soils and for high incidence angles (Ferrazzoli et al. 2000; Mo et al. 1987). Moreover, it might be that the vegetation cover fraction is not well represented by the model, as the grassland might be not homogenous at the beginning and at the end of the monsoon season. Taking into account the vegetation cover fraction might provide a better agreement between the modelled output and the satellite data.

The largest discrepancy, in both pattern and absolute value, between C-band AMSR-E data and modelled $T_{b}$ occurs from 7 to 14 May. From 7 to 12 May AMSR-E observes a decrease of $T_{b}$ of approximately $16 \mathrm{~K}$ in $\mathrm{H}$ pol and $12 \mathrm{~K}$ in $\mathrm{V}$ pol, whereas Tor Vergata model simulates a $T_{b}$ decrease of approximately $5 \mathrm{~K}$ in both $\mathrm{H}$ and $\mathrm{V}$ pol (Figure 6.6). On 14 May $T_{b}$ increases according to AMSR-E observations, but not according to the model. As it is shown in Figure 6.3, LAI was still low in the first half of May, therefore the soil contribution to the surface emissivity was dominant. On 7 May the soil was relatively dry with soil moisture of approximately $0.26 \mathrm{~m}^{3} \mathrm{~m}^{-3}$ (Figure 6.2) and for this reason $T_{b}$ was higher than the previous days. In the 24 hours before the satellite acquisitions on both 12 and 14 May, about $7 \mathrm{~mm}$ of rain were collected at Maqu station and this caused a soil moisture increase to $0.38 \mathrm{~m}^{3} \mathrm{~m}^{-3}$ and $0.42 \mathrm{~m}^{3} \mathrm{~m}^{-3}$ respectively. Therefore, the large variation of observed $T_{b}$ from 7 to 12 May was mainly due to soil moisture increase. The modelled $e$ remains, however, constant 
and the decrease of Tor Vergata model $T_{b}$ is caused only by the decrease of the surface temperature. The decrease of the modelled $T_{b}$ is smaller than the observed one, regardless of the selected surface temperature (see Figure B.1). Possible reasons to explain this discrepancy might be related to the presence of litter, which can cause inaccuracies in the soil and litter moisture given as input, and in the modelling. The presence of litter on the surface reduces the depth of the effective layer contributing to the surface emissivity, which may become much shorter than the depth where the soil moisture was measured (i.e. $5 \mathrm{~cm}$ ). Moreover, the assumption that the litter moisture is equal to twice the soil moisture content might not always be valid. In dry conditions (i.e. on 7 May) the litter might be drier than expected and after a strong precipitation event (i.e. on 12 May) the litter might be wetter. In both cases, the moisture of the effective soil-litter layer might be different from that used as input and this would directly impact the emissivity. The approach used to model the soil-litter emissivity might be another cause for the reduced model sensitivity to soil moisture variations. As explained in Section 6.2.4, the soil-litter medium is considered a homogenous half-space with a permittivity depending on soil and litter permittivity. However, Della Vecchia et al. (2007) found that the resulting soil-litter permittivity is lower than that of the soil and it is less sensitive to soil moisture variations. When the litter effect is removed, the Tor Vergata model simulates a decrease of approximately $13 \mathrm{~K}$ from 7 to 12 May in $\mathrm{V}$ polarization, similar to what observed by AMSR-E. In these dates, removing the litter effect enhances the decrease of modelled $T_{b}$ in $\mathrm{H}$ polarization as well, up to $7 \mathrm{~K}$, but not enough to match the observations. This is due to the strong effect of the increasing LAI on the total H pol emissivity, especially when the surface is not covered by litter.

The discrepancy between modelled and observed data on 14 May has most likely a different origin. Due to the measured soil moisture increase, the model simulates a decrease in emissivity from 12 to 14 May, whereas AMSR-E data show an increase in $T_{b}$. This unexpected behaviour of AMSR-E observations might be attributed to the interception of the precipitation by the litter layer. If the precipitation occurred just before the satellite overpass, a large quantity of rain did not drain towards the short grass and the litter layer at the moment of AMSR-E observation, but was probably still 
on litter and vegetation. Saleh et al. (2006a) found that in this situation both the vegetation and the litter are strong absorbers, with the attenuation of soil emission and the increase of vegetation and litter emission as consequence. The latter effect is much stronger than the former and the total emissivity increases.

\subsubsection{Model validation over 2010 data}

The optimal set of input parameters found through the model calibration, without any further refinement, and the soil moisture and LAI estimated for 2010 monsoon season (shown in Figure 6.2 and Figure 6.3) were used to validate the Tor Vergata model. The simulated $\sigma^{0}$ time series was compared with ASCAT data directly (Figure 6.7), whereas the simulated $e$ was firstly multiplied by $T_{K a V}$ to obtain $T_{b}$, which was then compared with AMSR-E data (Figure 6.8).

In general the agreement between modelled and observed data in 2010 was slightly worse than in 2009. The comparison between modelled and observed $\sigma^{0}$ resulted in $R^{2}$ of $0.8, R M S E$ of $1 \mathrm{~dB}$, mean difference of $0.8 \mathrm{~dB}$ for low LAI and $0.5 \mathrm{~dB}$ for high LAI for fore beam data, and $R^{2}$ of $0.8, R M S E$ of $0.8 \mathrm{~dB}$, mean difference of $0.3 \mathrm{~dB}$ for the entire season for mid beam data. It can be observed that the agreement worsens for high incidence angles and dry conditions, i.e. low $\sigma^{0}$ values. In particular in April and May 2010, the ASCAT data reach lower values than in 2009 . However, the variability range of the observed soil moisture and LAI are similar for both years at the beginning of the season and for this reason the simulated backscattering coefficient cannot match the lowest ASCAT values. A lower moisture content of the soil-litter medium than expected might be the reason of observed low $\sigma^{0}$ values. In dry conditions, the soil moisture at $5 \mathrm{~cm}$ depth might be higher than the moisture at the penetration depth, as well as the litter might have lower moisture than the input information, i.e. twice the soil moisture. Moreover, the combination of slight differences in litter, surface roughness and vegetation between the 2009 and the 2010 seasons could cause the discrepancy between observations and simulations in 2010 . 

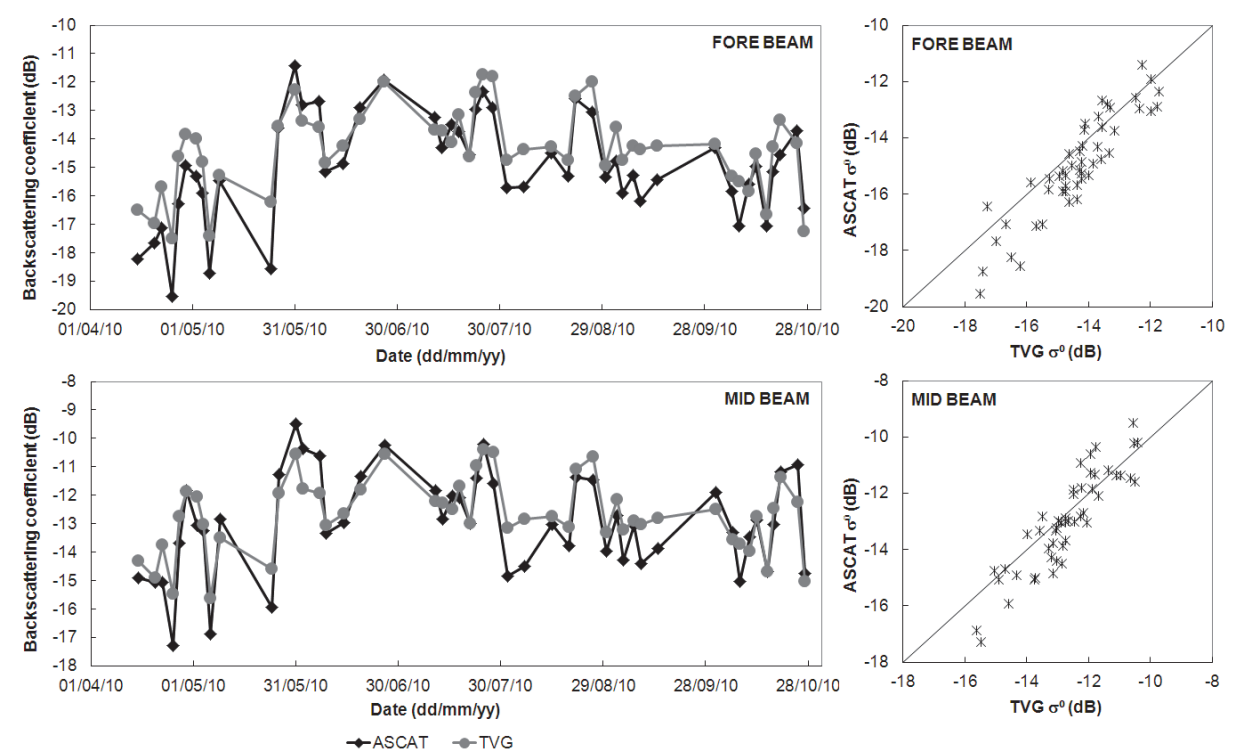

Figure 6.7 Backscattering coefficient obtained with the calibrated Tor Vergata (TVG) model compared with ASCAT data for fore (top) and mid (bottom) beam in 2010.
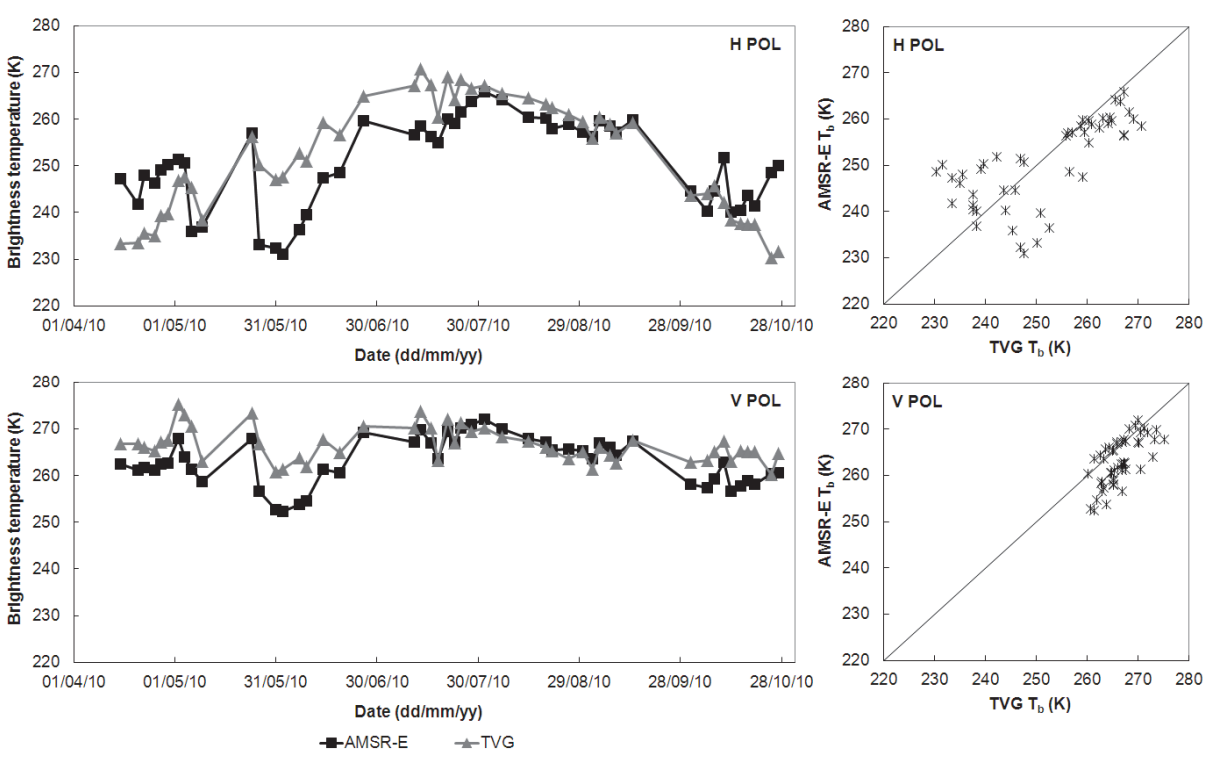

Figure 6.8 Brightness temperature obtained with the calibrated Tor Vergata (TVG) model (modelled emissivity multiplied by $T_{K a V}$ ) compared with the AMSR-E C-band data in $H$ polarization (top) and $V$ polarization (bottom) in 2010. 
For the passive case, $R^{2}$ of 0.5 and $R M S E$ of $8.7 \mathrm{~K}$ were calculated between the modelled $T_{b H}$ and the AMSR-E data, with an underestimation for low LAI values (mean difference of $6 \mathrm{~K}$ ) and an overestimation in June and July. Whereas, in $\mathrm{V}$ polarization there is a better agreement between modelled and observed data than in 2009, in particular at the beginning and the end of the monsoon season, with $R^{2}$ of $0.5, R M S E$ of $5 \mathrm{~K}$, mean difference of $5.5 \mathrm{~K}$ for $\mathrm{LAI}<1$ and mean difference of $2.0 \mathrm{~K}$ for LAI $>1$. As observed for 2009 data, the difference between modelled $\mathrm{H}$ and $\mathrm{V}$ polarisation signatures is overestimated for low values of LAI for 2010 data as well.

The agreement of 2010 simulations with AMSR-E data is strongly sensitive to the surface temperature accuracy, which is further explained in Appendix B.

The largest discrepancy between modelled and observed $T_{b}$ occurs at the end of May 2010 and this does not depend on the selected surface temperature. From 24 to 26 May AMSR-E measures a large $T_{b}$ decrease, of approximately $24 \mathrm{~K}$, in $\mathrm{H}$ polarization and a moderate decrease, of approximately $11 \mathrm{~K}$, in $\mathrm{V}$ polarization. Whereas, the modelled $T_{b}$ shows only a decrease of $6 \mathrm{~K}$ for both polarizations (Figure 6.8). From 26 May to 2 June, observed $T_{b}$ keeps low values, but the simulated values remain largely higher. Then the observations, as well as the simulations, increase until 26 June and the overestimation slowly decreases. The behaviour of AMSR-E data is easily explained by the precipitation and soil moisture pattern (Figure 6.2). From 25 May to 6 June, intensive precipitation events occurred that caused a large increase of soil moisture. Later, less intensive precipitations occurred and the soil moisture slowly decreases. The pattern of the modelled $T_{b}$ is correctly driven by the soil moisture variations, as well as by the LAI increase, but with a smaller range of variability than the AMSR-E data. Differently from 2009 , the litter effect appears not to be the most important cause for the discrepancy. Indeed, removing the litter component in the model simulations does not have a significant effect on the modelled $T_{b}$ range of variability from 24 to 26 May and on the pattern in the following days. The discrepancy might be more related to an overestimated attenuation of the surface component than to an overestimation of the litter effect. From 24 May to 26 June, LAI increases from 1 to $2 \mathrm{~m}^{2} \mathrm{~m}^{-2}$, therefore the attenuation of the surface 
component by the vegetation cover is important. However, it might be that the vegetation cover was not homogenous. Therefore, the discrepancy might have been smaller, if the vegetation cover fraction was taken into account in the model.

\subsection{Discussion on the combined use of active and passive microwave data}

The synergistic use of both active and passive microwave data was crucial in this study. As a requirement, the set of optimal input parameters should have realistic values and return the best match between model outputs and both AMSR-E and ASCAT signatures for the whole 2009 monsoon season. In order to investigate the advantage of combining active and passive microwave data, the model calibration was repeated either using active data only or using passive data only and the results were compared with those obtained using both datasets.

Firstly the model was calibrated by using active data only. The optimal set of input parameters was obtained by minimizing the sum of the first two terms of Equation 6.1 (the active terms). These parameters were used to run the model in the passive configuration, as well, and compute the full cost function. The set of input parameters, the sum of the active terms, the sum of the passive terms and the total cost function are reported in Table 6.3.

Then, the model was calibrated by using passive microwave data only, i.e. by minimizing the sum of the last two terms of Equation 6.1 (passive terms). The total cost function was obtained by applying the input parameters found in this way for the active configuration as well.

Table 6.3 clearly shows that the combination of active and passive microwave data leads to obtain a lower value of cost function than by using the active or passive data separately. Optimizing the match between model outputs and ASCAT data alone does not provide a good match with the AMSR-E data. Likewise, the optimization driven by passive data produces poor results for the active case. 
Table 6.3 Sum of the first two terms (active terms), sum of the last two terms (passive terms) and total value of the cost function for the case of model calibration using active microwave data only, including and discarding the litter, using passive microwave data only and using both active and passive microwave data.

\begin{tabular}{|c|c|c|c|}
\hline & $\begin{array}{l}\text { Sum of } \\
\text { active terms }\end{array}$ & $\begin{array}{l}\text { Sum of } \\
\text { passive terms }\end{array}$ & $\begin{array}{l}\text { Total cost } \\
\text { function }\end{array}$ \\
\hline $\begin{array}{l}\text { Active microwave only - no litter } \\
\text { (height standard dev.: } 0.3 \mathrm{~cm} \text {, } \\
\text { correlation length: } 5.0 \mathrm{~cm} \text {, } \\
\text { disc radius: } 1.4 \mathrm{~cm} \text {, } \\
\text { plant moisture content: } 0.8 \text { ) }\end{array}$ & 0.67 & 3.93 & 4.60 \\
\hline $\begin{array}{l}\text { Active microwave only } \\
\text { (height standard dev.: } 0.7 \mathrm{~cm} \text {, } \\
\text { correlation length: } 7.0 \mathrm{~cm}, \\
\text { disc radius: } 1.2 \mathrm{~cm}, \\
\text { plant moisture content: } 0.8, \\
\text { litter biomass: } 0.05 \mathrm{~g} \mathrm{~cm}^{-2} \text {, } \\
\text { litter moisture: } 2 \text { x soil moisture) }\end{array}$ & 0.50 & 1.53 & 2.03 \\
\hline $\begin{array}{l}\text { Passive microwave only } \\
\text { (height standard dev.: } 0.9 \mathrm{~cm} \text {, } \\
\text { correlation length: } 7.0 \mathrm{~cm} \text {, } \\
\text { disc radius: } 1.4 \mathrm{~cm} \\
\text { plant moisture content: } 0.9 \\
\text { litter biomass: } 0.05 \mathrm{~g} \mathrm{~cm}^{-2} \text {, } \\
\text { litter moisture: } 2 \text { x soil moisture) }\end{array}$ & 1.45 & 1.00 & 2.45 \\
\hline Active and passive microwave & 0.54 & 1.25 & 1.79 \\
\hline
\end{tabular}

It is worth to note that, if the litter presence was completely ignored, it was still possible to find a good match between model outputs and ASCAT data through calibration of the input parameters. Assuming an almost flat surface, i.e. with a height standard deviation of $0.3 \mathrm{~cm}$ and a correlation length of $5.0 \mathrm{~cm}$, and using all the other input values listed in Table 6.1, a good match between modelled $\sigma^{0}$ and ASCAT data was found for the entire season (Figure 6.9). However, the same set of input parameters did not return a good match between modelled and observed $T_{b}$ (Figure 6.10) and the variation of the input parameters did not lead to any significant improvement in the match. As the input LAI was low and the soil moisture was high at the beginning and the end of the monsoon season over Maqu (these were the two most important model inputs, as discussed in Section 6.4.1), it was not possible to simulate a surface emissivity as high as the observed one without including the litter effect. 


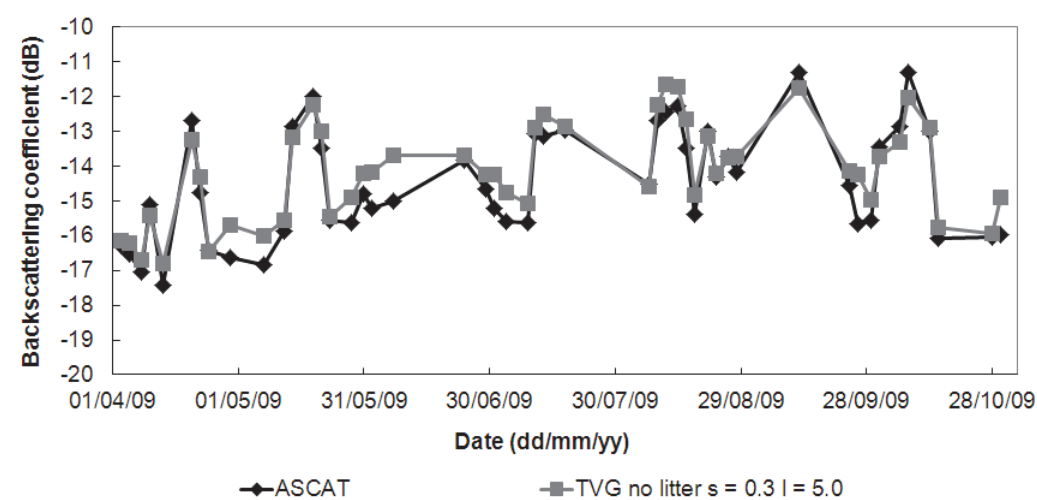

Figure 6.9 Modelled backscattering coefficient obtained ignoring the litter presence and using modified roughness parameters (height standard deviation (s) $0.3 \mathrm{~cm}$ and correlation length (l) $5.0 \mathrm{~cm}$ ) compared to ASCAT data in fore beam configuration.
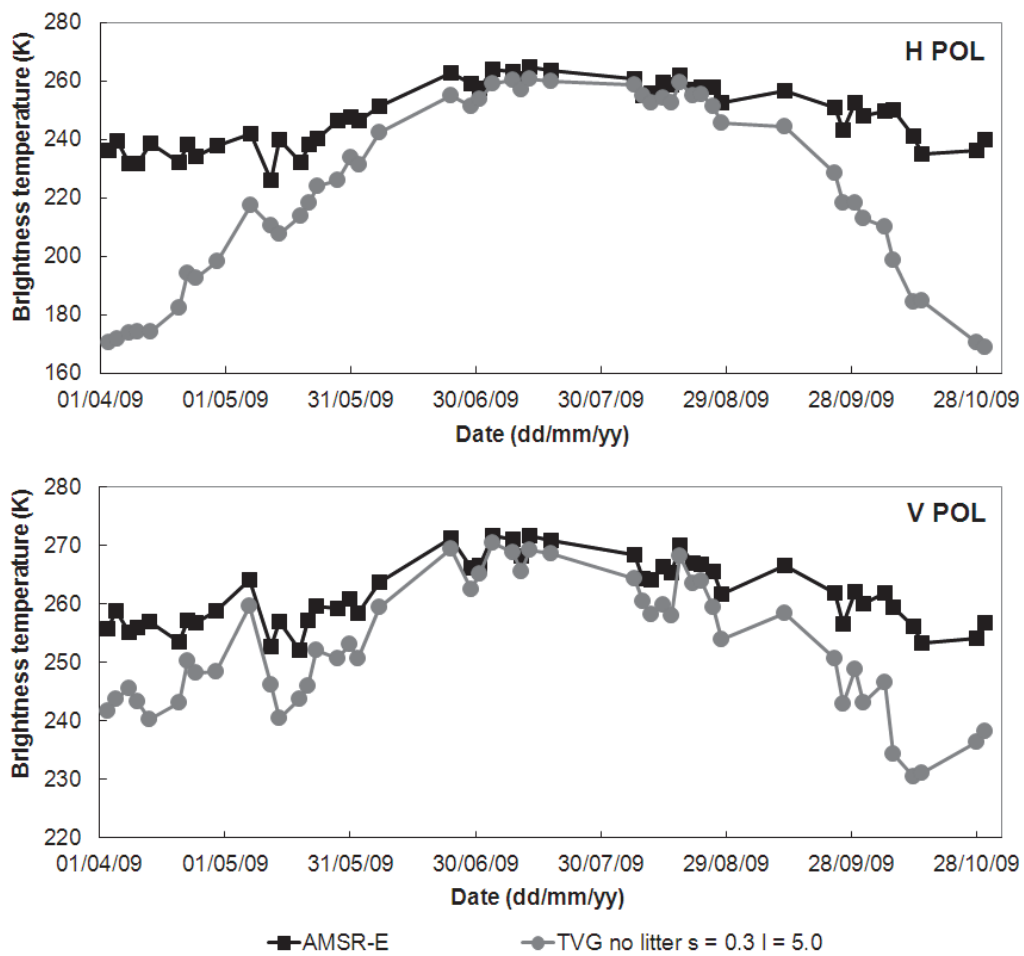

Figure 6.10 Modelled brightness temperature obtained ignoring the litter presence and using modified roughness parameters (height standard deviation $(\mathrm{s}) 0.3 \mathrm{~cm}$, correlation length (l) $5.0 \mathrm{~cm}$ ) compared to AMSR-E data in $\mathrm{H}$ pol (top) and $\mathrm{V}$ pol (bottom). 
If only the active data were used, wrong conclusions would have been drawn with unrealistic input values (too smooth surface roughness) and unrealistic representation of the surface conditions (absence of litter). Whereas, the synergistic use of active and passive data led to better represent the surface, to more accurate simulations and to a good match with both source of satellite data.

Realistic input values and a correct representation of the surface conditions could have only been obtained by running the model in both active and passive configuration and comparing the outputs with both the satellite brightness temperature and backscattering coefficient.

\subsection{Summary and conclusions}

This section reported on the advantage of combining active and passive microwave remote sensing data to improve the modelling, as well as the understanding, of emission and scattering mechanisms over the natural grassland in the Maqu region (Tibetan Plateau, China). The Tor Vergata discrete scattering model, driven by a single set of inputs, was used to simulate both the emissivity and the backscattering coefficient and the results were compared with AMSR-E and ASCAT signatures collected during the 2009 and 2010 monsoon seasons. The most important driving inputs were the measured soil moisture (average of measurements collected in 8 sites of the area) and the MODIS LAI (interpolated and smoothed). However, no detailed measurements were available for other model inputs, such as surface roughness, vegetation moisture content, vegetation structural parameters, litter moisture and biomass. A preliminary analysis was done to investigate the sensitivity of modelled emissivity and backscattering to these inputs. This analysis demonstrated the absorption effect of the litter layer present over the soil surface, which causes an increase in the total emissivity and a decrease of the total backscattering coefficient. The higher the litter biomass and moisture content are, the stronger is this effect.

A calibration was performed to overcome the lack of detailed information on the other model inputs, which consisted of varying 
the unknown parameters in a realistic range until the best match between model outputs and both AMSR-E and ASCAT signatures was reached. The calibration was carried out using the in situ and satellite data from April to October (monsoon season) 2009. The use of both active and passive microwave data was crucial in the calibration in order to find realistic values for the model inputs. It was shown that if the calibration was carried out only for the active case, a good agreement between modelled and observed backscattering coefficient was found by disregarding the presence of litter and by assuming a smooth surface roughness. However, these conditions were both unrealistic. With the same assumptions, it was not possible to reach a good match between the model outputs and the satellite data in the passive case, because the emissivity was largely underestimated without taking into account the litter effect.

Using the optimal set of input parameters, the model correctly took into account the variations in soil moisture and LAI, as well as the incidence angle variations, in the simulated backscattering coefficient for the entire 2009 monsoon season. $R^{2}$ of $0.9, R M S E$ of 0.5 $\mathrm{dB}$ and mean difference of $0.2 \mathrm{~dB}$ for the fore beam and of $-0.04 \mathrm{~dB}$ for the mid beam were found between model outputs and ASCAT time series. The results obtained in the passive case strongly depended on the surface temperature used to convert the modelled emissivity in brightness temperature. The best match with satellite observations was found when the surface temperature was obtained from Ka-band AMSR-E data. $R^{2}$ of 0.8 and RMSE of $6.3 \mathrm{~K}$ were found for $\mathrm{H}$ polarization with a general overestimation for high vegetation cover and $R^{2}$ of 0.5 and $R M S E$ of $5.9 \mathrm{~K}$ for $\mathrm{V}$ polarization with a general overestimation for low vegetation cover.

The validation results over the 2010 monsoon season showed a slightly worse agreement between modelled and AMSR-E and ASCAT signatures. For the active case, $R^{2}$ of 0.8 and $R M S E$ of $1 \mathrm{~dB}$ were found with a poor agreement for high incidence angles and dry conditions. For the passive case, $R^{2}$ of 0.5 and $R M S E$ of $8.7 \mathrm{~K}$ were calculated for $\mathrm{H}$ polarization and $R^{2}$ of 0.5 and $R M S E$ of $5 \mathrm{~K}$ for $\mathrm{V}$ polarization.

The results of this study showed some limitations that might be improved and need to be addressed in future works. The simulation accuracy will probably improve when the relationship between soil 
moisture and litter moisture in grasslands is assessed in dry and wet conditions, as well as in case of rain interception; when the sensitivity of the total emissivity to variations of litter moisture and litter biomass is better modelled; and when, in general, the understanding of the litter effect is improved for the grassland case. Another factor that might be worth to take into account is the fraction of vegetation cover, as the grass cover is probably not homogenous at the beginning and at the end of the monsoon season. With these improvements, the model will probably be more sensitive to soil moisture variations, in particular when the vegetation is partially covering the ground surface. The overestimation of the difference between $\mathrm{H}$ and $\mathrm{V}$ polarized emissivity for low vegetation cover should be further investigated as well.

Taking into account the uncertainties in the model inputs and the approximations and limitations of the Tor Vergata model, the results of this study are very promising, as the agreement between model output and satellite observations is generally good for both the active and the passive case. Two important conclusions can be drawn from this study: the first concerns the synergistic use of active and passive microwave data and the second the surface temperature. This study proves that the integration of the active and passive microwave data is a crucial point to better understand the microwave scattering interactions with the land surface and to improve their modelling. The role of a discrete scattering model is also important in this context as it provides a consistent framework for an unambiguous interpretation of active and passive microwave signals. Though the Tor Vergata model is more complex and it requires more inputs than other simplified models and approaches presented in literature, the use of both active and passive satellite information allowed to run the model without having a detailed knowledge of all the inputs, but using realistic parameters. It also allowed to correctly simulate the satellite signatures. If the model simulation accuracy is improved, it is expected that also the soil moisture retrieval obtained by model inversion will improve. The second important conclusion of this study is that there is the need of accurate surface temperature data in order to assess the accuracy of the Tor Vergata model, as well as other theoretical models, in the passive case. The accuracy of surface temperature strongly affects the agreement between modelled and observed brightness temperature. 
The available active and passive satellite data at C-band were used in this study, but the same approach can be applied to data in other bands. The Tor Vergata model can indeed simulate emissivity and scattering for a wide range of frequency. In particular, the application at L-band of the same approach described in this study can provide results certainly useful to support the understanding and the use of SMOS and SMAP L-band radiometer data combined with the data of an active C-band sensor, such as ASCAT scatterometer and Sentinel-1 radar. The same study can be applied to other regions, than Maqu, covered by grassland or short vegetation, where soil moisture and LAI are available. Whereas, the extension of this study to cropland areas and forests requires the use of appropriate vegetation growth models which relate input variable to each other and predict their variation with time. 


\section{Chapter 7}

\section{Synthesis and final remarks}

\subsection{Introduction}

Highly accurate monitoring of soil moisture on a global scale has remained an important challenge for the remote sensing scientific community over the last forty years due to the crucial role this variable plays in several land surface processes and in climate research. In this context, this study contributes to evaluating the accuracy of the current satellite-derived soil moisture products and proposes a valid method for optimising the use of active and passive microwave satellite data, by combining them into a single scattering and emission model to understand better the satellite signal and to reduce the uncertainties in the soil moisture retrieval process.

The main results obtained in this research are summarised and the final remarks and recommendations are reported in this chapter. 


\subsection{Validation of the satellite-derived soil moisture products}

Large soil moisture networks were set up in the Maqu region (China) and in the Twente region (The Netherlands) to provide the ground reference for the validation of AMSR-E, ERS, ASCAT and SMOS soil moisture products. Both networks measured soil moisture and soil temperature at a depth of $5 \mathrm{~cm}$ depth at twenty sites located in an area larger than one resolution cell of the currently operational soil moisture products. The distinctive features of these two regions allowed different aspects of the validation of satellite-derived soil moisture to be analysed.

The analysis of the collected datasets showed that both in Maqu and in Twente the measurements were consistent in space and time and in good agreement with the meteorological data. The soil moisture spatial variability has been well sampled, though the stratified sampling in the Maqu region is slightly disproportionate and two stations in the Twente network need to be moved to a more representative location. On the basis of these findings, it has been concluded that the weighted and the standard spatial average of the measurements collected at all sites are a good indicator of the soil moisture of the entire Maqu and Twente network area, respectively. For this reason, they were used as ground references for the validation of the satellite-derived soil moisture products.

Temporal agreement, correlation and bias between in situ measurements and satellite products were investigated. In order to analyse the seasonal patterns and autocorrelations of satellitederived soil moisture, the long time series of in situ data collected by the Oklahoma Mesonet network (USA), by the OzNet network (Australia) and by the REMEDHUS network (Spain) were used, as the time series collected in Maqu and Twente region were too short for this scope.

The main results of the validation are summarised in the following sections. 


\subsubsection{Validation of AMSR-E soil moisture products}

The validation of the soil moisture products derived from AQUA AMSR-E data by VUA and NASA confirmed the expectation of a general better agreement between the measurements of the Maqu network and the descending (night) data than the ascending (day) data. The validation of the descending data collected in the monsoon season of 2008, 2009 and 2010 showed a $R^{2}$ approximately equal to $0.5, R M S E$ to $0.06 \mathrm{~m}^{3} \mathrm{~m}^{-3}$ and a very low bias. The AMSR-E soil moisture products are able to estimate the general temporal behaviour and the mean value of the ground data, although they are characterised by noise, slight overestimation in April and underestimation in July and August.

The long time series analysis revealed that the seasonality of AMSR-E soil moisture is in a general good agreement with in situ data, in particular for the sites characterised by a short vegetation cover, such as in Australia, with a $R^{2}$ of 0.8 . Whereas, the correlation with fAPAR appears to be dominant in the selected sites of the Oklahoma Mesonet, where the vegetation cover can be higher than in Australia. In these sites, $R^{2}$ is lower than 0.7. Moreover, the AMSR-E data are affected by RFI in Oklahoma. A clear disagreement among the seasonalities was also found in the Salamanca site in spring, which might be due to the vegetation effects on the retrieval of soil moisture from dry soils. Although the anomalies from the seasonality of the satellite products are noisier than the in situ anomalies, the correlograms show that they are not completely random, but there are statistical similarities.

\subsubsection{Validation of ERS and ASCAT soil moisture products}

The coefficient of determination between ASCAT soil moisture products by TU Wien and in situ data is approximately equal to 0.5 for the Maqu region for the time period from 2008 to 2009, as for the AMSR-E data case. However, the former dataset show a generally noisier behaviour than the latter, often having an unrealistically large variability. The descending (day) products are noisier than the ascending (night) products, with an RMSE of $0.09 \mathrm{~m}^{3} \mathrm{~m}^{-3}$ and a mean 
overestimation of $0.05 \mathrm{~m}^{3} \mathrm{~m}^{-3}$ for the day data against an RMSE of $0.07 \mathrm{~m}^{3} \mathrm{~m}^{-3}$ and a negligible bias for the night data. Despite the noise, it can be concluded also for the ASCAT products that they are able to reproduce the general soil moisture behaviour monitored at the Maqu network.

The ERS soil moisture products (obtained by TU Wien, applying the same retrieval method used for the ASCAT products) were used to analyse the seasonality, the anomalies and the autocorrelation, in place of the ASCAT data, because they consisted of a longer time series. The large number of gaps in the ERS time series affected the agreement between ERS and in situ seasonality. The coefficient of determination between the seasonalities for the Australian sites is equal to 0.8 , but the correlogram of the ERS data does not show a seasonal oscillation at the Oklahoma sites. In contrast to the AMSR-E case, at Oklahoma the vegetation cover was not the main cause of disagreement between ERS and in situ seasonality. Though the agreement in spring for Spain is higher than for the AMSR-E case, the coefficient of determination between the seasonalities of ERS and in situ data is 0.6 in this region. The anomalies from the seasonality showed correlograms similar to those of in situ data in the ERS case as well.

\subsubsection{Validation of SMOS soil moisture products}

The SMOS soil moisture products were validated against in situ data collected in 2010 both in the Maqu and in the Twente regions. As the radiometer of SMOS operates at L-band, which is an optimal band for soil moisture retrieval, the SMOS soil moisture products were expected to be more accurate than those of AMSR-E and ASCAT (operating at C-band). However, the validation analysis did not show a distinctive performance of the SMOS data in comparison to the other products. The SMOS products are characterised by noise and systematic dry bias. The coefficient of determination between SMOS ascending products and measurements collected at both the Maqu and Twente regions is equal to that found for the AMSR-E and ASCAT cases (approximately 0.5), and the RMSE is equal to $0.13 \mathrm{~m}^{3} \mathrm{~m}^{-3}$ for the Chinese site and $0.17 \mathrm{~m}^{3} \mathrm{~m}^{-3}$ for the Dutch site. When the descending products were compared with the in situ data, $R^{2}$ 
decreased to 0.2 for the Maqu region and to 0.4 for the Twente region, and the $R M S E$ remained equal to $0.13 \mathrm{~m}^{3} \mathrm{~m}^{-3}$.

The SMOS data were further analysed to understand the reasons for the expectations not being met. Three causes of inaccuracy were identified: frozen soils and snow in winter, inaccurate assumptions about the land cover and RFI. During the winter, the frozen soil and the presence of snow were often not taken into account due to inaccurate input information at both the Maqu and Twente regions, and the retrieval was carried out as if for the nominal case. The erroneous information about the presence of forest in an area within the Maqu region led to the retrieval of the soil moisture as if for the case of forest. However, the most important cause of error in the SMOS retrieval at both sites was the RFI. The RFI filter was unable to recognise the presence of this interference in various SMOS data, which had been erroneously included in the retrieval process.

\subsection{Combined use of active and passive microwave data}

Given that active and passive microwave signatures have a different sensitivities to soil and vegetation parameters and provide complementary information, this dissertation proposed a new method to combine them with the objective of improving the soil moisture retrieval process. Active and passive microwave satellite data were synergistically used to constrain a discrete scattering model for the Maqu region. Driven by a single set of inputs, the Tor Vergata discrete scattering model was used to simulate both the emissivity and the backscattering coefficient and the results were compared with AMSR-E and ASCAT signatures. The combined use of active and passive microwave data provided a crucial advantage in the model calibration. The unknown input parameters of the model were varied to obtain a good match between model outputs and both AMSR-E emissivity and ASCAT backscattering coefficient observed in 2009. It was clearly demonstrated that the use of both active and passive microwave datasets led to calibrating the model with better accuracy than using a single set of data (passive only or active only). 
A good agreement was found between the calibrated model output and the satellite data: $R^{2}$ of 0.9 and $R M S E$ of $0.5 \mathrm{~dB}$ for the active case, $R^{2}$ of 0.8 and $R M S E$ of $6.3 \mathrm{~K}$ for the AMSR-E $\mathrm{H}$ polarised data and $R^{2}$ of 0.5 and RMSE of $5.9 \mathrm{~K}$ for $\mathrm{V}$ polarisation. The results obtained in the passive case strongly depended on the surface temperature used to convert the modelled emissivity in brightness temperature. The calibrated model was then validated for the 2010 data, obtaining a slightly worse agreement between the modelled and satellite data $\left(R^{2}\right.$ of 0.8 and $R M S E$ of $1 \mathrm{~dB}$ for the ASCAT data and $R^{2}$ of 0.5 and $R M S E$ of $7 \mathrm{~K}$ for the AMSR-E case).

\subsection{Final remarks and recommendations}

In conclusion, the validation analysis of AMSR-E, ASCAT and SMOS soil moisture products showed that the satellite-derived estimates describe the general seasonal behaviour of soil moisture for the Maqu and Twente regions in the period under study with an acceptable agreement. However, the satellite products were characterised by noise, occasional disagreements, unrealistically large variability and bias that limited the accuracy. From the analysis of the long time series, it can also be concluded that the satellite products can be affected by noise and systematic errors during specific seasons. Therefore, it was advised to evaluate the accuracy of the satellite-derived products site by site before using them for climatic studies. Several causes that could affect the accuracy of the satellite estimates were identified. These were related not only to the limitations of the retrieval methods and to the sensitivity to vegetation cover, but also to other factors such as RFI.

As demonstrated by this study, the accuracy of the satellite-derived soil moisture products can potentially be improved by synergistically using active and passive microwave data. With the proposed method, a discrete scattering model, such as the Tor Vergata model, which requires several input parameters generally unavailable on a large scale, can be successfully constrained, and the active and passive signatures can be unambiguously interpreted. A more accurate model simulation will certainly lead to an improved model inversion. 
Moreover, it is expected that the synergistic use of active and passive satellite data will also constrain the entire soil moisture retrieval process. For this reason, an important follow-up study of this research will involve quantitatively evaluating the effects of the combined use of active and passive microwave data on the accuracy of soil moisture retrieval.

This dissertation has raised different issues that would be interesting to address and discuss further in future studies. Therefore, possible follow-up studies and recommendations are summarised below.

There are a few issues concerning the accuracy of the ground reference used to validate the satellite products. An often-raised question is whether the in situ measurements collected from twenty sites and their average can provide a representative estimate of the soil moisture within an area covered by one or more pixels of ASCAT, AMSR-E and SMOS data. The number of sites monitored within the region and their locations cannot be fixed a priori, but should be carefully selected in accordance with the site characteristics, i.e. homogeneity, land cover, topography and soil texture, in order to assure the monitoring of the entire spatial variability range of soil moisture, taking into account the practical limitations (such as costs and site reachability). A well-designed sampling should be the basic requirement for a large soil moisture monitoring network. If the region is very homogenous, having more than twenty monitoring stations would only provide redundant information, but having fewer than twenty stations could probably be sufficient for accurate monitoring. Once a well-designed sampling has been assured, the simple or weighted average will provide an estimate of the soil moisture of the entire area, with an error that is certainly lower than the typical error of the satellite-derived products and, therefore, is acceptable.

Due to the practical difficulties encountered during the installation of the Twente monitoring network, the dataset collected in this region was available at a later stage of this research; therefore, it was not fully employed in this study. However, the validation study of the satellite-derived soil moisture products will certainly benefit from using the Twente dataset to evaluate the performances of the satellite products over an area with inhomogeneous vegetation cover and flat topography. Because of these characteristics, which are 
different from those in the Maqu region, it would be interesting to apply the Tor Vergata model and the proposed method of combining active and passive microwave data for the Twente region. In this case, it would be necessary to take into account the vegetation cover fraction in the scattering model and to use a vegetation growth model to estimate the temporal variability of the vegetation parameters.

For the sake of simplicity, this study was mainly focused on the warm seasons (with unfrozen soils). However, it would be interesting in a separate study to investigate the case of frozen soils. Frozen soils consist of an inhomogeneous mixture of soil particles, ice and unfrozen water with a low permittivity, and, for this reason, the $\mathrm{ECH}_{2} \mathrm{O}$ probes measure a low value of soil moisture, like for the case of dry soils. The accuracy of the measurements collected in the Maqu region under frozen conditions should be assessed. The $\mathrm{ECH}_{2} \mathrm{O}$ probes measure the unfrozen water content of the frozen soils, as demonstrated by Yoshikawa and Overduin (2005), but a specific calibration is needed. Active and passive microwave signatures can be used to monitor frozen soils, as demonstrated by previous studies (Rignot and Way 1994; Schwank et al. 2004; Wang et al. 2015). However, the relationship between the microwave satellite observations and frozen/liquid water content in frozen soils needs to be quantitatively analysed and the potential to retrieve the liquid water content needs to be investigated. Furthermore, it would be important to evaluate the accuracy of the Tor Vergata scattering model for frozen soils, adapting the dielectric model for the specific case.

The accuracy of the soil moisture retrieval from passive microwave data depends strongly on the uncertainty of the temperature of the soil effective emitting layer. For this reason further analyses of the surface temperature are needed that cover several aspects, such as the collection of ground reference for validation, the understanding of near surface temperature profiles, the retrieval of the surface temperature from in situ data (i.e. soil moisture and temperature), the accuracy of the currently available parameterisation of the effective temperature and the accuracy of the estimates from remote sensing data at a large scale. 
The scientific community have high expectations for the use of Lband remote sensing for soil moisture retrieval. Unfortunately, these data are strongly affected by RFI in many regions of the world. In both the Twente and the Maqu region the RFI is present, and, for this reason, the SMOS soil moisture accuracy does not satisfy the expectations. Before using L-band data in these two regions (as well as in all the other regions affected by RFI), studies on the detection and mitigation of RFI and on the filtering of the data affected by this problem should be carried out.

Finally, another important follow-up study to this dissertation would be to extend the proposed approach to L-band satellite observations, as this will certainly benefit the understanding and the use of these data for soil moisture retrieval. The Aquarius data (a NASA mission, operational from 2011 to 2015) could be used to investigate the advantage of combining active and passive L-band data acquired by sensors on board the same satellite. Another option would be to investigate the possibility of, and the advantage to, using the proposed method to combine active C-band data (i.e. ASCAT) with passive L-band data (i.e. SMAP and SMOS). 
Synthesis and final remarks 


\section{References}

Al Bitar, A., Leroux, D., Kerr, Y.H., Merlin, O., Richaume, P., Sahoo, A., \& Wood, E.F. (2012). Evaluation of SMOS Soil Moisture Products Over Continental U.S. Using the SCAN/SNOTEL Network. IEEE Transactions on Geoscience and Remote Sensing, 50, 1572-1586

Anterrieu, E., \& Khazaal, A. (2011). One year of RFI detection and quantification with L1a signals provided by SMOS reference radiometers. In, IEEE International Geoscience and Remote Sensing Symposium (IGARSS), 2011 (pp. 2245-2248)

ATBD (2011). SMOS level 2 processor soil moisture algorithm theoretical basis document (ATBD), SO-TN-ARR-L2PP-0037, Available at http://www.cesbio.ups-tlse.fr/data all/SMOSdoc/atbd/ATBD v3 4 20110124.pdf

Attema, E.P.W., \& Ulaby, F.T. (1978). Vegetation modeled as a water cloud. Radio Science, 13, 357-364

Bao, Q., Yang, J., Liu, Y.M., Wu, G.X., \& Wang, B. (2010). Roles of Anomalous Tibetan Plateau Warming on the Severe 2008 Winter Storm in CentralSouthern China. Monthly Weather Review, 138, 2375-2384

Barrett, B.W., Dwyer, E., \& Whelan, P. (2009). Soil Moisture Retrieval from Active Spaceborne Microwave Observations: An Evaluation of Current Techniques. Remote Sensing, 1, 210-242

Bracaglia, M., Ferrazzoli, P., \& Guerriero, L. (1995). A fully polarimetric multiple scattering model for crops. Remote Sensing of Environment, 54, 170-179

Chauhan, N.S. (1997). Soil moisture estimation under a vegetation cover: Combined active passive microwave remote sensing approach. International Journal of Remote Sensing, 18, 1079-1097

Chauhan, N.S., \& Levine, D.M. (1994). Discrete scatter model for microwave radar and radiometer response to corn - comparison of theory and data. IEEE Transactions on Geoscience and Remote Sensing, 32, 416-426 
Colliander, A., \& Xu, X.L. (2013). Normalized Residual Scattering Index Applied to Aquarius L-Band Measurements. Ieee Geoscience and Remote Sensing Letters, 10, 890-894

Cosh, M.H., Jackson, T.J., Moran, S., \& Bindlish, R. (2008). Temporal persistence and stability of surface soil moisture in a semi-arid watershed. Remote Sensing of Environment, 112, 304-313

Coupland, R.T. (1993). Natural grasslands : eastern hemisphere and résumé Amsterdam: Elsevier Scientific

dall'Amico, J.T., Schlenz, F., Loew, A., \& Mauser, W. (2011). First Results of SMOS Soil Moisture Validation in the Upper Danube Catchment. IEEE Transactions on Geoscience and Remote Sensing, PP, 1-10

Das, N.N., Entekhabi, D., \& Njoku, E.G. (2011). An Algorithm for Merging SMAP Radiometer and Radar Data for High-Resolution Soil-Moisture Retrieval. IEEE Transactions on Geoscience and Remote Sensing, 49, 1504-1512

de Jeu, R.A.M., Wagner, W., Holmes, T.R.H., Dolman, A.J., van de Giesen, N.C., \& Friesen, J. (2008). Global Soil Moisture Patterns Observed by Space Borne Microwave Radiometers and Scatterometers. Surveys in Geophysics, 29, 399-420

Della Vecchia, A., Ferrazzoli, P., Guerriero, L., Blaes, X., Defourny, P., Dente, L., Mattia, F., Satalino, G., Strozzi, T., \& Wegmuller, U. (2006). Influence of geometrical factors on crop backscattering at C-band. IEEE Transactions on Geoscience and Remote Sensing, 44, 778-790

Della Vecchia, A., Ferrazzoli, P., Guerriero, L., Ninivaggi, L., Strozzi, T., \& Wegmuller, U. (2008). Observing and Modeling Multifrequency Scattering of Maize During the Whole Growth Cycle. IEEE Transactions on Geoscience and Remote Sensing, 46, 3709-3718

Della Vecchia, A., Ferrazzoli, P., Wigneron, J.P., \& Grant, J.P. (2007). Modeling forest emissivity at L-band and a comparison with multitemporal measurements. Ieee Geoscience and Remote Sensing Letters, 4, 508-512

Dobson, M.C., Ulaby, F.T., Hallikainen, M.T., \& Elrayes, M.A. (1985). Microwave dielectric behavior of wet soil. 2. Dielectric mixing models. IEEE Transactions on Geoscience and Remote Sensing, 23, 35-46 
Draper, C.S., Walker, J.P., Steinle, P.J., de Jeu, R.A.M., \& Holmes, T.R.H. (2009). An evaluation of AMSR-E derived soil moisture over Australia. Remote Sensing of Environment, 113, 703-710

Eagleman, J.R., \& Lin, W.C. (1976). Remote sensing of soil moisture by a 21$\mathrm{cm}$ passive radiometer. Journal of Geophysical Research, 81, 3660-3666

Entekhabi, D., Njoku, E.G., O'Neill, P.E., Kellogg, K.H., Crow, W.T., Edelstein, W.N., Entin, J.K., Goodman, S.D., Jackson, T.J., Johnson, J., Kimball, J., Piepmeier, J.R., Koster, R.D., Martin, N., McDonald, K.C., Moghaddam, M., Moran, S., Reichle, R., Shi, J.C., Spencer, M.W., Thurman, S.W., Tsang, L., \& Van Zyl, J. (2010). The Soil Moisture Active Passive (SMAP) Mission. Proceedings of the Ieee, 98, 704-716

Eom, H.J., \& Fung, A.K. (1984). A scatter model for vegetation up to Ku-band. Remote Sensing of Environment, 15, 185-200

Escorihuela, M.J., Chanzy, A., Wigneron, J.P., \& Kerr, Y.H. (2010). Effective soil moisture sampling depth of L-band radiometry: A case study. Remote Sensing of Environment, 114, 995-1001

Ferrazzoli, P., \& Guerriero, L. (1996). Emissivity of vegetation: Theory and computational aspects. Journal of Electromagnetic Waves and Applications, 10, 609-628

Ferrazzoli, P., Luzi, G., Paloscia, S., Pampaloni, P., Schiavon, G., \& Solimini, D. (1989). Comparison between the Microwave Emissivity and Backscatter Coefficient of Crops. IEEE Transactions on Geoscience and Remote Sensing, 27, 772-778

Ferrazzoli, P., Wigneron, J.P., Guerriero, L., \& Chanzy, A. (2000). Multifrequency emission of wheat: Modeling and applications. IEEE Transactions on Geoscience and Remote Sensing, 38, 2598-2607

Figa-Saldana, J., Wilson, J.J.W., Attema, E., Gelsthorpe, R., Drinkwater, M.R., \& Stoffelen, A. (2002). The advanced scatterometer (ASCAT) on the meteorological operational (MetOp) platform: A follow on for European wind scatterometers. Canadian Journal of Remote Sensing, 28, 404-412

Fung, A.K. (1994). Microwave scattering and emission models and their applications. Boston etc.: Artech House

GCOS (2008). Future Climate Change Research and Observations: GCOS, WCRP and IGBP Learning from the IPCC Fourth Assessment Report, 
GCOS-117. Workshop and Survey report. In, GCOS reports (p. 58). http://www.wmo.int/pages/prog/gcos/Publications

GCOS (2010). Implementation Plan for the Global Observing System for Climate in Support of the UNFCCC, GCOS-138. In, GCOS Reports (p. 180). http://www.wmo.int/pages/prog/gcos/Publications

Gobron, N., Pinty, B., Melin, F., Taberner, M., Verstraete, M.M., Belward, A., Lavergne, T., \& Widlowski, J.L. (2005). The state of vegetation in Europe following the 2003 drought. International Journal of Remote Sensing, 26, 2013-2020

Gobron, N., Pinty, B., Verstraete, M.M., \& Widlowski, J.L. (2000). Advanced vegetation indices optimized for up-coming sensors: Design, performance, and applications. IEEE Transactions on Geoscience and Remote Sensing, 38, 2489-2505

Grant, J.P., Wigneron, J.P., Van de Griend, A.A., Kruszewski, A., Sobjaerg, S.S., \& Skou, N. (2007). A field experiment on microwave forest radiometry: L-band signal behaviour for varying conditions of surface wetness. Remote Sensing of Environment, 109, 10-19

Gruhier, C., de Rosnay, P., Kerr, Y., Mougin, E., Ceschia, E., Calvet, J.C., \& Richaume, P. (2008). Evaluation of AMSR-E soil moisture product based on ground measurements over temperate and semi-arid regions. Geophysical Research Letters, 35

Guerriero, L., Ferrazzoli, P., \& Rahmoune, R. (2012). A synergyc view of Lband active and passive remote sensing of vegetated soil. In, 12th Specialist Meeting on Microwave Radiometry and Remote Sensing of the Environment (MicroRad), 2012 (pp. 1-3)

Hall, F.G., Townshend, J.R., \& Engman, E.T. (1995). Status of remote-sensing algorithms for estimation of land-surface state parameters. Remote Sensing of Environment, 51, 138-156

Hansen, M.C., Defries, R.S., Townshend, J.R.G., \& Sohlberg, R. (2000). Global land cover classification at $1 \mathrm{~km}$ spatial resolution using a classification tree approach. International Journal of Remote Sensing, 21, 1331-1364

Holmes, T.R.H., De Jeu, R.A.M., Owe, M., \& Dolman, A.J. (2009). Land surface temperature from Ka band $(37 \mathrm{GHz})$ passive microwave observations. Journal of Geophysical Research-Atmospheres, 114 
Immerzeel, W.W., \& Bierkens, M.F.P. (2010). Seasonal prediction of monsoon rainfall in three Asian river basins: the importance of snow cover on the Tibetan Plateau. International Journal of Climatology, 30, $1835-1842$

Jackson, T.J., Bindlish, R., Cosh, M.H., Zhao, T., Starks, P.J., Bosch, D.D., Seyfried, M., Moran, M.S., Goodrich, D.C., Kerr, Y.H., \& Leroux, D. (2012). Validation of Soil Moisture and Ocean Salinity (SMOS) Soil Moisture Over Watershed Networks in the U.S. IEEE Transactions on Geoscience and Remote Sensing, 50, 1530-1543

Jackson, T.J., Le Vine, D.M., Hsu, A.Y., Oldak, A., Starks, P.J., Swift, C.T., Isham, J.D., \& Haken, M. (1999). Soil moisture mapping at regional scales using microwave radiometry: The Southern Great Plains Hydrology Experiment. IEEE Transactions on Geoscience and Remote Sensing, 37, 2136-2151

Jackson, T.J., Schmugge, J., \& Engman, E.T. (1996). Remote sensing applications to hydrology: Soil moisture. Hydrological Sciences Journal, $41,517-530$

Kerr, Y.H., Waldteufel, P., Richaume, P., Wigneron, J.P., Ferrazzoli, P., Mahmoodi, A., Al Bitar, A., Cabot, F., Gruhier, C., Juglea, S.E., Leroux, D., Mialon, A., \& Delwart, S. (2012). The SMOS Soil Moisture Retrieval Algorithm. IEEE Transactions on Geoscience and Remote Sensing, 50, 1384-1403

Kerr, Y.H., Waldteufel, P., Wigneron, J.P., Delwart, S., Cabot, F., Boutin, J., Escorihuela, M.J., Font, J., Reul, N., Gruhier, C., Juglea, S.E., Drinkwater, M.R., Hahne, A., Martin-Neira, M., \& Mecklenburg, S. (2010). The SMOS Mission: New Tool for Monitoring Key Elements of the Global Water Cycle. Proceedings of the Ieee, 98, 666-687

Kerr, Y.H., Waldteufel, P., Wigneron, J.P., Martinuzzi, J.M., Font, J., \& Berger, M. (2001). Soil moisture retrieval from space: The Soil Moisture and Ocean Salinity (SMOS) mission. IEEE Transactions on Geoscience and Remote Sensing, 39, 1729-1735

Knowles, K.W., Savoie, M.H., Armstrong, R.L., \& Brodzik, M.J. (2012). AMSRE/Aqua Daily Global Quarter-Degree Gridded Brightness Temperatures. In. Boulder, Colorado USA: National Snow and Ice Data Center. Digital media 
Kornelsen, K.C., \& Coulibaly, P. (2013). Advances in soil moisture retrieval from synthetic aperture radar and hydrological applications. Journal of Hydrology, 476, 460-489

Kuenzer, C., Zhao, D., Scipal, K., Sabel, D., Naeimi, V., Bartalis, Z., Hasenauer, S., Mehl, H., Dech, S., \& Wagner, W. (2009). El Nino southern oscillation influences represented in ERS scatterometer-derived soil moisture data. Applied Geography, 29, 463-477

Lacava, T., Matgen, P., Brocca, L., Bittelli, M., Pergola, N., Moramarco, T., \& Tramutoli, V. (2012). A First Assessment of the SMOS Soil Moisture Product With In Situ and Modeled Data in Italy and Luxembourg. IEEE Transactions on Geoscience and Remote Sensing, PP, 1-11

Le Vine, D.M., Meneghini, R., Lang, R.H., \& Seker, S.S. (1983). Scattering from arbitrarily oriented dielectric disks in the physical optics regime. Journal of the Optical Society of America, 73, 1255-1262

Lee, K.H., \& Anagnostou, E.N. (2004). A combined passive/active microwave remote sensing approach for surface variable retrieval using Tropical Rainfall Measuring Mission observations. Remote Sensing of Environment, 92, 112-125

Legates, D.R., Mahmood, R., Levia, D.F., DeLiberty, T.L., Quiring, S.M., Houser, C., \& Nelson, F.E. (2010). Soil moisture: A central and unifying theme in physical geography. Progress in Physical Geography

Li, L., Njoku, E.G., Im, E., Chang, P.S., \& Germain, K.S. (2004). A preliminary survey of radio-frequency interference over the U.S. in Aqua AMSR-E data. IEEE Transactions on Geoscience and Remote Sensing, 42, 380-390

Liu, Y.Y., Parinussa, R.M., Dorigo, W.A., De Jeu, R.A.M., Wagner, W., van Dijk, A.I.J.M., McCabe, M.F., \& Evans, J.P. (2011). Developing an improved soil moisture dataset by blending passive and active microwave satellitebased retrievals. Hydrology and Earth System Sciences, 15, 425-436

Liu, Y.Y., van Dijk, A., de Jeu, R.A.M., \& Holmes, T.R.H. (2009). An analysis of spatiotemporal variations of soil and vegetation moisture from a 29year satellite-derived data set over mainland Australia. Water Resources Research, 45 
Loew, A., Holmes, T., \& de Jeu, R. (2009). The European heat wave 2003: Early indicators from multisensoral microwave remote sensing? Journal of Geophysical Research-Atmospheres, 114

Loveland, T.R., \& Belward, A.S. (1997). The IGBP-DIS global $1 \mathrm{~km}$ land cover data set, DISCover: first results. International Journal of Remote Sensing, $18,3291-3295$

Loveland, T.R., Reed, B.C., Brown, J.F., Ohlen, D.O., Zhu, Z., Yang, L., \& Merchant, J.W. (2000). Development of a global land cover characteristics database and IGBP DISCover from $1 \mathrm{~km}$ AVHRR data. International Journal of Remote Sensing, 21, 1303-1330

Makridakis, S., S., W., R., H., \& Y., C. (1998). Forecasting Methods and Applications. 3rd ed. New York: John Wiley \& Sons, Inc.

Martin, R.D., Asrar, G., \& Kanemasu, E.T. (1989). C-band scatterometer measurements of a tallgrass prairie. Remote Sensing of Environment, 29, 281-292

Martinez-Fernandez, J., \& Ceballos, A. (2005). Mean soil moisture estimation using temporal stability analysis. Journal of Hydrology, 312, 28-38

Masson, V., Champeaux, J.L., Chauvin, F., Meriguet, C., \& Lacaze, R. (2003). A global database of land surface parameters at $1-\mathrm{km}$ resolution in meteorological and climate models. Journal of Climate, 16, 1261-1282

Mätzler, C. (1994). Microwave (1-100 GHZ) dielectric model of leaves. IEEE Transactions on Geoscience and Remote Sensing, 32, 947-949

McMullan, K.D., Brown, M.A., Martin-Neira, M., Rits, W., Ekholm, S., Marti, J., \& Lemanczyk, J. (2008). SMOS: The payload. IEEE Transactions on Geoscience and Remote Sensing, 46, 594-605

Mironov, V.L., De Roo, R.D., \& Savin, I.V. (2010). Temperature-Dependable Microwave Dielectric Model for an Arctic Soil. IEEE Transactions on Geoscience and Remote Sensing, 48, 2544-2556

Misra, S., \& Ruf, C.S. (2012). Analysis of Radio Frequency Interference Detection Algorithms in the Angular Domain for SMOS. IEEE Transactions on Geoscience and Remote Sensing, PP, 1-10 
Mladenova, I.E., Jackson, T.J., Njoku, E., Bindlish, R., Chan, S., Cosh, M.H., Holmes, T.R.H., de Jeu, R.A.M., Jones, L., Kimball, J., Paloscia, S., \& Santi, E. (2014). Remote monitoring of soil moisture using passive microwavebased techniques - Theoretical basis and overview of selected algorithms for AMSR-E. Remote Sensing of Environment, 144, 197-213

Mo, T., Choudhury, B.J., Schmugge, T.J., Wang, J.R., \& Jackson, T.J. (1982). A Model for Microwave Emission From Vegetation-Covered Fields. Journal of Geophysical Research-Oceans, 87, 11229-11237

Mo, T., Schmugge, T.J., \& Wang, J.R. (1987). Calculations of the microwave brightness temperature of rough soil surfaces - bare field. IEEE Transactions on Geoscience and Remote Sensing, 25, 47-54

Monteith, J., \& Unsworth, M. (2008). Principles of environmental physics. (Third edition ed.). Amsterdam etc.: Elsevier

Naeimi, V., Scipal, K., Bartalis, Z., Hasenauer, S., \& Wagner, W. (2009). An Improved Soil Moisture Retrieval Algorithm for ERS and METOP Scatterometer Observations. IEEE Transactions on Geoscience and Remote Sensing, 47, 1999-2013

Njoku, E.G., Jackson, T.J., Lakshmi, V., Chan, T.K., \& Nghiem, S.V. (2003). Soil moisture retrieval from AMSR-E. IEEE Transactions on Geoscience and Remote Sensing, 41, 215-229

O'Neill, P.E., Chauhan, N.S., \& Jackson, T.J. (1996). Use of active and passive microwave remote sensing for soil moisture estimation through corn. International Journal of Remote Sensing, 17, 1851-1865

Owe, M., de Jeu, R., \& Holmes, T. (2008). Multisensor historical climatology of satellite-derived global land surface moisture. Journal of Geophysical Research-Earth Surface, 113

Owe, M., \& Van de Griend, A.A. (2001). On the relationship between thermodynamic surface temperature and high-frequency $(37 \mathrm{GHz})$ vertically polarized brightness temperature under semi-arid conditions. International Journal of Remote Sensing, 22, 3521-3532

Piles, M., Entekhabi, D., \& Camps, A. (2009). A Change Detection Algorithm for Retrieving High-Resolution Soil Moisture From SMAP Radar and Radiometer Observations. IEEE Transactions on Geoscience and Remote Sensing, 47, 4125-4131 
Ran, Y.H., Li, X., Lu, L., \& Li, Z.Y. (2011). Large-scale land cover mapping with the integration of multi-source information based in the DempsterShafer theory. International Journal of Geographical Information Science, in press

Reynolds, C.A., Jackson, T.J., \& Rawls, W.J. (2000). Estimating soil waterholding capacities by linking the Food and Agriculture Organization Soil map of the world with global pedon databases and continuous pedotransfer functions. Water Resource Research, 36, 3653-3662

Rignot, E., \& Way, J.B. (1994). Monitoring Freeze-Thaw Cycles along NorthSouth Alaskan Transects using ERS-1 SAR. Remote Sensing of Environment, 49, 131-137

Rodell, M., Houser, P.R., Jambor, U., Gottschalck, J., Mitchell, K., Meng, C.J., Arsenault, K., Cosgrove, B., Radakovich, J., Bosilovich, M., Entin, J.K., Walker, J.P., Lohmann, D., \& Toll, D. (2004). The global land data assimilation system. Bulletin of the American Meteorological Society, 85, 381-394

Rudiger, C., Calvet, J.C., Gruhier, C., Holmes, T.R.H., de Jeu, R.A.M., \& Wagner, W. (2009). An Intercomparison of ERS-Scat and AMSR-E Soil Moisture Observations with Model Simulations over France. Journal of Hydrometeorology, 10, 431-447

Saatchi, S.S., Levine, D.M., \& Lang, R.H. (1994). Microwave Backscattering and Emission Model for Grass Canopies. IEEE Transactions on Geoscience and Remote Sensing, 32, 177-186

Saatchi, S.S., Njoku, E.G., \& Wegmuller, U. (1995a). Synergism of active and passive microwave data for estimating bare soil surface moisture. In B.J. Choudhury, Kerr Y.H., Njoku E.G., Pampaloni P. (Ed.), Passive Microwave Remote Sensing of Land-Atmosphere Interactions (pp. 205-224). UtrechtTokyo: VSP

Saatchi, S.S., vanZyl, J.J., \& Asrar, G. (1995b). Estimation of canopy water content in Konza Prairie grasslands using synthetic aperture radar measurements during FIFE. Journal of Geophysical ResearchAtmospheres, 100, 25481-25496

Sahoo, A.K., Houser, P.R., Ferguson, C., Wood, E.F., Dirmeyer, P.A., \& Kafatos, M. (2008). Evaluation of AMSR-E soil moisture results using the in-situ 
data over the Little River Experimental Watershed, Georgia. Remote Sensing of Environment, 112, 3142-3152

Saleh, K., Wigneron, J.P., de Rosnay, P., Calvet, J.C., Escorihuela, M.J., Kerr, Y., \& Waldteufel, P. (2006a). Impact of rain interception by vegetation and mulch on the L-band emission of natural grass. Remote Sensing of Environment, 101, 127-139

Saleh, K., Wigneron, J.P., de Rosnay, P., Calvet, J.C., \& Kerr, Y. (2006b). Semiempirical regressions at L-band applied to surface soil moisture retrievals over grass. Remote Sensing of Environment, 101, 415-426

Sánchez, N., Martínez-Fernández, J., Scaini, A., \& Pérez-Gutiérrez, C. (2012). Validation of the SMOS L2 Soil Moisture Data in the REMEDHUS Network (Spain). IEEE Transactions on Geoscience and Remote Sensing, $50,1602-1611$

Schmugge, T., Gloersen, T.T., Wilheit, T., \& Geiger, F. (1974). Remote sensing of soil moisture with microwave radiometers. Journal of Geophysical Research, 79, 317-323

Schmugge, T., \& Jackson, T.J. (1994). Mapping Surface Soil-Moisture with Microwave Radiometers. Meteorology and Atmospheric Physics, 54, 213223

Schmugge, T.J. (1983). Remote sensing of soil moisture - recent advances. IEEE Transactions on Geoscience and Remote Sensing, 21, 336-344

Schmugge, T.J., Wang, J.R., \& Asrar, G. (1988). Results from the push broom microwave radiometer flights over the Konza prairie in 1985. IEEE Transactions on Geoscience and Remote Sensing, 26, 590-597

Schneider, K., Huisman, J.A., Breuer, L., Zhao, Y., \& Frede, H.G. (2008). Temporal stability of soil moisture in various semi-arid steppe ecosystems and its application in remote sensing. Journal of Hydrology, $359,16-29$

Schwank, M., Stahli, M., Wydler, H., Leuenberger, J., Matzler, C., \& Fluhler, H. (2004). Microwave L-band emission of freezing soil. IEEE Transactions on Geoscience and Remote Sensing, 42, 1252-1261 
Scipal, K., Drusch, M., \& Wagner, W. (2008). Assimilation of a ERS scatterometer derived soil moisture index in the ECMWF numerical weather prediction system. Advances in Water Resources, 31, 1101-1112

Skou, N., Balling, J.E., Sobjarg, S.S., \& Kristensen, S.S. (2010). Surveys and analysis of rfi in the smos context. In, IEEE International Geoscience and Remote Sensing Symposium (IGARSS), 2010 (pp. 2011-2014)

Song, J.H., Kang, H.S., Byun, Y.H., \& Hong, S.Y. (2010). Effects of the Tibetan Plateau on the Asian summer monsoon: a numerical case study using a regional climate model. International Journal of Climatology, 30, 743-759

Su, Z., de Rosnay, P., Wen, J., Wang, L., \& Zeng, Y. (2013). Evaluation of ECMWF's soil moisture analyses using observations on the Tibetan Plateau. Journal of Geophysical Research: Atmospheres, 118, 5304-5318

Su, Z., Wen, J., Dente, L., van der Velde, R., Wang, L., Ma, Y., Yang, K., \& Hu, Z. (2011). The Tibetan Plateau observatory of plateau scale soil moisture and soil temperature (Tibet-Obs) for quantifying uncertainties in coarse resolution satellite and model products. Hydrology and Earth System Sciences, 15, 2303-2316

Theis, S.W., Blanchard, A.J., \& Blanchard, B.J. (1986). Utilization of active microwave roughness measurements to improve passive microwave soil moisture estimates over bare soils. IEEE Transactions on Geoscience and Remote Sensing, GE-24, 334-339

Ulaby, F.T. (1974). Radar measurement of soil moisture content. Ieee Transactions on Antennas and Propagation, 22, 257-265

Ulaby, F.T., Moore, R.K., \& Fung, A.K. (1982). Microwave remote sensing : active and passive : Vol. II radar remote sensing and surface scattering and emission theory. Reading etc.: Addison-Wesley

Vachaud, G., Silans, A.P.D., Balabanis, P., \& Vauclin, M. (1985). Temporal Stability of Spatially Measured Soil Water Probability Density Function. Soil Science Society of America Journal, 49, 822-828

Van de Griend, A.A. (2001). The effective thermodynamic temperature of the emitting surface at $6.6 \mathrm{GHz}$ and consequences for soil moisture monitoring from space. IEEE Transactions on Geoscience and Remote Sensing, 39, 1673-1679 
Wagner, W., Bloschl, G., Pampaloni, P., Calvet, J.C., Bizzarri, B., Wigneron, J.P., \& Kerr, Y. (2007a). Operational readiness of microwave remote sensing of soil moisture for hydrologic applications. Nordic Hydrology, 38, 1-20

Wagner, W., Lemoine, G., \& Rott, H. (1999). A Method for Estimating Soil Moisture from ERS Scatterometer and Soil Data. Remote Sensing of Environment, 70, 191-207

Wagner, W., Naeimi, V., Scipal, K., de Jeu, R., \& Martinez-Fernandez, J. (2007b). Soil moisture from operational meteorological satellites. Hydrogeology Journal, 15, 121-131

Wang, J.R., \& Choudhury, B.J. (1981). Remote Sensing of Soil Moisture Content, Over Bare Field at $1.4 \mathrm{GHz}$ Frequency. Journal of Geophysical Research-Oceans, 86

Wang, J.R., \& Schmugge, T.J. (1980). An Empirical Model for the Complex Dielectric Permittivity of Soils as a Function of Water Content. IEEE Transactions on Geoscience and Remote Sensing, GE-18, 288-295

Wang, Q., van der Velde, R., Su, Z., \& Wen, J. (2015). Aquarius L-band scatterometer and radiometer observations over a Tibetan Plateau site. International Journal of Applied Earth Observation and Geoinformation

Wang, Y.X., Zhao, P., Yu, R.C., \& Rasul, G. (2010). Inter-decadal variability of Tibetan spring vegetation and its associations with eastern China spring rainfall. International Journal of Climatology, 30, 856-865

Wen, J., Su, Z., \& Ma, Y.M. (2003). Determination of land surface temperature and soil moisture from Tropical Rainfall Measuring Mission/Microwave Imager remote sensing data. Journal of Geophysical Research-Atmospheres, 108

Wigneron, J.P., Calvet, J.C., Pellarin, T., Van de Griend, A.A., Berger, M., \& Ferrazzoli, P. (2003). Retrieving near-surface soil moisture from microwave radiometric observations: current status and future plans. Remote Sensing of Environment, 85, 489-506

Wigneron, J.P., Kerr, Y., Waldteufel, P., Saleh, K., Escorihuela, M.J., Richaume, P., Ferrazzoli, P., de Rosnay, P., Gurney, R., Calvet, J.C., Grant, J.P., Guglielmetti, M., Hornbuckle, B., Matzler, C., Pellarin, T., \& Schwank, M. (2007). L-band Microwave Emission of the Biosphere (L-MEB) Model: 
Description and calibration against experimental data sets over crop fields. Remote Sensing of Environment, 107, 639-655

Wigneron, J.P., Laguerre, L., \& Kerr, Y.H. (2001). A simple parameterization of the L-band microwave emission from rough agricultural soils. IEEE Transactions on Geoscience and Remote Sensing, 39, 1697-1707

$\mathrm{Wu}$, J. (2010). Soil moisture temporal stability and its application in remote sensing products validation. In (p. 92). Enschede: University of Twente, Faculty of Geo-Information and Earth Observation (ITC)

Xie, H., Ye, J.S., Liu, X.M., \& E, C.Y. (2010). Warming and drying trends on the Tibetan Plateau (1971-2005). Theoretical and Applied Climatology, 101, 241-253

Yoshikawa, K., \& Overduin, P.P. (2005). Comparing unfrozen water content measurements of frozen soil using recently developed commercial sensors. Cold Regions Science and Technology, 42, 250-256

You, Q.L., Kang, S.C., Pepin, N., Flugel, W.A., Sanchez-Lorenzo, A., Yan, Y.P., \& Zhang, Y.J. (2010). Climate warming and associated changes in atmospheric circulation in the eastern and central Tibetan Plateau from a homogenized dataset. Global and Planetary Change, 72, 11-24

Zhan, X.W., Houser, P.R., Walker, J.P., \& Crow, W.T. (2006). A method for retrieving high-resolution surface soil moisture from hydros L-band radiometer and radar observations. IEEE Transactions on Geoscience and Remote Sensing, 44, 1534-1544

Zhao, D.M., Kuenzer, C., Fu, C.B., \& Wagner, W. (2008). Evaluation of the ERS scatterometer-derived soil water index to monitor water availability and precipitation distribution at three different scales in China. Journal of Hydrometeorology, 9, 549-562 
References 


\section{Appendix A}

\section{Fieldwork report - Maqu monitoring network}

The area selected for the installation of an extensive soil moisture monitoring network is located to the South of Maqu city, on the border between Gansu and Sichuan province, in China. The network is on the north-eastern fringe of the Tibetan Plateau $\left(33^{\circ} 30^{\prime}-34^{\circ} 15^{\prime} \mathrm{N}\right.$, $101^{\circ} 38^{\prime}-102^{\circ} 45^{\prime} \mathrm{E}$ ) and at the first major meander of the Yellow River. It covers the large valley of the river and the surrounding hills, characterised by a uniform land cover of short grassland used for grazing by sheep and yaks. In this area the elevation ranges between $3430 \mathrm{~m}$ and $3750 \mathrm{~m}$ a.s.l. Figure A.1 shows the typical landscape of the area (hills, valleys, river, wetlands, grassland and bare areas). Wetlands, with typically organic soils, characterise a large part of the valley, while silt loam soils can be found on the hills. According to the Koeppen Classification System, the climate of this region is defined as wet and cold, with dry winters and rainy summers due to the monsoon.

The installation of the soil moisture and soil temperature probes started in May 2008 at the sites CST_01-05 and was concluded at the end of June 2008 at all the other sites. Therefore since July 2008 the complete network is in operation.

The network covers an area of approximately $80 \mathrm{~km} \mathrm{x} 40 \mathrm{~km}$ and the sites were selected in order to monitor the area extensively at different altitudes and for different soil characteristics. 11 monitoring sites were set up in the valleys of the Yellow River and 
Black River (CST_01, CST_02 NST_01, NST_02, NST_06, NST_07, NST_08, NST_09, NST_12, NST_13, NST_14), 3 sites in the valleys between hills (CST_03, CST_04, CST_05), 4 sites on steep hill slopes (NST_03, NST_05, NST_10, NST_15) and 2 sites in wetlands (NST_04, NST_11).

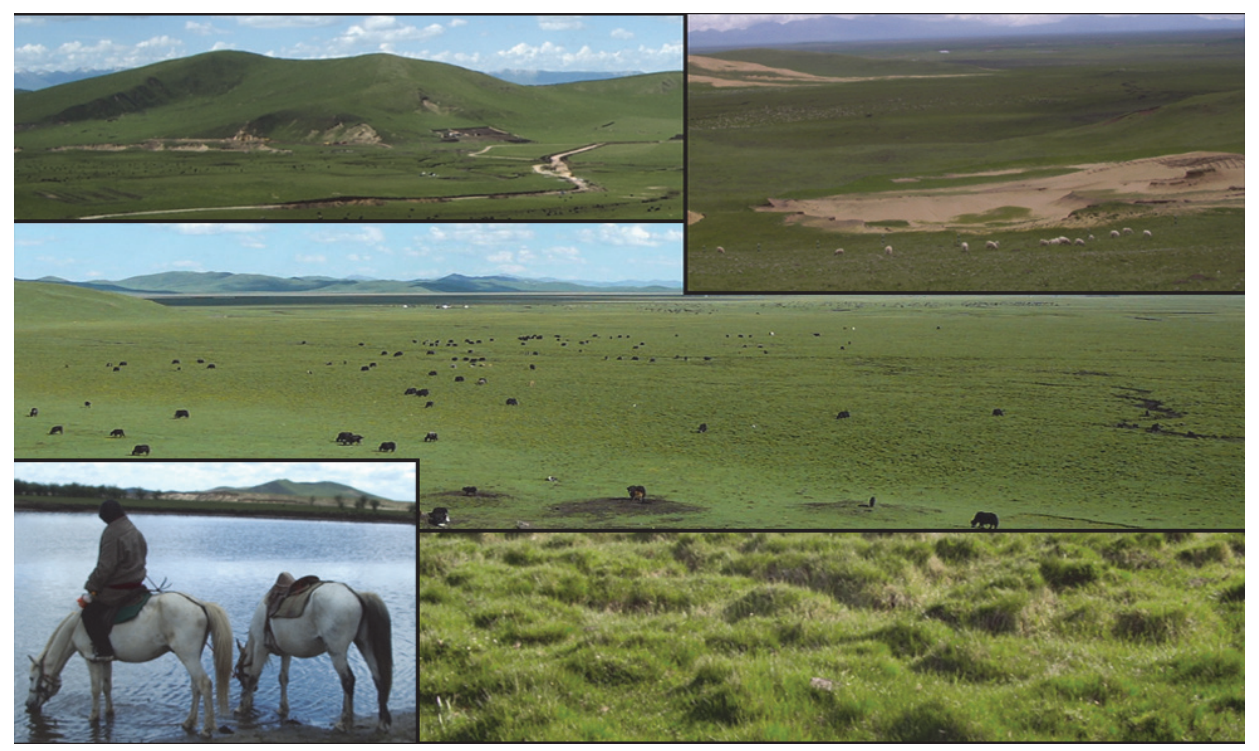

Figure A.1 Typical landscape of Maqu area: hills (top left), grassland and bare areas (top right), river valleys (centre), Yellow River (bottom left), wetlands (bottom right).

During the installation, soil samples were collected in order to analyse bulk density, particle size distribution and organic matter content. The samples for particle size and organic matter were collected at a depth between 5 and $15 \mathrm{~cm}$. A laser scanner (Mastersizer S Ver. 2.18 by Malvern Instruments Ltd.) was employed to estimate the soil particle size distribution and the standard method for the organic matter content. Soil sample rings (aluminium cylinders of known volume) were collected at $5 \mathrm{~cm}$ depth and oven dried at $105^{\circ} \mathrm{C}$ to estimate the bulk density (i.e. dry soil mass in a known volume). When the soil profile showed a variation at deeper layers, the sample collection and the analyses were repeated for the second horizon as well. 
Most of the monitoring sites are located in silt loam soils (which is the most common soil in the area), except NST_09 characterised by sandy loam soil and NST_08 by loam-silt loam soil. The wetland locations NST_04 and NST_11 have the highest organic matter content (above $130 \mathrm{~g} / \mathrm{kg}$ ), the locations NST_03 and NST_15 have about $50 \mathrm{~g}$ of organic matter per $\mathrm{kg}$ of soil and all the other sites have a low organic content.

Soil moisture and soil temperature are monitored at each station at different depths. At 7 out of the 20 sites 5 probes measure data at 5 , $10,20,40$ and $80 \mathrm{~cm}$ depth (CST_01-05, NST_01, NST_12), at 4 sites 4 different depths are monitored down to $40 \mathrm{~cm}$ (NST_05, NST_06, NST_10, NST_13) and at all the other sites data are collected only at 5 and $10 \mathrm{~cm}$ depth (NST_02, NST_03, NST_04, NST_07, NST_08, NST_09, NST_11, NST_14, NST_15).

Figure A.2 shows the land cover in June 2008 and Figure A.3 the landscape of all the sites.

Each network station consists of one $\mathrm{Em} 50 \mathrm{ECH}_{2} \mathrm{O}$ data logger (by Decagon), which records the data collected by two to five EC-TM $\mathrm{ECH}_{2} \mathrm{O}$ probes (by Decagon) able to measure both soil moisture and soil temperature.

For the installation, a deep hole in the soil was dug and the probes were installed on one of the hole walls, at different depths and with the pins in horizontal direction. Then probes and data logger (closed in a box) were completely buried (see Figure A.4).

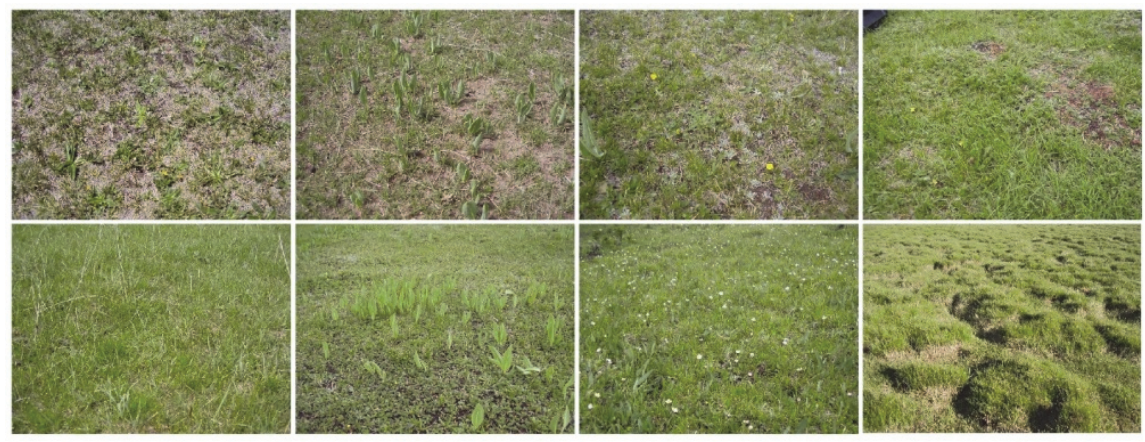

Figure A.2 Land cover in Maqu area at the end of June 2008. 

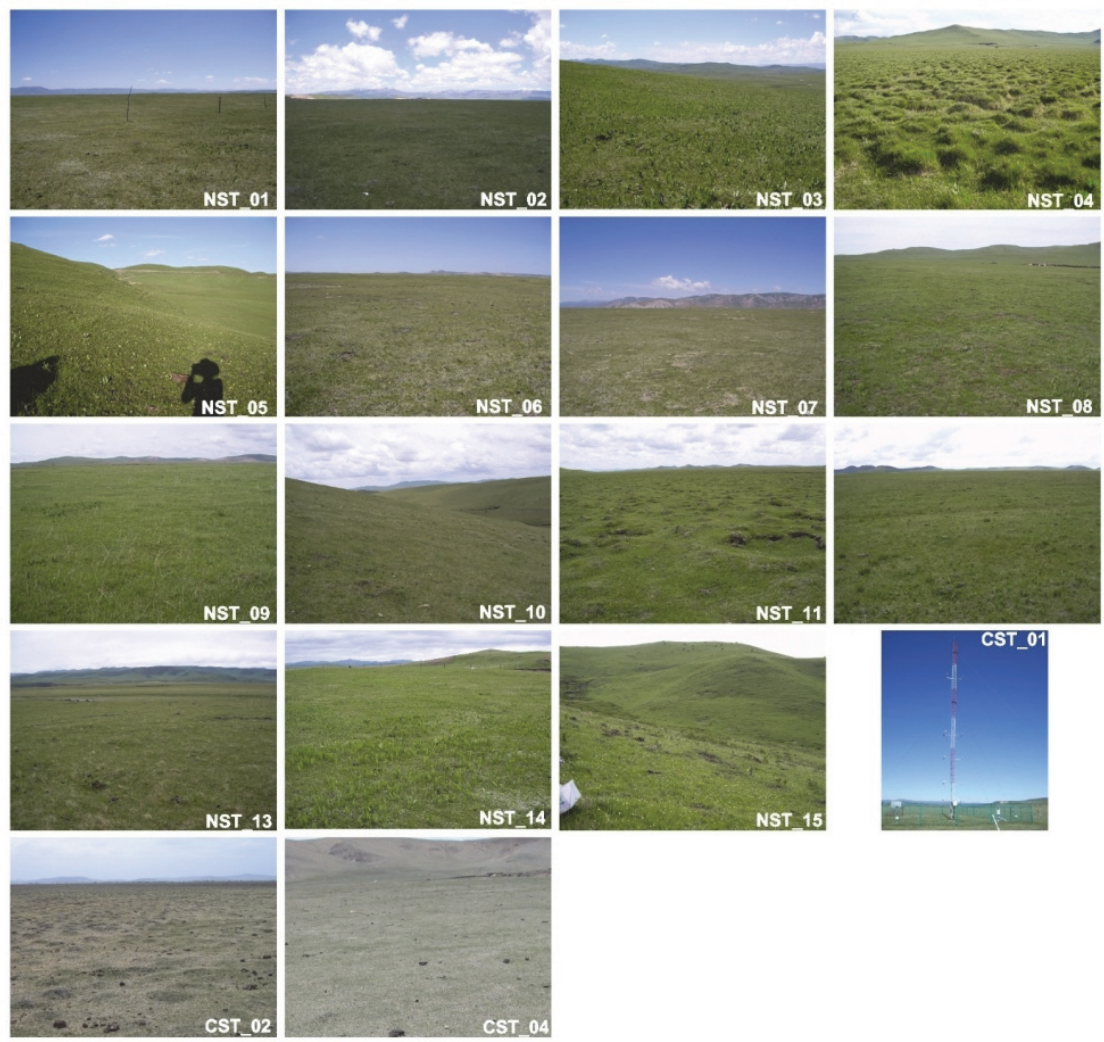

Figure A.3 Landscape of all the network sites (except CTS_03 and CST_05)

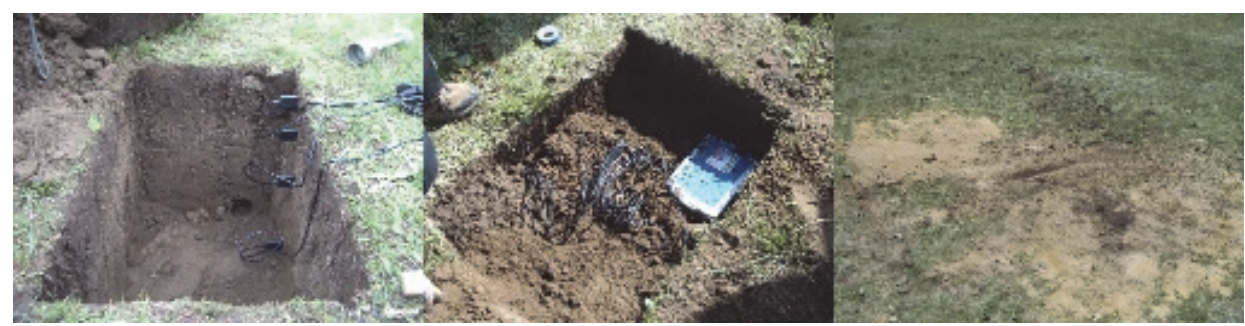

Figure A.4 Installation procedure.

The data logger was set to store data every 15 minutes, which generates a data volume that can be stored by the data logger memory capacity of a bit longer than one year. The data logger batteries instead last much longer (depending on the temperature and humidity level in the data logger). 
To ensure complete data continuity, the data are downloaded twice per year: at the beginning of the monsoon season (in May) and at the end (in October).

EC-TM $\mathrm{ECH}_{2} \mathrm{O}$ probe consists of 3 flat pins $5.2 \mathrm{~cm}$ long. It is a capacitance sensor measuring the dielectric permittivity of the soil surrounding the pins. The dielectric permittivity is then converted in volumetric soil moisture according to a standard calibration equation. The soil temperature is measured using a thermistor located on the same probe.

A specific calibration of the probes was needed for the soil type of Maqu area.

$\mathrm{EC}-\mathrm{TM} \mathrm{ECH}_{2} \mathrm{O}$ probes estimate the volumetric water content of the soil by measuring the dielectric constant of the soil. However the dielectric properties of the soils depend on soil texture and salinity. Decagon has determined a generic calibration equation (applied by default by the data logger), which is valid for all fine textured mineral soils with an accuracy of approximately $\pm 3 \%$. This accuracy can be increased to $1-2 \%$, performing a soil-specific calibration.

For this reason about 5-6 kg of soil were collected in each location at a depth of about 5-15 cm (as well as at deeper layers, in case the soil profile was different) in order to carry out a laboratory specific calibration, following the instruction guide provided by Decagon.

The following steps were carried out for each sample:

1) The soil was air dried.

2) The soil was packed into the calibration container at approximately the field bulk density.

3) The $\mathrm{ECH}_{2} \mathrm{O}$ probe was inserted in the soil.

4) A probe reading was recorded.

5) A soil sample ring was collected from the calibration container.

6) $200-300 \mathrm{~mL}$ of water were added to the soil.

7) The soil was carefully mixed by hands or a trowel until the mixture was again homogenous.

8) Steps 2 to 7 were repeated until the soil was saturated (collecting in total about 6-7 samples).

9) The soil sample rings were weighed and oven dried at $105^{\circ} \mathrm{C}$ for 24 hours.

10) Then the dry soil sample rings were weighed again. 
11) The volumetric soil moisture was computed [(wet_weightdry_weight)/dry_weight $\mathrm{x}$ bulk density]

12) The volumetric soil moisture measured by rings was plotted against the probe outputs and the best fit was found.

As the soil texture is quite homogeneous at soil upper layers in all the sites, the main difference between the sites is the organic matter content. Moreover in most of the sites the soil profile is homogeneous down to more than $40 \mathrm{~cm}$ depth. In the sites where an inhomogeneous profile was found (NST_01, NST_05 and NST_12), a specific calibration was carried for the soil deeper layers. Therefore, the calibration data were grouped according to the organic matter content and the depth of sampling, obtaining 3 different linear calibration equations for the following groups:

1) Silt loam soil with a relatively low organic content: NST_01, NST_02, NST_03, NST_05, NST_06, NST_07, NST_08, NST_09, NST_10, NST_12, NST_13, NST_14 and CST_01, CST_02, CST_03, CST_04 and CST_05;

2) Silt loam soil with a high organic content: NST_04, NST_11, NST_15;

3) Deep layers (probes at 40 and $80 \mathrm{~cm}$ depth): NST_01, NST_05, NST_12 and CST_01-05.

Though NST_03 has a relatively higher organic content, the calibration data fits better within the first group than in the second.

The calibration data of NST_09 and NST_10 fit very well with the calibration equation of the silt loam soils, though in these areas the soil is different.

The calibration was not carried out for CST_01-05. Moreover the soil texture and organic matter content of these sites is not available. However, they are very probably located in silt loam soils with low organic matter content. For this reason the calibration equation found for the first group has been applied also to the probes at 5, 10 and $20 \mathrm{~cm}$ depth of these sites and the equation of the third group to the probes at 40 and $80 \mathrm{~cm}$ depth.

The plot of the volumetric soil moisture measured by rings against the soil moisture measured by the probes during the calibration process is reported in Figure A.5 with the fit lines, the equations and 
$R^{2}$, for the three groups. As a reference the 1:1 line is also included (which corresponds to the default calibration).

Using the default calibration equation, the probes generally underestimates the volumetric soil moisture content in all Maqu stations. The slope of the new calibration equations is not very different from each other and from the default calibration. The soil specific calibration was then useful to reduce an almost constant bias of the measurements.

In conclusion, the calibration has led to a decrease of the RMSE between the volumetric soil moisture measured by the rings and that measured by the probes from 0.06 to $0.02 \mathrm{~m}^{3} \mathrm{~m}^{-3}$.

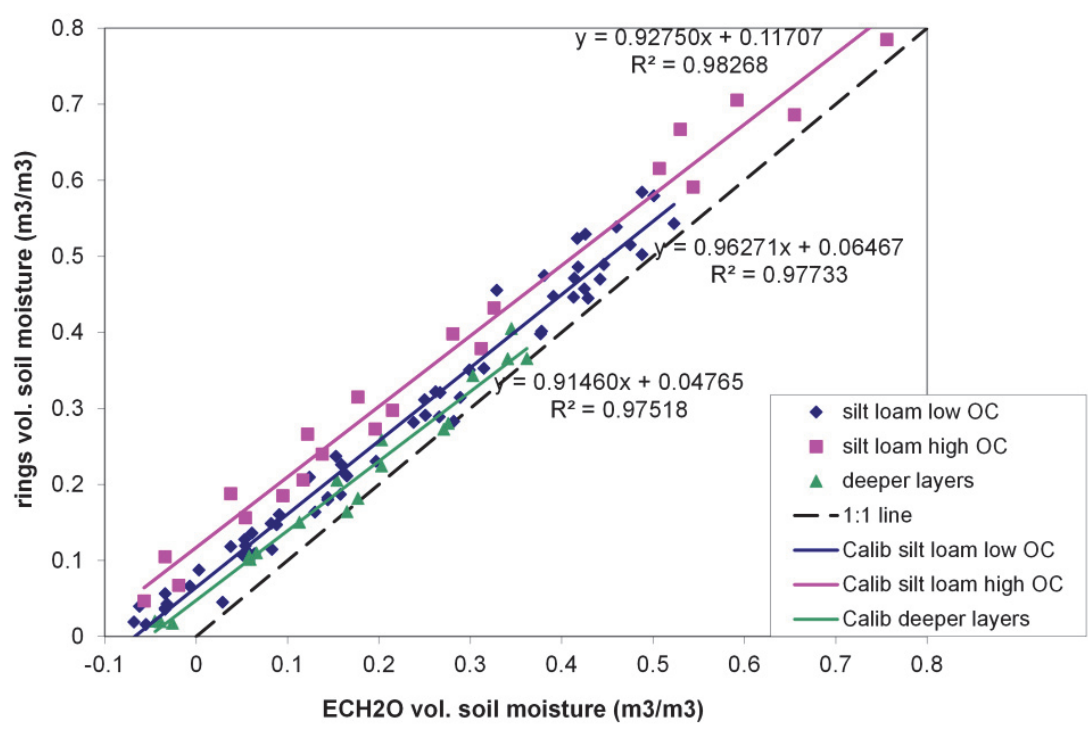

Figure A.5 Results of the soil specific calibration of $\mathrm{ECH}_{2} \mathrm{O}$ probes.

The data show an interesting trend from dry to wet and from cold to warm conditions responding to the weather events. Most of the probes and dataloggers have been working properly. Only few data are missing and the main reasons are: malfunctioning probes due to mice bites on the cables or not perfect connection to the datalogger or malfunctioning dataloggers. 
The quality of the data has been checked by comparing their trends with meteorological data and with soil moisture satellite products.

A micrometeorological tower of CAREERI-CAS is located next to station CST_01, providing, among the other parameters, precipitation data accumulated every 10 minutes. Volumetric soil moisture and soil temperature measured at different depths by CST_01 station from middle of May to end of August 2008 are compared with precipitation measured at the tower (unfortunately rainfall data are missing between 4 and 17 July 2008). The result is shown in Figure A.6.

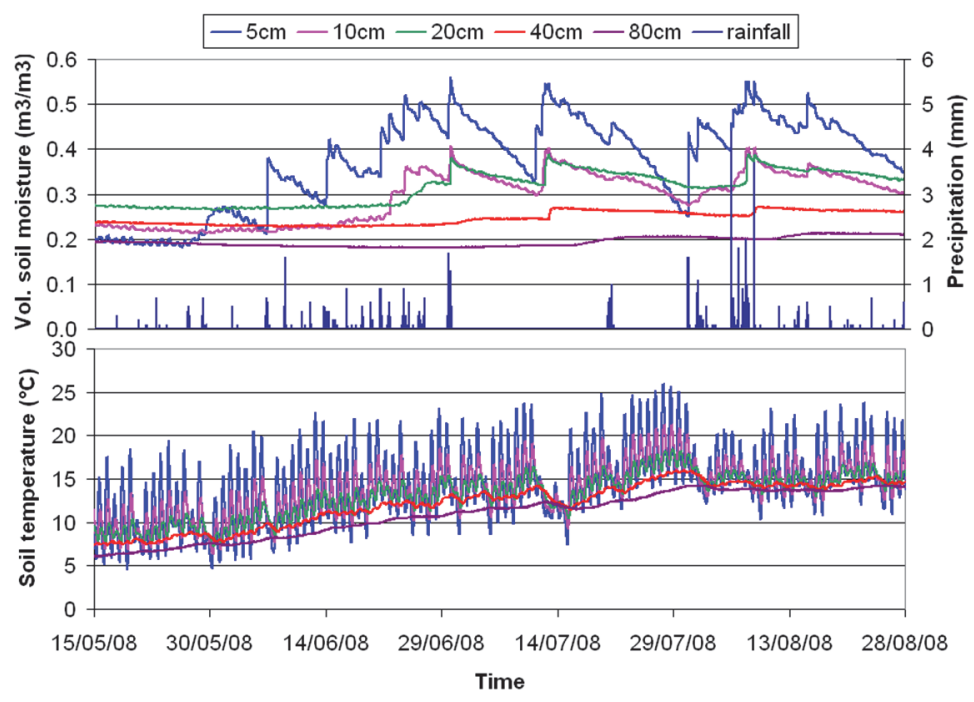

Figure A.6 CST_01 volumetric soil moisture and soil temperature at different depths compared with precipitation data collected at CARRERI-CAS micrometeorological tower.

There is a good agreement between $5 \mathrm{~cm}$ soil moisture trend and precipitation, showing a good response of the $\mathrm{ECH}_{2} \mathrm{O}$ probes to soil wetting and drying. The soil layers at 10 and $20 \mathrm{~cm}$ depth are dryer and show a smoother trend than the surface layer, as well as in agreement with it. The lower layers, at 40 and $80 \mathrm{~cm}$ depth, are even dryer, meaning that the water table in this area is much lower than $80 \mathrm{~cm}$. At these depths, the soil moisture slightly increases only after about two months from the beginning of the rainy season. The soil 
temperature, especially at 5 and $10 \mathrm{~cm}$ depth, shows a reasonable decrease in correspondence of heavy rainfall. The whole soil profile warms up during the monsoon season.

Figure A.7 shows the calibrated volumetric soil moisture measured at $5 \mathrm{~cm}$ depth in all the stations from 1 July to 31 August 2008. There is a large temporal variability of soil moisture in Maqu in this period of the year. After winter the soil is dry and the soil moisture is very sensitive to rainfall events especially at $5 \mathrm{~cm}$ depth, increasing rapidly the water content without reaching the saturation. As soon the rainfall event ends, the soil surface dries out due to the warm temperatures reached during day time.

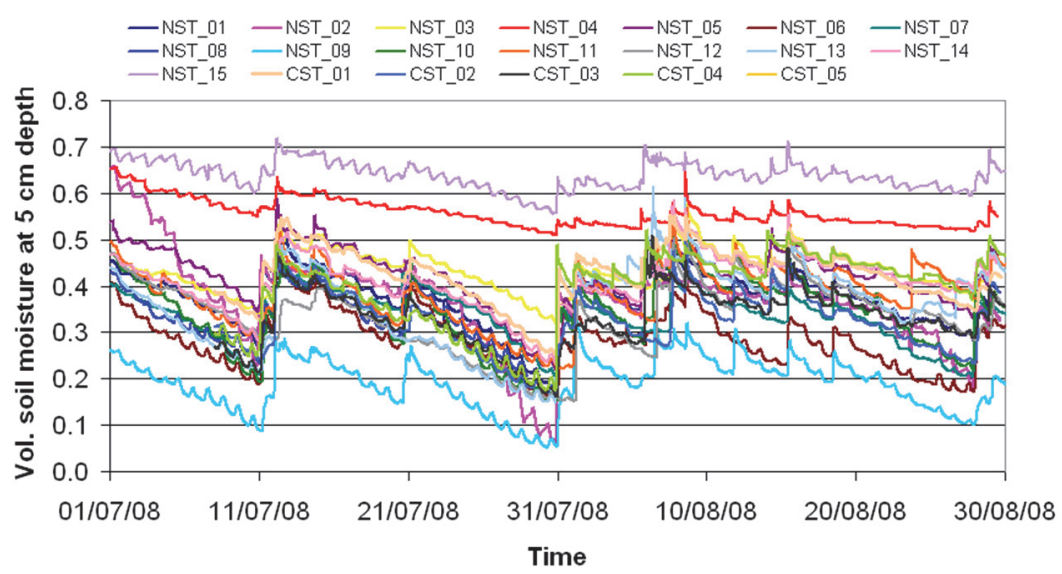

Figure A.7 Calibrated volumetric soil moisture measured at $5 \mathrm{~cm}$ depth in the 20 sites of Maqu network.

The data show also an interesting spatial variability in the area, mainly due to the soil texture differences. The two time series which show very high values of soil moisture in Figure A.7 corresponds to soils with higher organic content (stations NST_04 and NST_15). A similar trend was expected for station NST_11 but this is not the case. The time series with lower soil moisture values corresponds to station NST_09 characterised by a sandy loam soil. All the other time series in between these extremes are collected in silt loam soils with low organic content. Their variability is then due to topography 
Fieldwork report: Maqu monitoring network

differences between the station locations, hill slope or valley more or less exposed to the sunlight. 


\section{Appendix B}

\section{Comparison of different methods to estimate the surface temperature}

This chapter is based on:

Dente L., Ferrazzoli P., Su Z., van der Velde R., Guerriero L. (2014). Combined use of active and passive microwave data to constrain a discrete scattering model. Remote Sensing of Environment, 155, 222-238

Three different methods were compared with the one described in Section 6.2.5 to estimate the surface temperature, in order to evaluate the uncertainty introduced by this variable: i) using the in situ measurements of soil temperature at $5 \mathrm{~cm}$ depth, ii) using the in situ measurements of long wave upward radiation, and iii) using the ERA Interim-land dataset.

The first was obtained through harmonic equations applied on the soil temperature measured at deeper layers to extrapolate the temperature near the surface. The thickness of the soil layer which determines the surface emissivity is thought to be only several tenths of a wavelength thick (Schmugge 1983), and it is inversely related to the average moisture content of the layer. For this reason, the thickness of the emitting layer was assumed to be not deeper than $1 \mathrm{~cm}$ and it was estimated with this method. Firstly, the model described in (Monteith and Unsworth 2008) was used to describe the temporal variations of soil temperature for different depths. It 
was possible to disregard the diurnal variations of soil temperature and to limit the analysis to the annual variations because the AMSR-E data considered in this study were collected at the same time of the day. Considering the ground as a semi-infinite homogeneous solid with constant thermal properties, the soil temperature at time $t$ and depth $z, T(z, t)$, can be modelled as:

$T(z, t)=\bar{T}+A_{0} e^{-z / D} \sin (\omega t-z / D+\phi)$

where $\bar{T}$ is the mean annual temperature, $A_{0}$ is the amplitude of the annual surface temperature variations, $\omega$ is the angular frequency ( $\omega=2 \pi / 365$ ), $\phi$ is the phase constant, $D$ is the damping depth. The unknown parameters, such as $A_{0}, D$ and $\phi$, were found by fitting the temperature function with the measured data at 5,10 and $20 \mathrm{~cm}$ depth. Applying equation (B.1) at two different depths, $z_{1}$ and $z_{2}$, and combining the two soil temperature equations, the soil temperature at $z_{1}$ can be approximated as a function of the soil temperature at $z_{2}$ :

$T\left(z_{1}, t\right)=T\left(z_{2}, t\right)+A_{0} e^{-z_{1} / D} \sin \left(\omega t-z_{1} / D+\phi_{1}\right)-A_{0} e^{-z_{2} / D} \sin \left(\omega t-z_{2} / D+\phi_{2}\right)$

Assuming $z_{1}=1 \mathrm{~cm}$ and $z_{2}=5 \mathrm{~cm}$ depth and $\phi_{1}=\phi_{2}$ (which is an acceptable assumption for these two depths and daily values of soil temperature), the soil temperature at $1 \mathrm{~cm}$ depth was determined (hereafter referred to as $T_{1 \mathrm{~cm}}$ ). The main cause of inaccuracy of this method was the assumption of semi-infinite homogenous medium with constant thermal properties for the soil. This might be not valid, especially near the surface. Moreover, the determination of the exact depth of the emitting layer is not straightforward, especially in presence of a litter layer over the soil surface.

In the second method the surface temperature (hereafter referred to as $T_{L W}$ ) was estimated by means of the Stefan-Boltzmann law and of

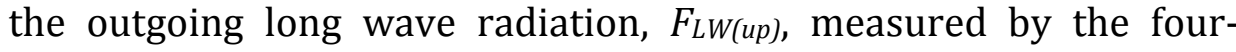


component net radiometer at a micrometeorological station located at the centre of the test area:

$F_{L W(u p)}=e_{T I R} \sigma T^{4} L W$

where $e_{T I R}$ is the broadband emissivity for the entire thermalinfrared spectral region, fixed to 0.97 for the case of grassland, and $\sigma$ is the Stefan-Boltzmann's constant. The outgoing long wave radiation measurements were available from 21 May to end of October 2009. The large spatial variability of outgoing long wave radiation might be a limitation for this method, as only a point measurement was available for the entire area of interest (i.e. approximately $25 \mathrm{~km} \mathrm{x}$ $25 \mathrm{~km})$.

As third data source, the simulated skin temperature of the ERA Interim Land data set was taken, which is available at the archive of the European Centre for Medium-Range Weather Forecast (ECMWF http://apps.ecmwf.int/datasets/data/interim land/). The data were available every 6 hours and with a resolution of $0.25^{\circ} \times 0.25^{\circ}$. The data provided at 18:00 (UTC) were used in this study (hereafter referred to as $\left.T_{E R A}\right)$.

Figure B.1 shows the comparison between C-band AMSR-E $T_{b}$ and the results obtained by multiplying the model emissivity by $T_{1 \mathrm{~cm}}, T_{L W}$ and $T_{E R A}$. Table B. 1 reports $R^{2}, R M S E$ and mean difference for low and high values of LAI between the C-band AMSR-E data and the brightness temperature obtained by multiplying the modelled emissivity with $T_{K a V}, T_{1 c m}, T_{L W}$ and $T_{E R A}$. 

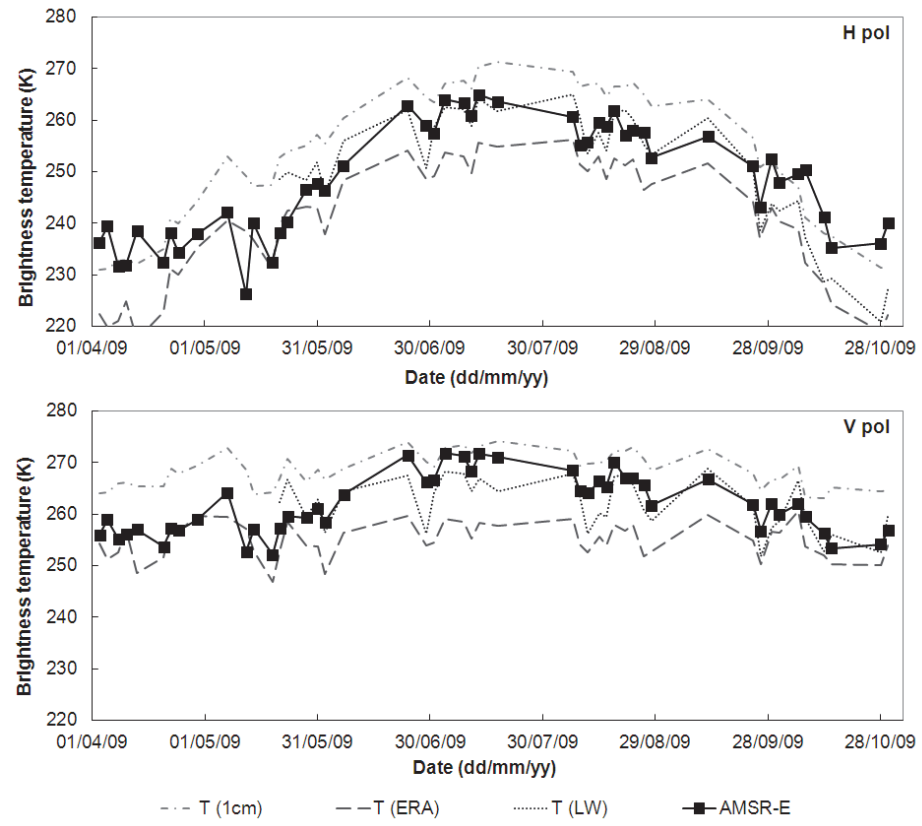

Figure B.1 AMSR-E C-band data compared with the brightness temperature obtained by multiplying the Tor Vergata (TVG) emissivity by $T_{1} \mathrm{~cm}$, $T_{L W}$ and $T_{E R A}$, for $H$ polarization (top) and for $\mathrm{V}$ polarization (bottom).

Table B.1 Coefficient of determination $\left(R^{2}\right)$, root mean square error $(R M S E)$ and mean difference between AMSR-E C-band data and brightness temperature obtained by multiplying the modelled emissivity by $T_{K a V}, T_{1 c m}, T_{L W}$ and $T_{E R A}$ for 2009 and 2010.

\begin{tabular}{|c|c|c|c|c|c|c|}
\hline & & & $R^{2}$ & RMSE (K) & $\begin{array}{c}\text { Mean diff. } \\
\text { LAI }<1\end{array}$ & $\begin{array}{c}\text { Mean diff. } \\
\text { LAI > } 1\end{array}$ \\
\hline \multirow{8}{*}{2009} & \multirow{4}{*}{ H pol } & $T_{K a V}$ & 0.8 & 6.3 & -1.7 & 5.1 \\
\hline & & $T_{1 \mathrm{~cm}}$ & 0.8 & 8.2 & 0.5 & 7.8 \\
\hline & & $T_{E R A}$ & 0.8 & 9.7 & -10.0 & -6.4 \\
\hline & & $T_{L W^{i \mathrm{v}}}$ & 0.7 & 6.2 & -10.0 & 0.4 \\
\hline & \multirow{4}{*}{ V pol } & $T_{K a V}$ & 0.5 & 5.9 & 7.9 & 2.3 \\
\hline & & $T_{1 \mathrm{~cm}}$ & 0.7 & 7.5 & 9.2 & 5.3 \\
\hline & & $T_{E R A}$ & 0.3 & 8.2 & -2.5 & -9.3 \\
\hline & & $T_{L W^{i \mathrm{v}}}$ & 0.5 & 4.1 & 0.4 & -2.4 \\
\hline \multirow{6}{*}{2010} & \multirow{3}{*}{ H pol } & $T_{K a V}$ & 0.5 & 8.7 & -6.0 & 6.3 \\
\hline & & $T_{1 \mathrm{~cm}}$ & 0.4 & 11.2 & -5.2 & 10.9 \\
\hline & & $T_{E R A}$ & 0.4 & 13.6 & -18.4 & -3.9 \\
\hline & \multirow{3}{*}{ V pol } & $T_{K a V}$ & 0.5 & 5.0 & 5.5 & 2.0 \\
\hline & & $T_{1 \mathrm{~cm}}$ & 0.6 & 7.3 & 6.4 & 6.2 \\
\hline & & $T_{E R A}$ & 0.3 & 9.2 & -7.9 & -8.3 \\
\hline
\end{tabular}

iv $\mathrm{T}_{\mathrm{LW}}$ is available only from $21 / 05 / 2009$ to $30 / 10 / 2009$. 
The same grid spacing and acquisition time of C-band and Ka-band AMSR-E data are the most important characteristics that determine a better accuracy in the surface temperature estimates. When $T_{L W}$ is multiplied with the modelled emissivity, the good match found between the simulated and the AMSR-E brightness temperatures for high values of LAI worsens at the end of the season. The point measurement of long wave upward radiation might not well represent the variability in a $0.25^{\circ} \times 0.25^{\circ}$ area especially at the end of the season, causing an underestimation of the surface temperature. The use of $T_{E R A}$ leads to a general underestimation of the brightness temperature throughout the entire season. Indeed, Su et al. (2013) found that in the Maqu area, as well as other parts of the Tibetan Plateau, ECMWF model underestimates the soil temperature.

The brightness temperature obtained by multiplying the modelled emissivity with $T_{1 \mathrm{~cm}}$ is generally smoother and higher than the satellite observations. The assumption at the base of the method used to estimate $T_{1 \mathrm{~cm}}$ of homogenous soil with constant thermal properties might be the main cause of error, because especially near the surface this might be not valid. As a consequence of this assumption, the estimates might not well reproduce the expected soil temperature variations at $1 \mathrm{~cm}$ depth, but a smoother pattern.

The results obtained for 2010 data confirm what was obtained for 2009. In conclusion, the best match with satellite data is obtained when $T_{K a V}$ is used. A general overestimation of the brightness temperature is observed when $T_{1 \mathrm{~cm}}$ is multiplied by the modelled emissivity and a general underestimation when $T_{E R A}$ is used. 


\section{Acknowledgements}

I would have never been able to write this thesis without the support, help, collaboration, contribution, trust, love and smile of many people. I would like to thank everyone who was involved in this extraordinary and long experience.

I am indebted to Prof. Bob Su. He gave me the opportunity to be a Ph.D. researcher at ITC trusting my experience, knowledge and qualities. During all these years he guided me with useful discussions, constructive criticisms, precious advices, full support and infinite patience. I will never forget that even after 9 years from the beginning of the Ph.D. he was still confident I will succeed. I would like to thank Zoltán Vekerdy, my supervisor for the first four years. His optimistic, friendly and open attitude was exactly what I needed when I moved to the cold and gray Netherlands. I always enjoyed a lot our weakly coffee-meetings, a mix of informal chats and useful scientific discussions. During those meetings we built together the bases of this thesis.

I am grateful to Richard de Jeu and Paolo Ferrazzoli, who had an important role at the beginning and at the end of this Ph.D. research, respectively. With Richard I have gained experience in the passive microwave remote sensing and it was a pleasure to collaborate with him for the first article of this study. The collaboration with Paolo, and later with Leila Guerriero, was crucial in a difficult period of my Ph.D. and my life. His deep experience in discrete scattering models, his constant availability for discussions and advices, his infinite patience stimulated me to invest again energy in my Ph.D. research. The last and most important article of this study is the result of an intense collaboration with Paolo and Leila.

I would like to thank Prof. Jun Wen, the collaboration with him was essential to succeed in this study. He arranged everything for the fieldwork in the Maqu region and he hosted me for one month at CAREERI. Both were unforgettable experiences. I am indebted to the technicians and students of CAREERI that helped me in the fieldwork and that regularly went to Maqu to download the data. 
Installing 20 monitoring stations in Twente was not easy and took much longer than expected. Therefore I want to thank Murat Ucer for his support and help. I enjoyed our trips around Twente.

I would like to say thank you to all the inhabitants of the Maqu and the Twente regions that allowed me to install strange instrumentation in their soil and to walk around in their fields.

Special thanks to: Yijian Zeng for being kind friend, helpful colleague and perfect office mate, impossible to list all the times he helped me in the last years; Lichun Wang for the data processing and for the nice friendship; Rogier van der Velde for the interesting scientific discussions and collaboration; Boudewijn de Smeth for the support in the laboratory experiments; Bert Boer for being a very kind and helpful person; Benno Masselink for his patient help in designing my posters and thesis cover, short before the deadlines; Anke de Koning and Tina Butt-Castro for their constant logistic and personal support, always a pleasure to chat with them; Loes Colenbrander for kindly helping me in different stages of my Ph.D; all the colleagues of the WRS department.

During the long days spent in room 5-116, I had the pleasure to meet nice students and visiting scientists, we shared not only the office, but also experiences, successes, worries, frustrations, laughs, cooking recipes: Mariela, Alain, Leonardo, Enrico, Guido, Chandra, Syarif, Ella, Zhong Lei, Xuelei, Fang Shen and many others. We did not share the same office, but certainly we shared nice moments: Mustafa, Diana, Joris, Fouad, Christiaan, Wiwin, Lal, Kitsiri, Alex, Jennifer, Marcel, Wim, Jahanzeb, Ha, Ulan. A good friendship is always very precious, therefore many thanks to: Carolina and Ard, Claudia and Henry, Filiz, Beata and Eddy, Simona, Carmen and Alfonso.

Enormous thanks go to my parents for the enormous support they always gave me. Papà, se solo avessi finito in tempo questa tesi, avresti potuto esserci anche tu, con il tuo sorriso oroglioso e la tua mano sulla mia spalla. Grazie per avermi sempre dato la certezza di poter contare su di te. Mamma, nonostante avresti preferito avere figlia e nipoti vicino, hai sempre sostenuto con orgoglio la mia scelta di ottenere il dottorato all'estero. Sei una mamma meravigliosa. Grazie per esserti presa dei bimbi durante le tue lunghe permanenze in Olanda, lasciandomi il tempo di lavorare. Vincenzo, thanks for 
taking care of several family issues especially in the last years. You are a wonderful big brother and Wen is a lovely sister-in-law. Pity that life has brought us far from each other. Jans and Gezina, thank you very much for your precious support, for taking care of the children to allow me to work and for all the quiet and relaxing weekends in Smilde. Alina and Andree, thank you for always being interested in my progresses and for patiently listening to all my Ph.D. stories.

Finally, the most important thanks go to Anton, Simon and Matteo, my boys, my priceless treasure. I am grateful for the love you gave me and for accepting my love, for the time you allowed me to steal from you and for the time you have stolen from my Ph.D., for all the times that I was fully concentrated on my numbers and you brought me back to the real life, for being patient with a tired and nervous mama and for helping me to train my patience, for the smiles and for the tears, for the worries and for the successes. Every single word of this thesis contains all of this. Therefore, this achievement is partly also yours. Anton, simply thank you for being part of my life ..... "viva la felicità"! 